
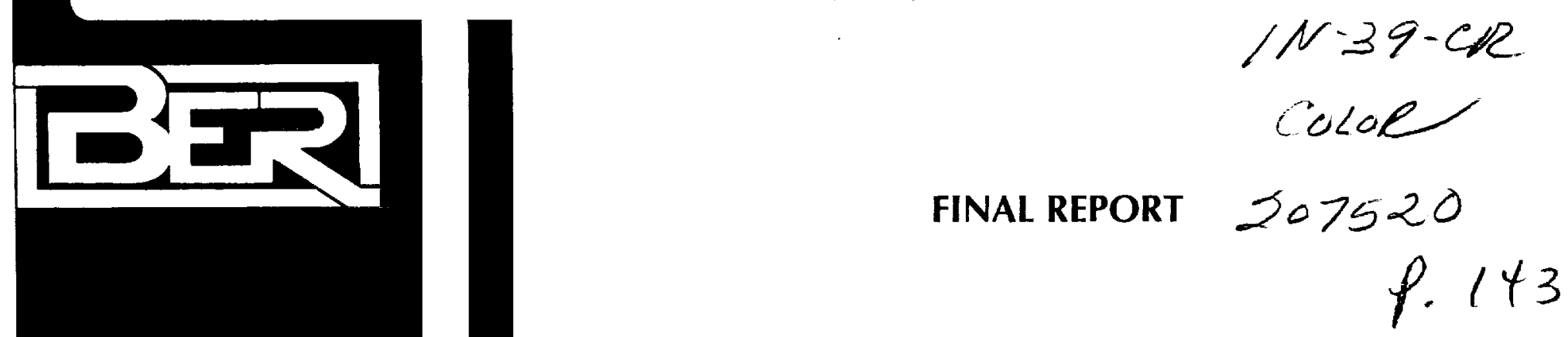

\title{
USE OF PHOTOSTRESS TO CHARACTERIZE THE MECHANICAL BEHAVIOR OF WELDMENTS
}

Prepared by

Dr. S. C. Gambrell, Jr.

Department of Engineering Mechanics

College of Engineering

The University of Alabama

Tuscaloosa, Alabama

Prepared for

NASA

through the University of Alabama in Huntsville

Contract No. NAG8-212

SUB 92-195

BER Report No. 570-97

\section{September 1992}

The University of Alabama College of Engineering Bureau of Engineering Research Box 870201

Tuscaloosa, Alabama 35487.0201 Telephone: (205) 348-1591
(NASA-CR-195201) USE OF

PHOTCSTRESS TO CHARACTERIZE THE

MECHANICAL PEHAVIOR JF WELOMENTS

final Report (Alabama Univ.)

$143 p$
N94-25267

Unclas 


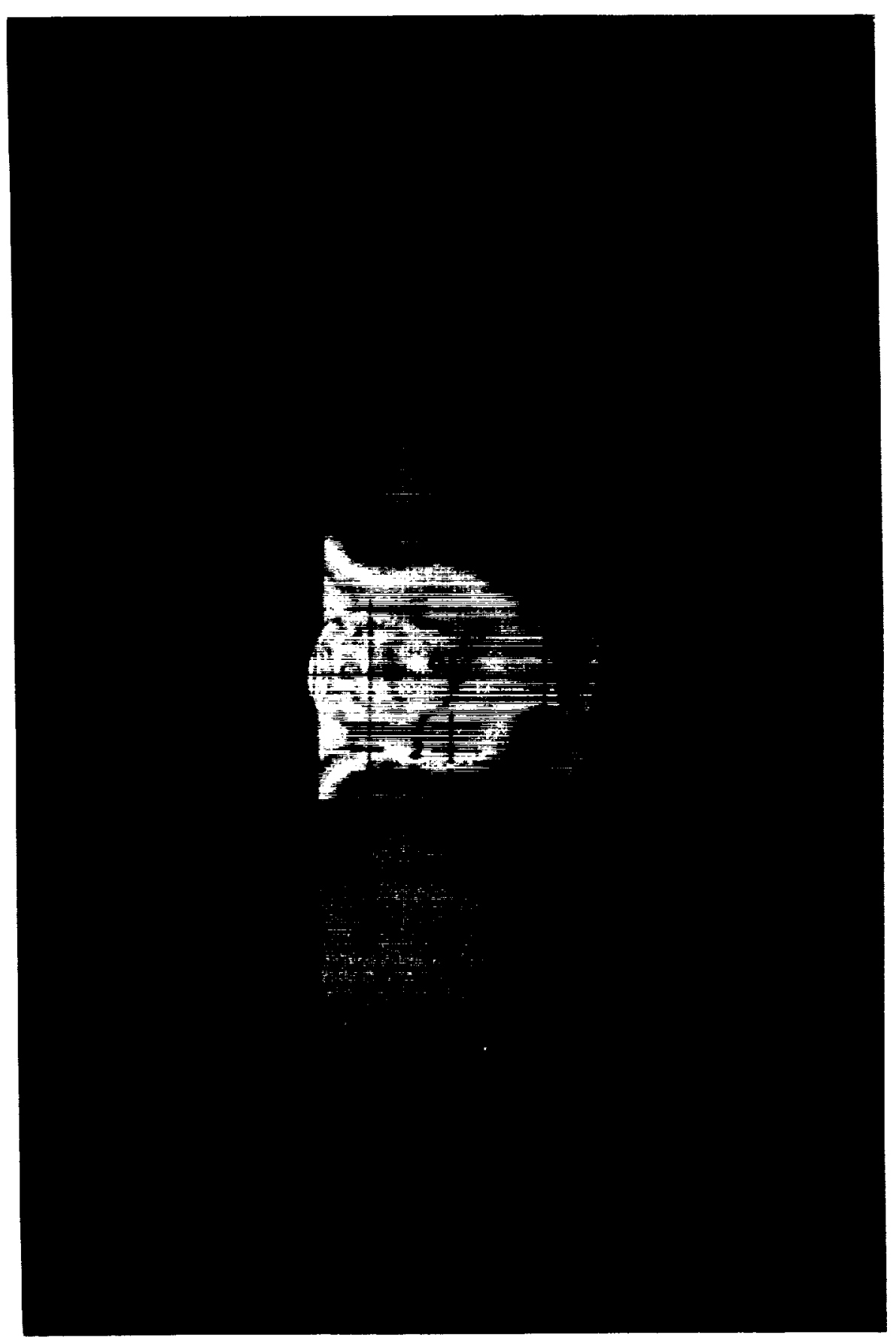

Non-Uniform Yielding, TIG Weld

2219-T87 Aluminum

2319 Weld Material 


\section{FINAL REPORT}

\section{USE OF PHOTOSTRESS TO CHARACTERIZE THE MECHANICAL BEHAVIOR OF WELDMENTS}

$$
\text { Prepared by }
$$

Dr. S.C. Gambrell, Jr. Department of Engineering Mechanics College of Engineering The University of Alabama Tuscaloosa, Alabama

$$
\text { Prepared for }
$$

NASA

through the University of Alabama in Huntsville

Contract No. NAG8-212

SUB $92-195$

BER Report No. 570-97

September 1992 


\section{Page}

List of photographs..........................

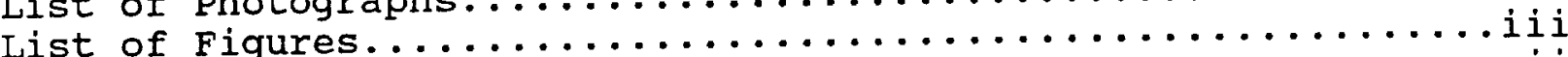

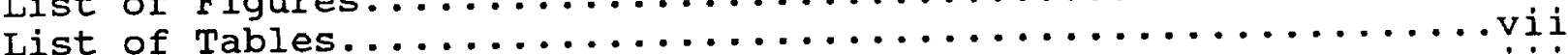

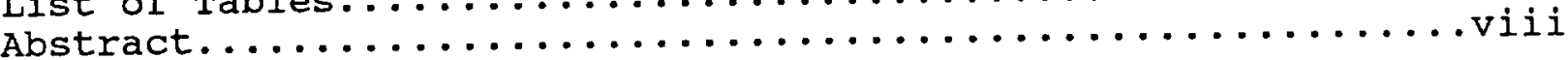

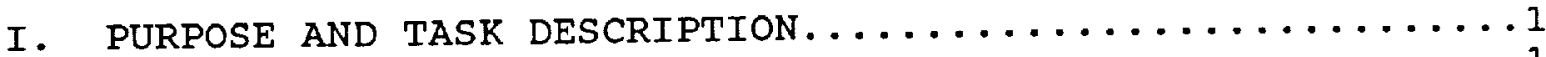

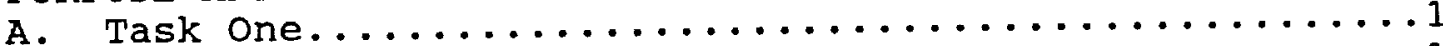

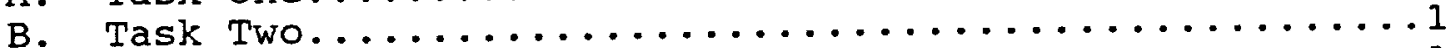

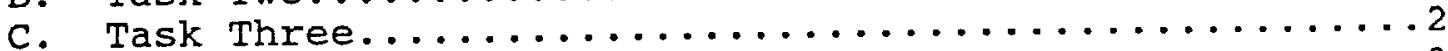

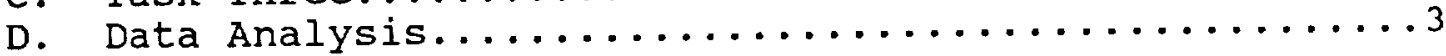

II. BACKGROUND............................

III. ORIENTATION FOR DATA COLLECTION, AND EQUIPMENT........6

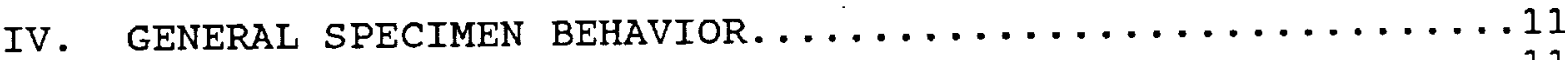

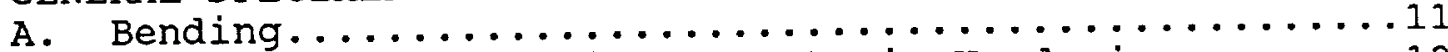

B. Discontinuous Yielding and strain Hardening.......12

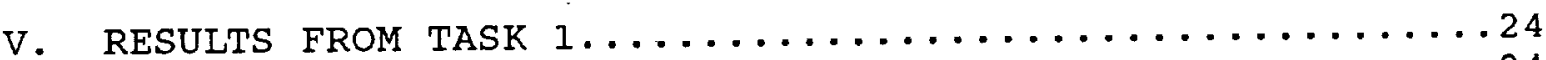

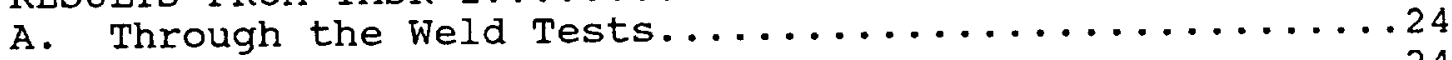

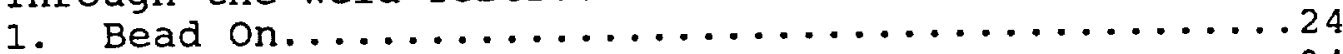

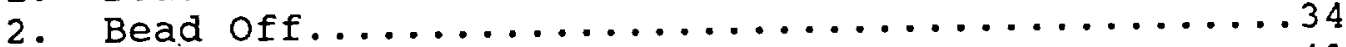

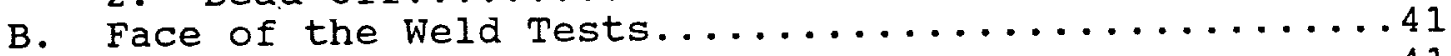

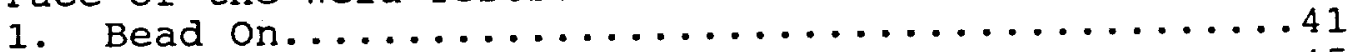

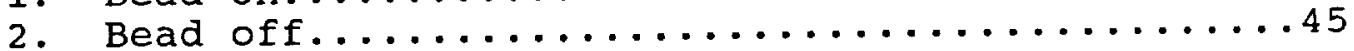

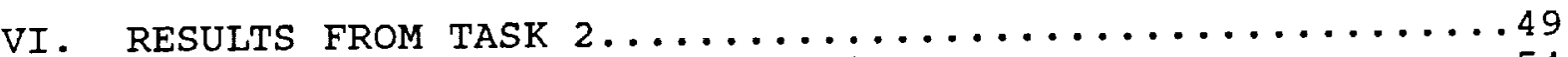

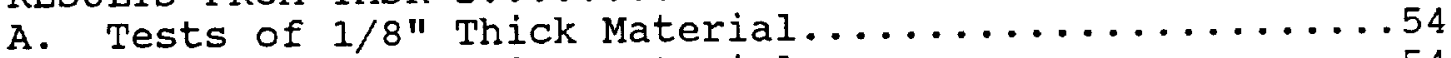

B. Tests of $1 / 2$ " Thick Material.................. 54

VII. RESULTS FROM TASK $3 \ldots \ldots \ldots \ldots \ldots \ldots \ldots \ldots \ldots$

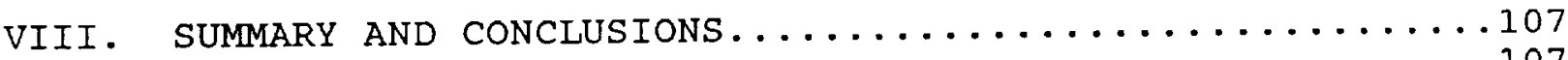

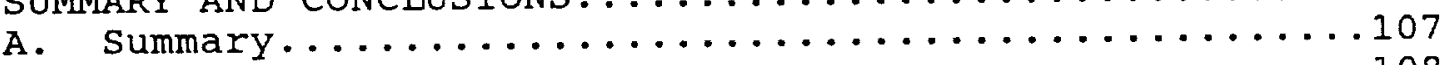

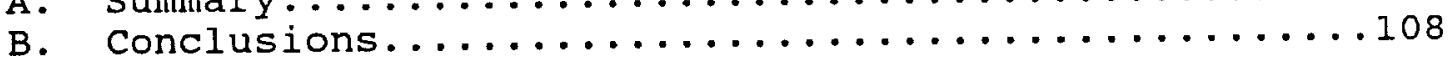

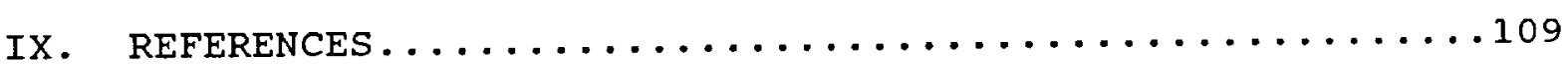

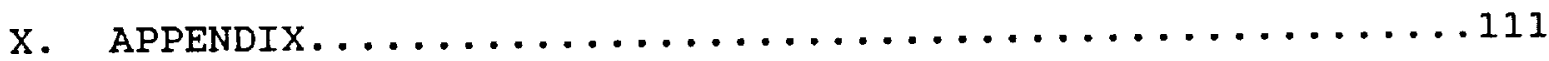




\section{LIST OF PHOTOGRAPHS}

Photo \#

1 .

2 .

3.

4 .

5.

6.

7.

8.

9.

10.

11.

12.

13.

14 .

15 .

16 .

17 .

18 .

19.

20 .
Title

Page

Typical specimen.......................

Typical Weld, Bead on, 1.4" Material..........8

Typical Weld, Bead off, 1.4" Material..........8

Typical Weld, Bead off, 1/2" Material..........10

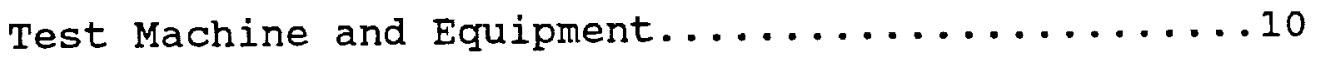

Shear Strain, Through Weld, Bead on............25

Comparison of Shear Strain, Wide and26

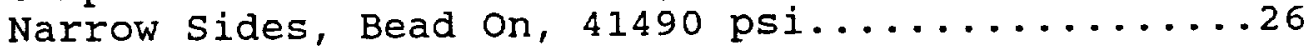

Shear strain, wide side of weld, Bead on........28

Shear Strain, Through Weld, Bead off...........35

Comparison of Shear strain, Wide and

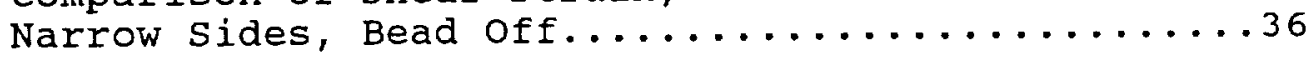

Shear strain on Face of Weld, Bead on,

wide side.

Comparison of Shear strain, Bead on,

36500 psi............................ 43

Shear Strain, Face of Weld, Bead on, 36050 psi.............................. 44

Comparison of Shear Strain, Bead off,

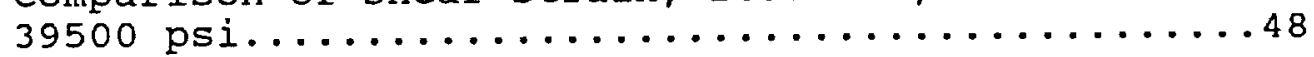

Uniform shear strain, 1/8" Material...........55

Symmetrical Shear Strains, 1/8" Material,

24845 psi...........................56

Non-Uniform Shear Strain, 1/2" Material........66

Yield Zones, 1/2" Material, 25520 psi.........67

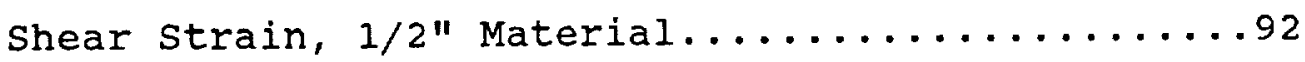

Yield Zones, 1/2" Material, 23800 psi..........101 


\section{IIST OF FIGURES}

Figure \#

Figure 1.

Figure 2 .

Figure 3 .

Figure 4 .

Figure 5 .

Figure 6 .

Figure 7 .

Figure 8 .

Figure 9.

Figure 10.

Figure 11.

Figure 12 .

Figure 13.

Figure 14.

Figure 15.

Figure 16.

Figure 17.

Figure 18.

Figure 19.

Figure 20.

Figure 21.

Figure 22.

Figure 23 .
Title

Page

Sketch of specimen....................

Discontinuous Yielding, 1/4" Strain Gage.......13

Energy Required for Slip, Centerline...........15

Energy Required for Slip, 1/4" Line...........16

Energy Required for Slip, 1/8" Line...........17

Energy Required for Slip, 1/2" Line............ 18

First Loading Curve, Centerline, 1/2" Material...19

second Loading Curve, Centerline, 1/2" Material..20

Second Loading Curve, 1/4" Line, 1/2" Material...21

Second Loading Curve, 1/8" Line, 1/2" Material...22

Second Loading Curve, 1/2" Line, 1/2" Material...23

Behavior, weld on, Vertical Centerline........29

Behavior, Weld on, Horizontal Centerline.......30

Behavior, Weld on, Horizontal 1/4" Line........31

Behavior, Weld on, Horizontal 1/2" Line........32

Average Mechanical Properties, Weld on,

Vertical Centerline, 0.71" x 1.4" Specimens.....33

Behavior, Weld off, Vertical Centerline........37

Behavior, Weld off, Horizontal Centerline......38

Behavior, Weld off, Horizontal 1/4" Line.......39

Average Mechanical Properties, Weld off,

Vertical Centerline, 0.71" $x 1.4 "$ Specimens.....40

Behavior, weld on, wide side of Weld,

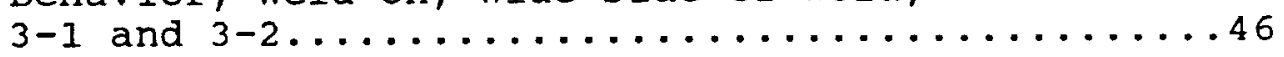

Behavior, weld on, wide side of weld, $3-3 \ldots \ldots .47$

Behavior, Weld off, Wide Side of Weld,

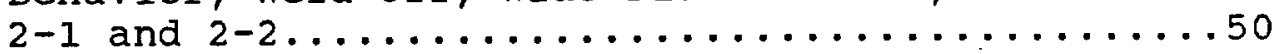


Figure 24.

Figure 25.

Figure 26.

Figure 27 .

Figure 28 .

Figure 29.

Figure 30.

Figure 31.

Figure 32 .

Figure 33.

Figure 34 .

Figure 35.

Figure 36.

Figure 37.

Figure 38 .

Figure 39.

Figure 40.

Figure 41 .

Figure 42 .
Behavior, weld off, Narrow side of

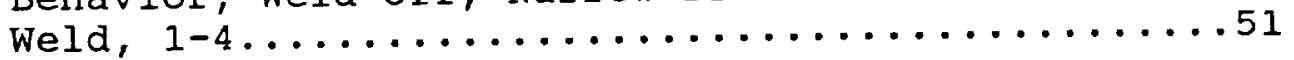

Average Mechanical Properties, Weld off, Wide Side of Weld, 0.71" $x 1.4 "$ Specimens.......52

Mechanical Properties, Weld off, Narrow Side of Weld, $0.71 " \times 1.4 "$ Specimen $1-4 \ldots \ldots \ldots . \ldots \ldots 3$

Behavior, wide side of Weld................. 57

Behavior, Narrow side of weld.................. 58

Behavior at Centerline, wide and Narrow

Sides of weld.......................59

Behavior at 1/8" Line, Wide and Narrow

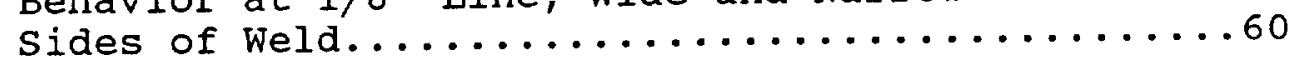

Behavior at $1 / 4 "$, Wide and Narrow sides

of Weld.............................

Behavior at 1/8" Line, wide and Narrow

Sides of weld.......................62

Behavior at $1 / 2 "$ Line, Wide and Narrow

sides of weld.......................63

Behavior at $3 / 4 "$ and $1 "$ Lines, wide and

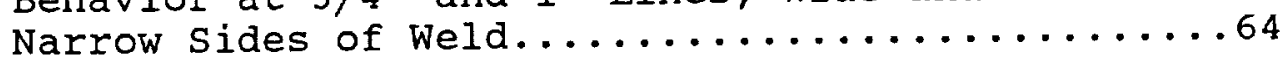

Average Mechanical Properties,

$1 / 8 " \mathrm{x} 1.25 "$ Specimens..................65

Behavior, wide side of Weld.................69

Behavior, Narrow side of Weld...............

Behavior, centerline, wide and

Narrow sides of weld..................

Behavior, 1/4" Line, wide and Narrow

Sides of weld........................

Behavior, 1/8" Line, Wide and Narrow

Sides of weld.........................

Behavior, 1/2" Line, wide and Narrow

Sides of weld........................ 74

Behavior, 3/4" and 1" Lines, wide and

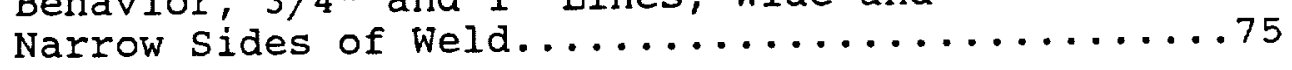


Figure 43. Yield Zones and Discontinuous

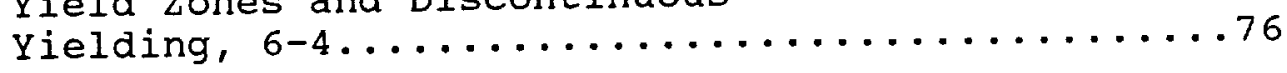

Figure 44. Yield Zones and Discontinuous

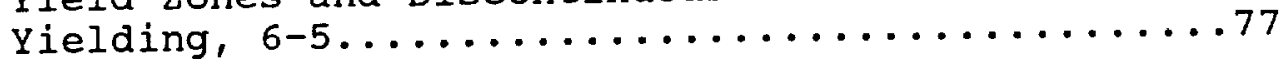

Figure 45. Yield Zones and Discontinuous

Yielding, $7-1 \ldots \ldots \ldots \ldots \ldots \ldots \ldots \ldots \ldots \ldots \ldots \ldots . \ldots \ldots$

Figure 46. Average Mechanical Properties,

$1 / 2 "$ x $1.25 "$ specimens.................... 80

Figure 47. Behavior Using $1 / 4$ " Strain Gage.............81

Figure 48. Behavior Using 1/8" Strain Gage............ 82

Figure 49. Behavior Using 1/16" Strain Gage.............83

Figure 50. Behavior Using 1/32" Strain Gage............. 84

Figure 51. Behavior Using 1/64" Strain Gage............ 85

Figure 52. Behavior at Centerline, All Gages............. 87

Figure 53. Behavior at 1/4" Line, All Gages...........88

Figure 54. Behavior at 1/2" Line, All Gages............. 89

Figure 55. Behavior at $3 / 4 "$ Line, All Gages.............90

Figure 56. Behavior at $1 "$ Line, All Gages............... 91

Figure 57. Behavior, wide side of weld.................

Figure 58. Comparison of Corrected Shear Strain

with Normal Strain Along Centerline..........94

Figure 59. Comparison of corrected Shear Strain

with Normal Strain Along 1/4" Line...........95

Figure 60. Comparison of Corrected Shear Strain

with Normal Strain Along 1/8" Line...........96

Figure 61. Comparison of Corrected Shear Strain

with Normal Strain Along $1 / 2 "$ Line............97

Figure 62. Comparison of corrected Shear Strain

with Normal Strain Along $3 / 4 "$ Line............98

Figure 63. Comparison of Corrected Shear Strain

with Normal Strain Along $1 "$ Line..............99

Figure 64. Yield Zones and Discontinuous

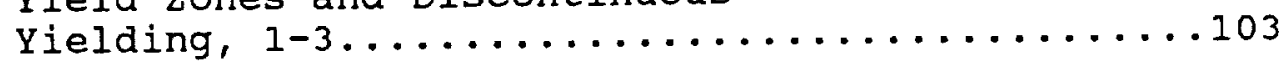


Figure 65. Yield Zones and Discontinuous

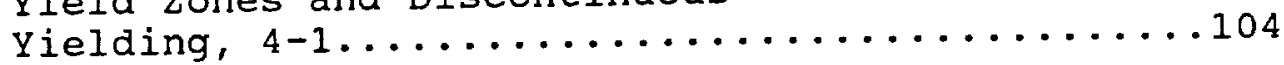

Figure 66. Yield Zones and Discontinuous

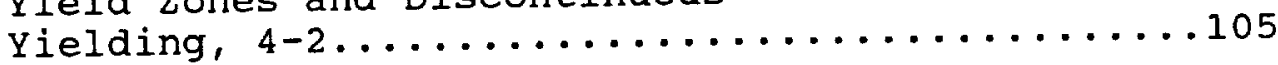

Figure 67. Average Mechanical Properties,

$1 / 2 " \times 2 "$ Specimens......................... 106

Figure 68. Tangent Modulus, Weld and Parent Material......113

Figure 69. Contraction Ratios, Weld and Parent Material....114

Figure 70. Curve Fit and scatter, Centerline,

$1 / 4$ " strain Gage........................ 115

Figure 71. Curve Fit and Scatter, 1/4"

Line, $1 / 4$ " Strain Gage................116

Figure 72. Curve Fit and Scatter,

$1 / 2$ " Line, $1 / 4$ " Strain Gage...............117

Figure 73. Curve Fit and Scatter,

$3 / 4 "$ Line, $1 / 4 "$ Strain Gage............... 118

Figure 74. Curve Fit and Scatter, I" Line,

$1 / 4$ " Strain Gage........................ 119

Figure 75. Curve Fit and Scatter, Centerline,

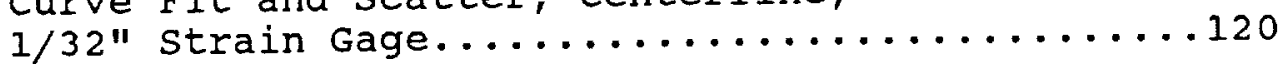

Figure 76. Curve Fit and Scatter, 1/4"

Line, $1 / 32$ " Strain Gage..................... 121

Figure 77. Curve Fit and scatter, 1/2"

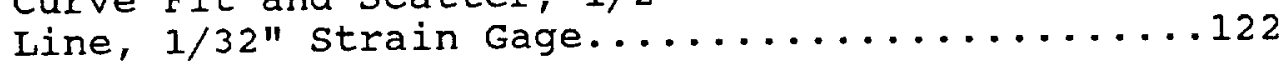

Figure 78. Curve Fit and Scatter, $3 / 4 "$

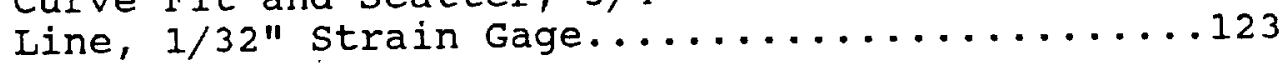

Figure 79. Curve Fit and Scatter, 1" Line,

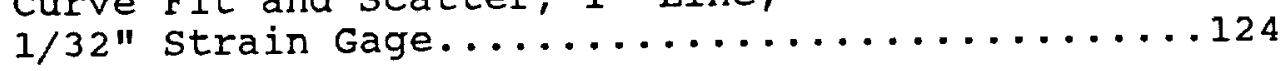

Figure 80. Curve Fit and Scatter, Centerline, Photostress..125

Figure 81. Curve Fit and Scatter, 1/4" Line, Photostress...126

Figure 82. Curve Fit and Scatter, 1/8" Line, Photostress...127

Figure 83. Curve Fit and Scatter, 1/2" Line, Photostress...128

Figure 84. Curve Fit and Scatter, 3/4" Line, Photostress...129

Figure 85. Curve Fit and Scatter, 1" Line, Photostress....130 


\section{LIST OF TABLES}

\section{Table \#}

Title

Page

1.

Examples of Bending Strain, (Microstrain)........12

2 .

Yield Zone Location and Thickness (Inches)

$1 / 2 " \times 1.25 "$ Specimens..................68

3.

Yield Zone Location and Thickness (Inches)

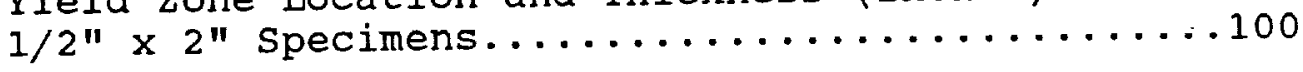

4 .

specimens Tested. 


\section{- ABSTRACT}

Welded aluminum is an important part of many space structures. Knowledge of the properties and behavior of weld material and the material surrounding the weld is important for modeling and design of the structures. Photoelastic coatings (Photostress) and strain gages were used to determine behavior of heat treated and as welded joints made from 2219T87 parent material and 2319 weld material subjected to tensile loads. TIG welds of $\frac{1}{8}, \frac{1}{2}$, and 1.4 inches thickness were investigated. Discontinuous yielding was observed in all tests and highly non-uniform behavior through the weld thickness was observed in joints having welds 1.4 inches thick. Joints having welds $\frac{1}{8}$ and $\frac{1}{2}$ inches thick had only small differences in behavior through the thickness of the weld. Joints in the $\frac{1}{2}$ inch thick material contained distinct zones of constant strain within the normal strain gradient extending outward from the weld centerline. These zones had different thickness and locations. Points at the weld centerline, and for a distance of nearly one inch from the centerline, exhibited very nonlinear behavior during the first loading but exhibited near perfect strain hardening during the second loading. 


\section{PURPOSE AND TASK DESCRIPTION}

The purpose of this research is to characterize the mechanical behavior of basic 2219T87 aluminum welded joints using photoelastic coatings (Photostress). The overall project consisted of three primary tasks in which welded tensile specimens $\frac{1}{8}, \frac{1}{2}$, and 1.4 inches thick were tested to determine the stress-strain relationships at points beginning at the centerline of the weld and extending in one direction to locations of $\frac{1}{4}, \frac{3}{8}, \frac{1}{2}, \frac{3}{4}$, and 1 inch from the centerline. To better describe the material behavior, color photographs were made and used to present the yield characteristics of the welded joints including the weld material, the heat affected zone, and the parent material. Primary tasks for the project were initially identified as:

\section{A. Task one}

Using large, heat treated, dogbone specimens 1.40 inches thick, evaluate the extent of the heat affected zone on the wide side of the weld. Tests will be conducted using specimens having photoelastic coatings on the face of the weld and also on the side for both the bead off and bead on conditions. The size of the various zones, where the zones are located with respect to the weld centerline, and a stress-strain curve for each zone will be determined.

\section{B. Task Two}

Using as welded, bead off, dogbone specimens of $\frac{1}{8}$ and $\frac{1}{2}$ inch thickness having a common width of 1.25 inches, evaluate the extent of the heat affected zone on the wide and narrow 
sides of the weld. Information obtained will be the position, relative to the centerline of the weld, locating the onset of yielding as a function of applied stress for both the wide and narrow sides of the weld. For specimens having a thickness of only $\frac{1}{8}$ inch, tests will be conducted initially on both sides of the specimen to determine if there is a difference in material properties, on a point by point basis, between the two sides. It is already known that there is a difference between material properties at similar points on the wide and narrow sides of some welds for specimens $\frac{1}{2}$ inch thick.

\section{Task Three}

Using as welded, bead off, dogbone specimens having $\frac{1}{2}$ inch thickness and 2 inch width, correlate the strain in the various zones obtained by use of strain gages with the strain obtained by use of photoelastic coatings. All measurements will be made on the wide side of the weldment. Strain gages having $\frac{1}{32}, \frac{1}{16}, \frac{1}{8}$, and $\frac{1}{4}$ inch gage lengths will be used to evaluate the effect of gage length on strain averaging. Data from strain gages and photoelastic coatings will be obtained at points located the same distance from the centerline of the weld, including the point at the weld centerline. Gages will be placed specifically at $y=0, y=0.25, y=0.50$, and $y=0.75$ inches from the weld centerline. Strains measured by the strain gages will be limited to a maximum of $1.5 \%\left(15,000 \times 10^{-6}\right)$ in order to make use of regular, rather than post yield, strain gages. The CEA group of strain gages from Measurements Group, Inc., along with M-Bond 200 Cement, is capable of measuring strains in this range. Photoelastic coatings will be of the PS-1 and PL-1 types used with PC- 8 adhesive. 


\section{Data Analysis}

Each test was designed for three repetitions so that a least squares fit of the data scatter could be made. Except for special cases where variations were made in the three repetition sequence to emphasize a particular material behavior, curves shown in all graphs represent three tests. A software package installed on an IBM RS6000 work station which uses both a linear and nonlinear analysis for curve fitting was used to produce graphs from the complete data base obtained from the three specimens in a set. Results obtained from each of the three primary tasks will be presented in detail in the following sections of this report.

\section{BACKGROUND}

Consideration for this research project began during the summer of 1991 when testing of 2219-T87 aluminum welded specimens using Photostress was started in the Metallurgy Research Branch, Metallic Materials Division, Materials and Processes Laboratory of NASA at the Marshall Space Flight Center. Gambrell (1) and other personnel of the Metallurgy Research Branch tested approximately twenty tensile test specimens to determine if Photostress was of value in characterizing the mechanical behavior of welded joints. Success was obtained in several areas and, in perhaps the most important aspect of the work, a whole

field understanding of the stress-strain behavior of the joint was obtained by observing the fringe pattern in the photoelastic coating covering the joint.

Since Photostress is used to measure the maximum shearing strain, $\gamma$, at a point rather than measuring normal strain, Chakrabarty's (2) approximation for the contraction ratio of 
both parent and pure weld material was used to convert from maximum shearing strain to normal strain in the tensile test specimens. For tensile specimens, the strain-optic law states that

$$
\gamma_{\max }=\epsilon_{1}-\epsilon_{2}=\frac{N \lambda}{2 t_{p} K}=N f
$$

where $N=$ fringe order

$$
\begin{aligned}
& \lambda=\text { wavelength of light }=22.7 \times 10^{-6} \text { inches, } \\
& t_{p}=\text { thickness of coating, and } \\
& K=\text { calibration constant of coating. }
\end{aligned}
$$

Since $\epsilon_{2}=-\mu \epsilon_{1}$ for uniaxial tension, equation [1] may be written for the elastic range as

$$
\epsilon_{1}=\frac{N f}{(1+\mu)}
$$

where $\mu=$ Poisson's ratio. For the inelastic range, Poisson's ratio must be replaced by the contraction ratio, $\alpha$, which Chakrabarty approximates as

$$
\alpha=0.05-(0.5-\mu)\left(\frac{E_{t}}{E}\right)
$$

where $E_{t}=$ the tangent modulus and

$$
E=\text { the modulus of elasticity. }
$$

Thus, equation [2] becomes 


$$
\epsilon_{1}=\frac{N f}{(1+\alpha)}
$$

for the inelastic range. The contraction ratio may be calculated for each value of uniaxial stress using a tangent modulus curve constructed from an engineering stress-strain curve. Contraction ratios for the 2319 weld material and the 2219 -T87 parent material were calculated during the summer work and are given in the appendix to this report. Tangent modulus curves are also given.

Using carefully machined test specimens of 2219-T87 parent material and 2319 pure weld material during the summer of 1991 , it was verified that Chakrabarty's approximation could be used to successfully determine the stress versus normal strain relationship in regular, unconstrained test specimens. Graphs showing these stress-strain relationships are contained in reference (1). After verifying the applicability of Photostress to analyze behavior of parent and pure weld material, it was used to obtain the stress versus maximum shearing strain behavior of a number of tensile specimens having various types of welded joints at their center. Many graphs showing the behavior of specimens having welded joints are contained in reference (1).

Experience in the summer of 1991 indicated that, to accurately observe strains in the .015 to .030 range, the thickness of the photoelastic coating would need to be around 0.01 inches when using PS-1 plastic which has a strain-optic constant of $K=0.15$. Therefore, for all tests except those having coatings on the full weld bead (task 1), a thickness of 0.01 inches was used. For the photoelastic coating used on the full weld bead, PL-1 plastic was required 
since it had to be poured and contoured over the weld bead in its semi-polmerized state. Since the strain- optic constant for PL-1 is only 0.10 , a thickness of 0.02 inches was selected. Also, since it is extremely difficult to pour and handle plastic that is 0.01 inches thick, the thicker material provided for slightly better, more accurate pouring and application.

\section{ORIENTATION FOR DATA COLLECTION, AND EQUIPMENT}

Photo 1 shows the general, dogbone type, test specimen used in all tests. Panels of parent material were TIG welded by NASA personnel at the junction of the two halves of parent material and were taken to the University of Alabama for machining in the College of Engineering machine shop. All specimens were made having 12.5 inches between hole centers and had different test section dimensions depending upon the task number. Figure 1 is a sketch of the specimen showing basic locations for data collection beginning at the centerline of the weld and moving downward on the specimen. Specimens for task 1 had, in addition to the vertical centerline, another vertical grid line on either side of the centerline to facilitate data collection along horizontal lines through the thickness of the weld (1.4 inches). These additional lines will be seen in photographs of the 1.4 inch thick specimens.

Photo 2 shows face and side view etchings of welds in $0.71^{\prime \prime} \times 1.4$ " specimens used in task 1 which had full weld beads on both surfaces. All graphs presenting the stress-strain relationships refer to the "wide" and "narrow" sides of welds. The wide side for these specimens was defined as that surface having the protruding weld material which had the greatest distance between the fillets connecting the weld to the parent material. In Photo $2(a)$, this wide side is seen as the face view and it is also seen as the left protruding weld in 

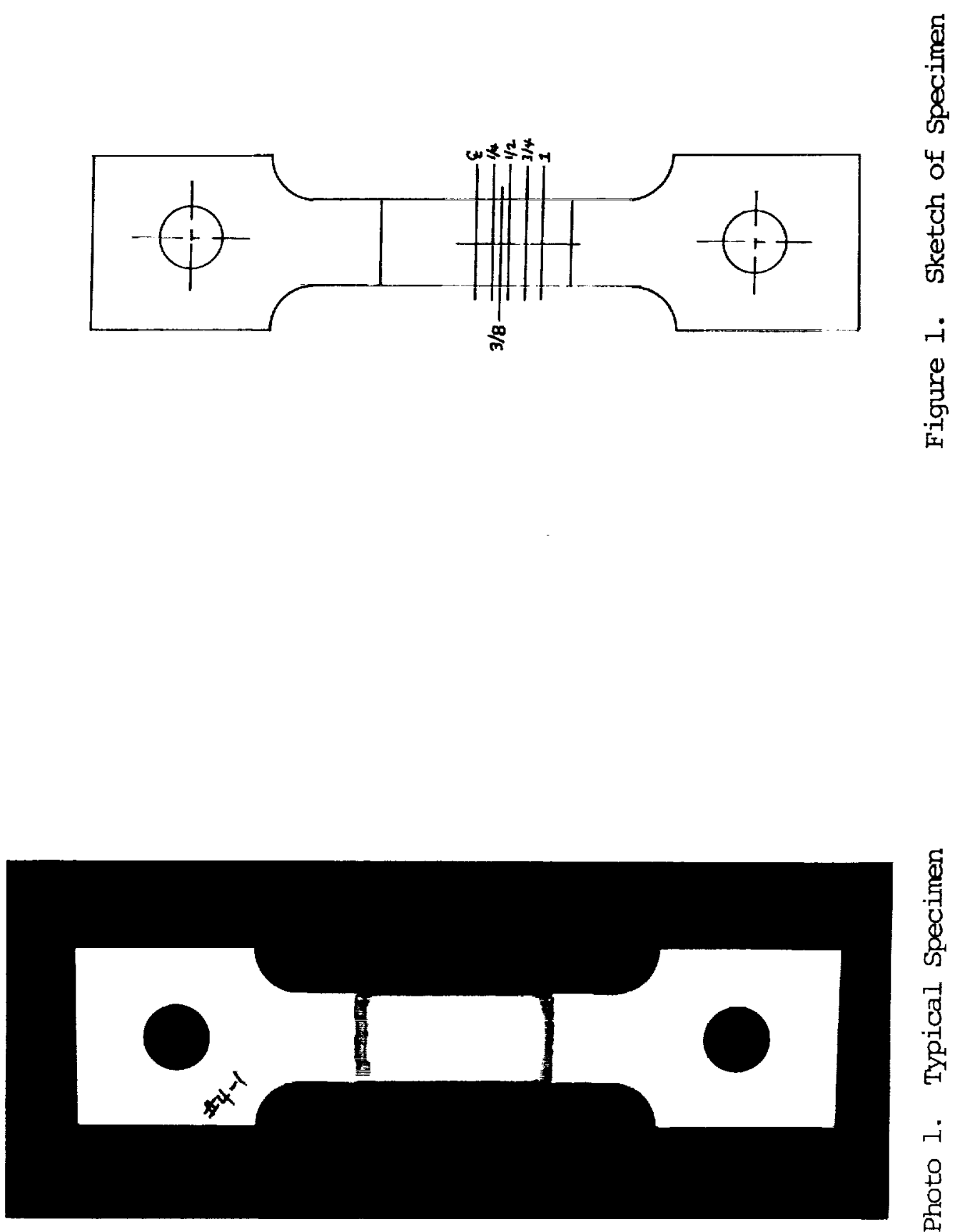

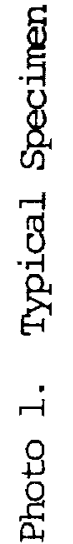




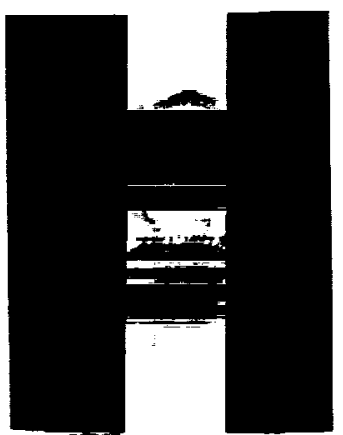

(a) Face View

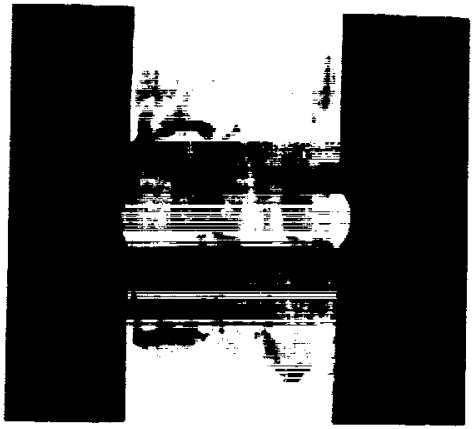

(b) Side View

Photo 2. Typical Weld, Bead On, 1.4" Material

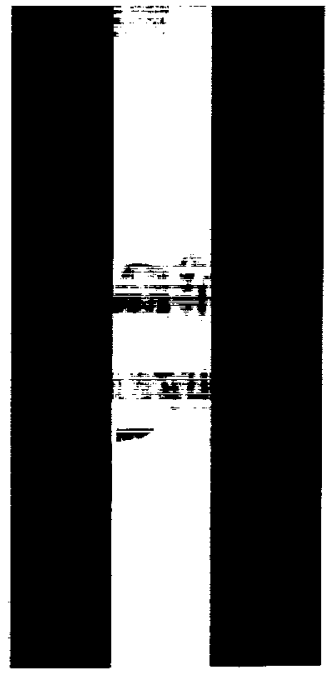

(a) Face View

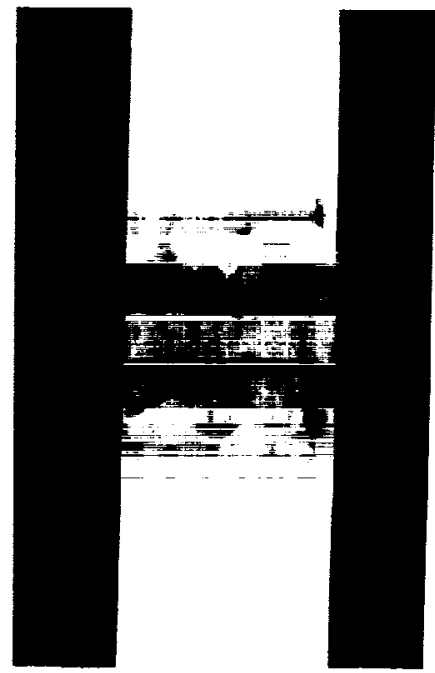

(b) Side View

Photo 3. Typical Weld, Bead Off, 1.4" Material 
the side view of Photo 2(b). All welds in the $1.4^{\prime \prime}$ thick material had the same general shape and appearance as those seen here.

Photo 3 shows face and side view etchings of welds in $0.71^{\prime \prime} \times 1.4^{\prime \prime}$ specimens used in task 1 which had the weld beads ground off. The wide side of the weld was defined in the same manner as for those specimens having the full bead on and can be seen in Photo 3(a). It also appears as the left surface of the specimen seen in Photo 3(b). In Photos 2(b) and 3(b) note the highly irregular, non-uniform shape of the weld in the $1.4^{\prime \prime}$ thick material.

Photo 4 shows face and side view etchings of welds in the $\frac{1}{2}^{\prime \prime} \times 2^{\prime \prime}$ and $\frac{1}{2}^{\prime \prime} \times 1.25^{\prime \prime}$ specimens used in tasks 2 and 3 . The wide side was defined as that surface being the greatest distance from the narrow "neck" as seen in Photo 4(b). All welds in the $\frac{1}{2}$ inch thick material had the same general shape and appearance as those seen here. The neck was always nearer to the narrow side of the specimen. Welds on the face of specimens $\frac{1}{8}$ " thick looked like those in Photo 4(a) but, because they were so thin, did not have a neck or any other characteristic feature in their side view.

Tests for the three tasks in this project were conducted using a SATEC 55 kip universal testing machine as seen in Photo 5. Other items of equipment shown include a reflection polariscope with uniform field compensator, a digital automatic recorder-printer for measuring maximum shearing strain, and a model P-3500 static strain indicator used for taking data from strain gages. A SB-10 switching and balancing unit (not shown) was used for multiple gage installations. 


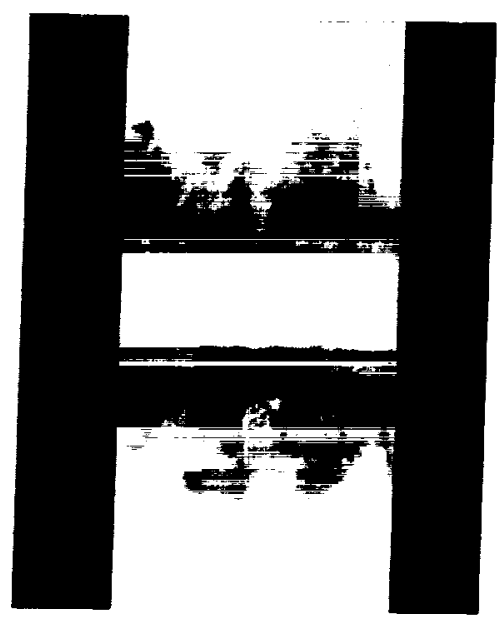

(a) Face View

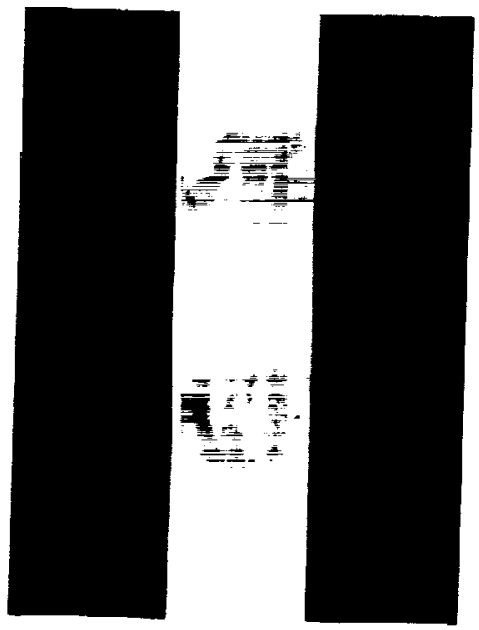

(b) Side View

Photo 4. Typical Weld, Bead Off, 1/2" Material

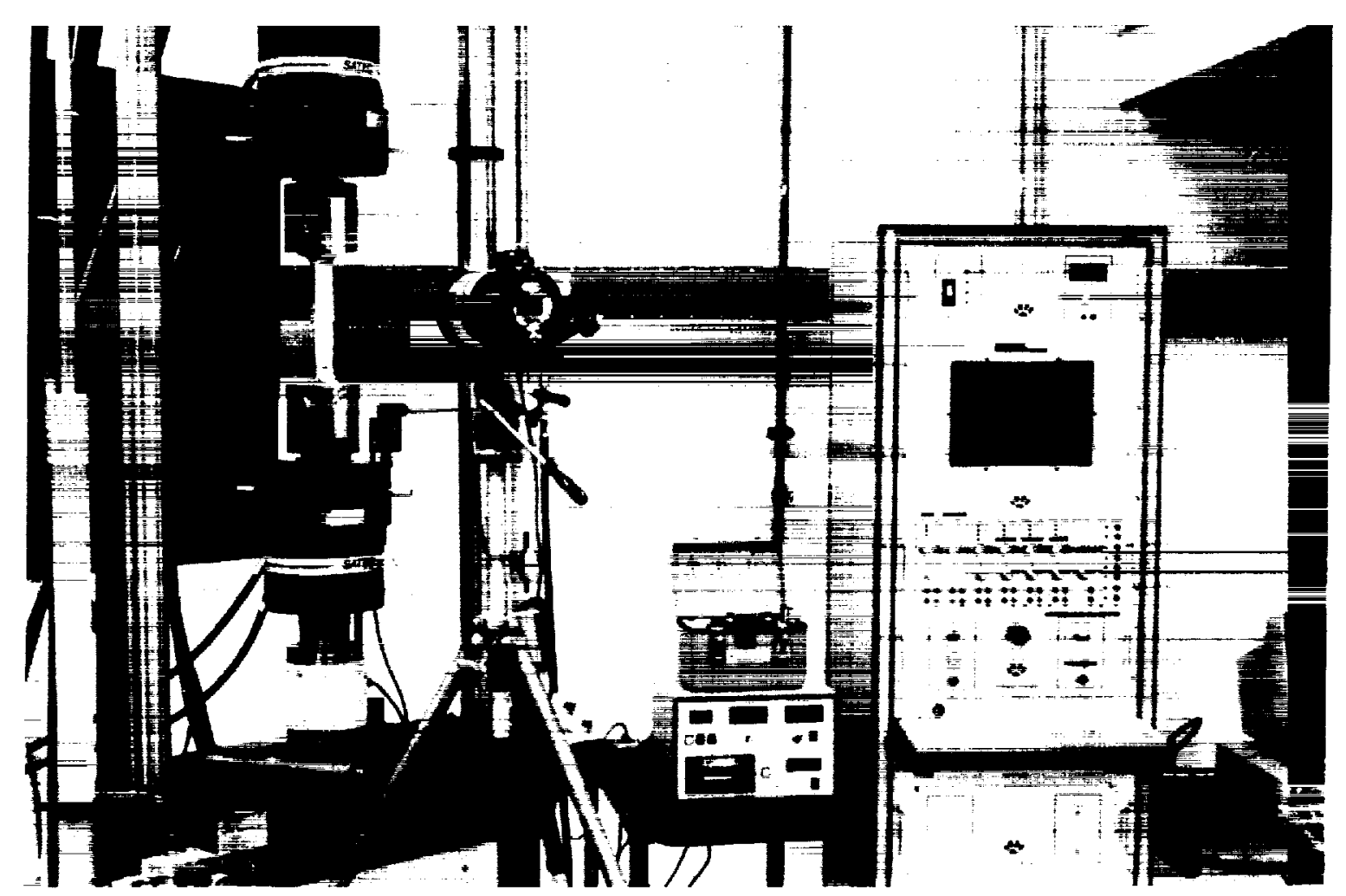

Photo 5. Test Machine and Equipment 


\section{GENERAL SPECIMEN BEHAVIOR}

\section{A. Bending}

Although test panels were fabricated by NASA personnel in a manner as careful and uniform as possible, specimens made from these panels were not nearly identical. No specimen was completely straight and, for most specimens, the parent material sections on either side of the weld did not lie in the same plane. Therefore, there was bending present in all specimens and, because of progressive non-uniform yielding starting in the weld and moving outward toward the parent material, the magnitude of the bending strain changed as the stress increased. In most graphs depicting stress-strain behavior of the specimens, the initial bending strain in the specimen may be clearly seen as an offset on the strain axis at zero stress. Therefore, one must not consider the stress-strain curves in this report as being obtained from ASTM type tensile tests for material properties. Rather, they represent the realistic, non-uniform behavior of an imperfect welded specimen subjected to tension.

To provide an indication as to the magnitude of bending strain present in the specimens, strains were measured at three stress levels on both sides of several specimens at a point $\frac{3}{4}^{\prime \prime}$ away from the centerline of the weld. Bending strains were then extracted from these data. As the stress-strain curves show, this $\frac{3}{4}^{\prime \prime}$ point remained elastic at the three stress levels. Table 1 gives examples of the extent of bending strain present in several specimens of each type. 
TABLE 1. Examples of Bending Strain, (Microstrain)

\begin{tabular}{|c|c|c|c|}
\hline \multirow{2}{*}{ Specimen Size } & \multicolumn{3}{|c|}{ Stress, psi } \\
\cline { 2 - 4 } Specimen No. & 10,000 & 20,000 & 30,000 \\
\hline$\frac{1 / 2 " \times 2 "}{8-2}$ & & & \\
$8-3$ & 209 & 136 & 54 \\
$8-4$ & 339 & 330 & 290 \\
$1 / 8 " \times 1.25 "$ & 204 & 127 & 37 \\
\hline $2-1$ & & & \\
$2-4$ & 24 & 261 & 454 \\
$3-1$ & 269 & 298 & 219 \\
$3-2$ & 260 & 255 & 319 \\
$1 / 2 " \times 1.25 "$ & 263 & 400 & 385 \\
$6-1$ & & & \\
$6-2$ & 32 & 327 & 243 \\
$6-3$ & 183 & 293 & 446 \\
$0.71 " \times 1.4 "$ & 357 & 322 & 393 \\
$2-1$ & & & \\
$2-2$ & 468 & 523 & 654 \\
$1-4$ & 578 & 753 & 740 \\
& 535 & 507 & 452 \\
\hline
\end{tabular}

\section{B. Discontinuous Yielding and Strain Hardening}

All specimens except one (\# 3-4, $\frac{1}{8}$ " gage, centerline and $\frac{1}{4}^{\prime \prime}$ line, $\frac{1}{2}^{\prime \prime} \times 2^{\prime \prime}$ specimen) exhibited distinct discontinuous yielding characteristics. This behavior was observed when using strain gages as large increases in strain which occurred for small increases in load and when using photoelastic coatings as instantaneous jumps or changes in the fringe pattern while the load increased in at a uniform rate. For the as welded, $\frac{1}{8}$ and $\frac{1}{2}^{\prime \prime}$ thick specimens, discontinuous yielding usually began between 20 and $25 \mathrm{ksi}$ whereas in the $1.4^{\prime \prime}$ thick heat treated material, it began between 35 and 40 ksi. Figure 2 shows an example of the discontinuous yielding in $\frac{1}{2}^{\prime \prime}$ thick material when using a $\frac{1}{4}^{\prime \prime}$ strain gage attached to a specimen at 


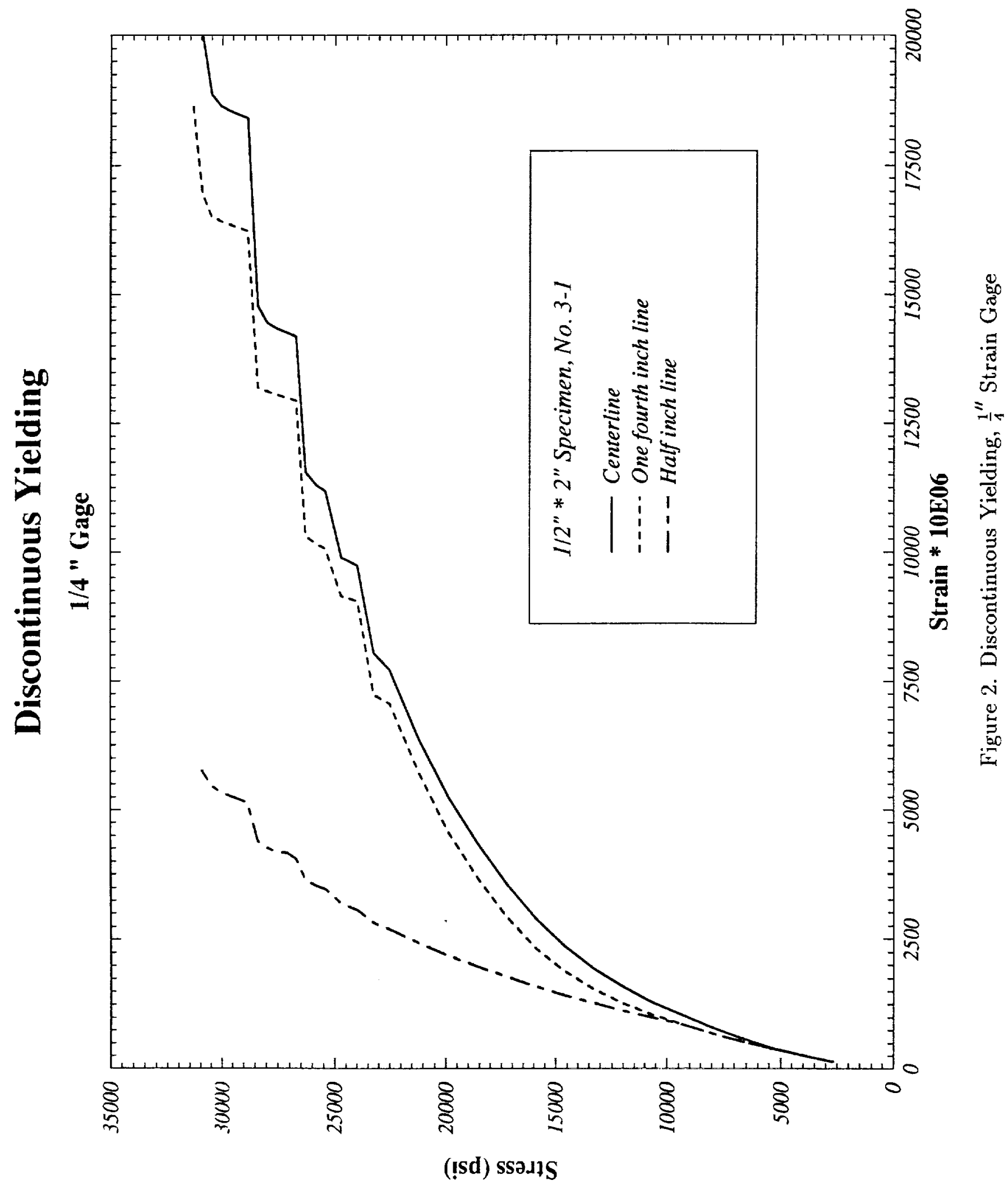


three different locations. No discontinuous yielding was observed at points $\frac{3}{4}$ " and 1 " from the centerline of the weld. Fifteen $\frac{1}{2}^{\prime \prime}$ thick specimens were tested using strain gages having five different gage lengths ranging from $\frac{1}{4}^{\prime \prime}$ to $\frac{1}{64}$.

Discontinuous yielding is the result of a slip-hold- slip-hold process in which the energy required to slip from one hold position to another hold position is represented by the area under the segmented portions of the stress-strain curves. A computer program was written to calculate those areas using the input stress-strain data taken from all fifteen specimens. Figures 3-6 show the energy per unit volume required for slip at various stress levels in the $\frac{1}{2}$ "thick material at the centerline of the weld and at three different locations relative to the centerline. A linear least squares fit was obtained for the scatter, and as seen in Figures 3-5, there are no significant differences in the average energy required for slip at the center, $\frac{1}{4}$, and $\frac{3}{8}^{\prime \prime}$ lines. Energy requirements for slip at the $\frac{1}{2}^{\prime \prime}$ line (Figure 6 ) in the parent material are seen to be quite different from those at locations closer to the weld centerline.

Having noted the highly inelastic action of the material near the weld centerline, tests were conducted to determine the general stress-strain behavior of the $\frac{1}{2}^{\prime \prime}$ thick as welded material in its virgin state and for the second load application. Figures 7 and 8 show the material behavior at the weld centerline for the first and second loadings. Data were taken using a $\frac{1}{16}^{\prime \prime}$ strain gage. Note in Figure 8 the near perfect strain hardening characteristic of the material. Similar characteristics for the second loading of other specimens are shown in Figures 9-11 for points $\frac{1}{4} ", \frac{3}{8}^{\prime \prime}$, and $\frac{1}{2}^{\prime \prime}$ from the weld centerline. Note that near perfect strain hardening has occurred up to the stress applied during the first loading. Note also 


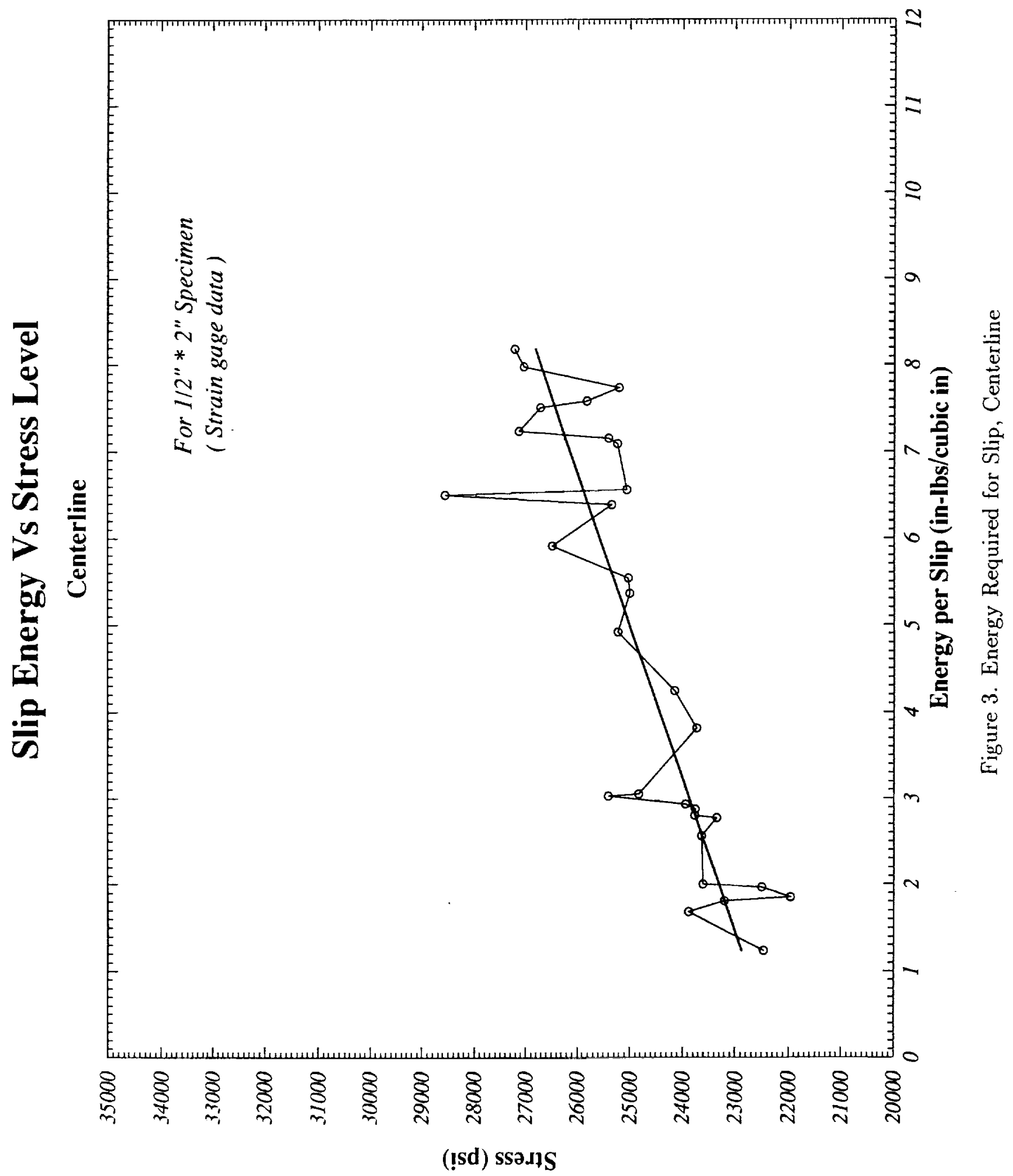




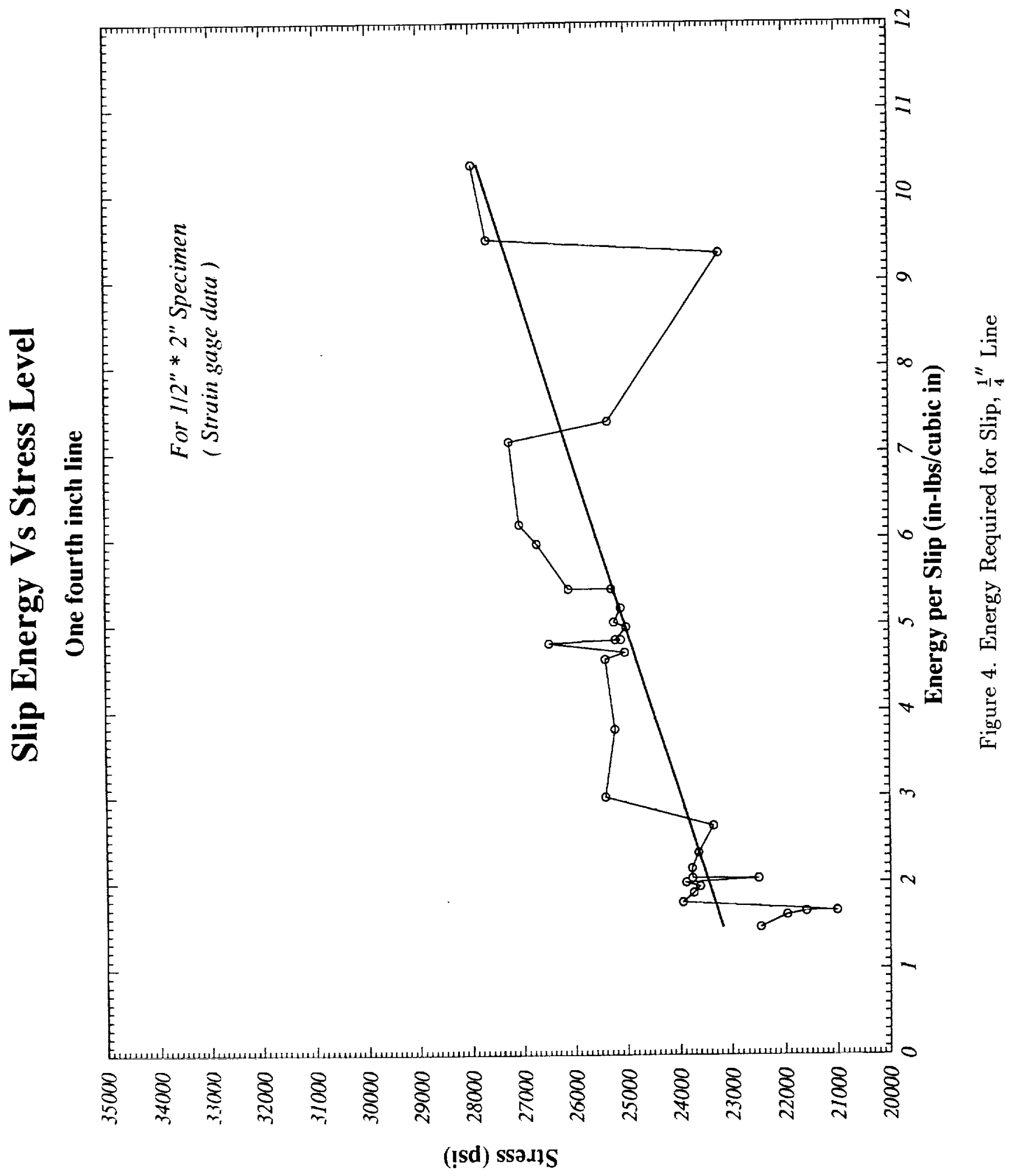




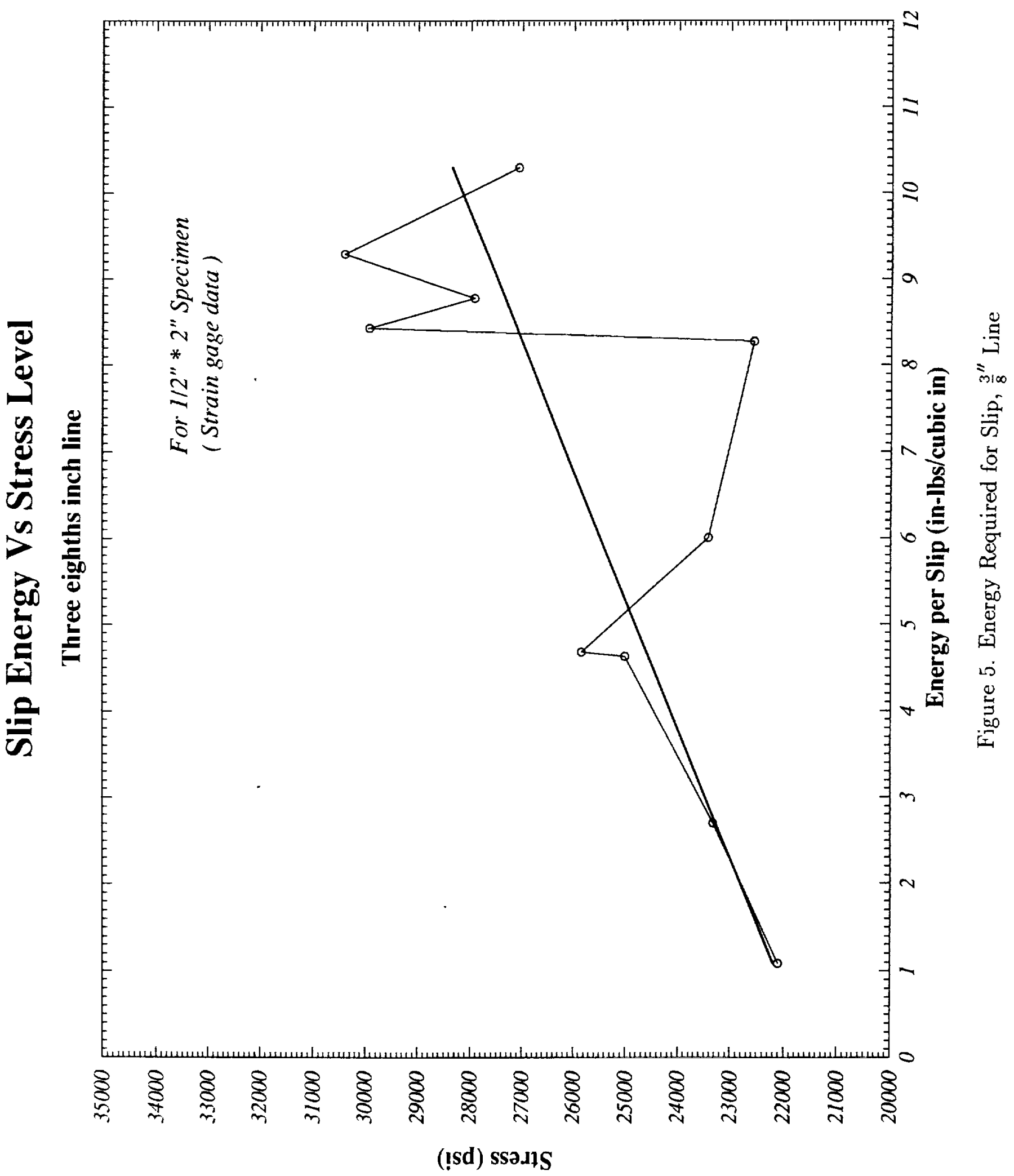




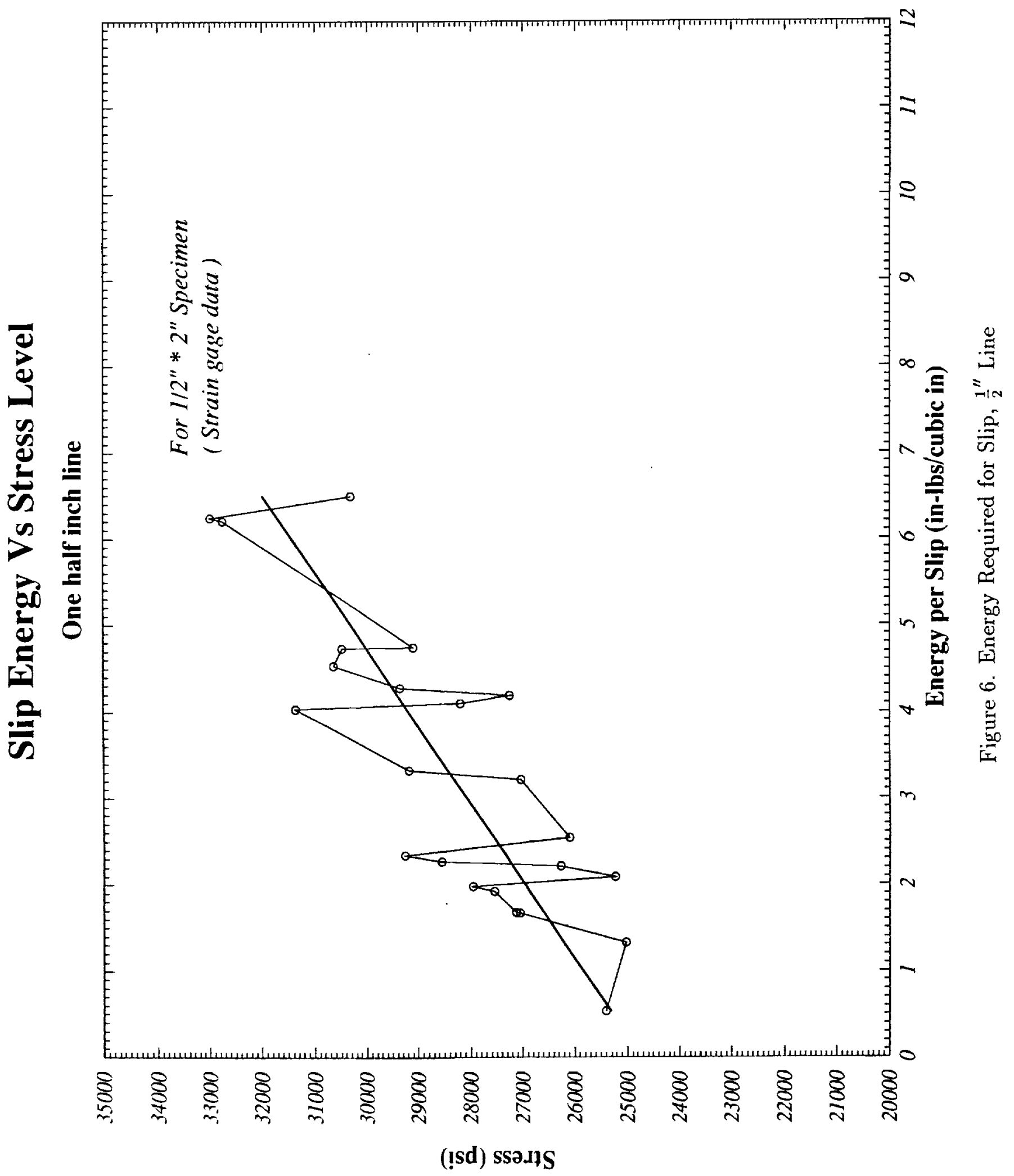




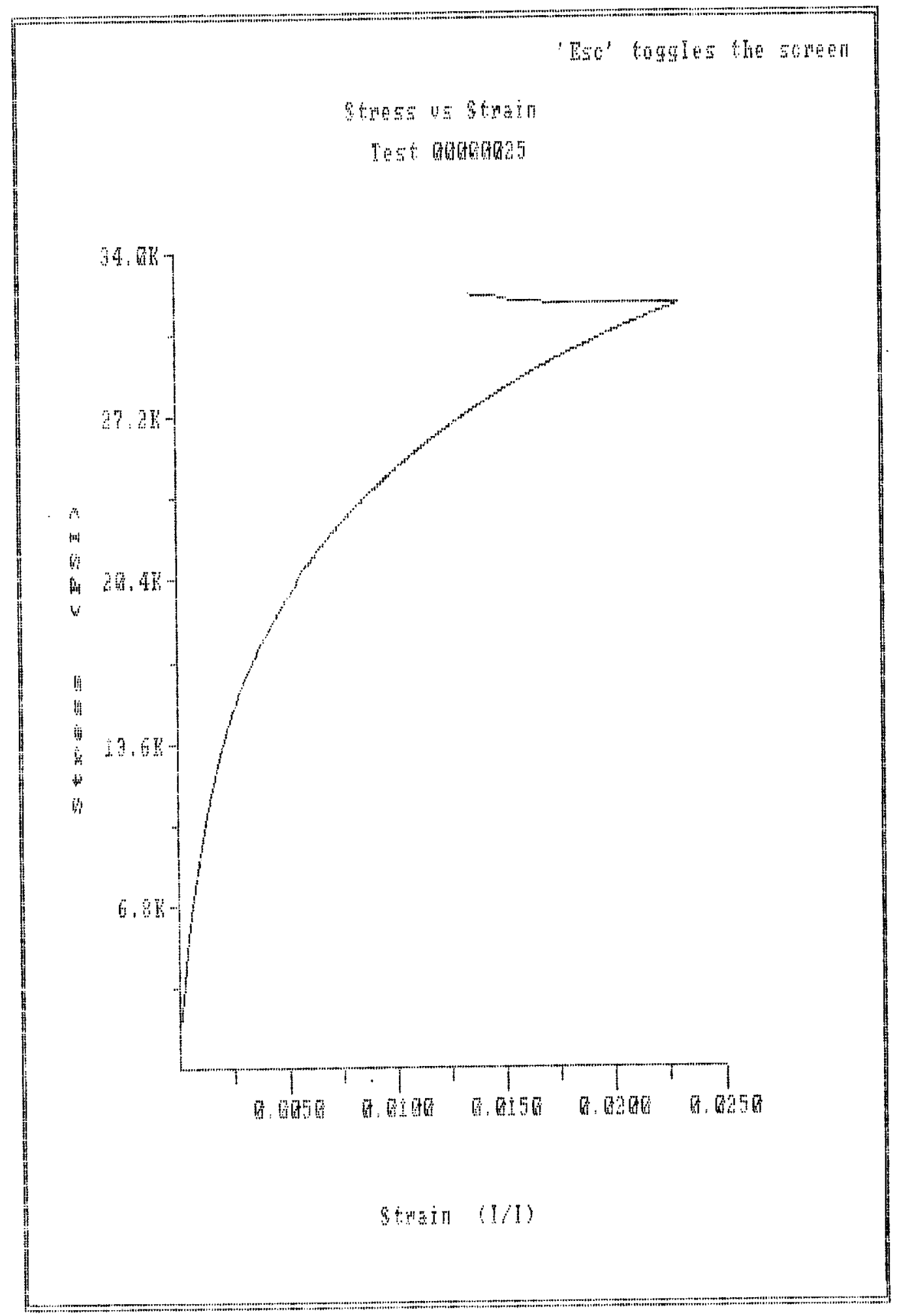

Figure 7. First Loading Curve, Centerline, $\frac{1}{2}^{\prime \prime}$ Material 


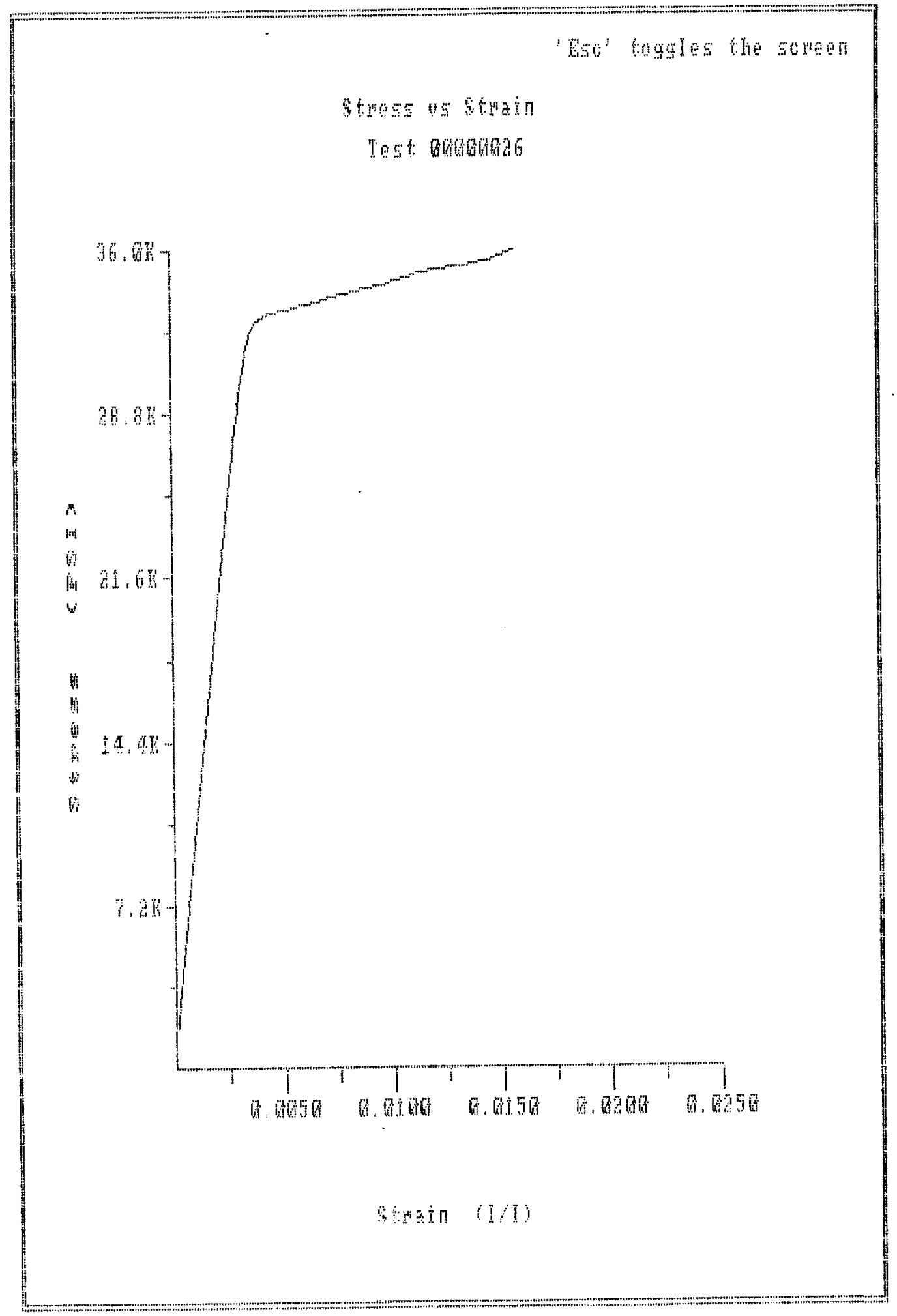

Figure 8. Second Loading Curve, Centerline, $\frac{1}{2}$ "Material 


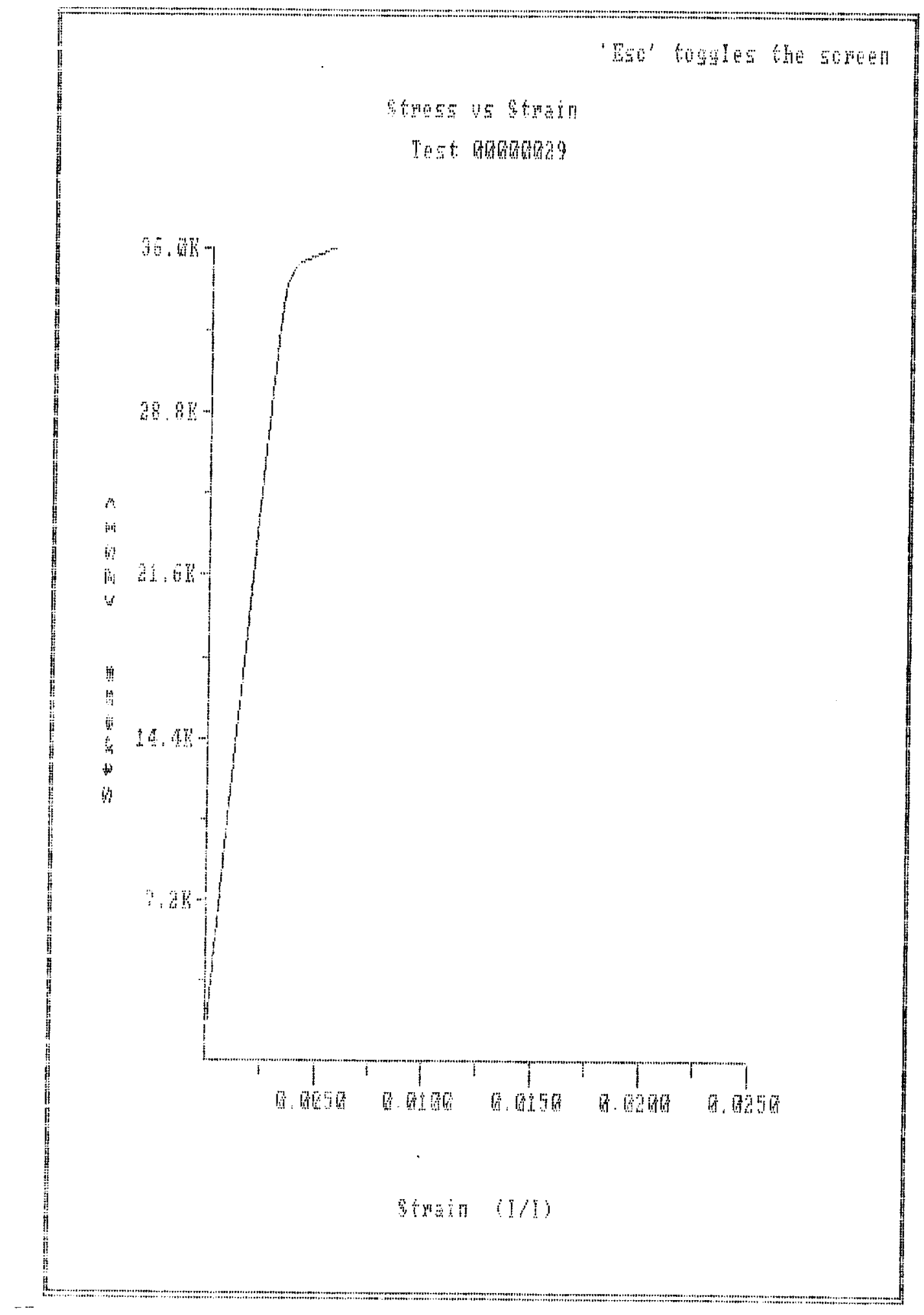

Figure 9. Second Loading Curve, $\frac{1}{4}$ Line, $\frac{1}{2}^{\prime \prime}$ Material 


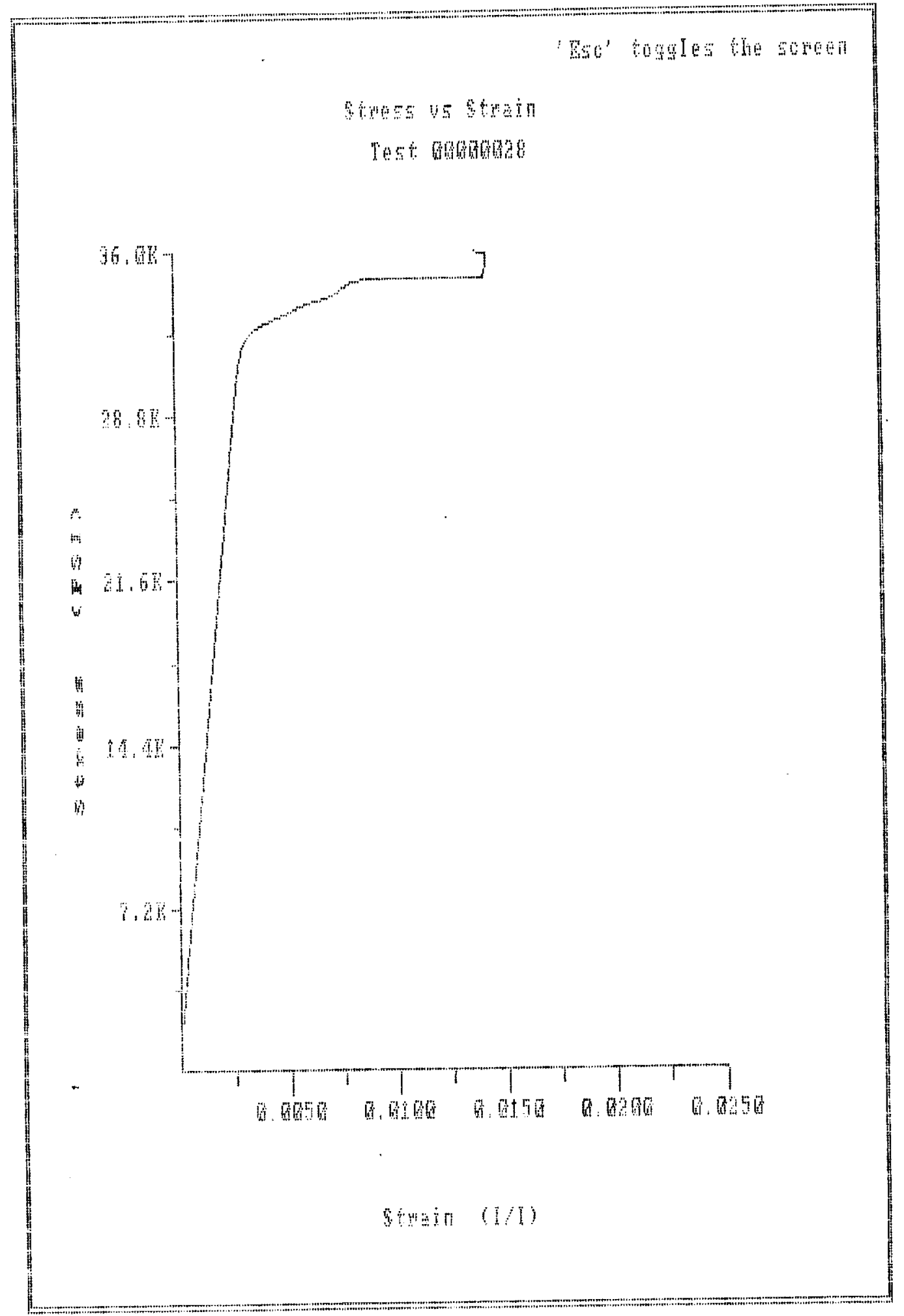

Figure 10. Second Loading Curve, $\frac{3^{\prime \prime}}{8}$ Line, $\frac{1}{2}^{\prime \prime}$ Material 


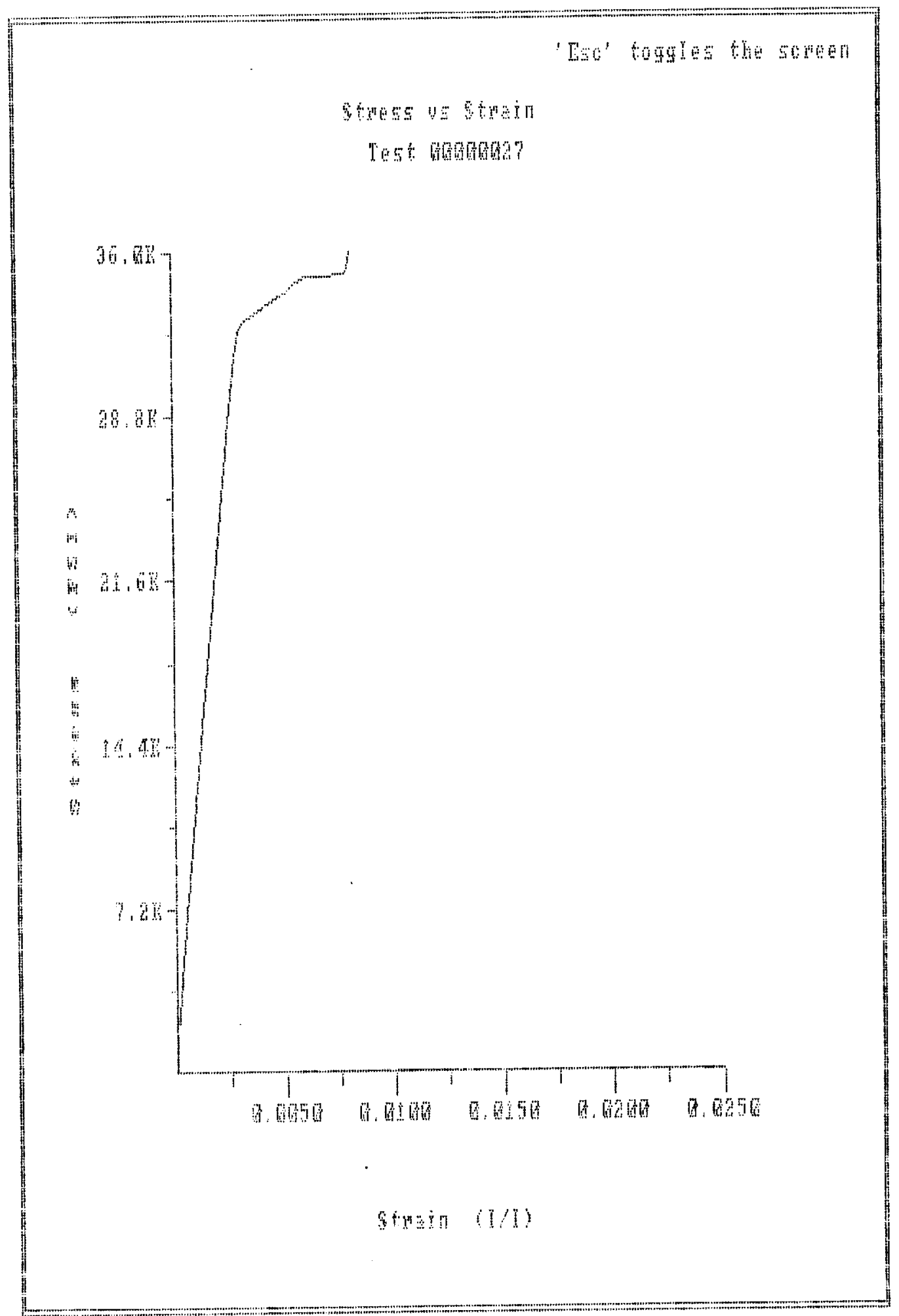

Figure 11. Second Loading Curve, $\frac{1}{2}^{\prime \prime}$ Line, $\frac{1}{2} "$ Material 
in Figures 10 and 11 that clear examples of discontinuous yielding can be seen near the $36 \mathrm{ksi}$ stress level. In tests of specimens used for this project, discontinuous yielding was observed at stress rates from $2,266 \mathrm{psi} / \mathrm{min}$ to $10,000 \mathrm{psi} / \mathrm{min}$. Noting the strain hardening characteristics of the as welded material, it seems clear that more predictable performance of this material can be obtained if the welded joints are loaded once prior to their use in functioning structures.

\section{RESULTS FROM TASK 1}

\section{A. Through the Weld Tests}

\section{Bead On}

Photoelastic coatings (References 3-8) were applied to the $1.4^{\prime \prime}$ thick heat treated specimens to determine behavior of the joint as seen through the weld thickness (Photo 2(b)). The $1.4^{\prime \prime}$ thick specimens were made from 2219-T37 plate and 2319 weld material heat treated at $350^{\circ} \mathrm{F}$ for 18 hours. Behavior of the material through the weld thickness was highly irregular and non-uniform.

The wide side of the weld was substantially weaker and more ductile than the narrow side. This behavior can be clearly seen in Photo 6 which indicates shear strain patterns through the weld at three different stress levels. It is clear from the fringe patterns that the protruding beads carry only a small portion of the load. The difference in behavior between the wide and narrow sides of the weld can be clearly seen in Photo 7 which shows the wide side bead, the overall weld, and the narrow side bead at the same stress level of 41,490 psi. 


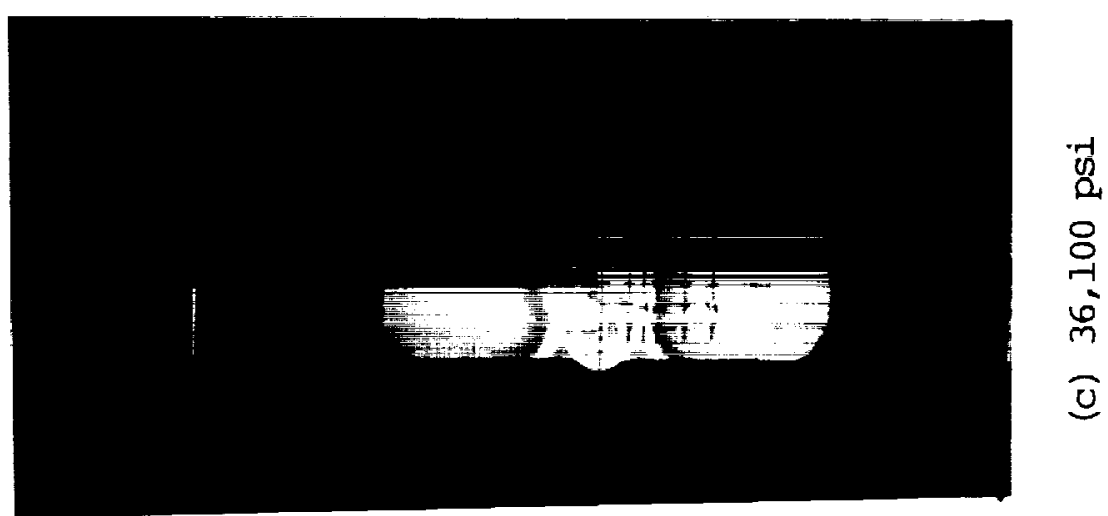

-
0
8
0
-1
0
'0
0

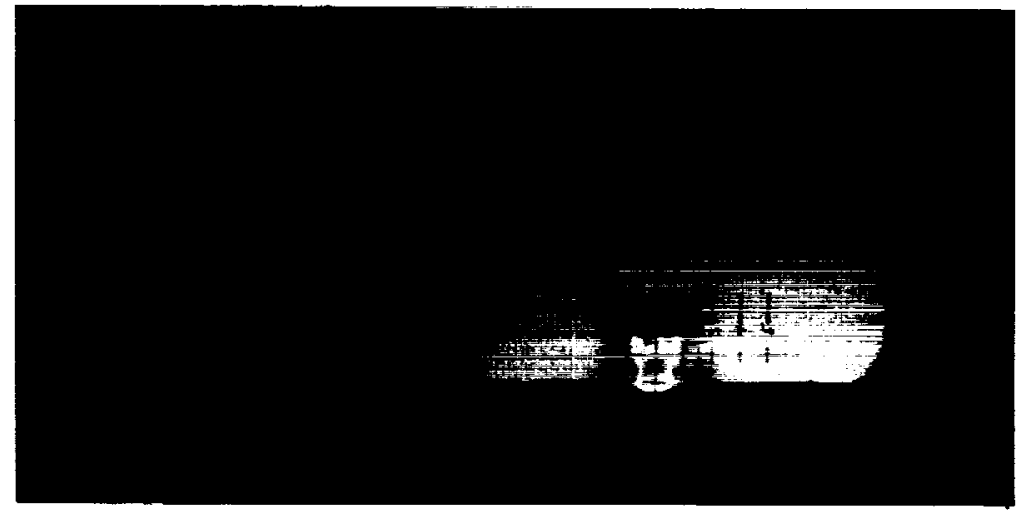

E
శ్
$\mathbb{8}$

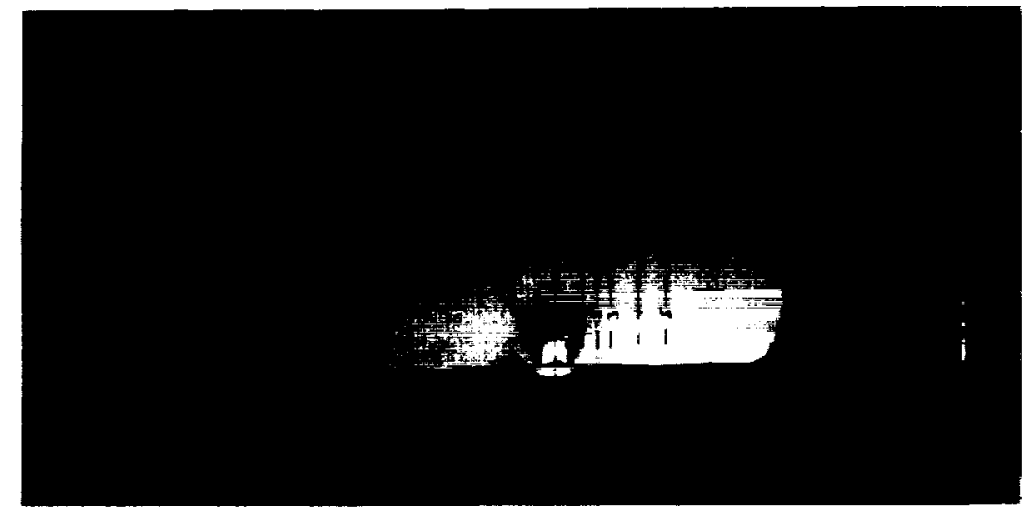

$\circ$

ข

$\stackrel{ก}{N}$ 

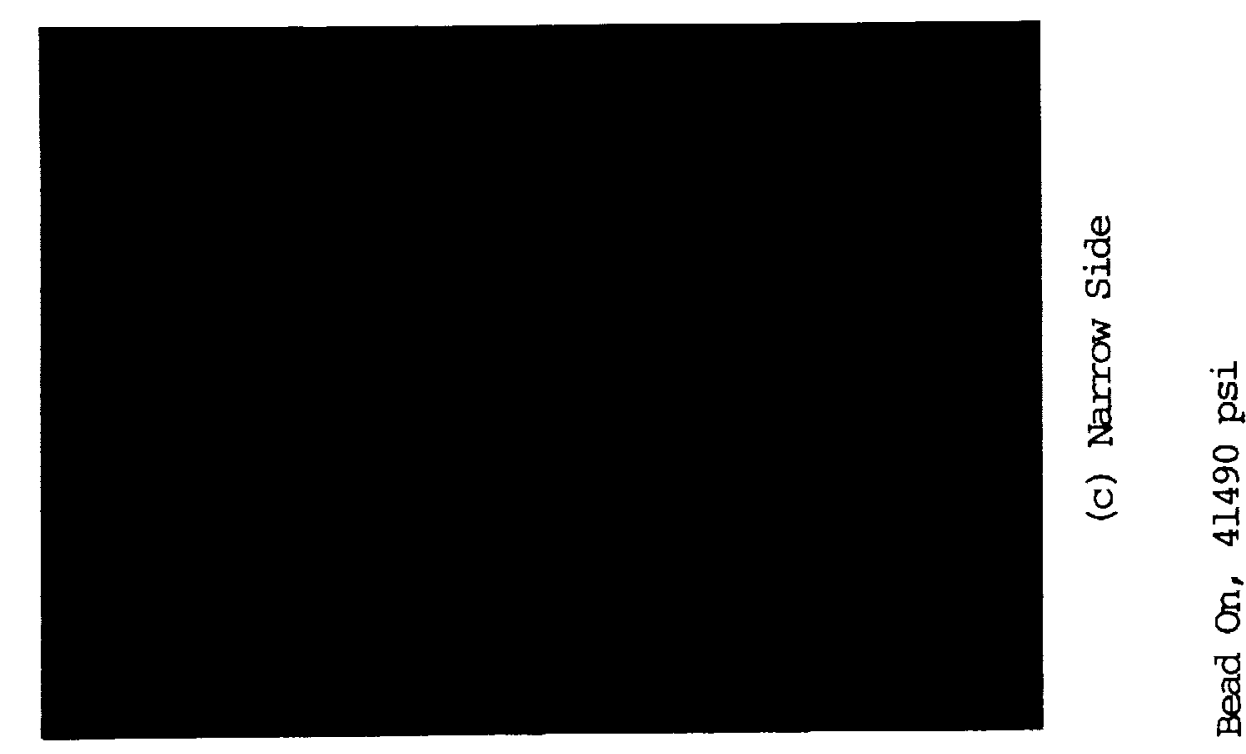

foxy

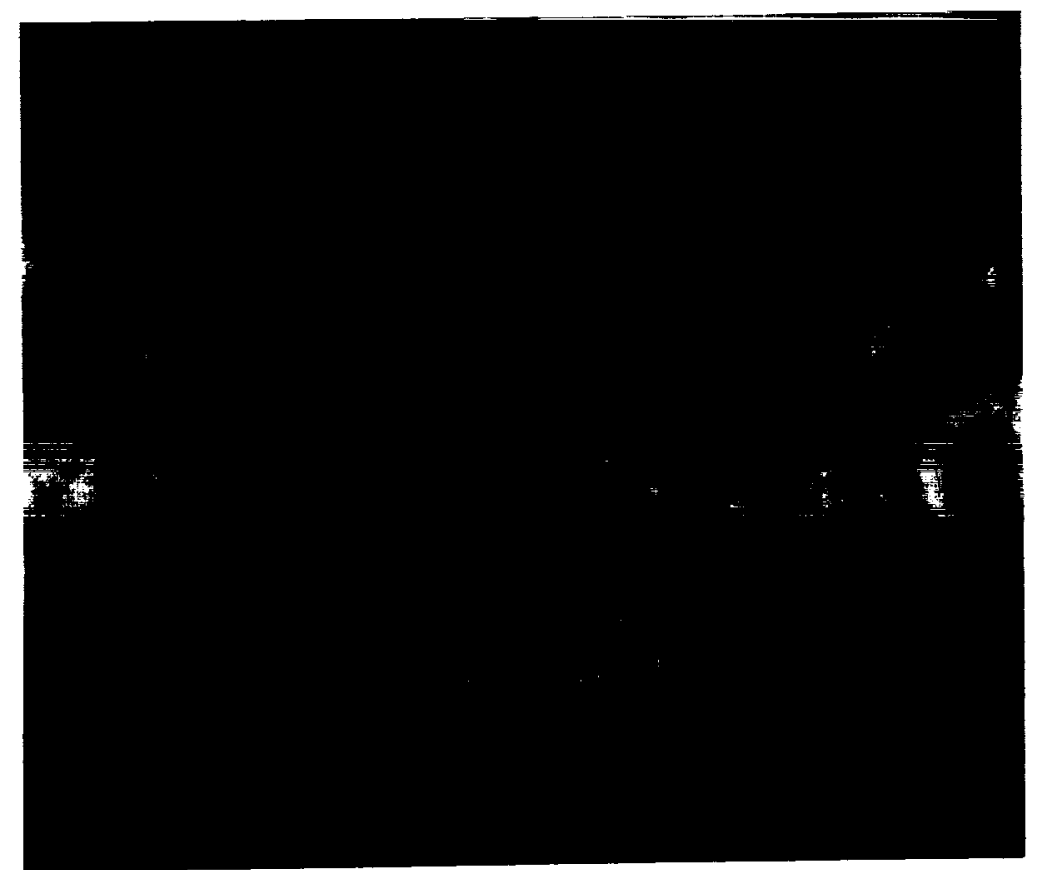


Note the high concentration of fringes on the wide side compared to those on the narrow side. In all tests having the full bead on, the largest strain was developed at the upper or lower fillet of the full bead on the wide side of the weld. When loaded to fracture, the specimen broke near the fusion boundary containing that fillet where the largest strain was initially observed. The sequence of strain development at the fillet of the bead can be clearly seen in Photo 8. For this specimen, the fracture initiated at the upper fillet on the bead seen in Photo 8. Figures 12-15 are Photostress-strain curves describing material behavior at specific locations in the welded joint. Figure 12 indicates behavior along a centerline parallel to the axis of loading. Note that points $\frac{3}{4}^{\prime \prime}$ and $1^{\prime \prime}$ away from the weld center were always elastic whereas significant yielding occurred at all other points. Figures 13-15 depict behavior along three lines, perpendicular to the load axis, at the center of the weld and at distances of $\frac{1}{4}$ " and $\frac{1}{2}$ " below the center. Curves labeled as "left centerpoint" and "right centerpoint" refer to those vertical lines seen in Photos 6 and 7 which lie on either side of the vertical centerline. These lines are positioned 0.35 inches to the left and right of the vertical centerline. In Figures 13 and 14, note the much greater ductility at the left center point than is seen for the center and right center points. This greater yielding at the left center point is clearly seen in Photos 6 and 7. However, along a line $\frac{1}{2}^{\prime \prime}$ below the weld, although considerable yielding was present, the behavior was much more uniform as seen in Figure 15. Average mechanical properties of proportional limit and yield strength along the vertical centerline are given in Figure 16. Values of $44 \mathrm{ksi}$ for the proportional limit and 54 ksi for the yield strength at the $1^{\prime \prime}$ location were taken from data contained in reference (1) 

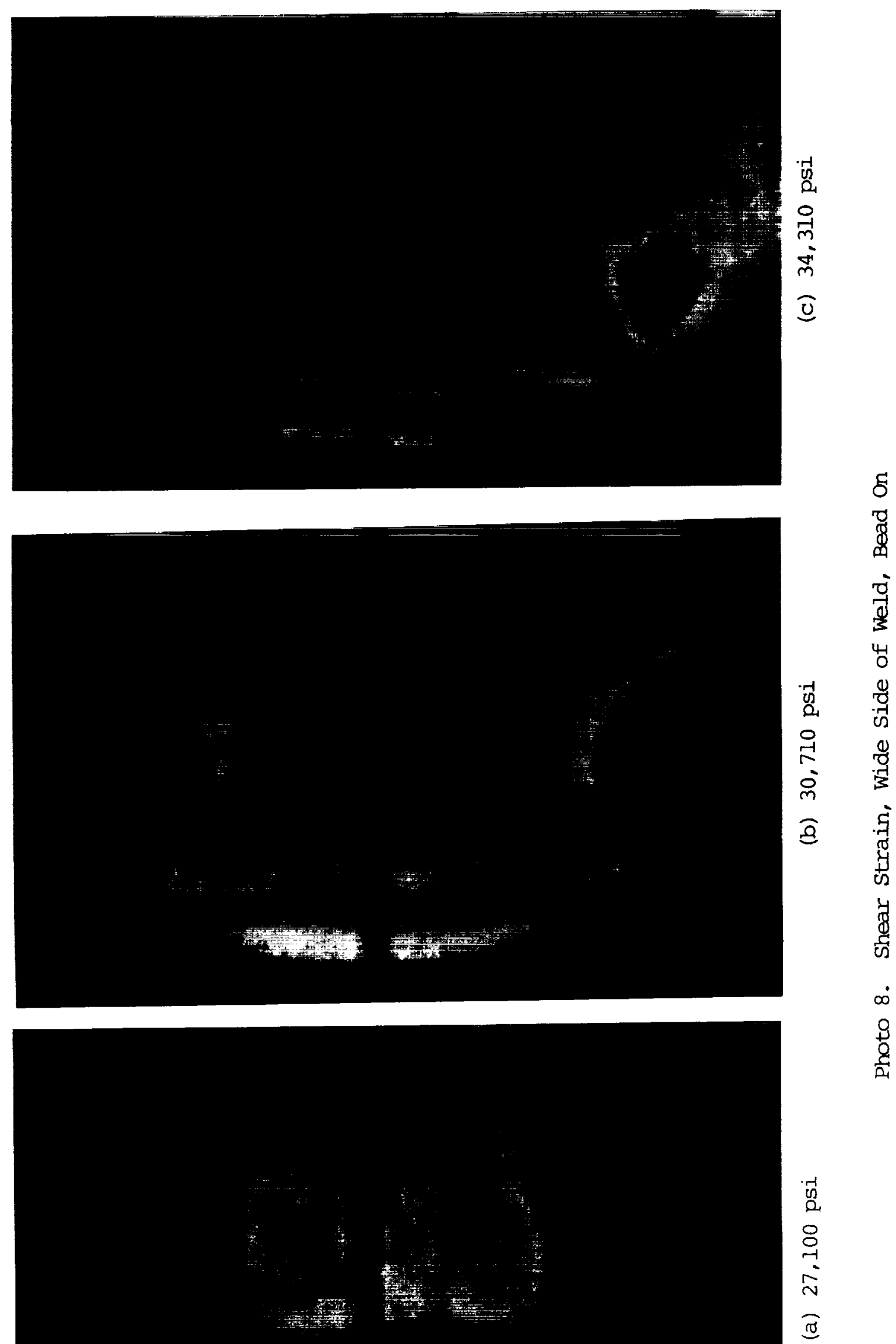

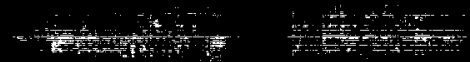




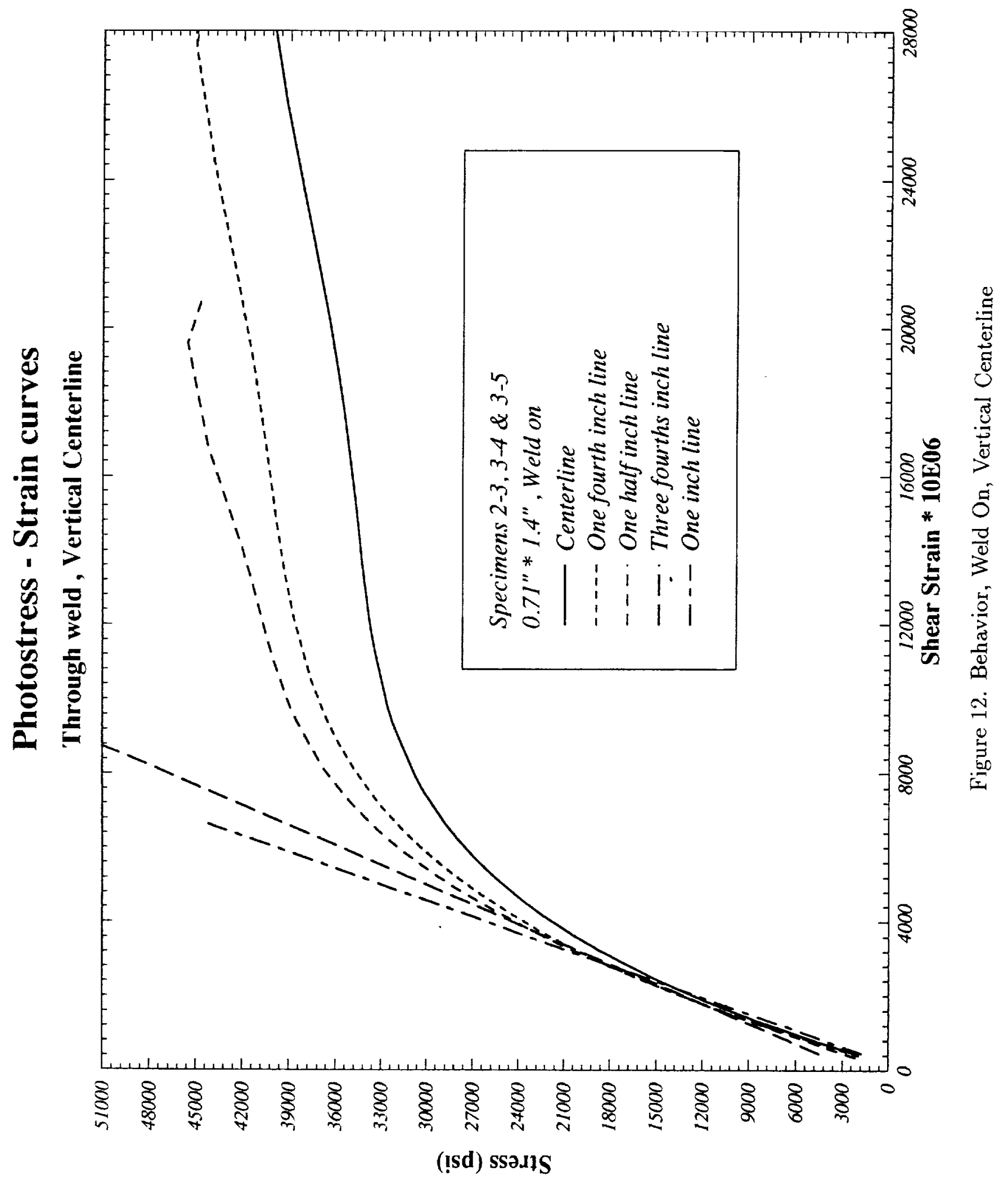




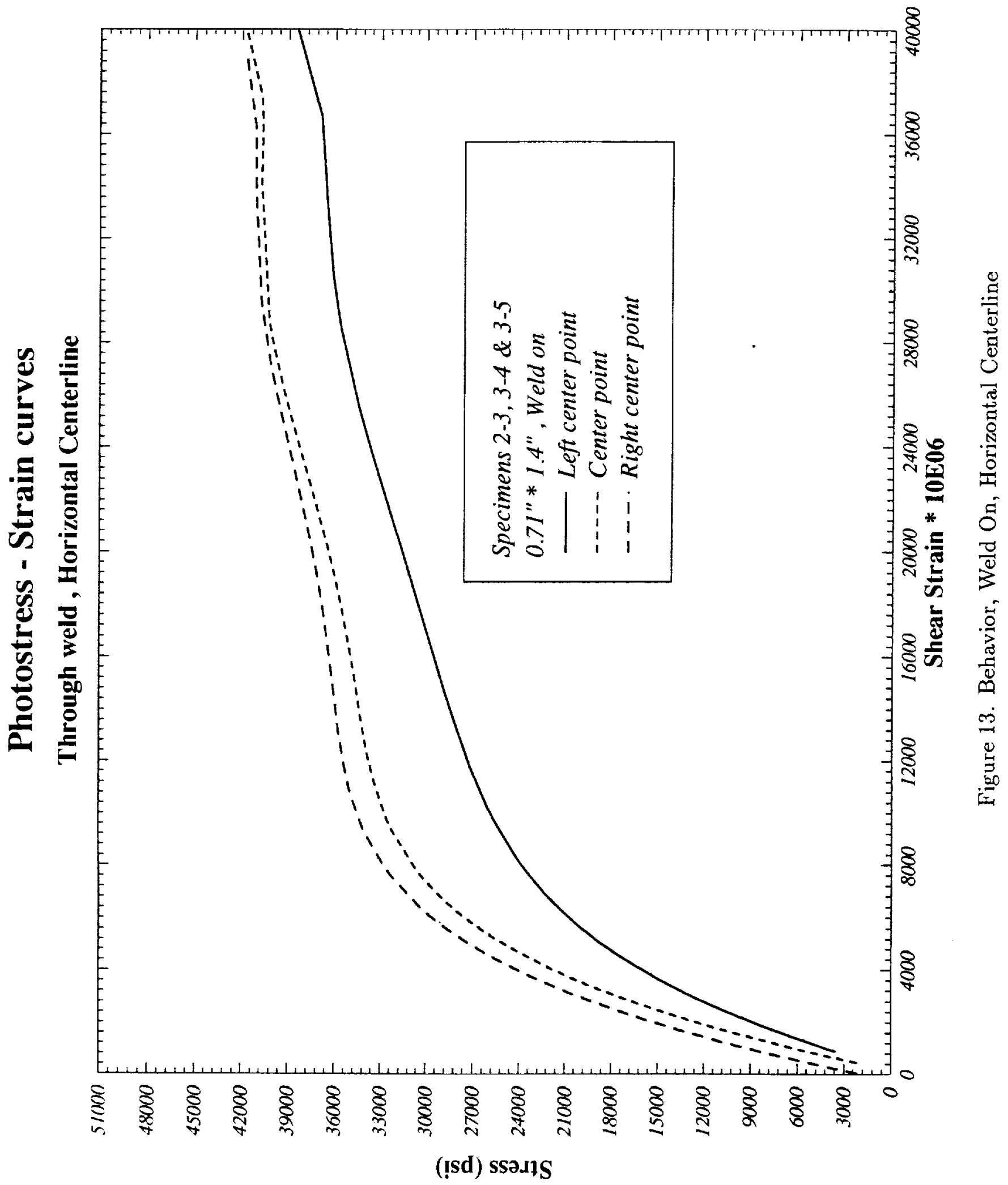




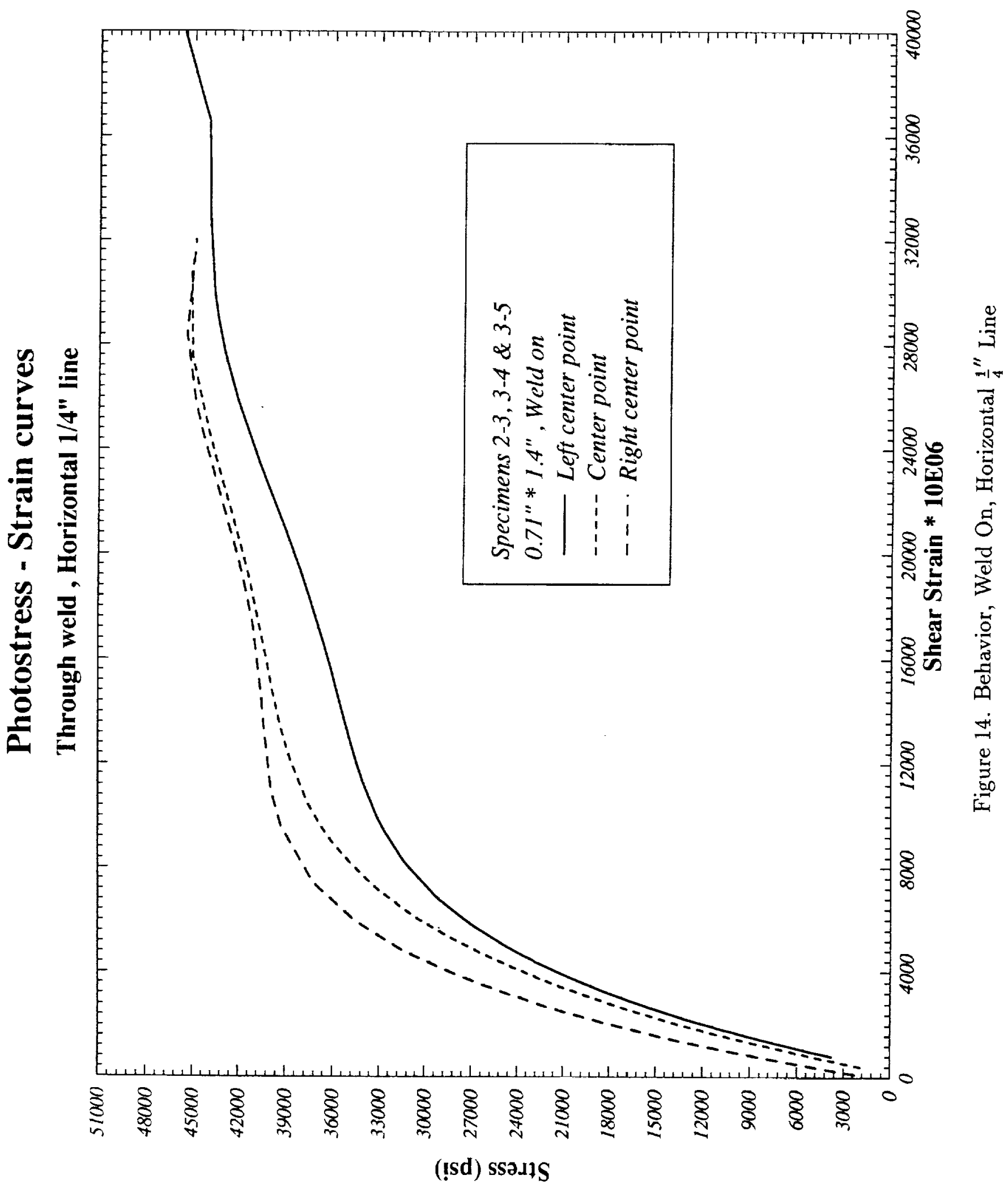




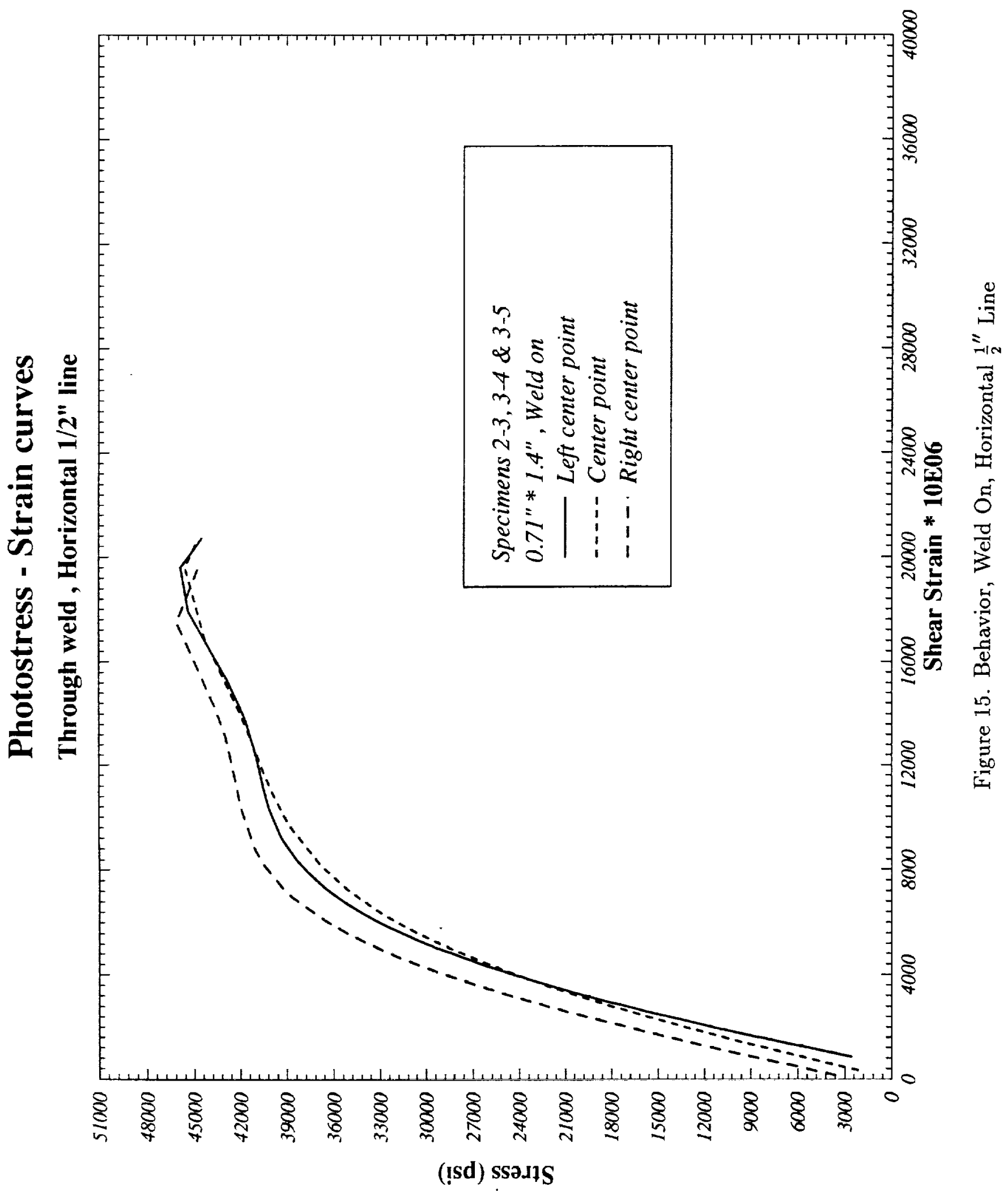




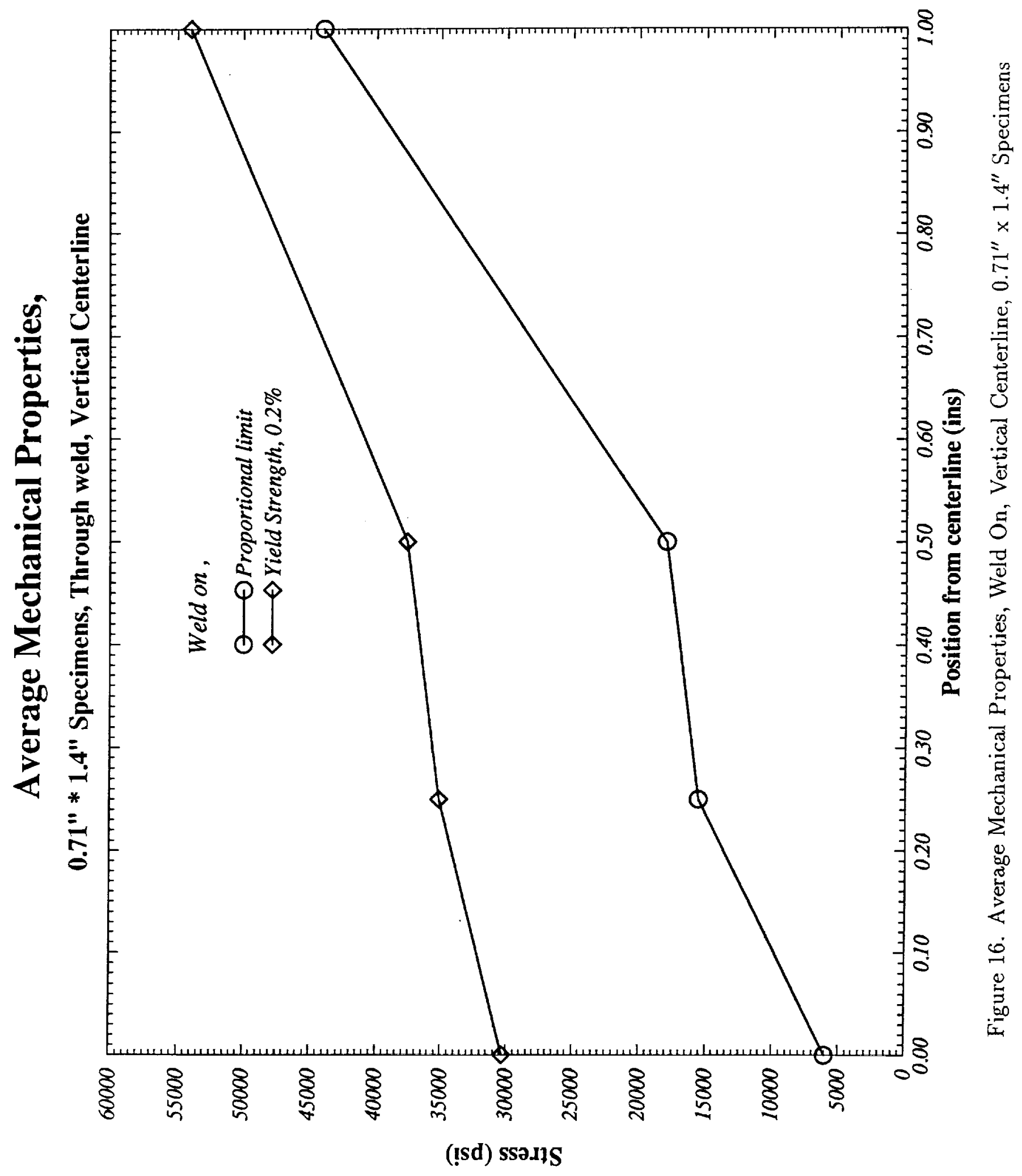


since yielding did not occur at the $\frac{3}{4}^{\prime \prime}$ and $1^{\prime \prime}$ locations during these tests.

\section{Bead Off}

Behavior of the $1.4^{\prime \prime}$ thick heat treated specimens having the bead ground off was determined in much the same manner as for specimens having the full bead on. Because of absence of the weld bead, fringe patterns were somewhat different from those having the bead on as seen in Photos 9 and 10. In Photo 9, note the fringe patterns as the stress increases. Progression of the fringe front from the wide side toward the center is quite clear in (a) and (b). In (b) and (c), one can note development of yielding from the narrow side toward the center. Fringes appear much like Luder's lines on the narrow side in (b) and (c). The Luder's line type fringe did not appear as clearly in specimens having the full bead on. In Photo 10(b), Luder's line fringes can also be seen. Photo 10(a) shows the wide side bead off pattern in which the two fillet locations can be seen as slightly blue dots just above and below the centerline. Photo $10(\mathrm{c})$ shows the narrow side fringe pattern at a higher stress in which the two fillet locations can be seen as dark red dots just above and below the centerline. Note that on both the wide and narrow sides the strains vary greatly from one point to another in any direction. Figures 17-19 are Photostress-strain curves describing material behavior at specific locations in the welded joint. Figure 17 shows material behavior at locations along the vertical centerline while Figures 18 and 19 give behavior along horizontal lines at the center of the weld and at a location $\frac{1}{4}$ " below the center. Only one specimen was tested for behavior along the horizontal $\frac{1}{4} "$ line. Average mechanical properties of proportional limit and yield strength along a vertical centerline are given in Figure 20. 


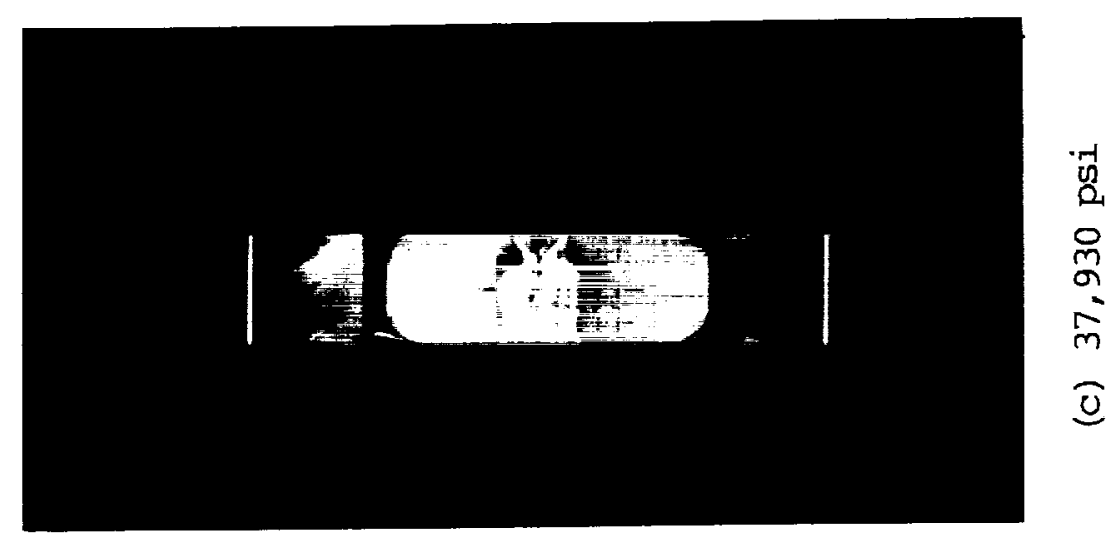

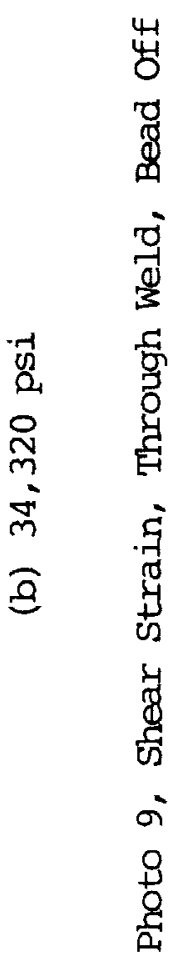

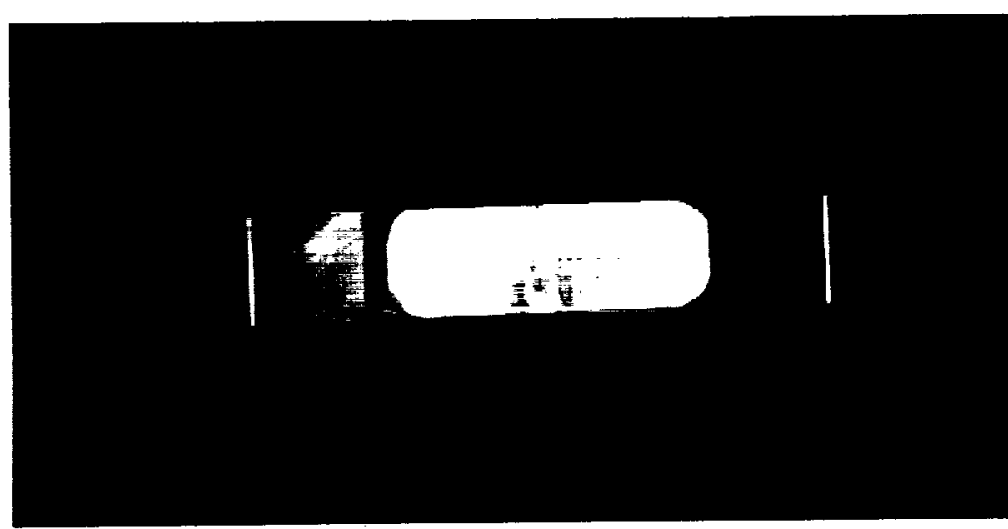

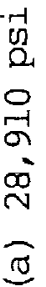




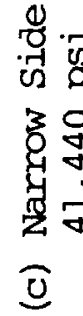

出

密

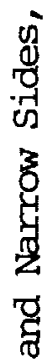

要

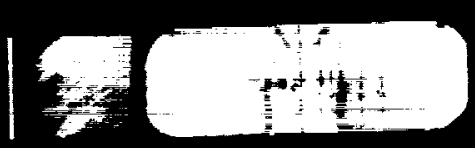

1

o 0 is

ㄴํำ

年

2

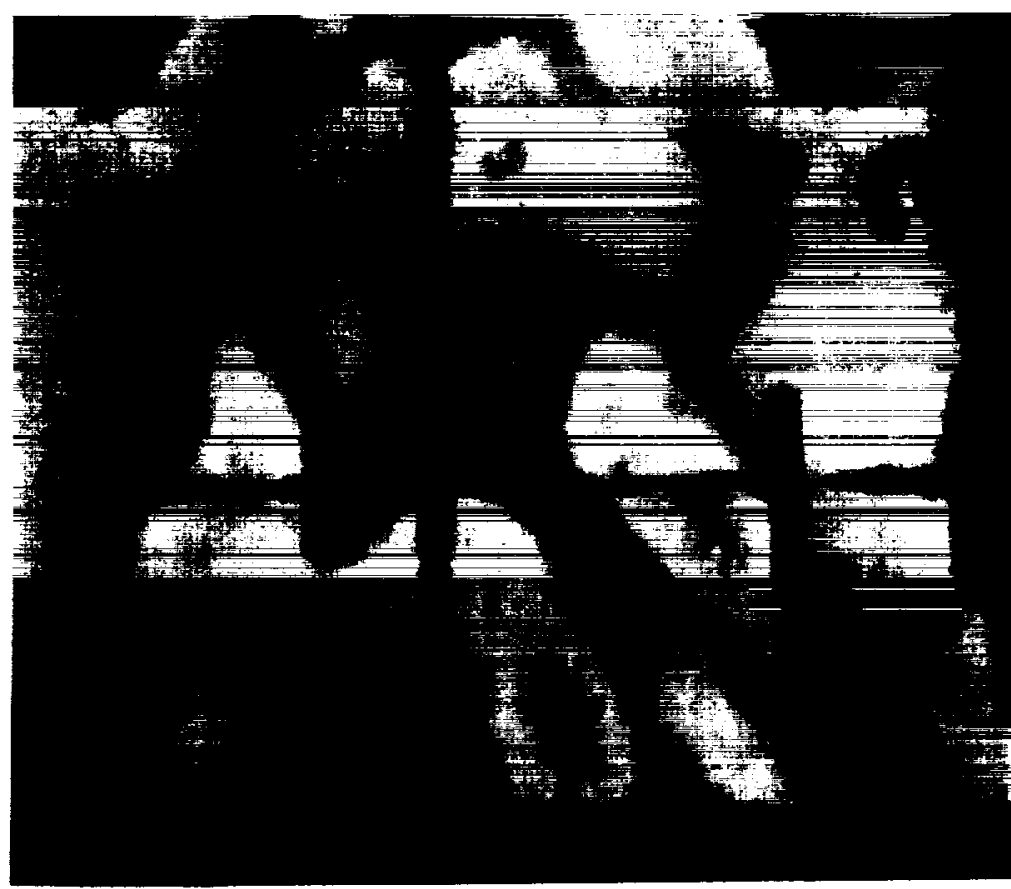




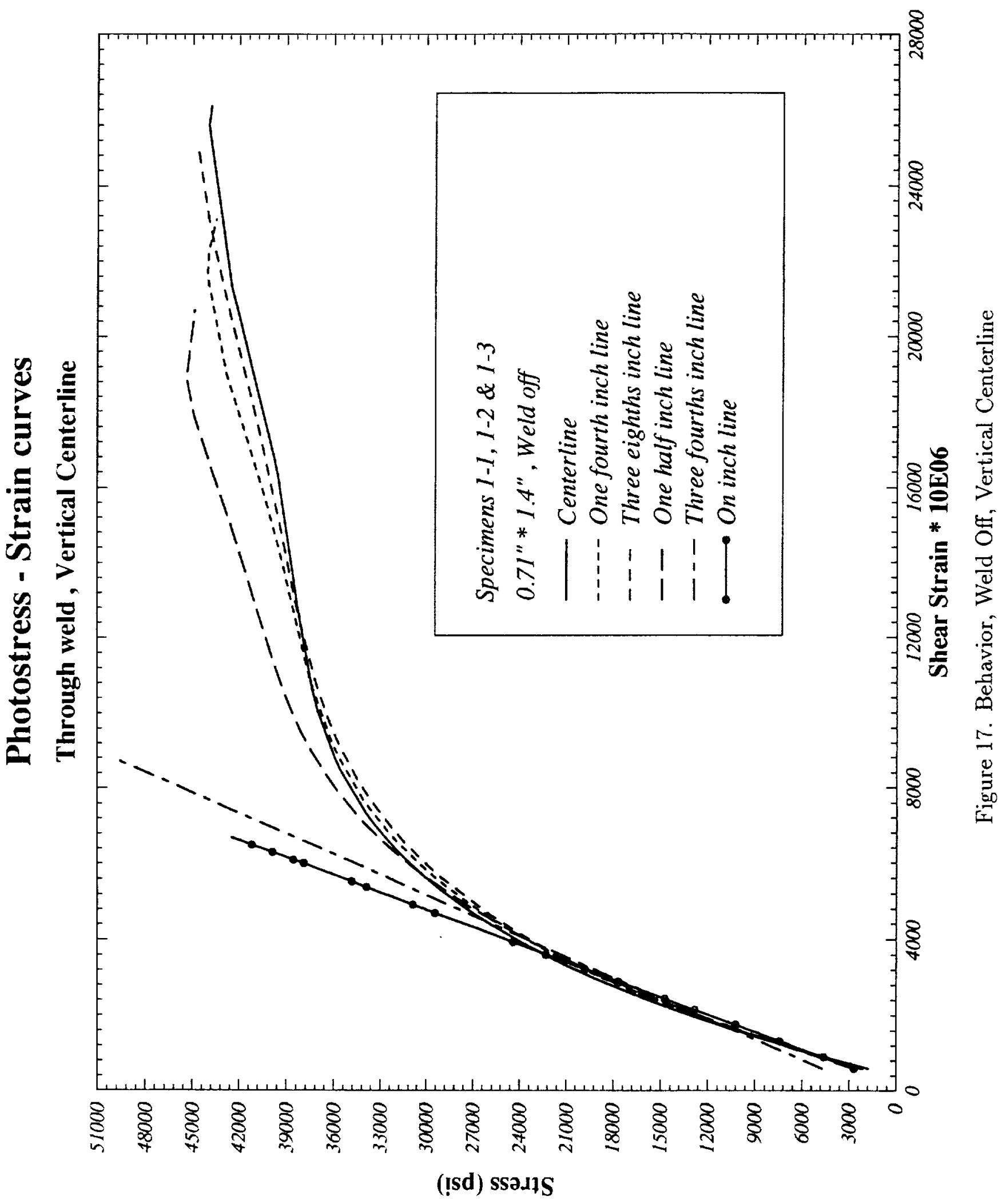




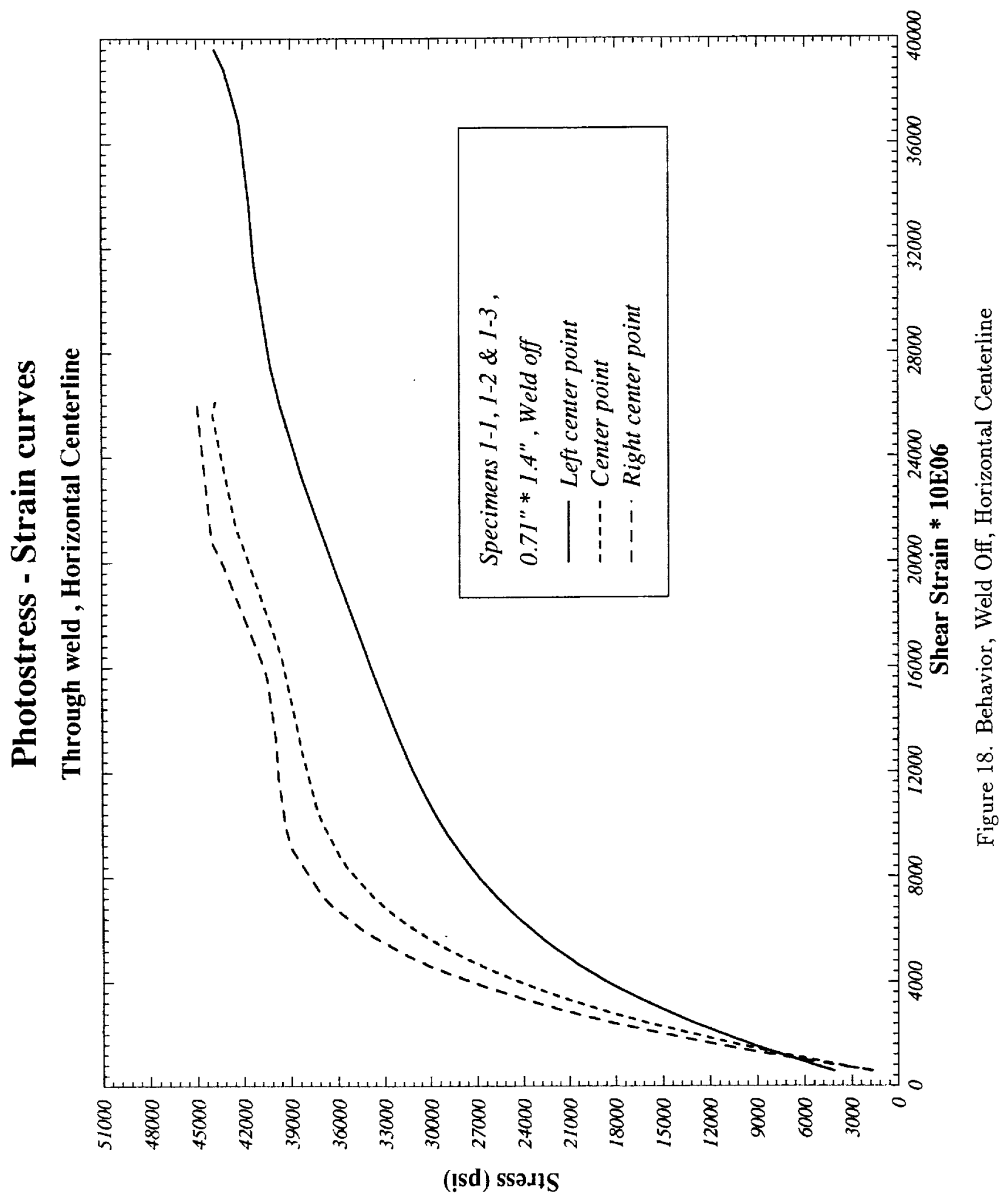




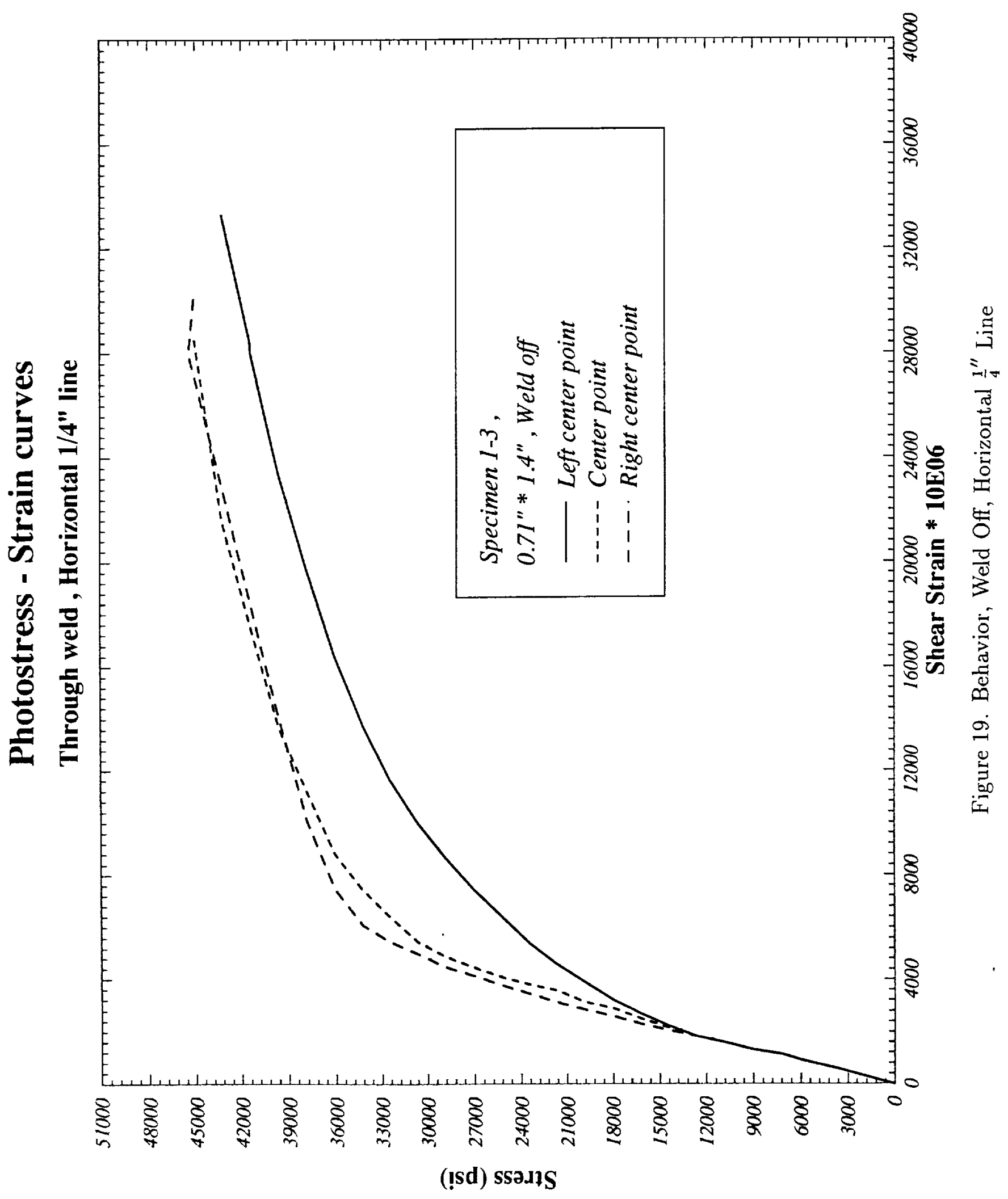




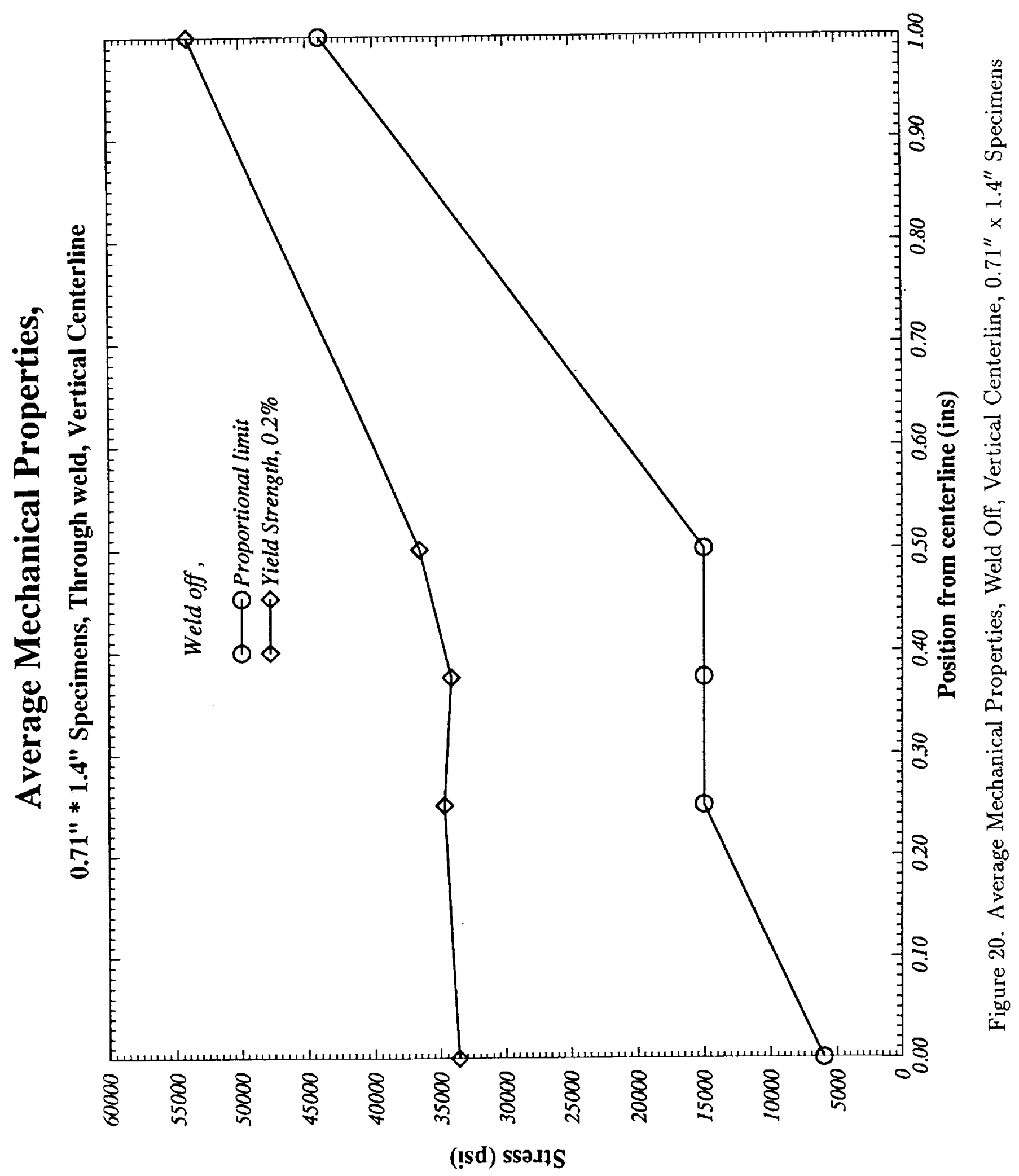




\section{B. Face of the Weld Tests}

\section{Bead On}

Special Photostress material 0.02 inches thick was made at Measurements Group in Raleigh, NC, and shipped to Tuscaloosa in a frozen, semi-polmerized state for thawing and contouring over the bead on the weld faces. This thin material was selected to produce a somewhat larger fringe order per unit strain and to allow for contouring down into the very small fillet between the parent material and the protruding bead. From the view toward the weld face, the fringe pattern with the bead on is quite different from the pattern with the bead off. Photo 11 shows the fringe pattern with the bead on at three different stress levels. Note that, relative to the centerline, fringes $\frac{1}{4}^{\prime \prime}$ and more away from the centerline have higher fringe orders. That this condition of lower fringe order at the centerline of the face of the protruding weld exists becomes obvious if one refers to Photos 6,7 , and 8 and notes the near zero fringe order at the outer extremity of the bead. In some instances, depending upon the overall geometry of the protruding bead, the fringe order at the outer extremity in two beads can be quite different at the same stress level. Photo 12 shows this difference in specimens 3-2 and 3-3. Specimen 3-2 shows a considerably larger fringe order at the centerline than does specimen 3-3 even though both specimens are under the same stress. Note the similarity of the two fringe patterns at points away from the weld. Photo 13 shows two views of a specimen with (a) being a microscopic view of (b). Near the fillet area of the weld between points zero and 1 , the fringe orders can be seen to increase as one moves down the curved surface of the weld toward the fillet located just above point 1 . Point 1 is 


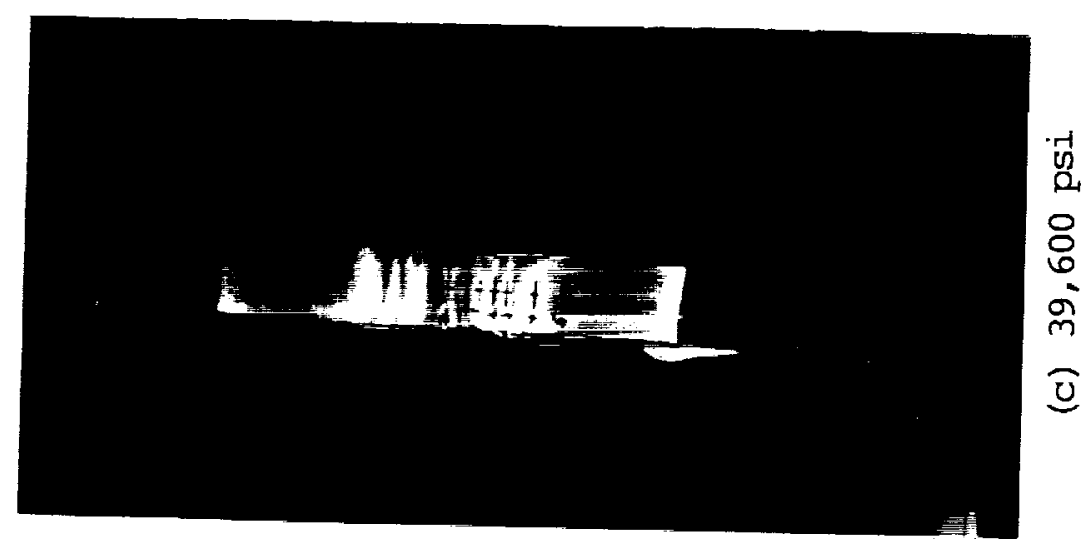

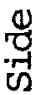
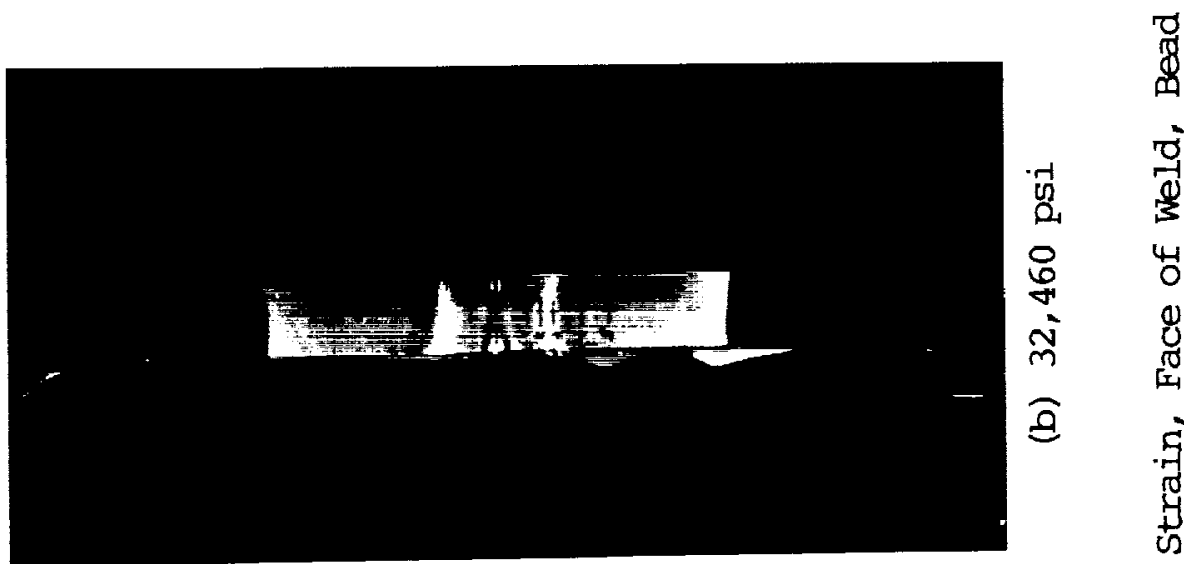

要

s

蛋

.

응

ले

ลิ

章

岁

न्न

量

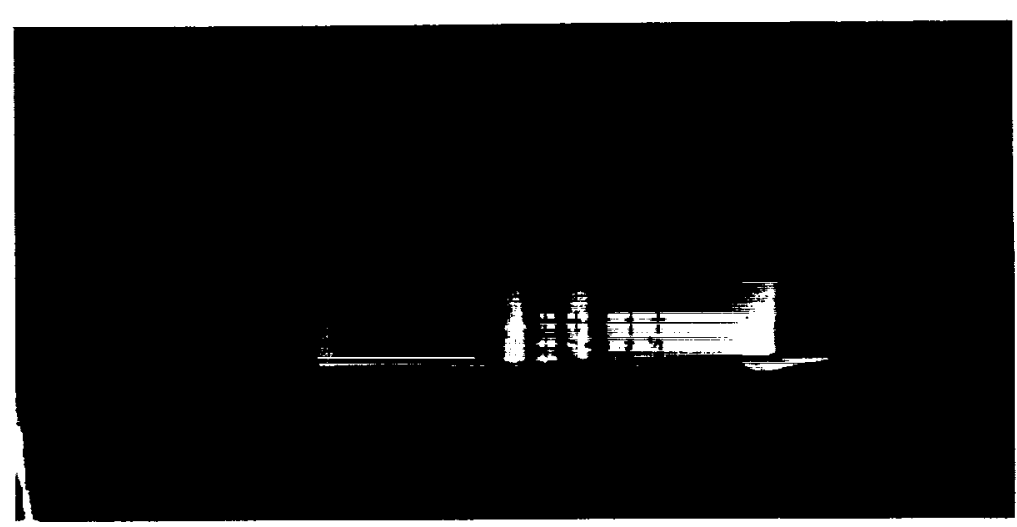

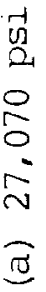




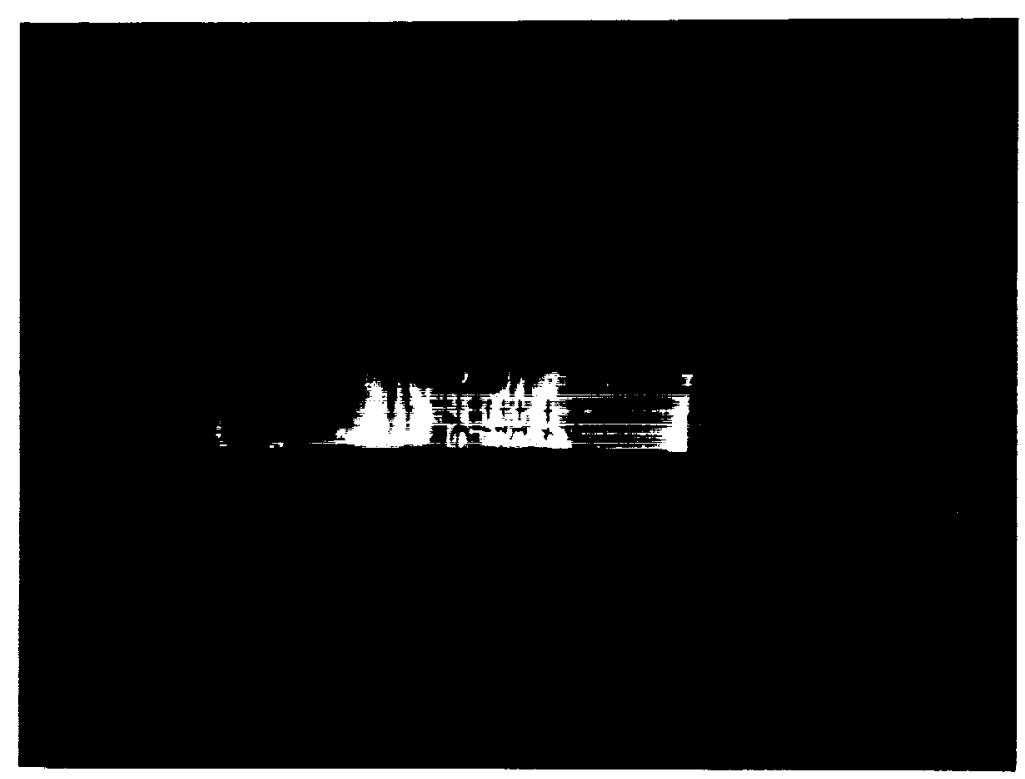

$N$

m

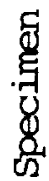

용

点

E

马्ष

謌

委

낭

8
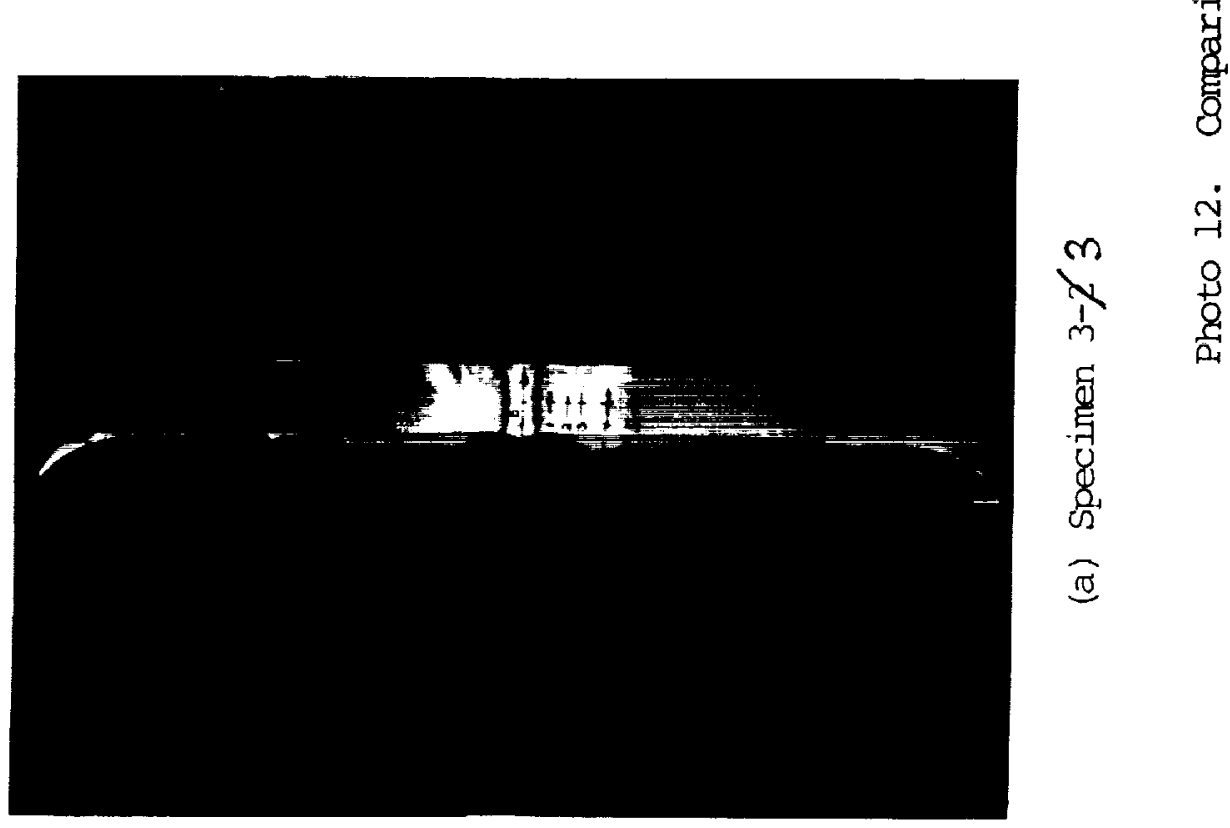

$\begin{array}{ll} & \dot{H} \\ m & 8 \\ \text { m } & \frac{8}{0}\end{array}$

둴

(1) 

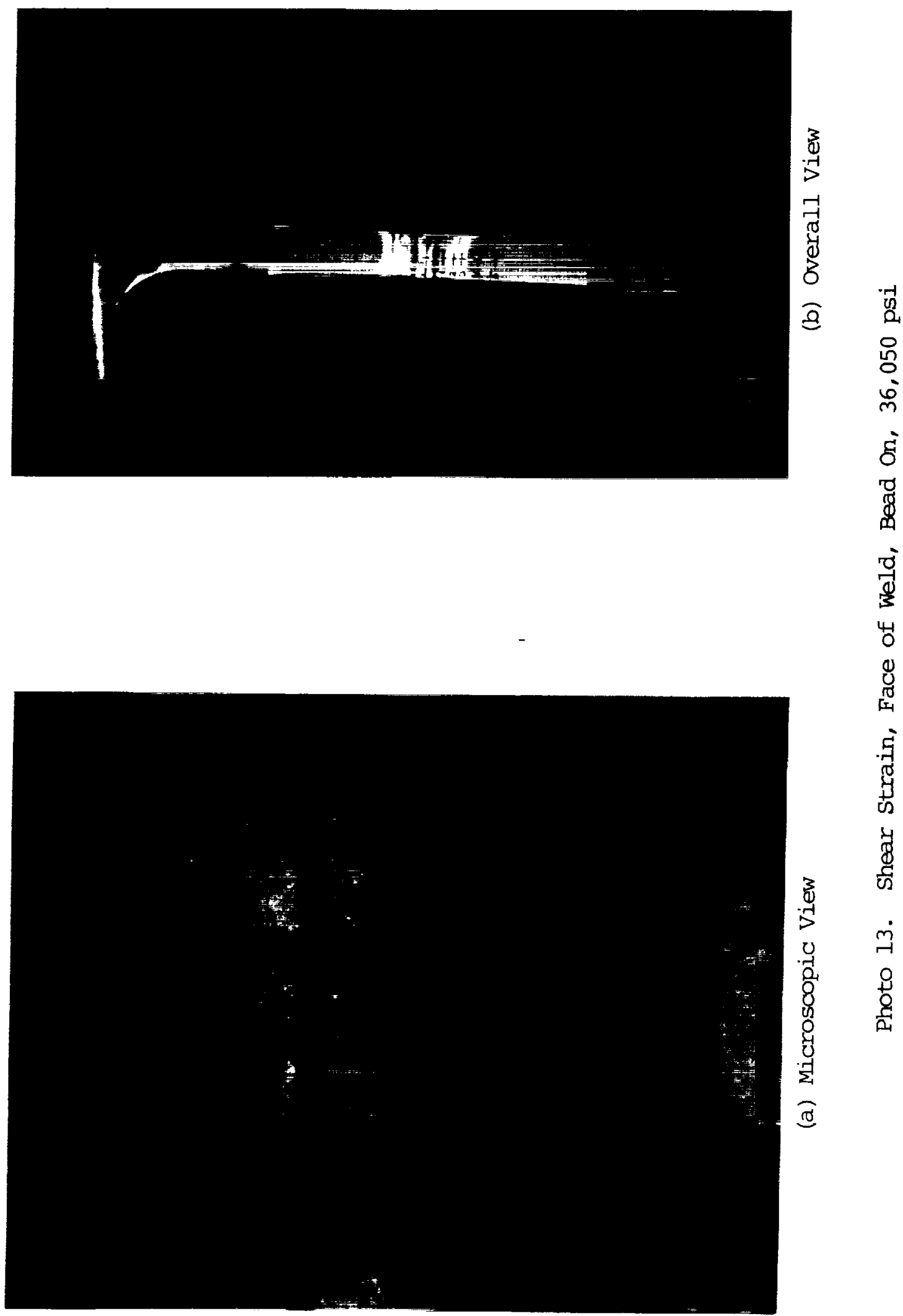
$\frac{1}{4}$ "below the centerline. Where the fringes concentrate at the fillet is also near the fusion boundary. By referring back to Photos 7 and 8 , these views through the weld thickness give a clear indication of how and why the concentrated fringes appeared in Photo 13.

Figures 21 and 22 show the Photostress-strain curves for the $1.4^{\prime \prime}$ thick heat treated material for various locations in the welded joint. In both figures, the curve labeled "centerline" should not be considered as an actual stress-strain curve. Recalling the fringe patterns in Photos $7,8,12$, and 13 , it is clear that data taken at the extremity of a protruding bead has no real relationship to a stress-strain curve since the protruding weld carries only a small portion of the applied load. It is easy to see that other locations in Figures 21 and 22 have similar stress- strain characteristics and therefore specimens $3-1,3-2$, and $3-3$ can be considered as a reasonably consistent group.

\section{Bead Off}

Heat treated specimens having the $1.4^{\prime \prime}$ thick weld were tested with the bead ground off and viewed from the face direction. When testing the thick weld specimens during the "through the weld" tests described in section V.A.1., it was clearly seen that the wide side of the weld was the preferential side for large yielding (Photos 6, 7,9). Knowing this, face of the weld tests were conducted with the bead off on both the wide and narrow sides. Photo 14 clearly shows the difference in overall fringe pattern between the wide and narrow sides of the weld. At a stress level of approximately $39,500 \mathrm{psi}$, shearing strains on the wide and narrow sides compared as follows: 


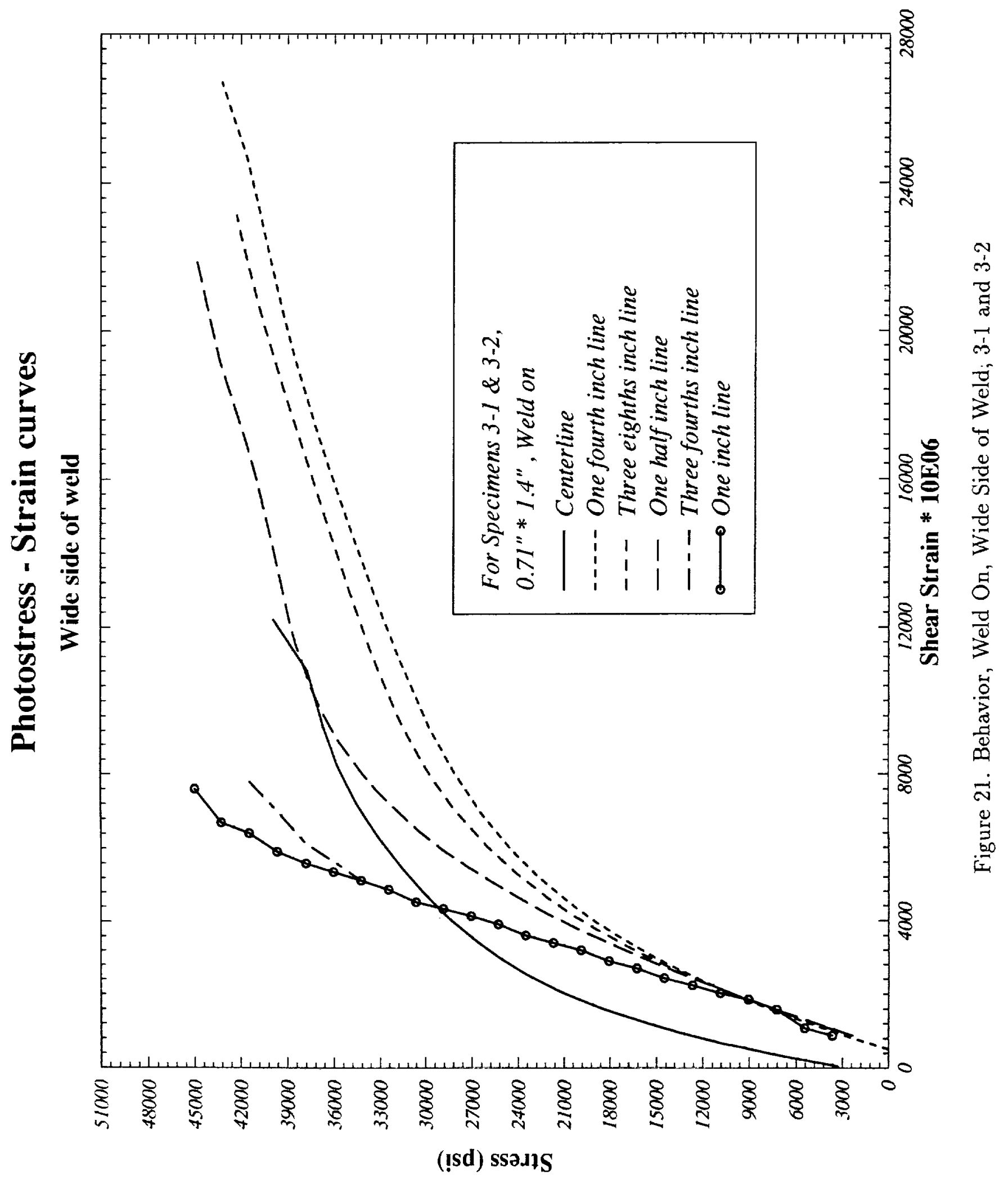




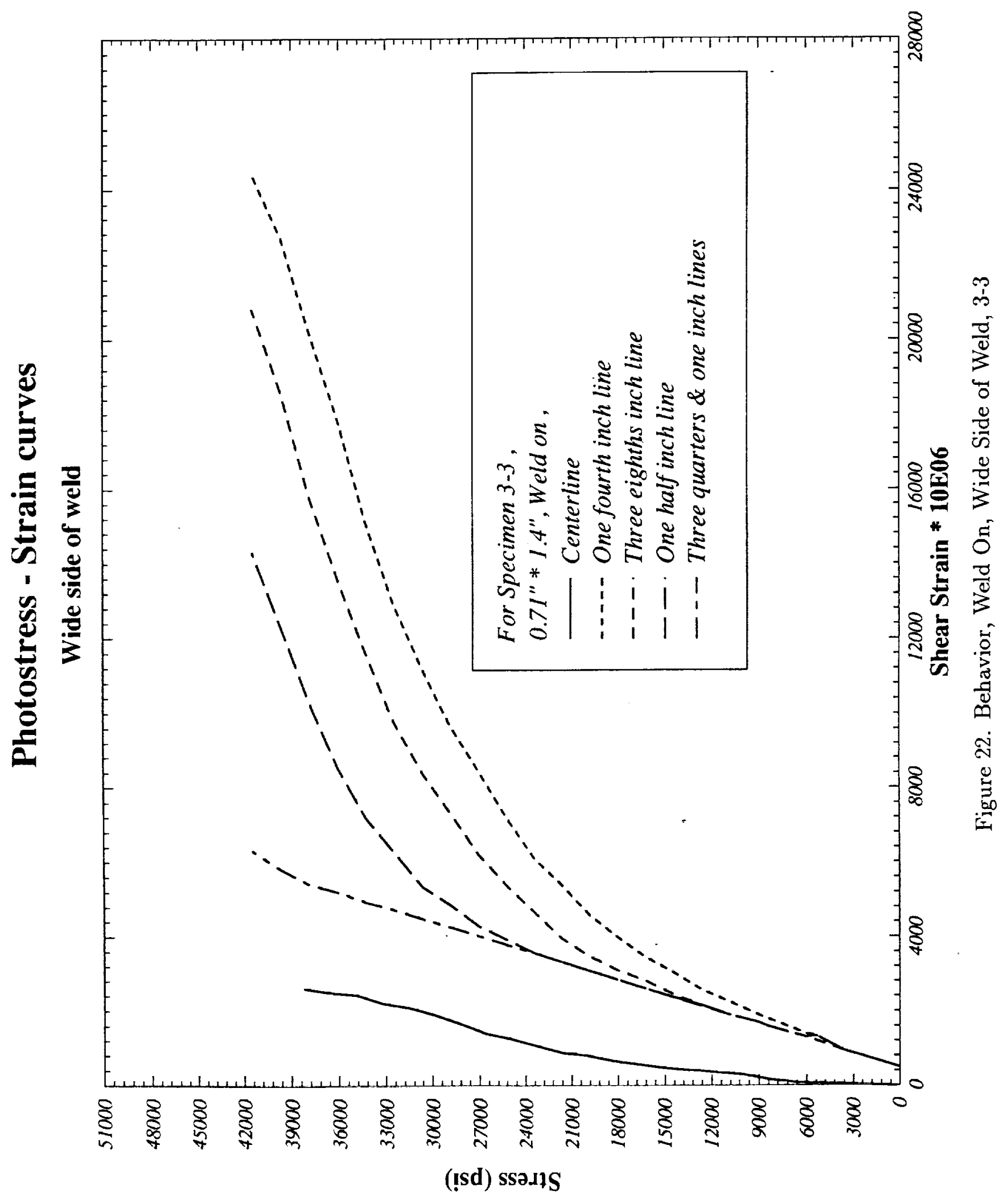




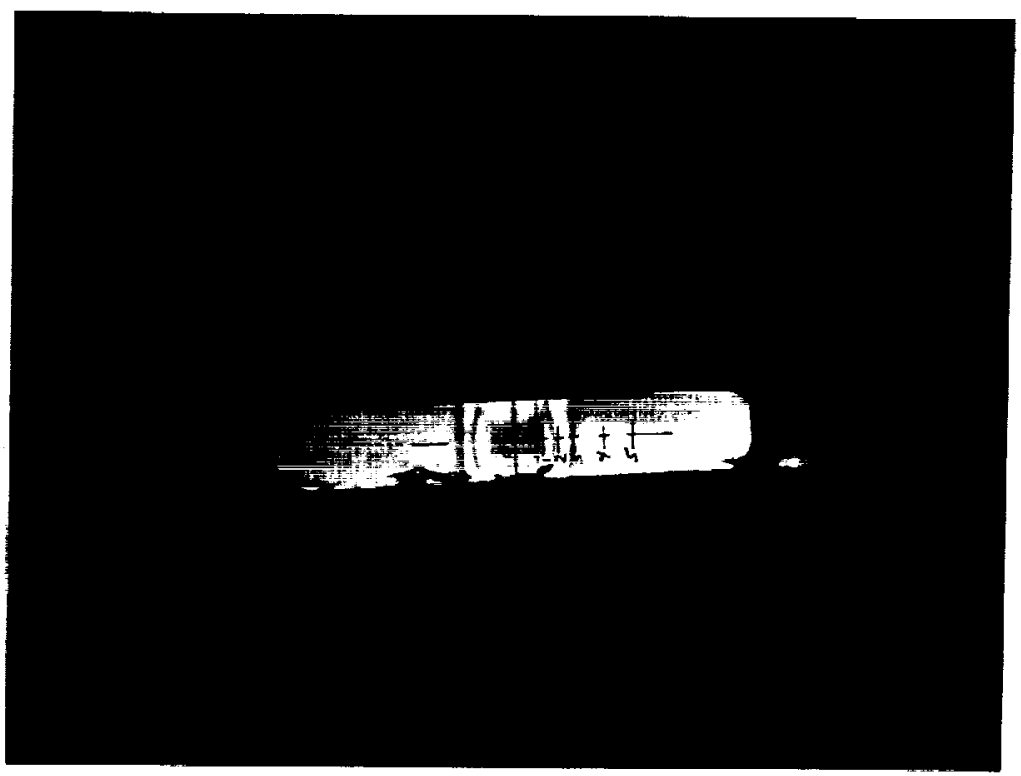

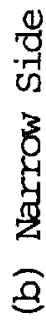

매

융

in

出

"8

.

है

㟧

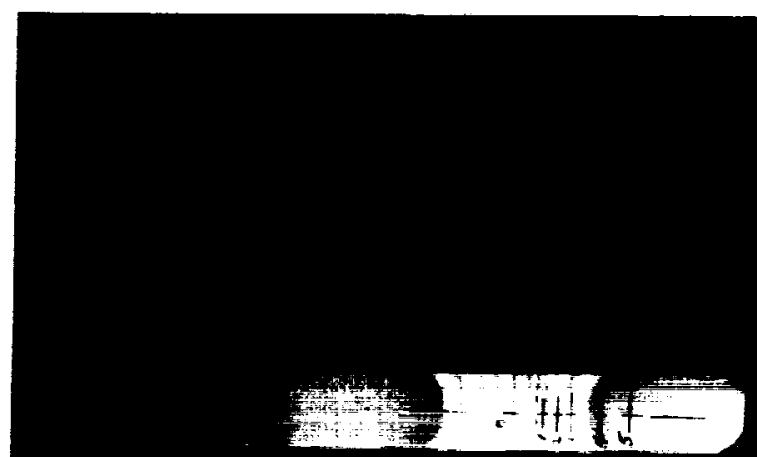

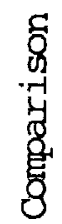

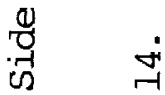

要

త్ర 


$\begin{array}{ccc}\text { Position } & \text { Wide } & \text { Narrow } \\ \text { Centerline } & 26,700 & 6,310 \\ \frac{3}{8}^{\prime \prime} \text { line } & 15,800 & 8,820 \\ \frac{1}{2}^{\prime \prime} \text { line } & 11,600 & 6,550\end{array}$

Figures 23 and 24 show the overall behavior of the joint for both the wide and narrow sides. Clearly, the narrow side is much stronger and less ductile at those locations in the vicinity of the weld whereas relatively small differences exist at the $\frac{3}{4} "$ and 1 inch locations. Mechanical properties of proportional limit and yield strength for the welded joint are seen in Figures 25 and 26 . Note that both properties are quite different for the wide and narrow sides of the weld in accordance with the difference in fringe patterns seen in Photo 14. All "through the weld" tests indicated a significant difference in material behavior between the two sides of the weld. It would appear that, if 2319 weld material is used throughout the weld, the process of fabricating the joint causes a very non-uniform behavior and should, perhaps, be investigated further.

\section{RESULTS FROM TASK 2}

Photostress was applied to the faces of welds in $\frac{1}{8}^{\prime \prime} \times 1.25^{\prime \prime}$ and $\frac{1}{2}^{\prime \prime} \times 1.25^{\prime \prime}$ specimens which were supplied in the "as welded" condition. The joints were made from 2219-T87 parent material and 2319 weld material. No "through the weld" tests were conducted for the $\frac{1}{8}^{\prime \prime}$ and $\frac{1}{2}^{\prime \prime}$ thick material. Tests on both the wide and narrow sides of the weld indicated that there were only slight differences in mechanical behavior between the two sides. 


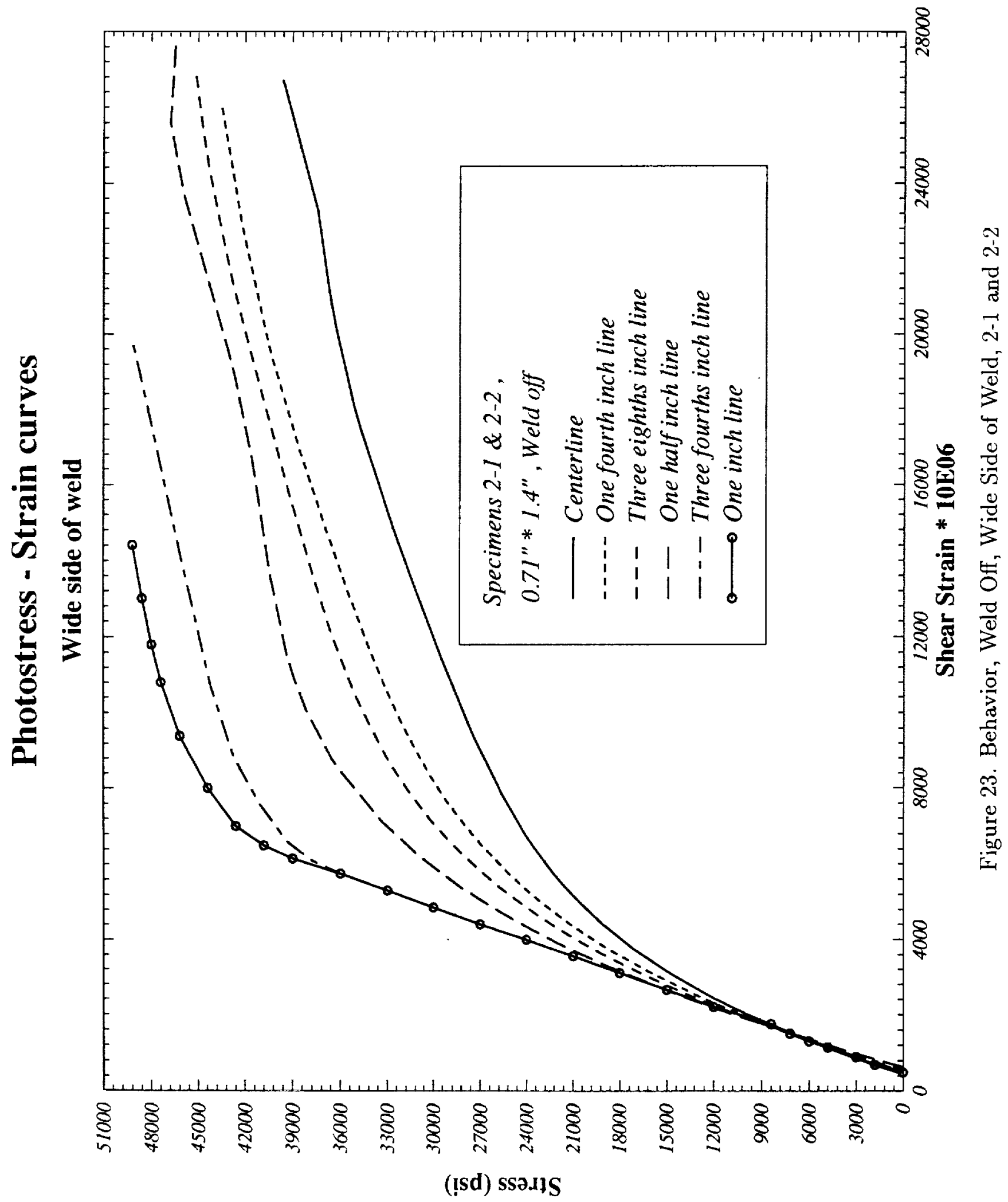




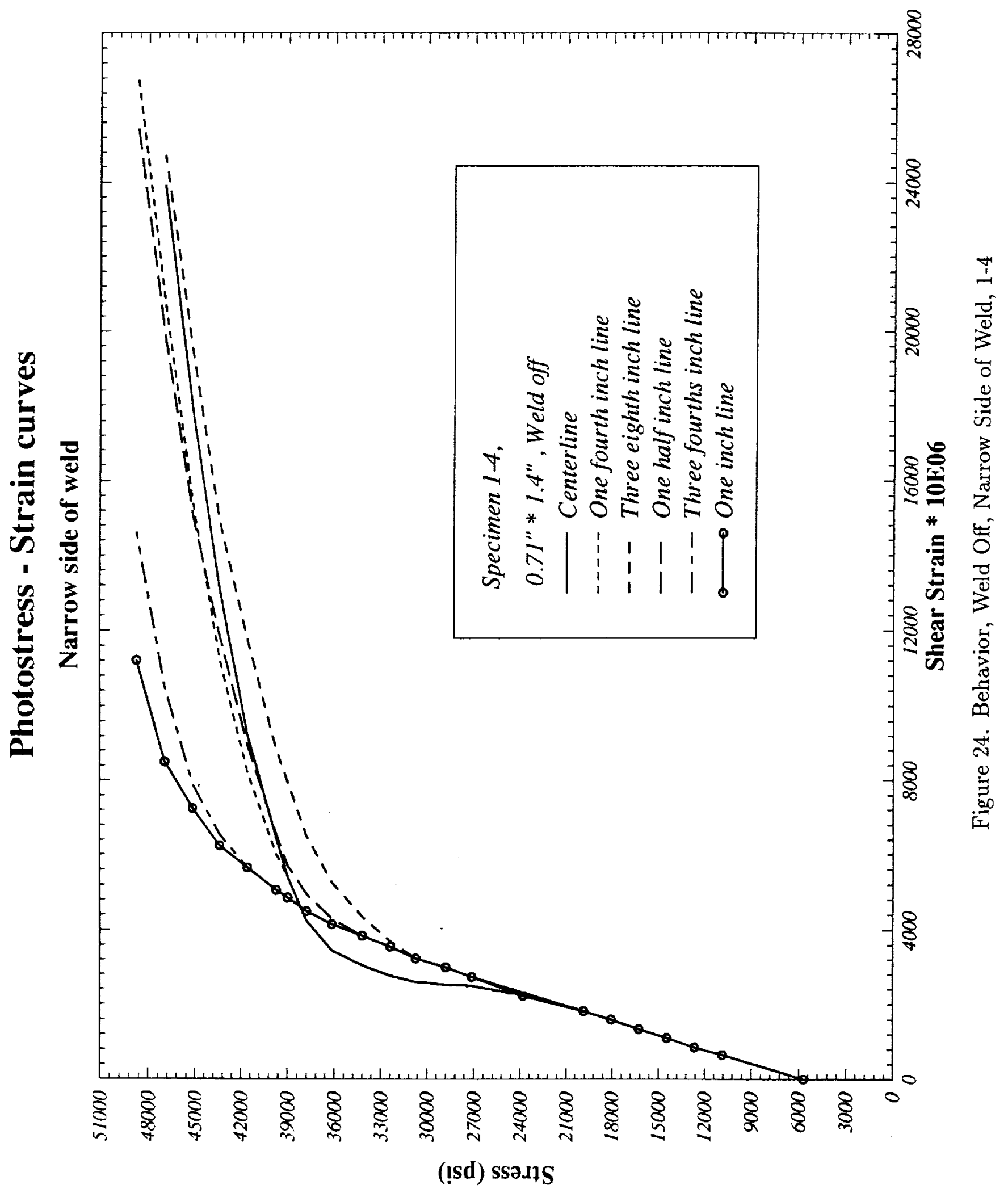




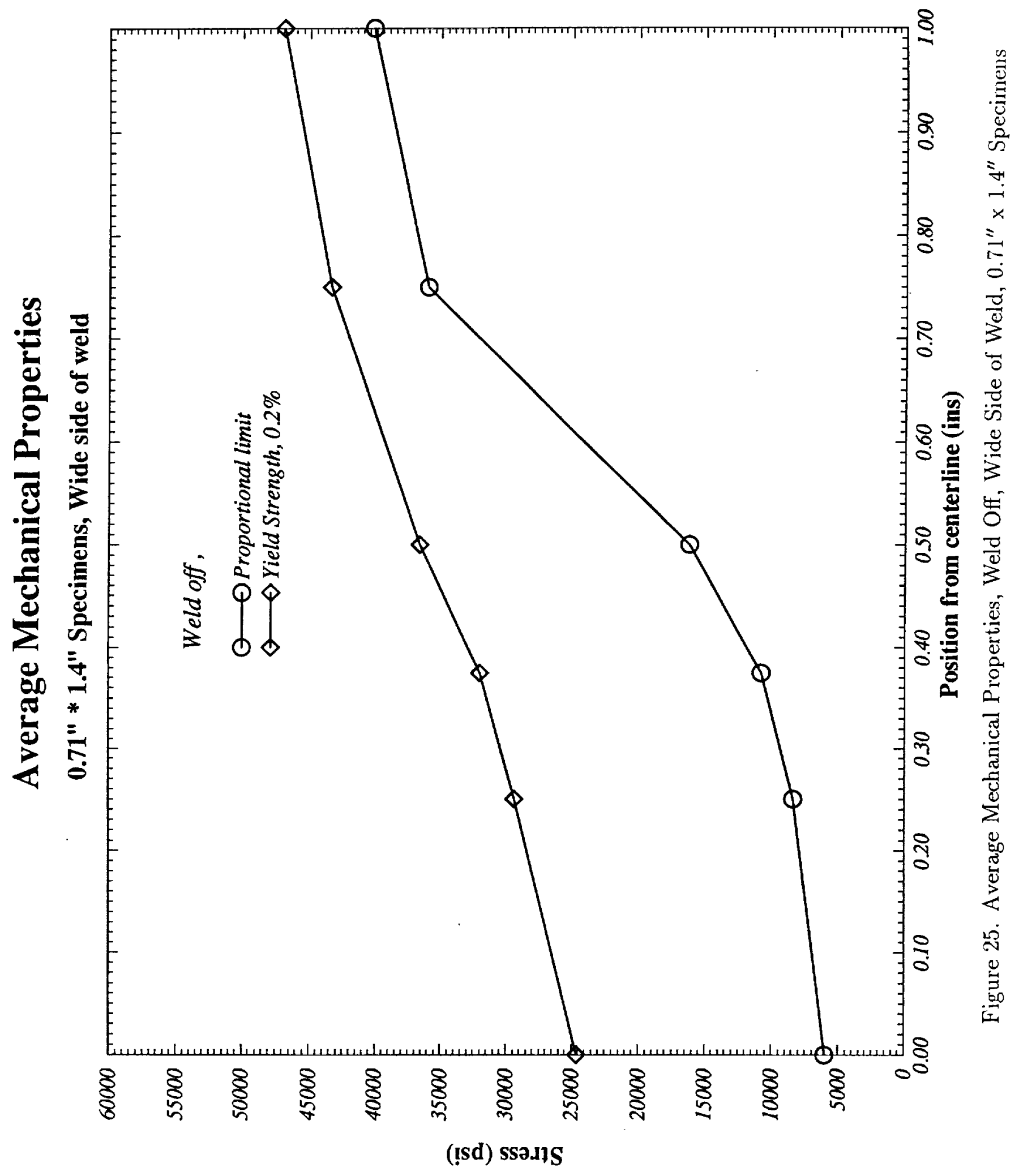




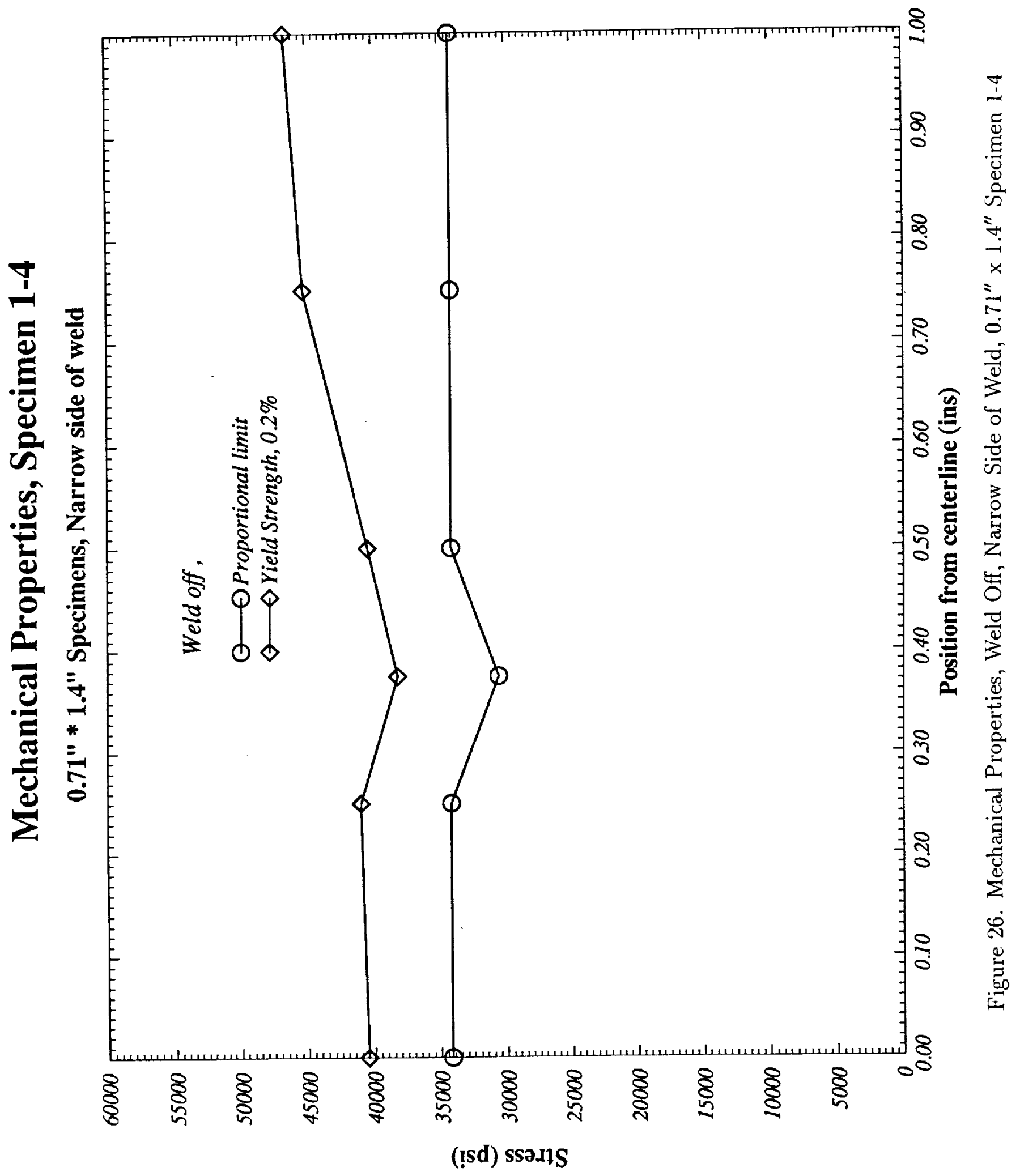




\section{A. Tests of $\frac{1}{8}$ "Thick Material}

Photos 15 and 16 show yielding characteristics of the $\frac{1}{8}^{\prime \prime}$ thick material. Yielding produced a generally uniform strain gradient between the centerline and the $1^{\prime \prime}$ location and no distinct, separate yield zones were observed. As indicated in Figures 27 and 28, large yielding was present at all locations except the $\frac{3}{4}$ and 1 inch lines, and in general, there were no large differences in behavior between the wide and narrow sides of the weld. Figures 29-34 show details of the differences between the wide and narrow sides of the weld for six specific locations from the centerline to the $1^{\prime \prime}$ line. As mentioned previously, bending was present in all specimens. The thin, $\frac{1}{8}$ " thick panels were quite "peaked" in the vicinity of the weld with respect to the ends of the specimen, and the effects of bending can be seen clearly in Figures 29-34. If one mentally corrects for the offset along the strain axis at zero stress, then the difference between the behavior on the wide and narrow sides of the weld is more fully recognized is its true perspective. Figure 35 gives the average mechanical properties, including both the wide and narrow sides of the weld, for the $\frac{1}{8}$ "thick material.

\section{B. Tests of $\frac{1}{2}^{\prime \prime}$ Thick Material}

Unlike the $\frac{1}{8}$ "thick material which yielded without distinct zones of strain concentration, the $\frac{1}{2}$ " thick material exhibited a generally non- uniform yielding characteristic and had distinct zones of strain concentration within the strain gradient between the centerline and the 1 " location. Photo 17 shows the fringes associated with a sequence of non-uniform yielding at three stress levels. Photo 18 shows a microscopic view of a distinctly separate 


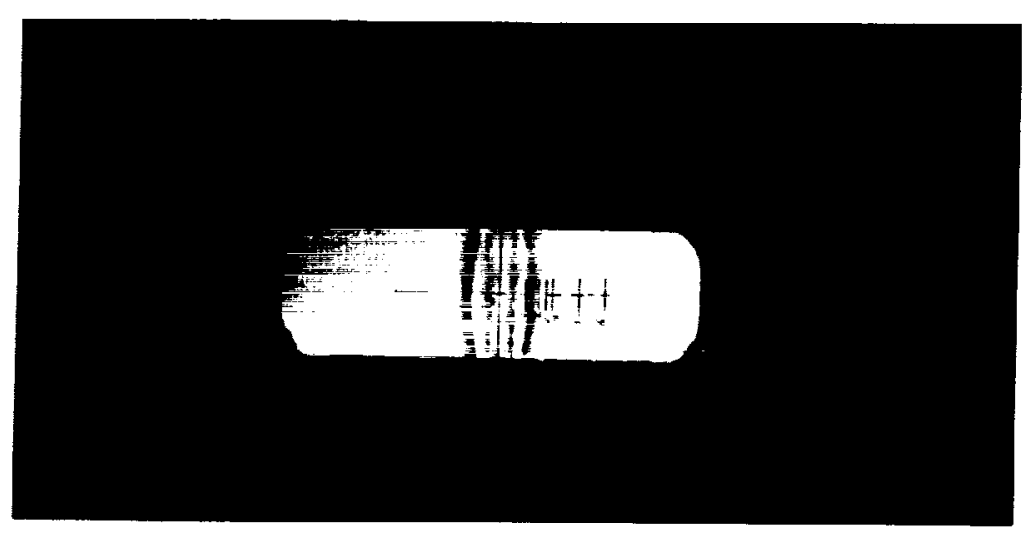

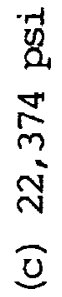
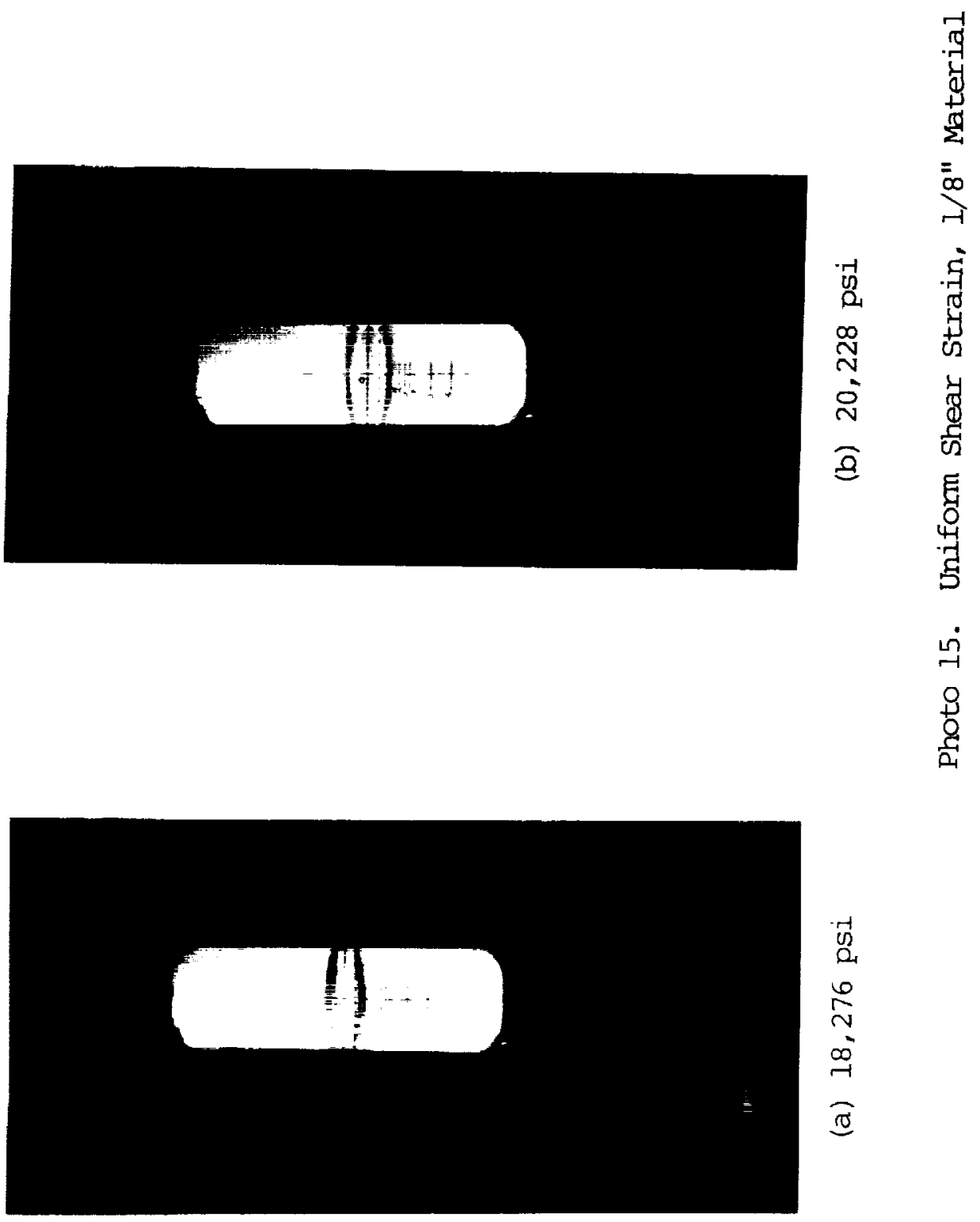

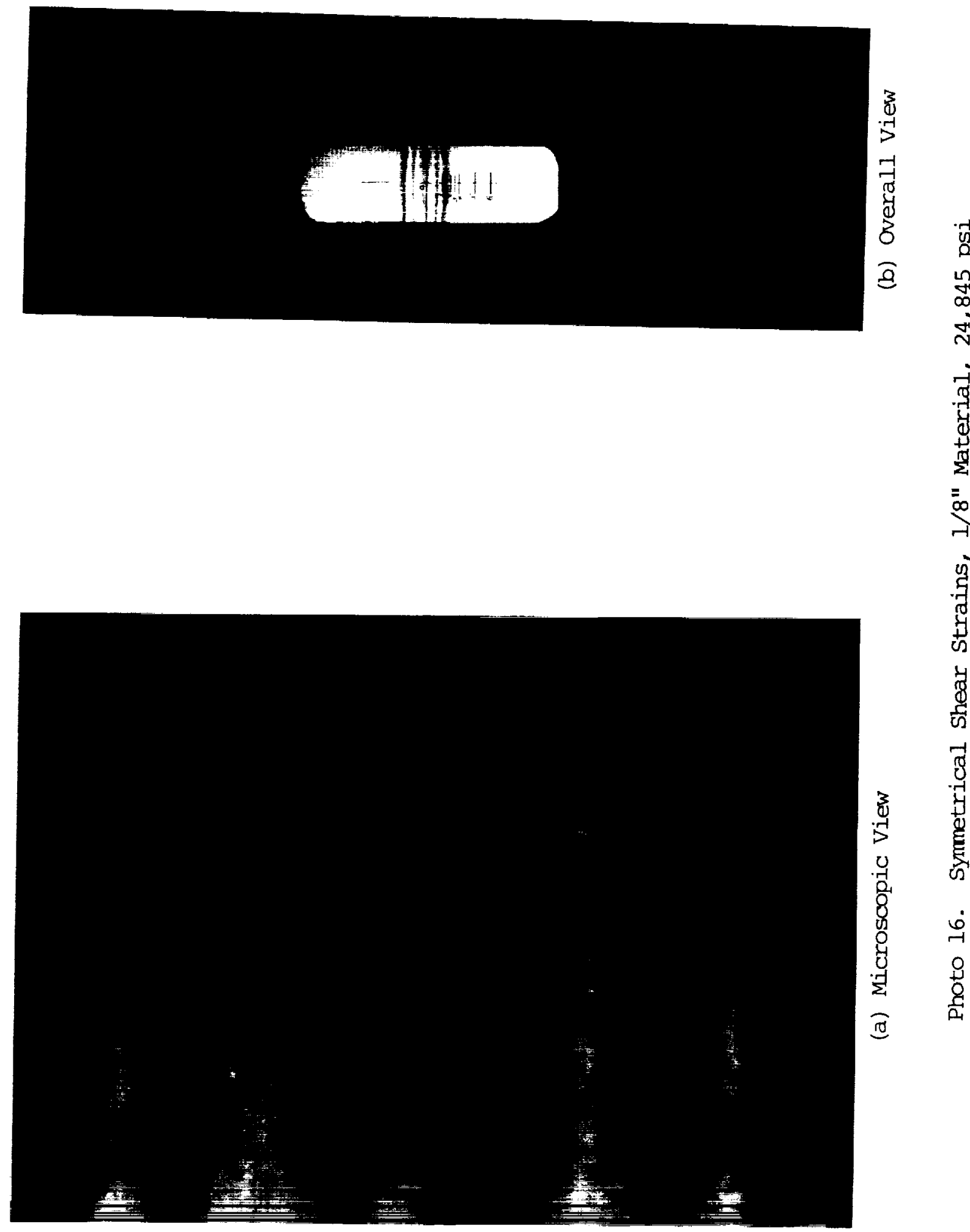

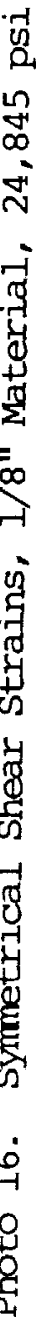




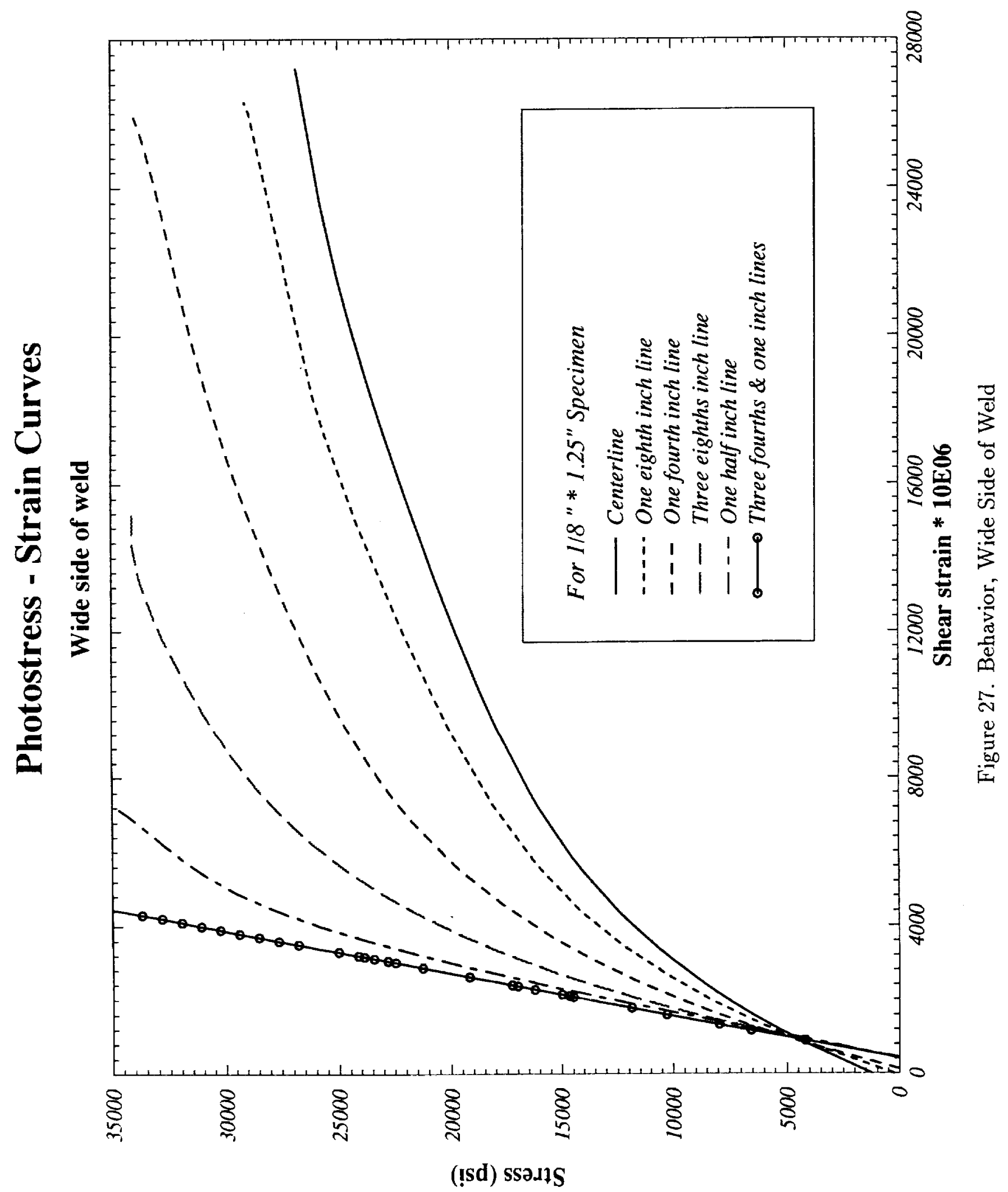




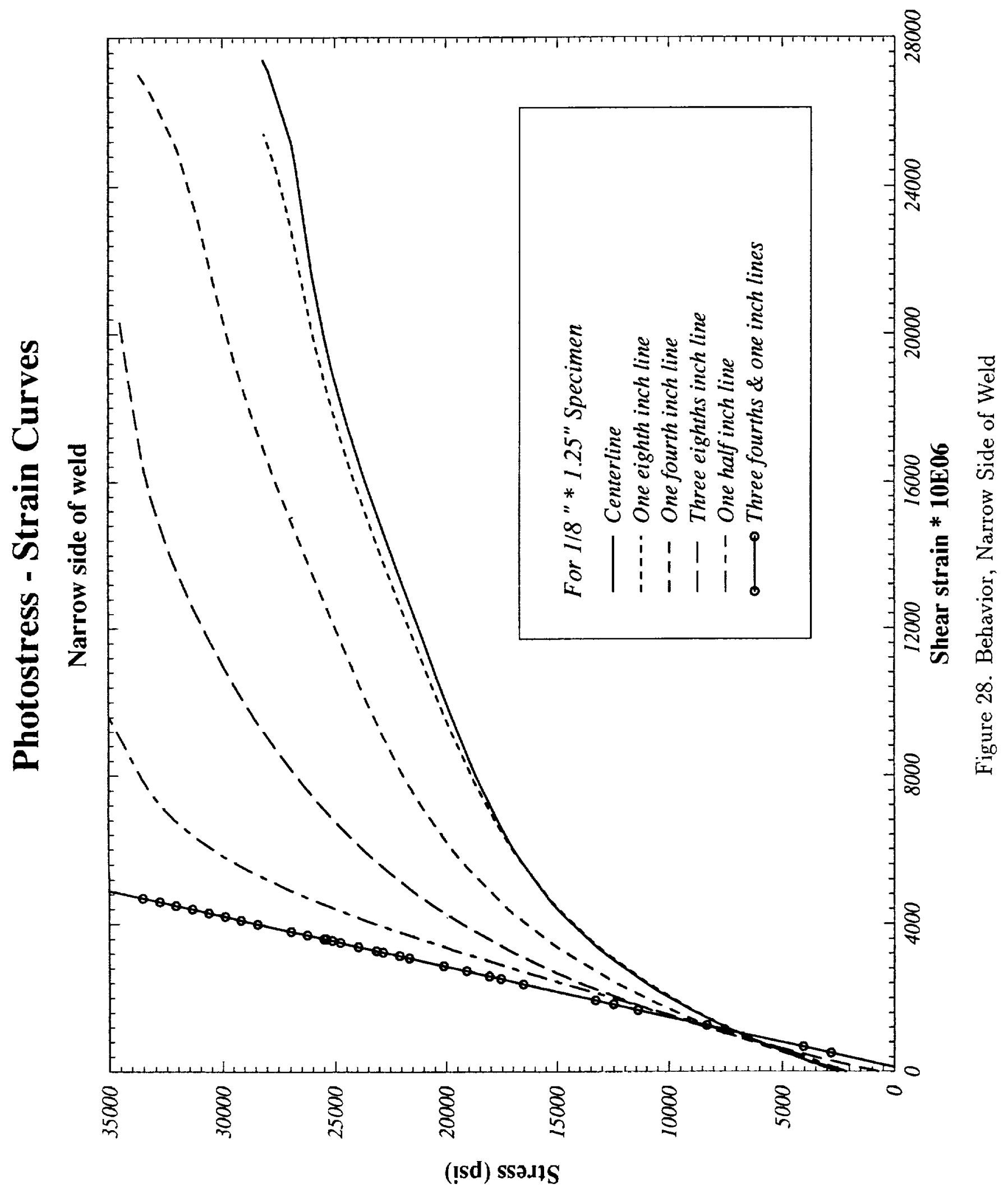




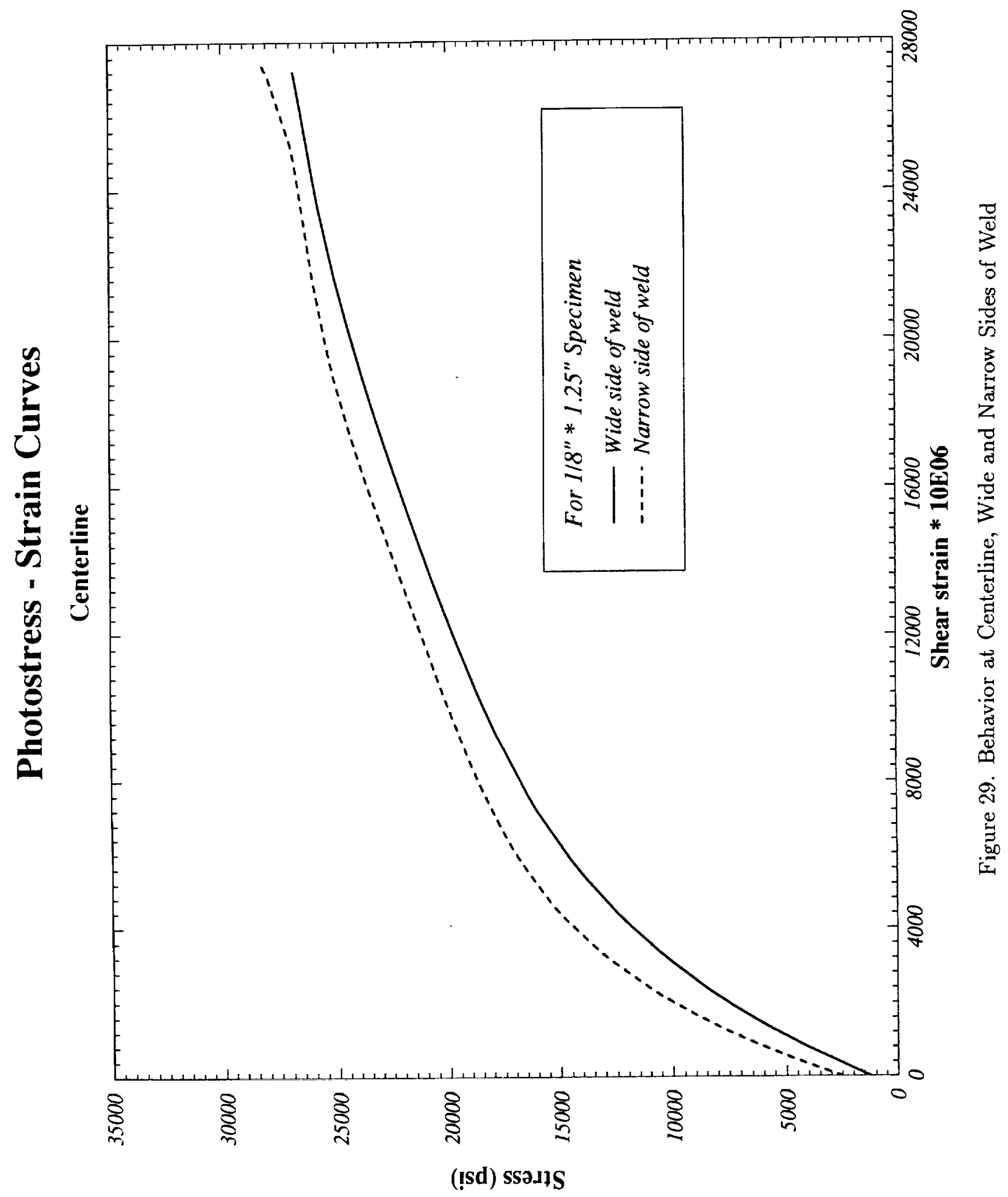




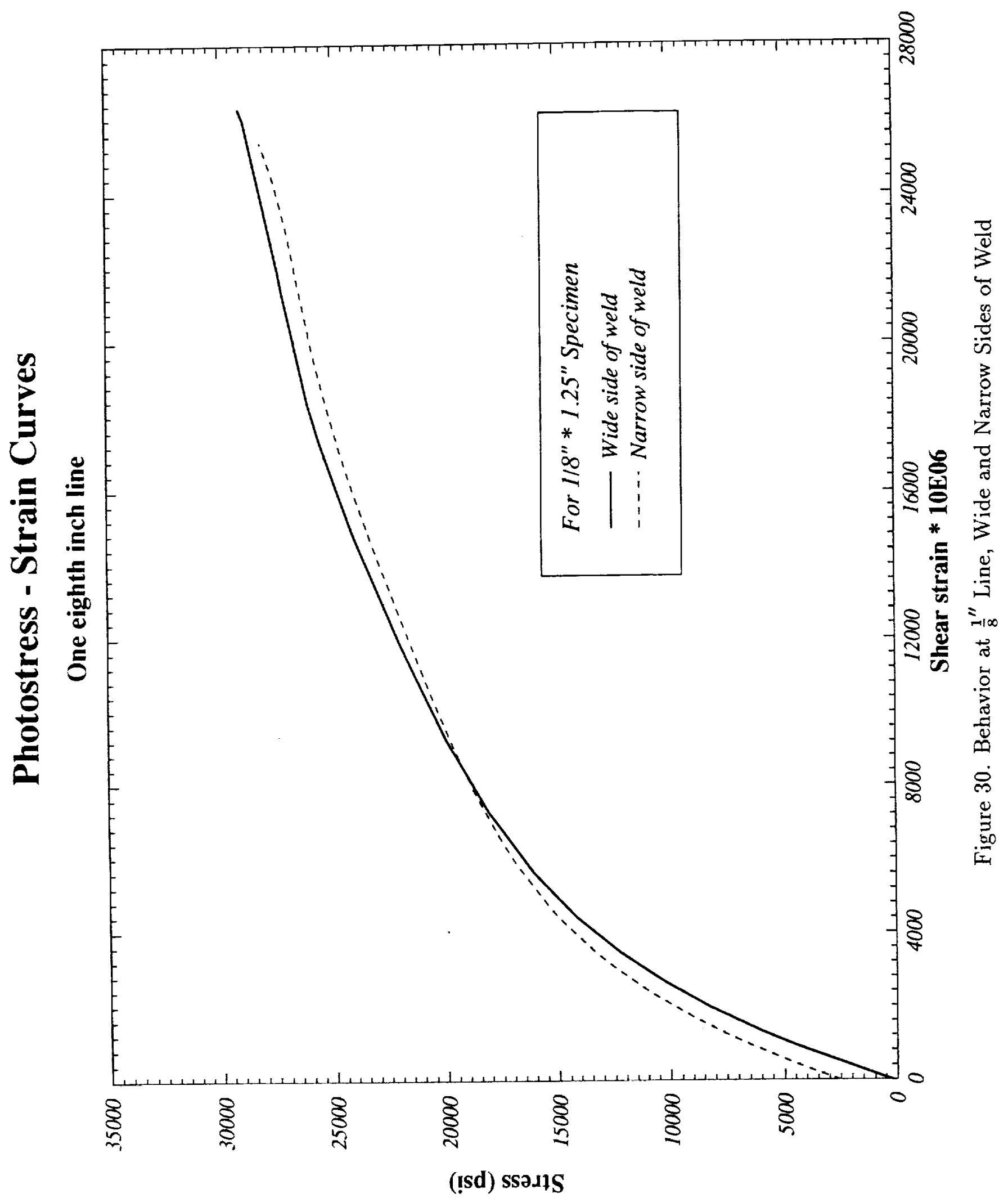




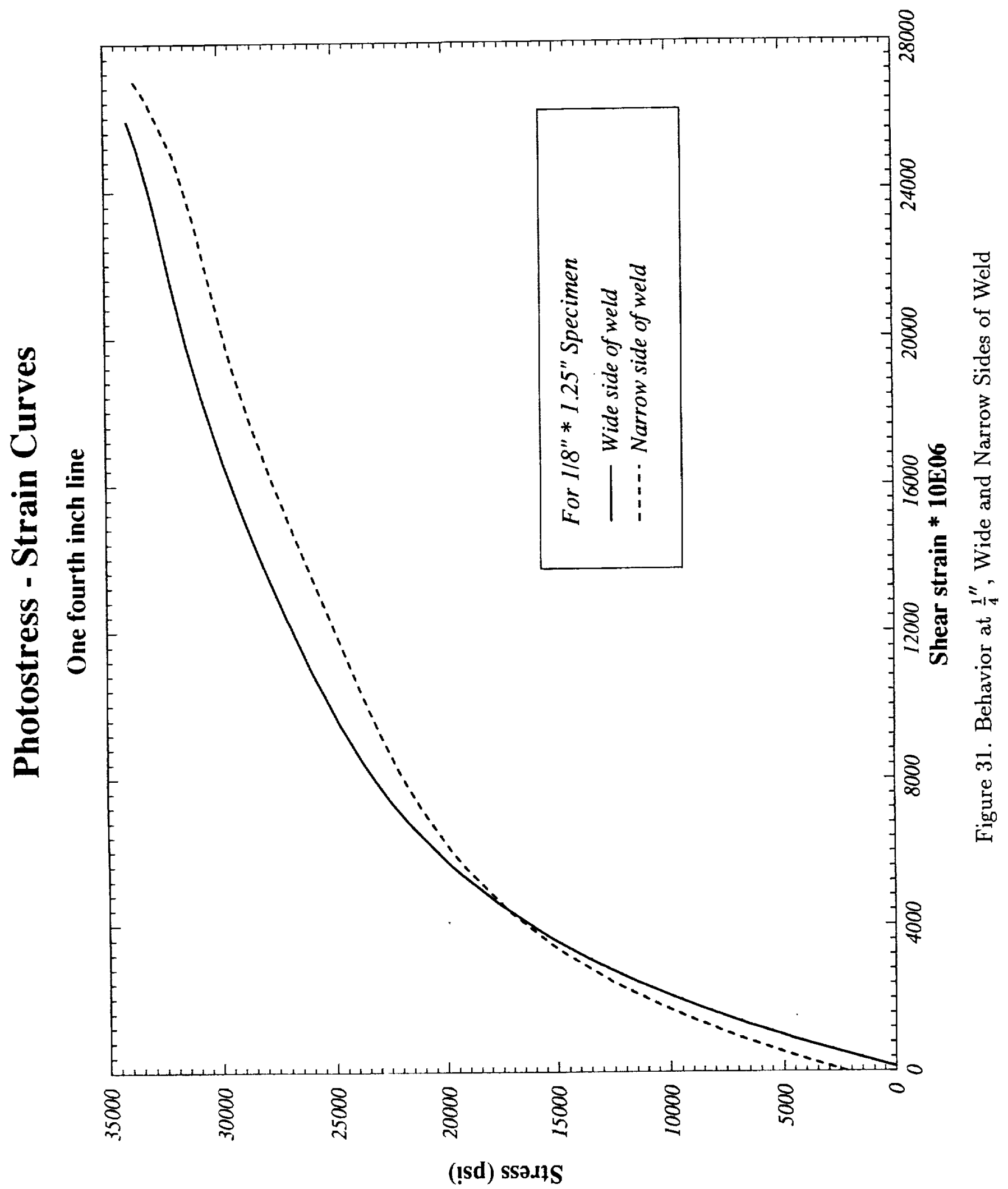




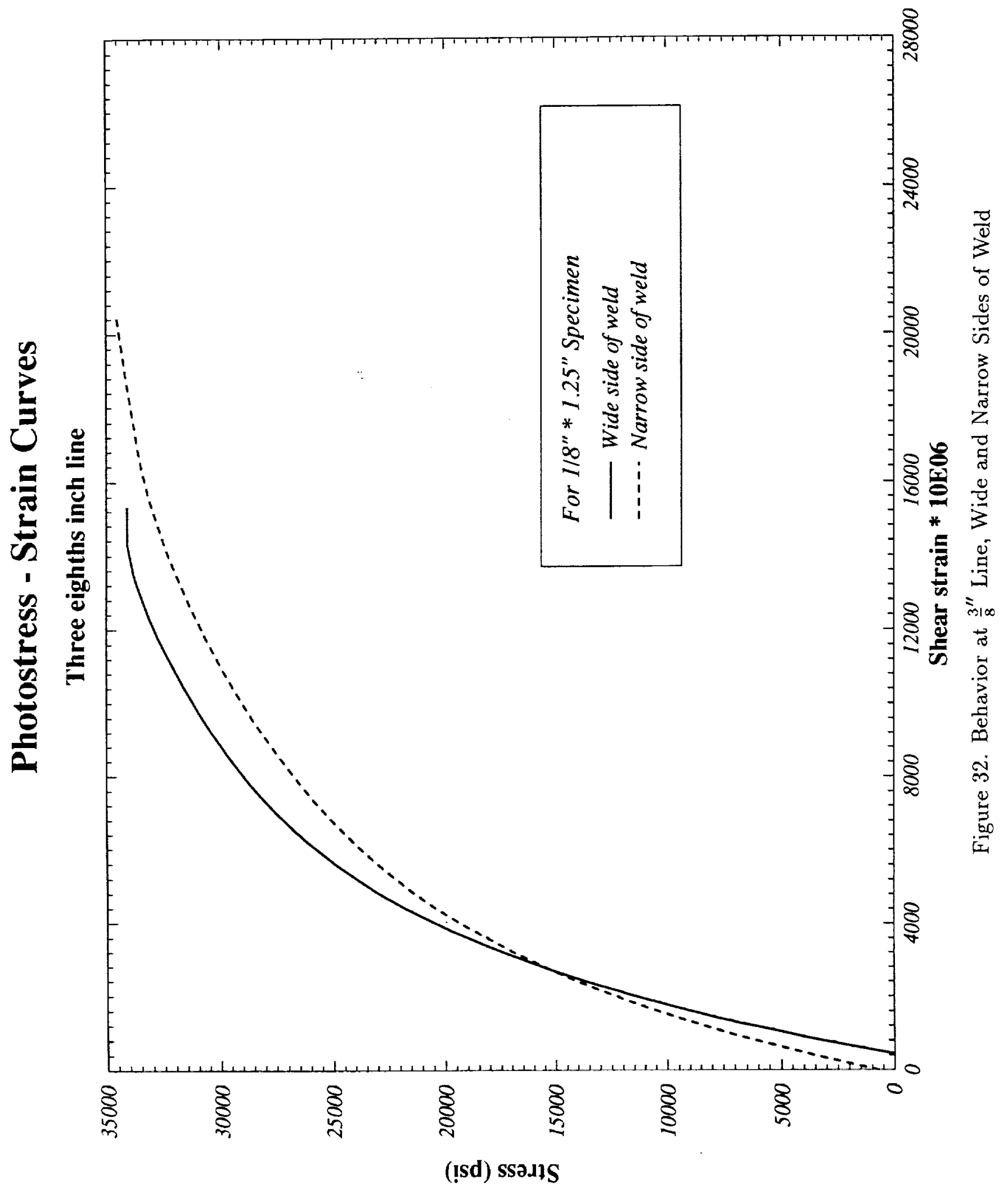




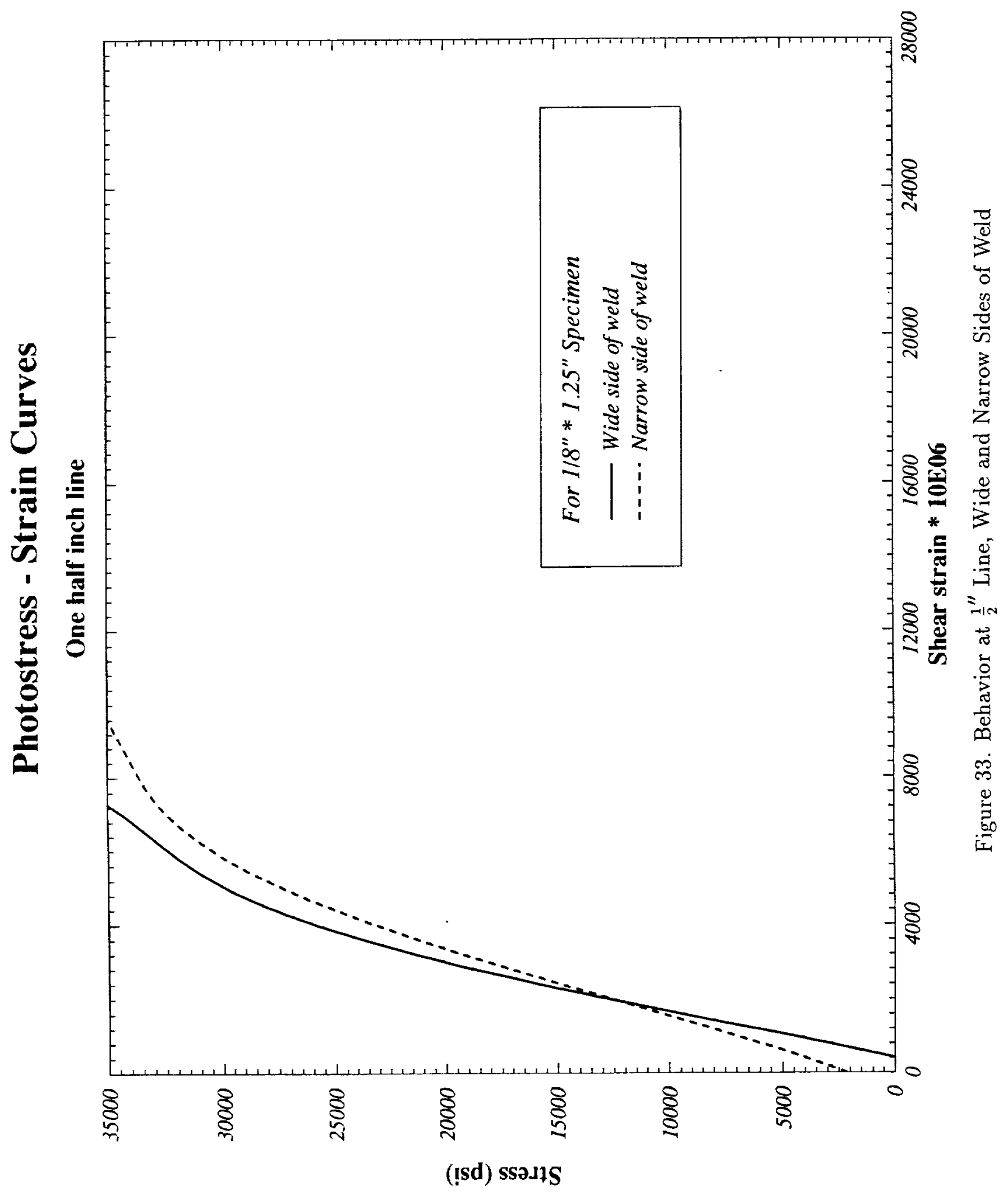




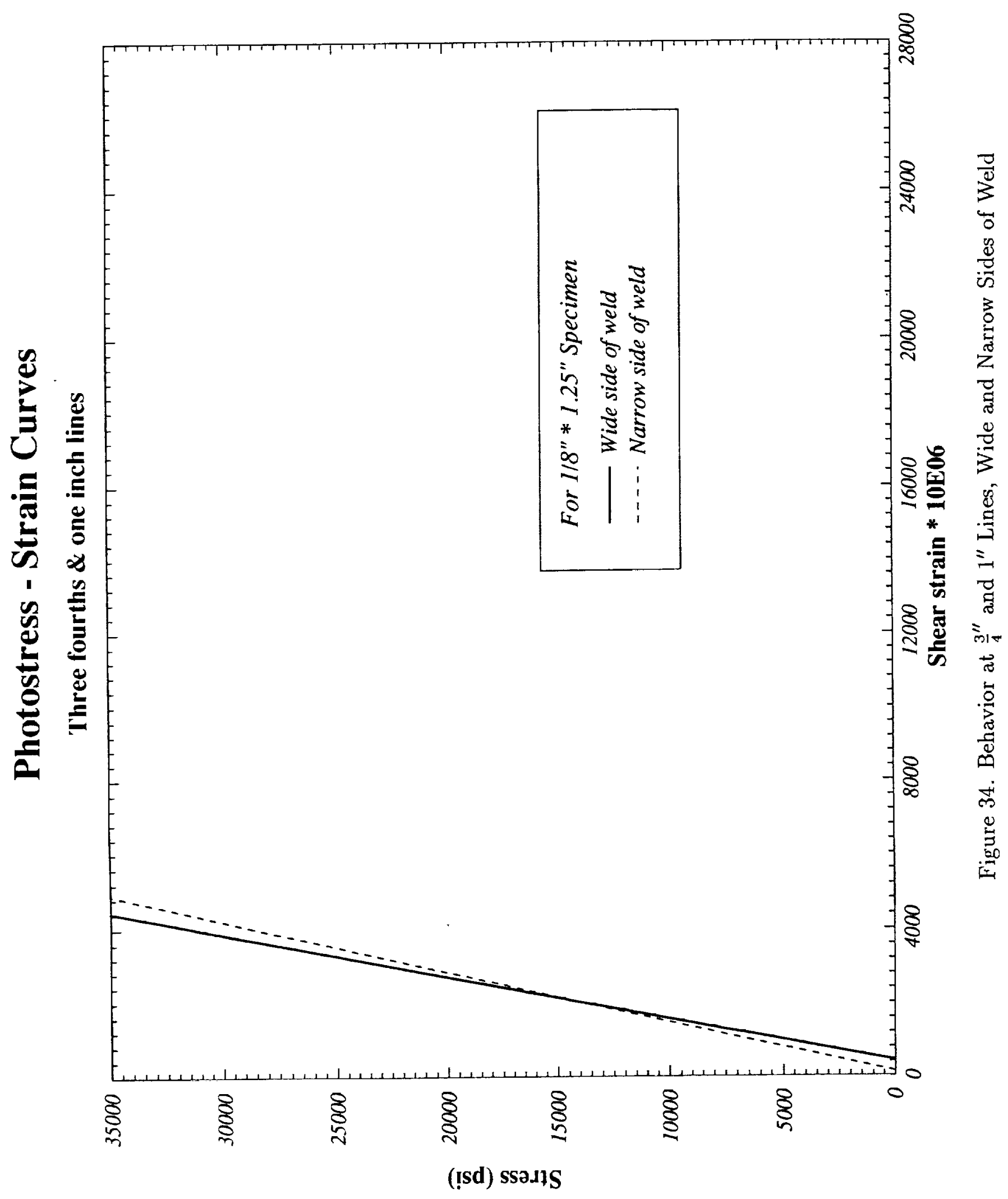




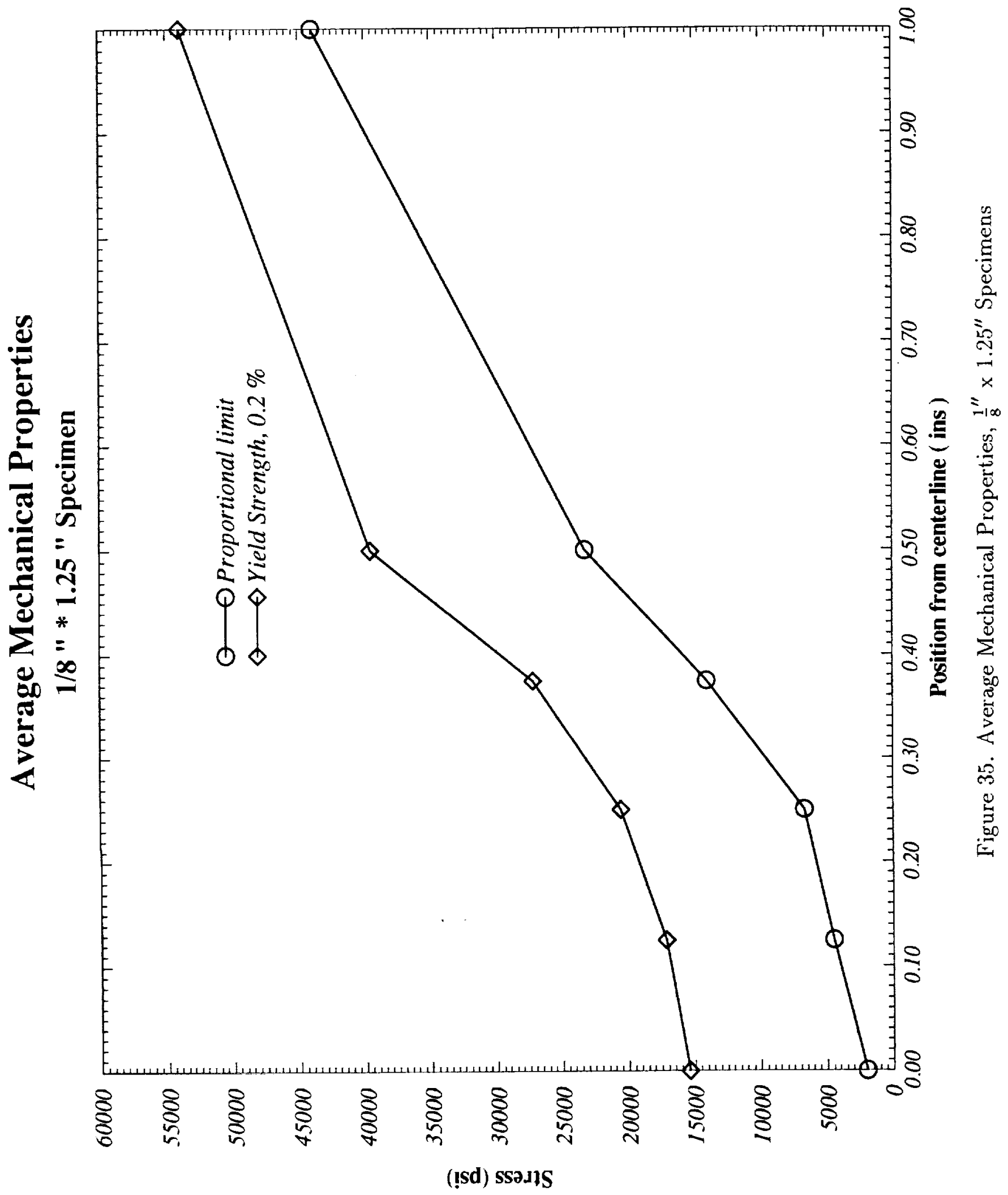



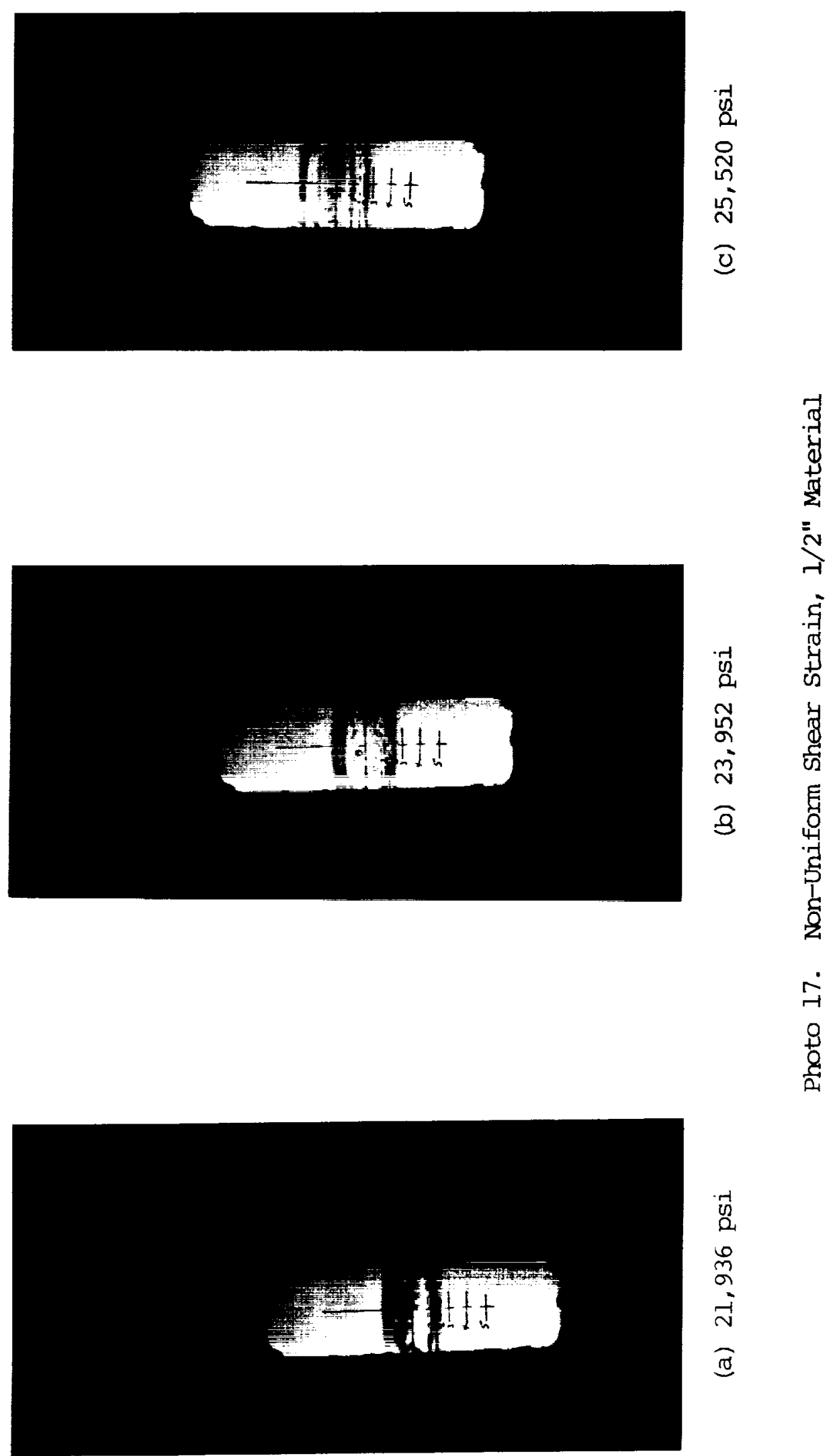

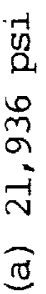




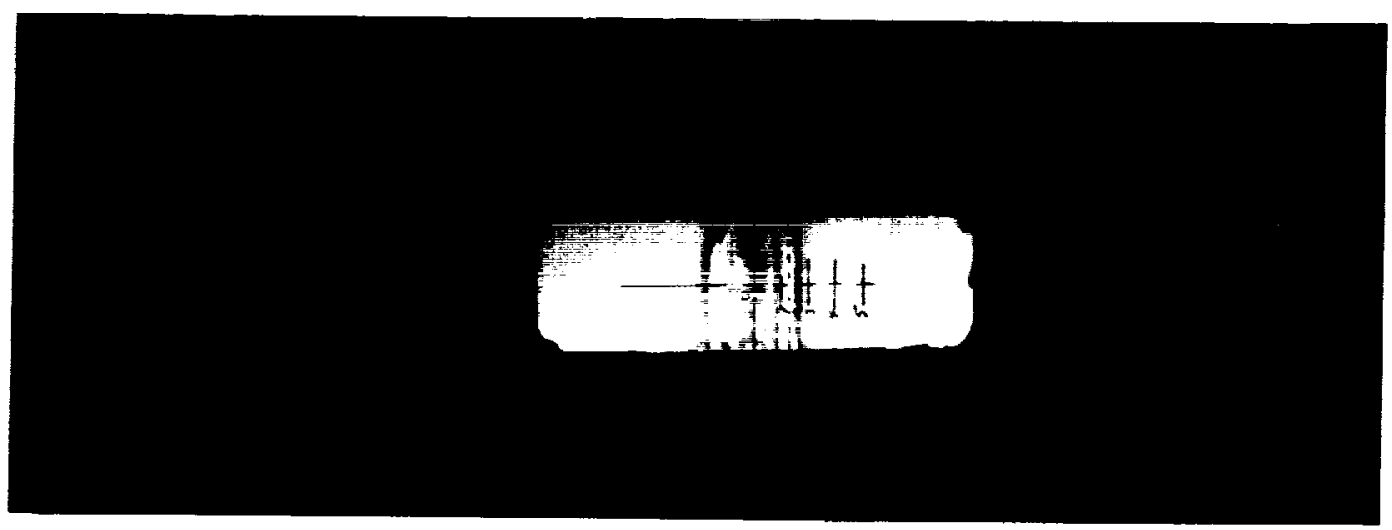

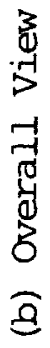

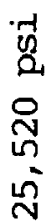
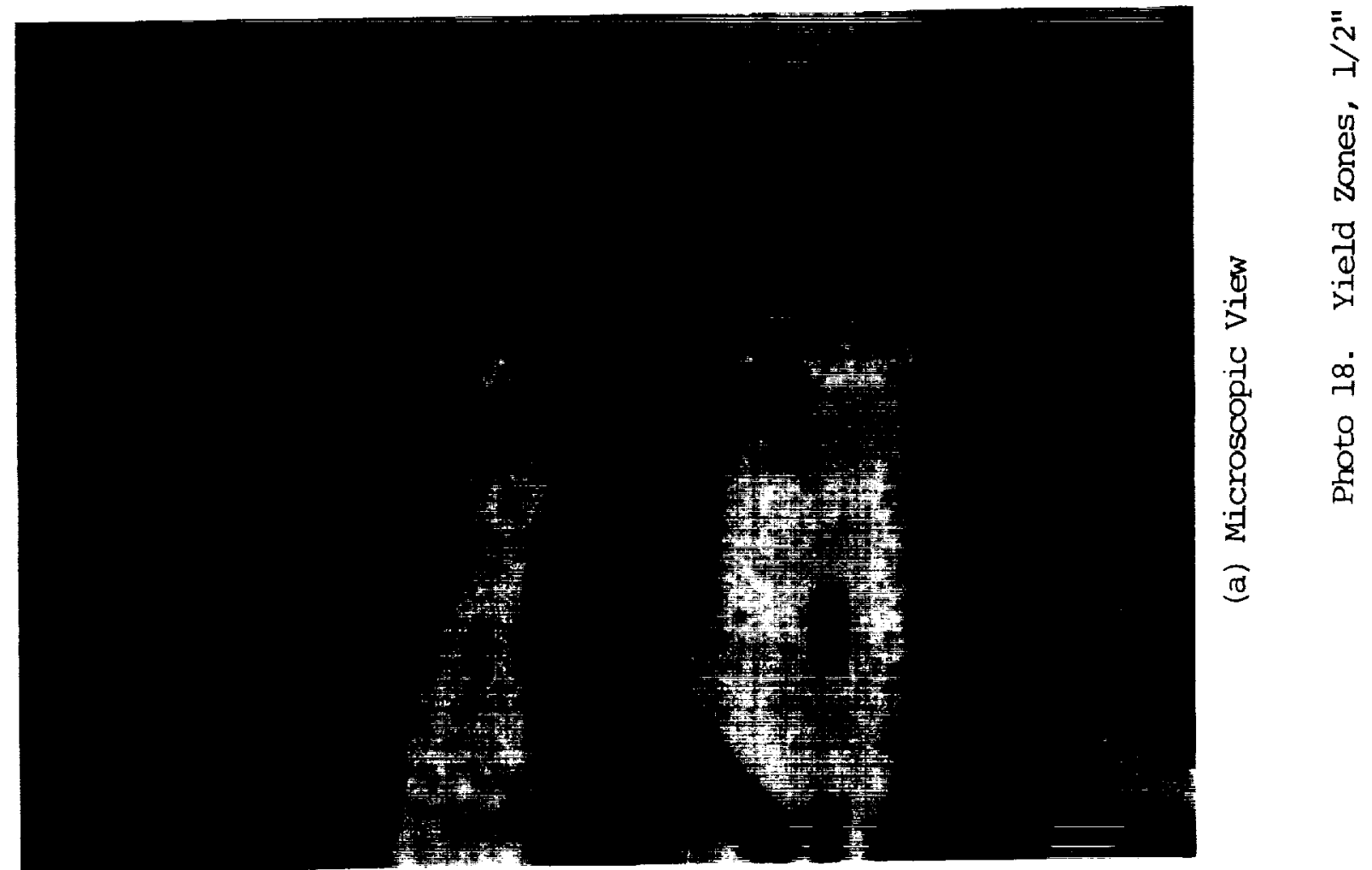
yield zone seen as a wide yellow band between the $\frac{1}{4}^{\prime \prime}$ and $\frac{3}{8}^{\prime \prime}$ locations. Such a band of constant color represents a relatively large region of material where the shear strain is constant rather than varying in accordance with the strain gradient pattern observed in the $\frac{1}{8}^{\prime \prime}$ thick material. Yield zones were observed in all $\frac{1}{2}^{\prime \prime}$ thick material. General behavior of the $\frac{1}{2}^{\prime \prime} \times 1.25^{\prime \prime}$ specimens is shown in Figures 36 and 37 for the wide and narrow sides of the weld. No distinction could be made in these tests between the $\frac{3}{4}^{\prime \prime}$ and $1^{\prime \prime}$ positions. It may be seen that only small differences exist between the behavior of the wide and narrow sides of the weld, and these differences are given in Figures 38-42. Again, note the offset along the strain axis caused by bending of the specimen.

TABLE 2. Yield Zone Location and Thickness (Inches) $\frac{1}{2}^{\prime \prime} \times 1.25^{\prime \prime}$ Specimens

\begin{tabular}{|c|c|c|c|c|c|c|}
\hline & \multicolumn{2}{|c|}{ Zone 1 } & \multicolumn{2}{c|}{ Zone 2 } & \multicolumn{2}{c|}{ Zone 3 } \\
\hline Specimen No. & $y$ & $t$ & $y$ & $t$ & $y$ & $t$ \\
\hline $6-4$ & .222 & .059 & .278 & .054 & .339 & .067 \\
$6-5$ & .151 & .061 & .214 & .066 & .305 & .116 \\
$7-1$ & .186 & .097 & .272 & .076 & .350 & .080 \\
\hline
\end{tabular}

Details of discontinuous yielding and yield zones for three specimens are given in Table 2 and Figures 43-45. For purposes of orientation, zone 1 is closest to the weld centerline, zone 2 is next, and zone 3 is the zone most distant from the centerline. No more than three different 


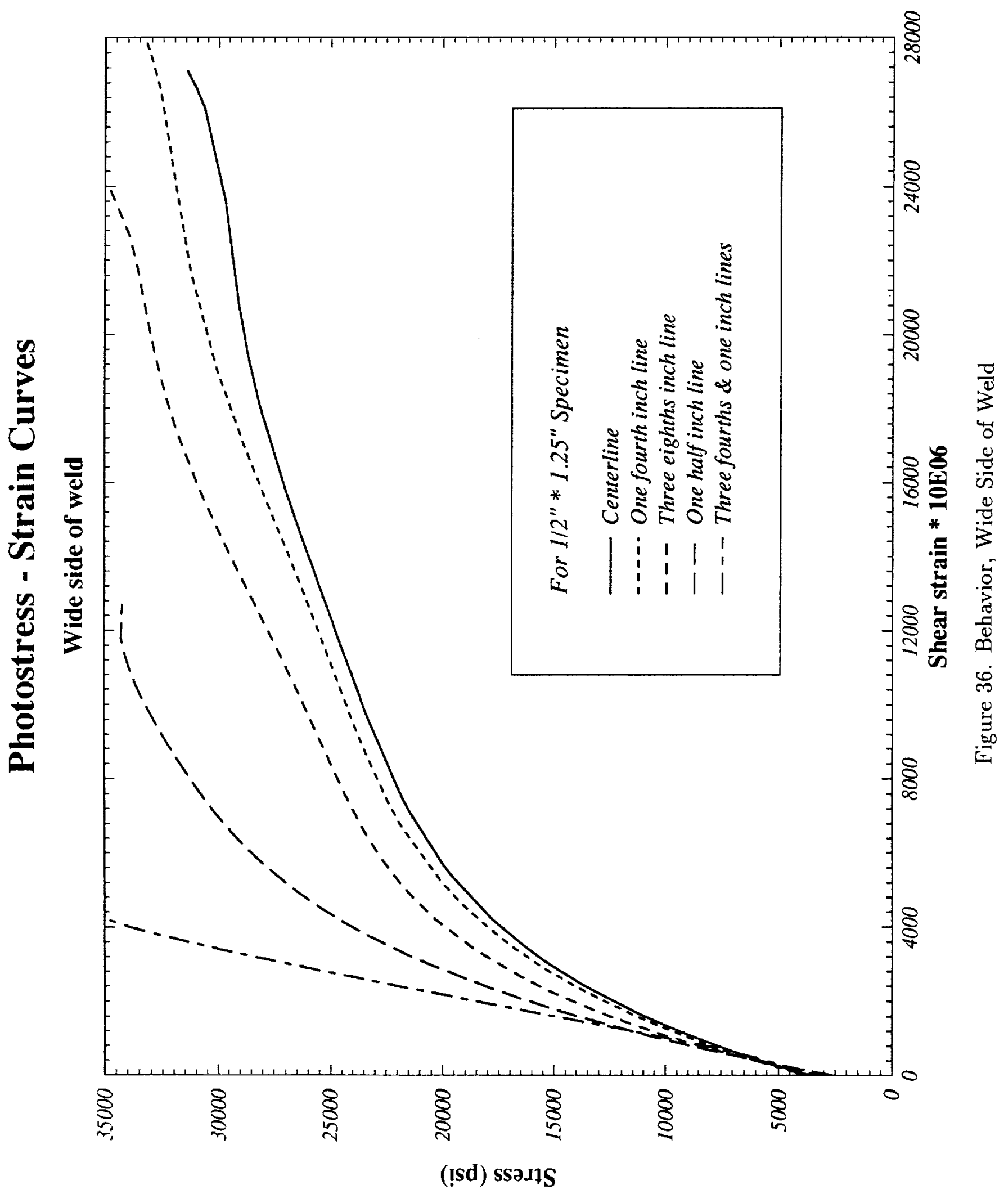




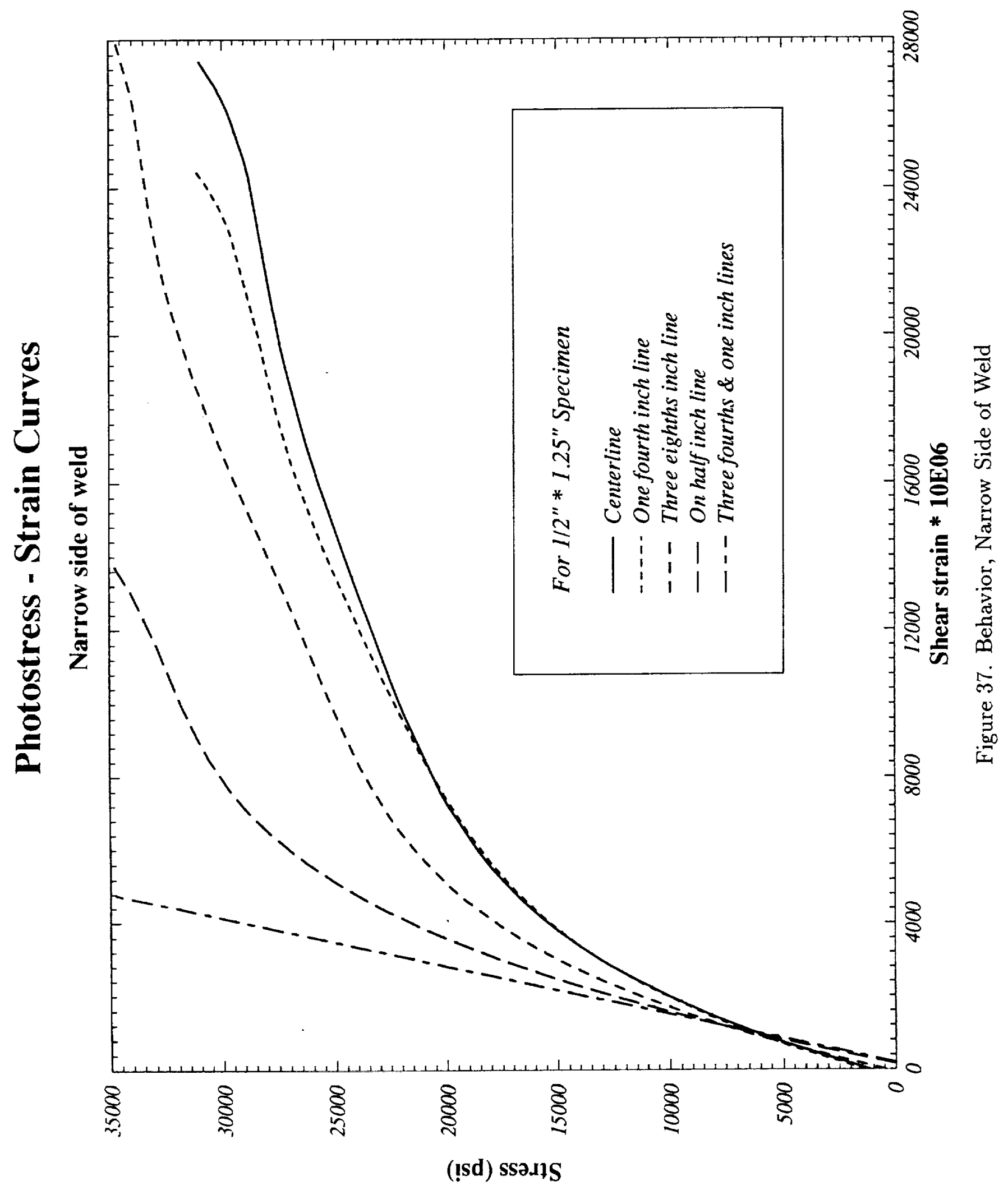




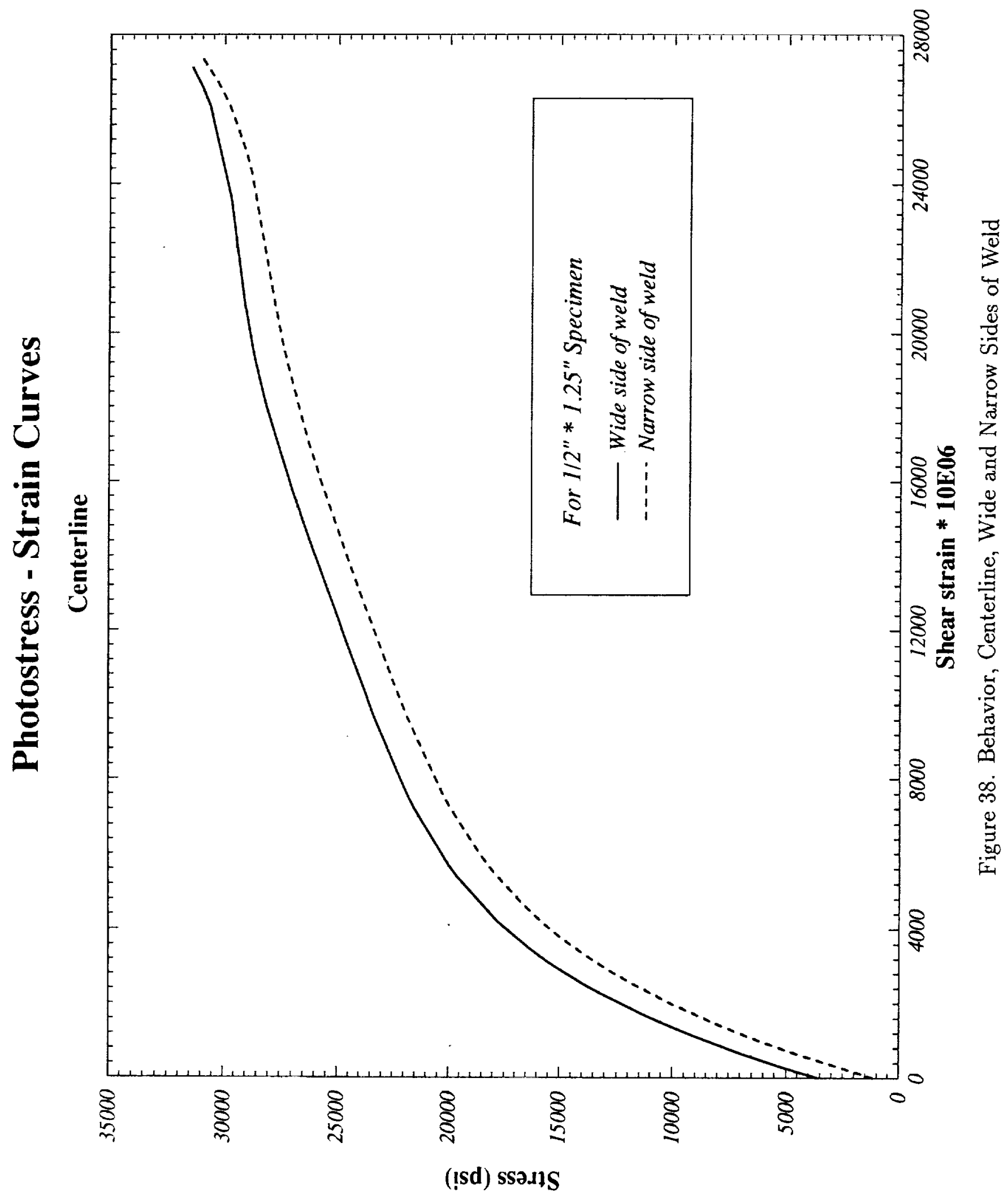




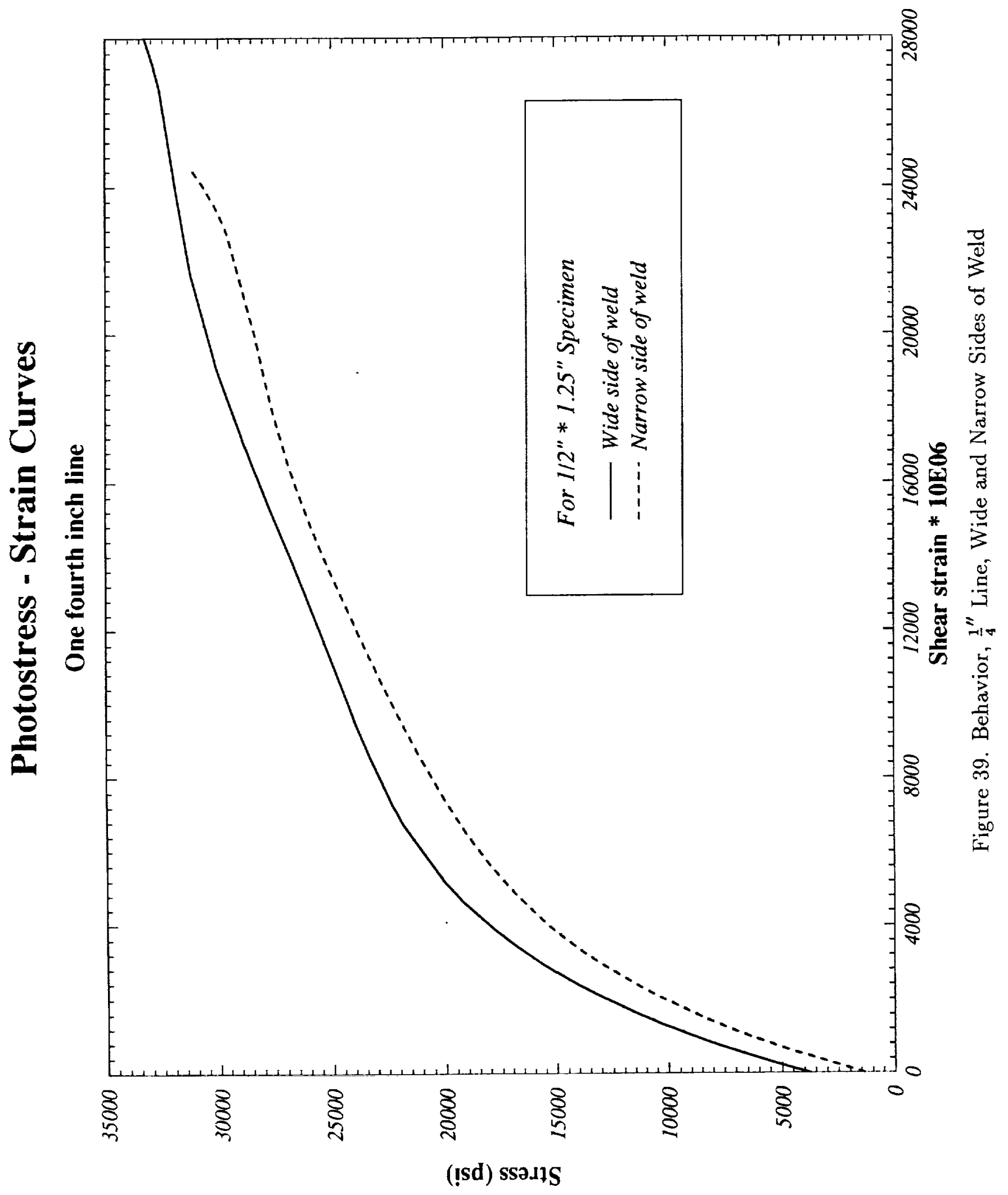




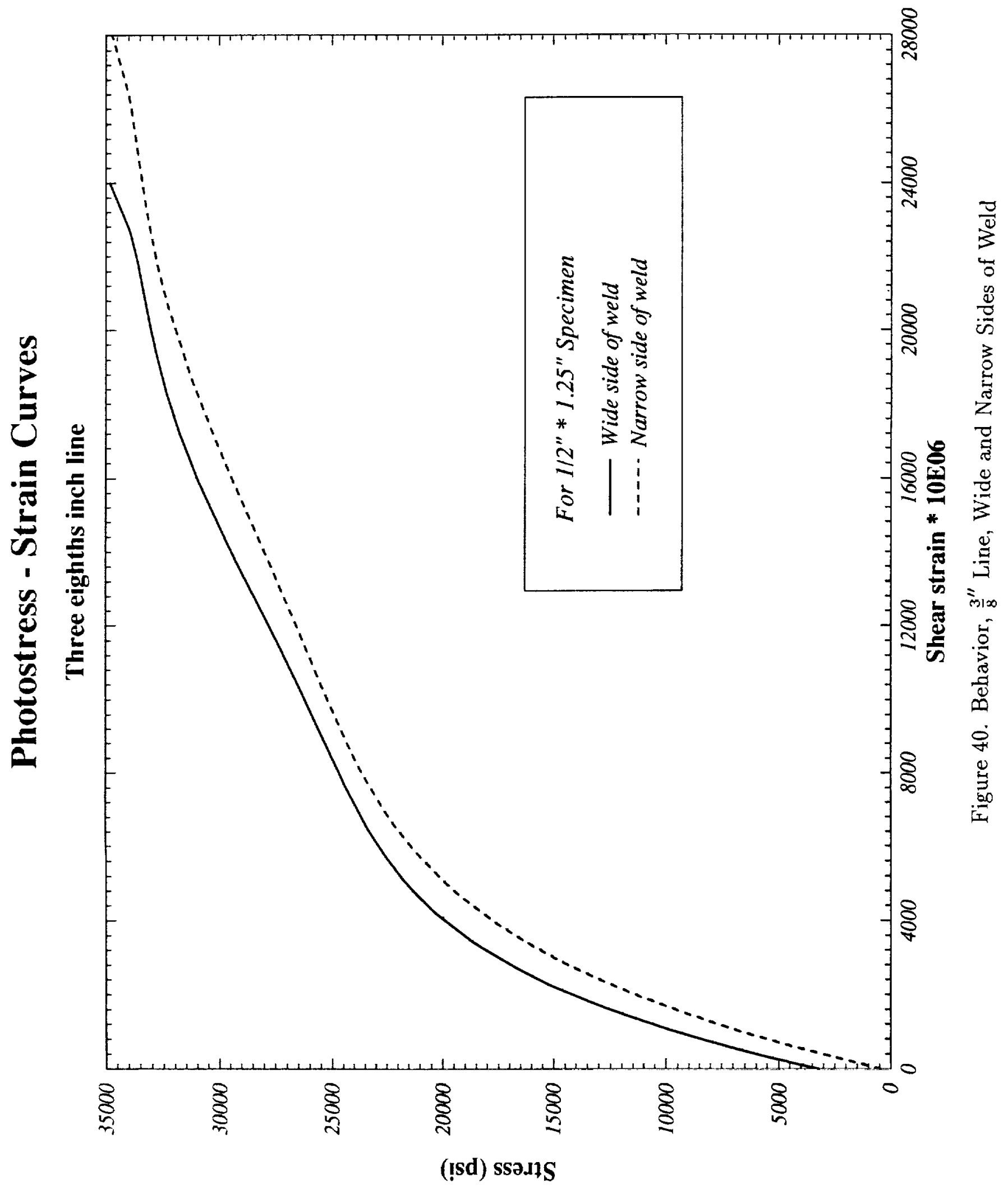




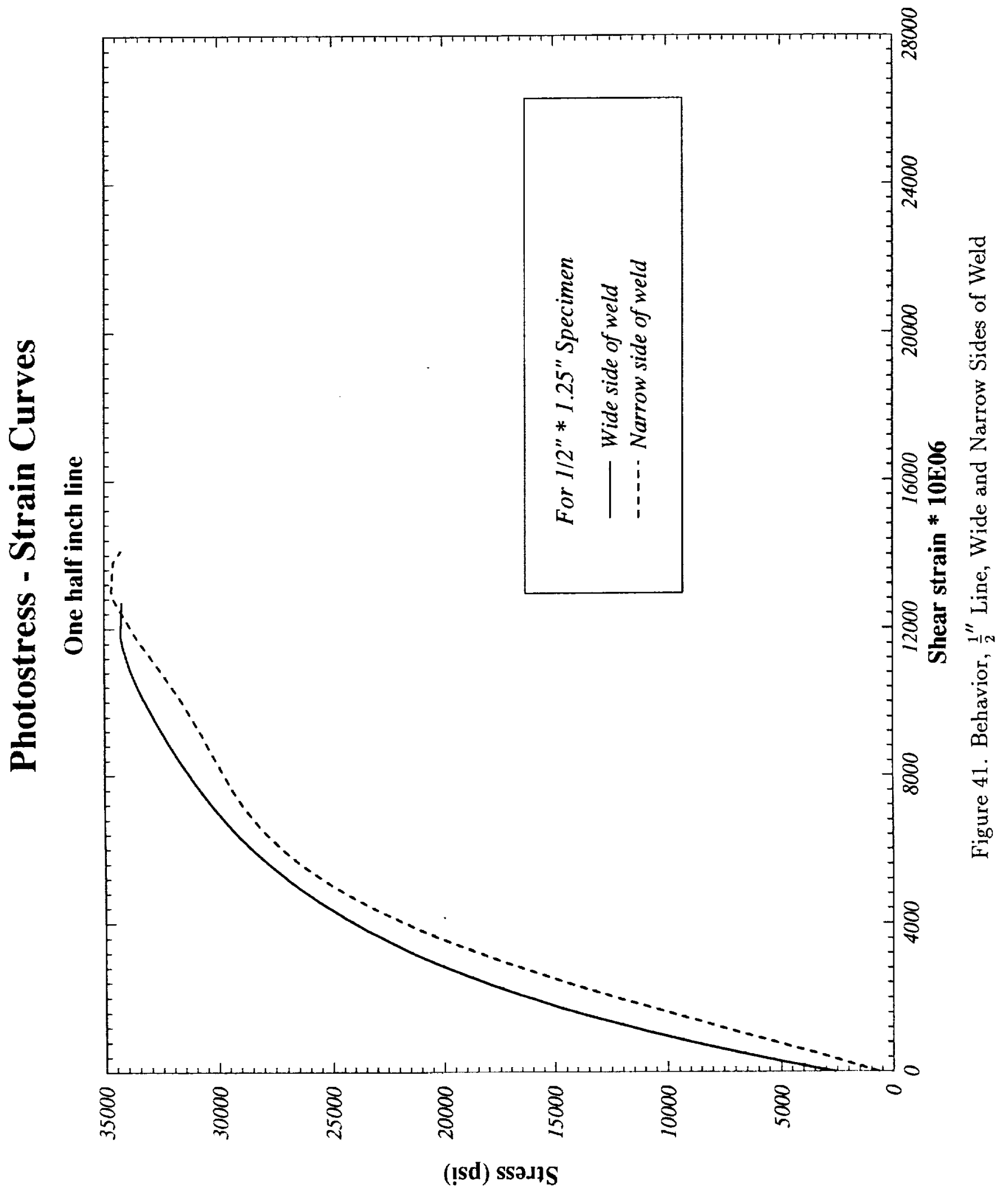




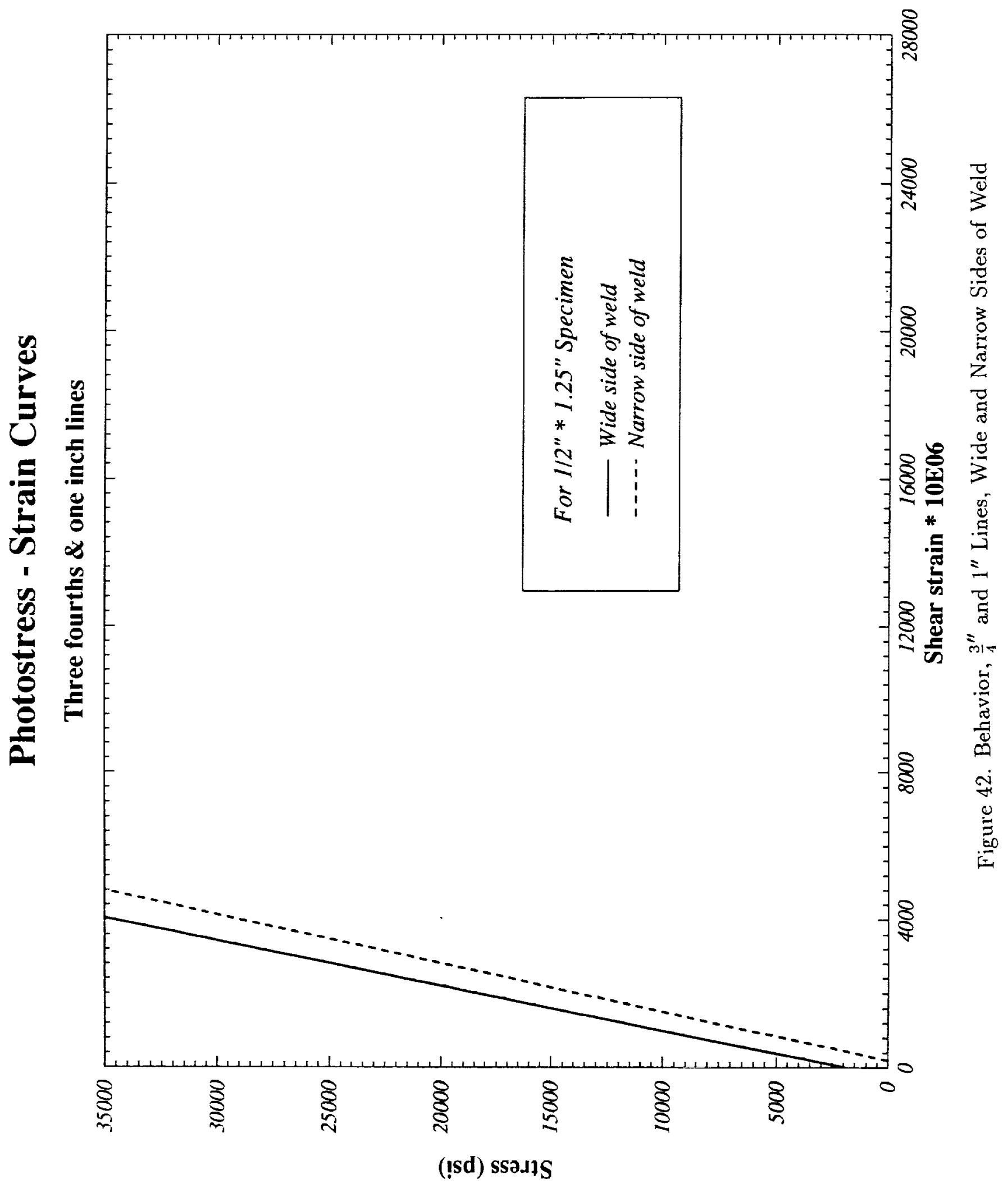




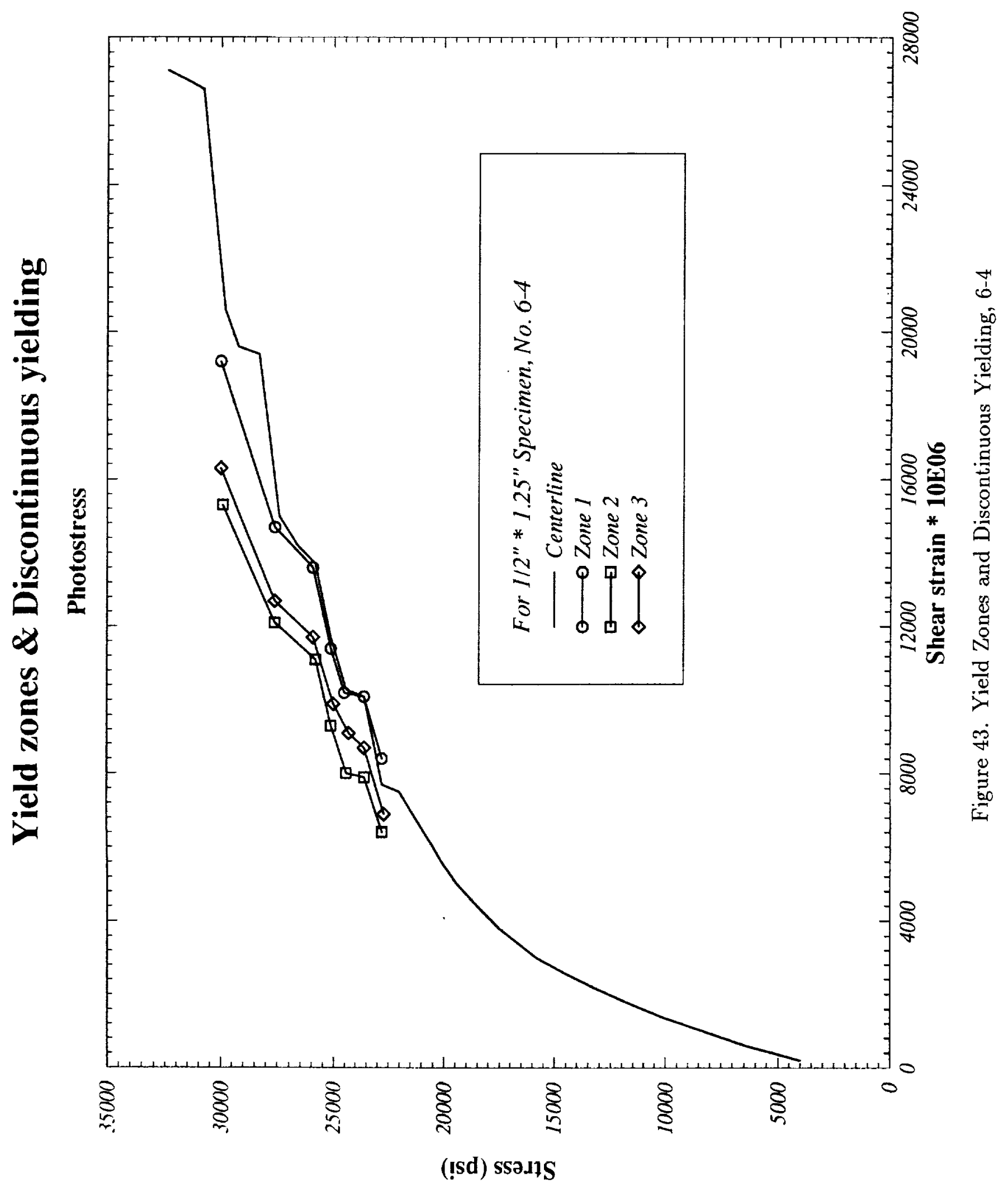




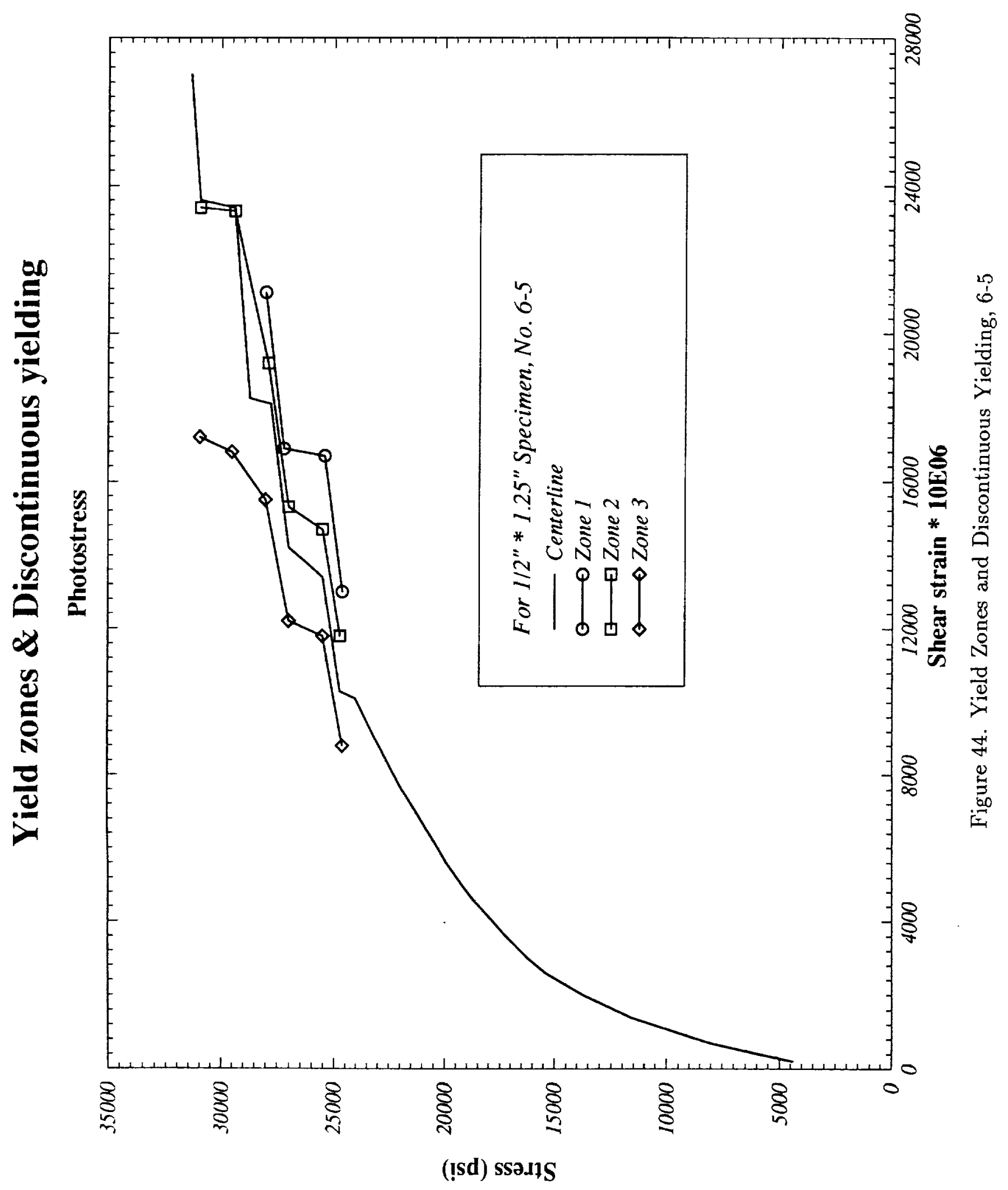




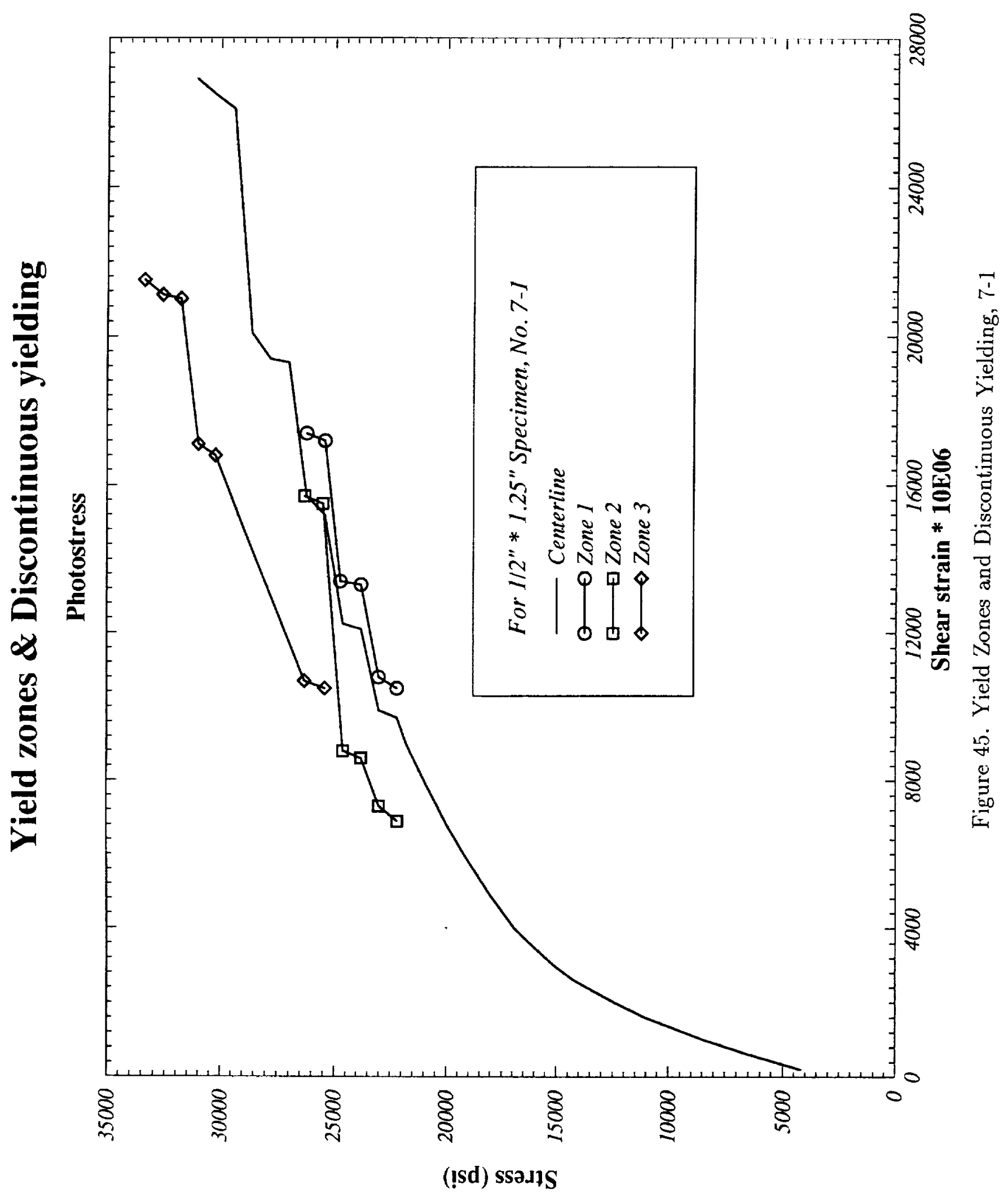


distinct zones were ever observed in any specimen. It may be seen in Table 2 that the zones are located at different distances $(y)$ from the centerline in different specimens and that the thickness $(t)$ of the zones also varies from specimen to specimen. Table 2 and Figures $43-45$ give an indication of the behavior of the highly non-homogeneous material in the welded joint, including the fusion boundary region. Yield zones did not appear in fringe patterns until a stress between 22 and 25 ksi was reached and, as seen in Figures $43-45$, exhibited stress-strain behavior both above and below the curve obtained for the centerline of the weld. Yield zones normally became non-distinct in the fringe pattern at stresses between 30 and 35 ksi. Figure 46 gives the average mechanical properties for the $\frac{1}{2}^{\prime \prime} \times 1.25^{\prime \prime}$ specimens including both the wide and narrow sides of the weld.

\section{RESULTS FROM TASK 3}

In task 3 a combination of strain gages and Photostress was used to characterize the behavior of welded joints in as welded specimens having dimensions of $\frac{1}{2}^{\prime \prime} \times 2^{\prime \prime}$. First, the stress-normal strain behavior was determined at positions along the centerline of the specimen using strain gages of $\frac{1}{64}^{\prime \prime}, \frac{1}{32}^{\prime \prime}, \frac{1}{16}^{\prime \prime}, \frac{1}{8}^{\prime \prime}$, and $\frac{1}{4}^{\prime \prime}$ gage length (References 9 and 10). Second, the stress-shear strain behavior was determined at the same locations using Photostress. Then third, the shear strain was converted to normal strain using Chakrabarty's approximation to see if Photostress could be used to obtain stress-normal strain behavior in the welded joint, heat affected zone, and parent material. Figures 47-51 show material behavior using the five different gage lengths at various locations along the centerline of the specimen. No yielding was observed at the $\frac{3}{4}^{\prime \prime}$ and 1 "locations. To determine the effect 


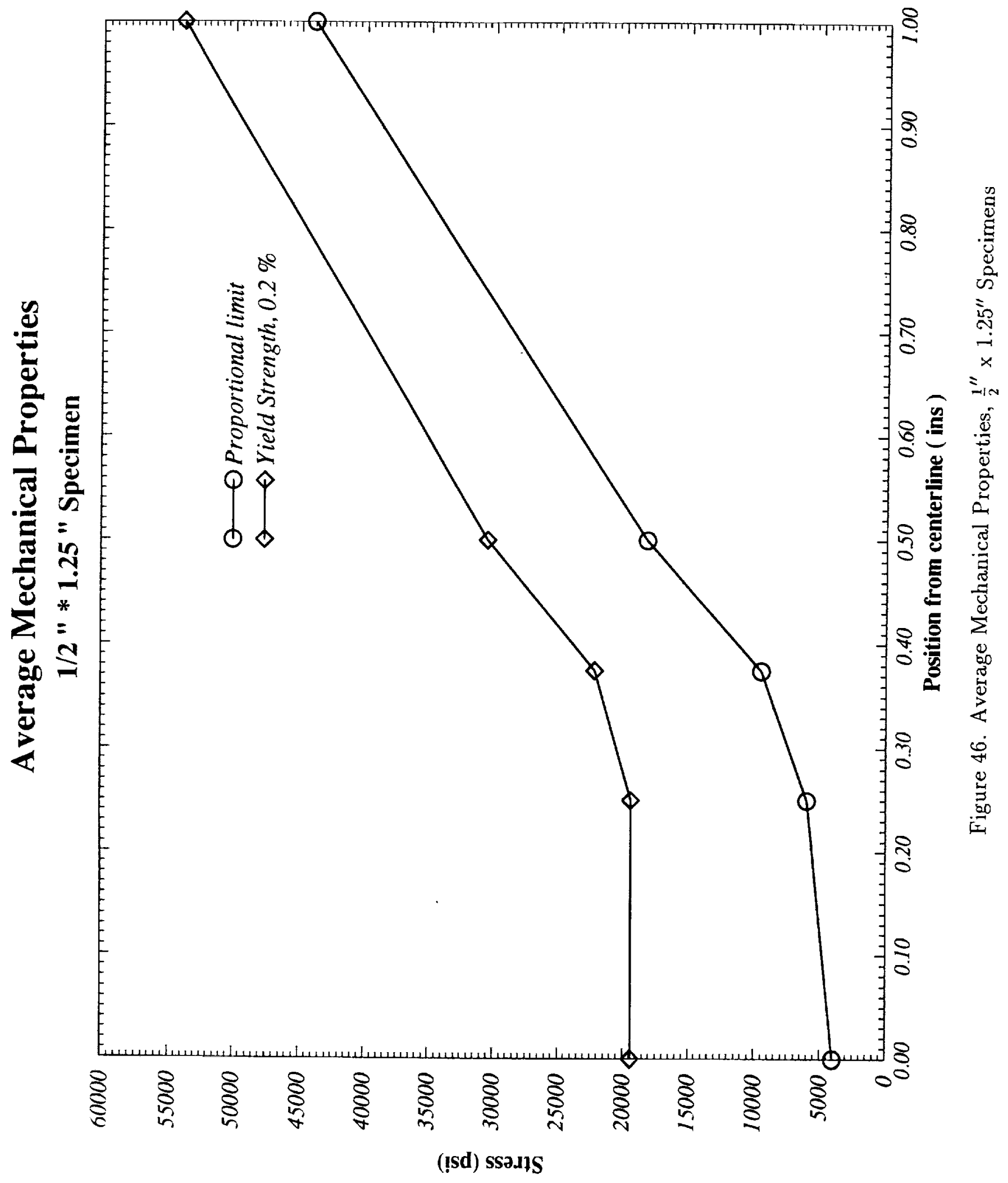




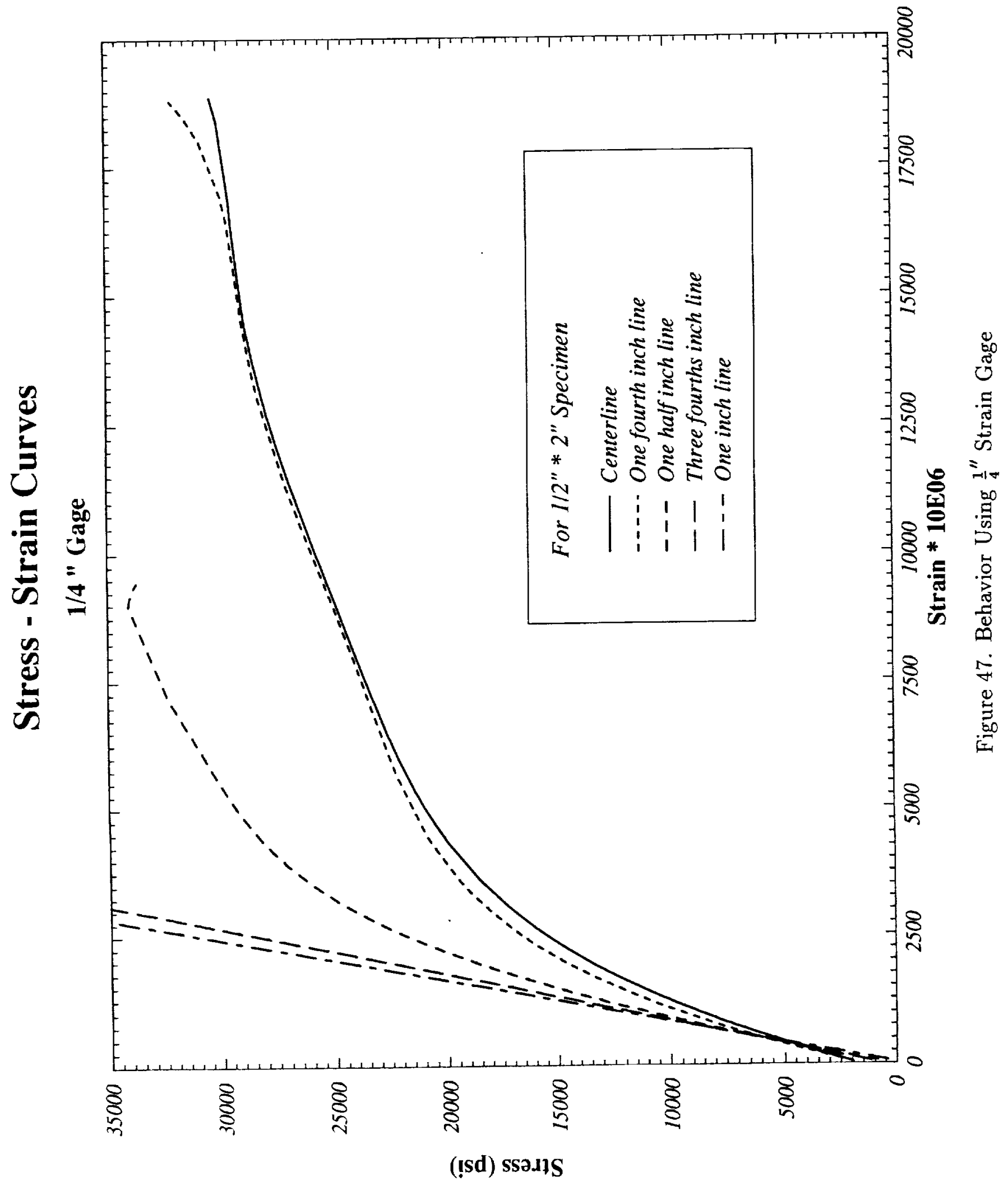




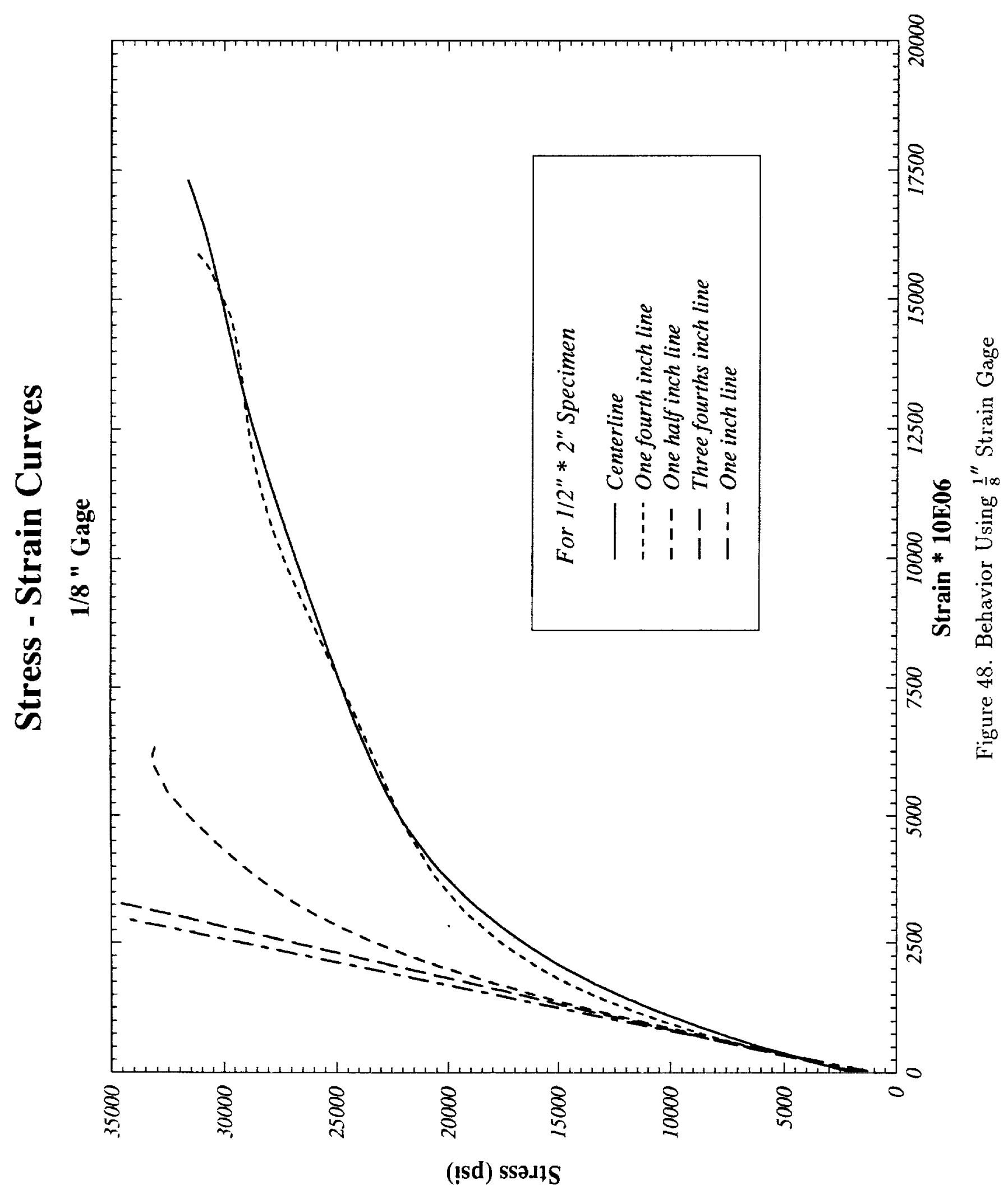




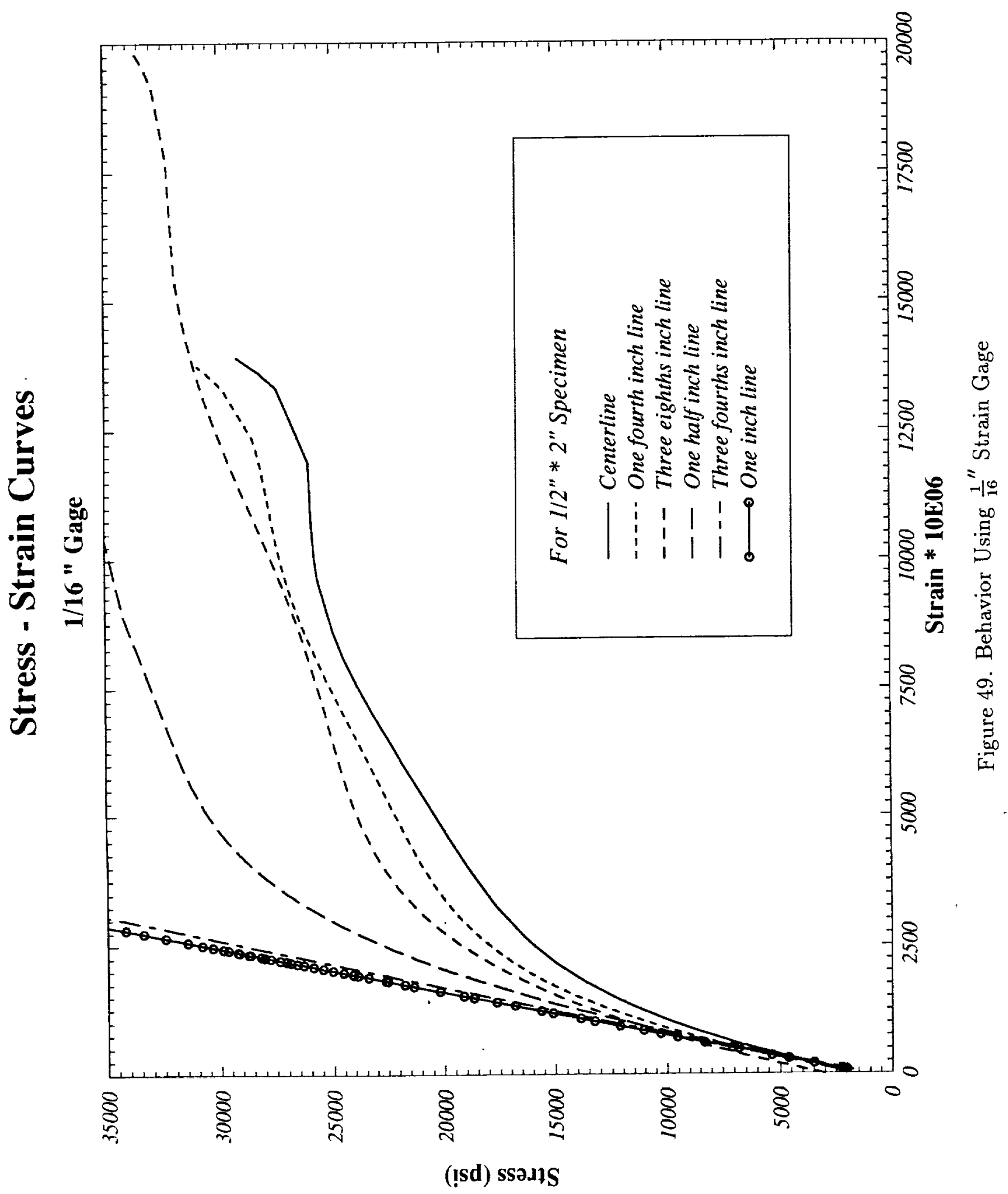




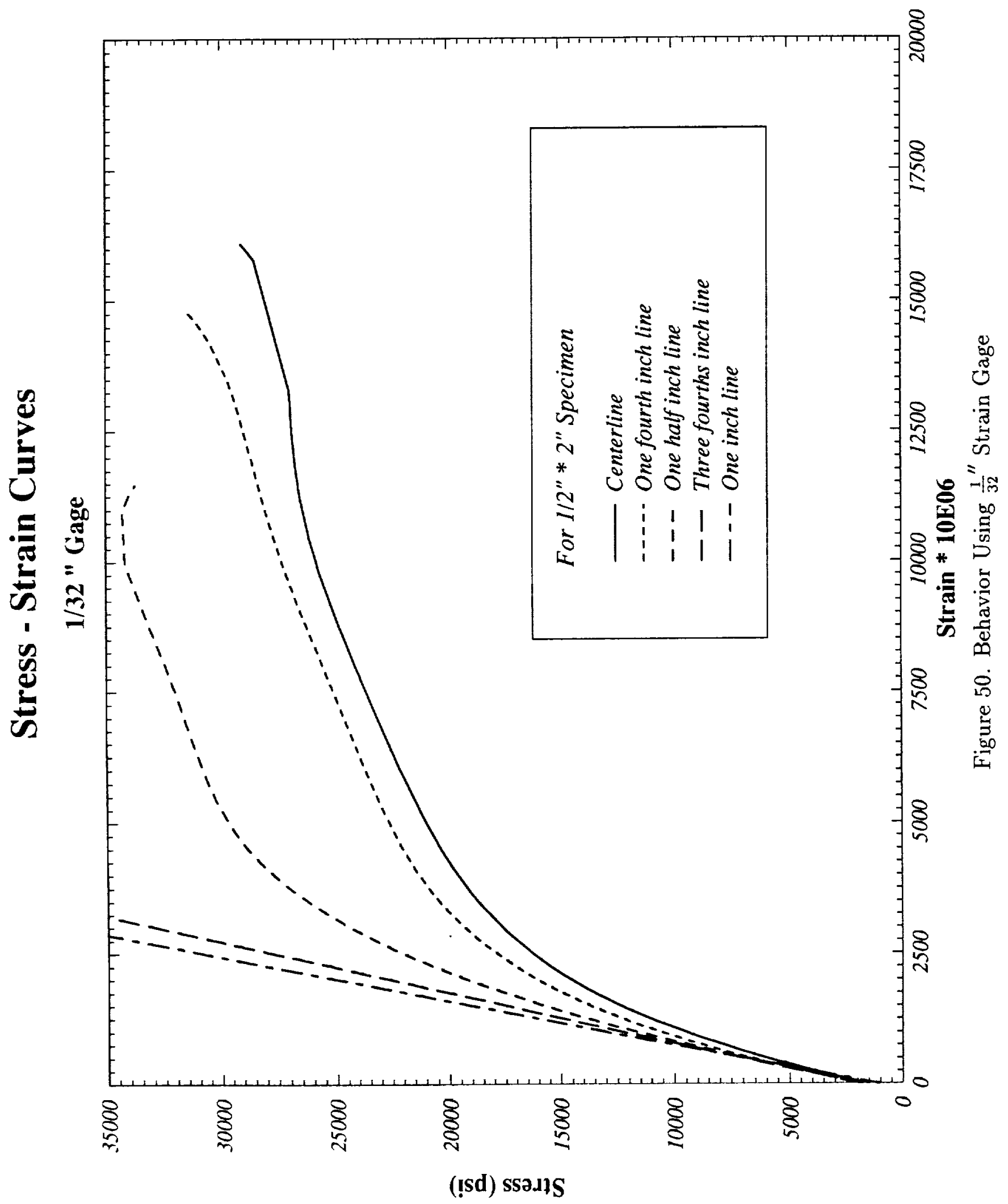




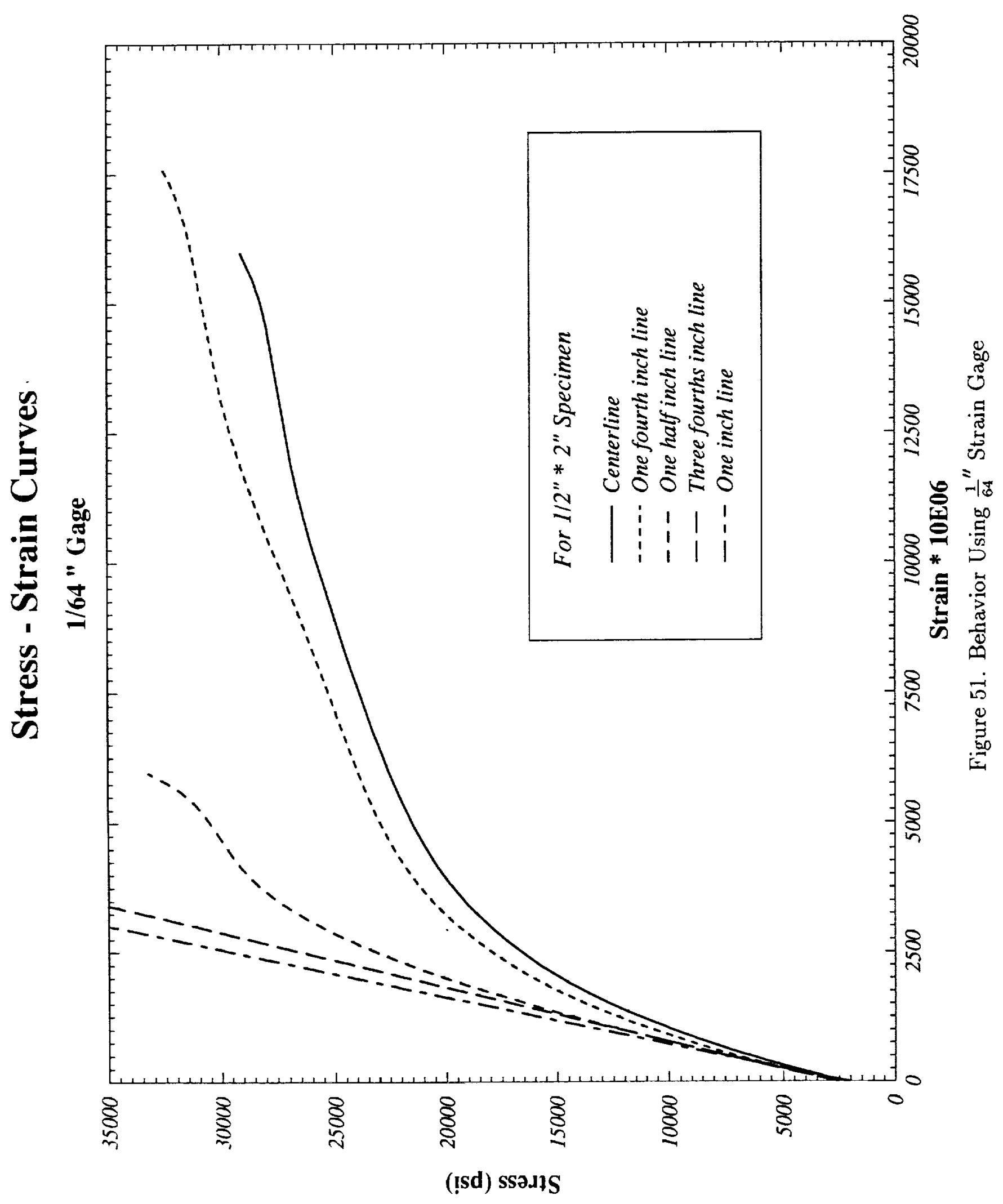

$c-2$ 
of gage length on strain measured at a specific location, data were also plotted as seen in Figures 52-56. It may be seen that, at a specific location, strains measured using all five different gage lengths are quite similar. Obviously, the averaging effect of the longer gage lengths causes the measured strain to approach the value obtained using the shorter gage lengths. It should be recalled, however, from observing the fringe patterns that there are many locations having greatly different strains under a strain gage of any appreciable size.

Photo 19 shows the general, characteristic yielding of the material at three different stress levels. Note in Photo 19 that the weld material, including the fusion boundary, exhibits a non-uniform fringe pattern vertically and from side to side. This was observed in nearly all tests of the $\frac{1}{2}$ "thick material. Figure 57 shows the Photostress-strain behavior of the specimens in this group of $\frac{1}{2}^{\prime \prime}$ thick material. It can be seen that, as in several of the stressnormal strain curves, the value of shear strain at the centerline, $\frac{1}{4}^{\prime \prime}$, and $\frac{3}{8}^{\prime \prime}$ lines does not differ greatly. In most specimens $\frac{1}{2}^{\prime \prime}$ thick, the etch lines seen in Photo 4 on either side of the weld are either at or very near to the $\frac{1}{4}^{\prime \prime}$ and $\frac{3}{8}^{\prime \prime}$ lines. Thus, there is a region in the vicinity of these lines in which widely varying strains can occur and these variations can be observed in most of the fringe patterns.

To determine the applicability of Chakrabarty's approximation for converting shear strain to normal strain, the three quantities of normal strain, shear strain, and corrected shear strain were plotted in Figures 58-63 for six different locations. In Figure 58, at the centerline of the weld, it is seen that epsilon is nearly equal to gamma and that the corrected value of shear strain does not compare closely with the normal strain. However, Figures 59-63 show that, at 


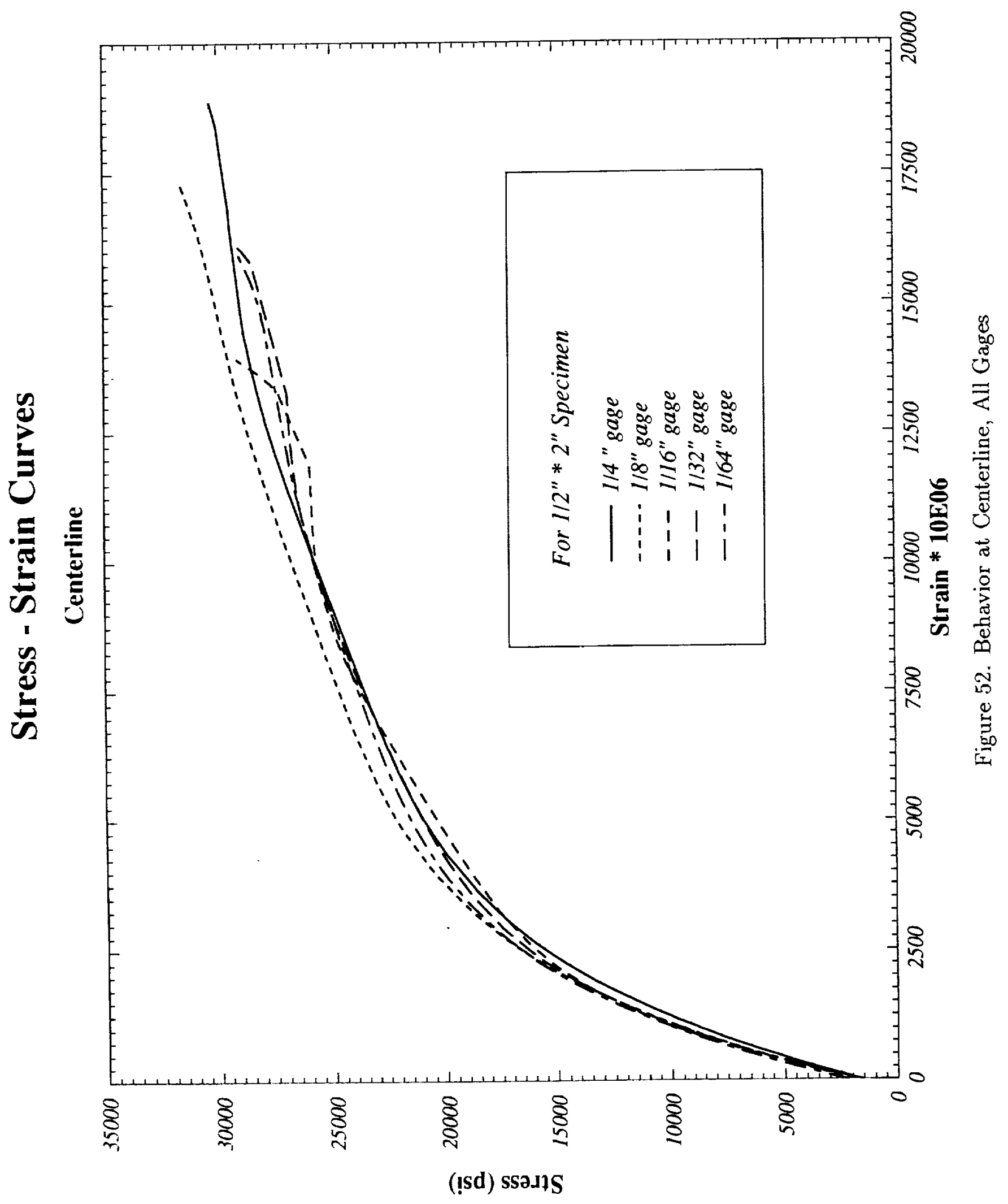




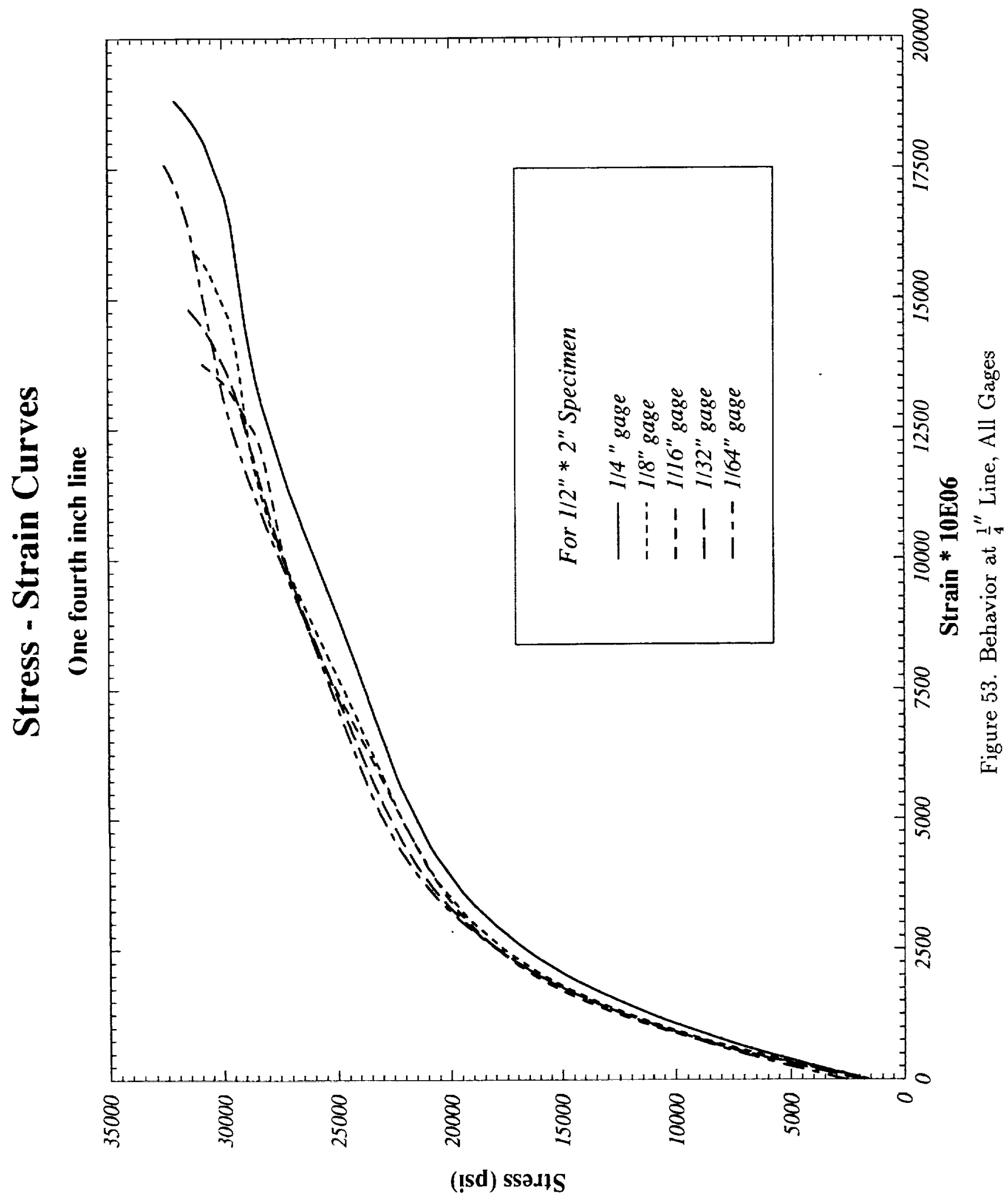




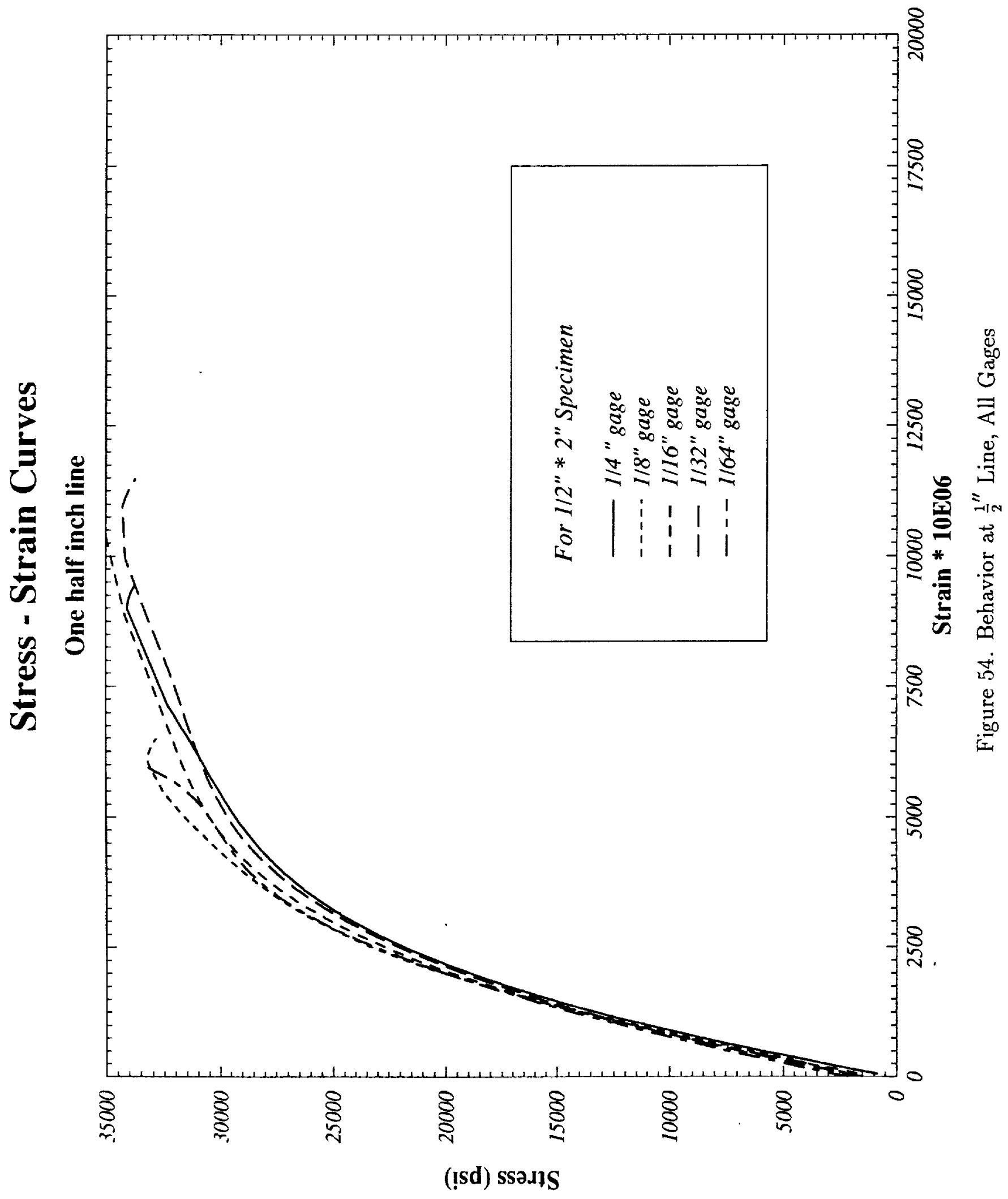




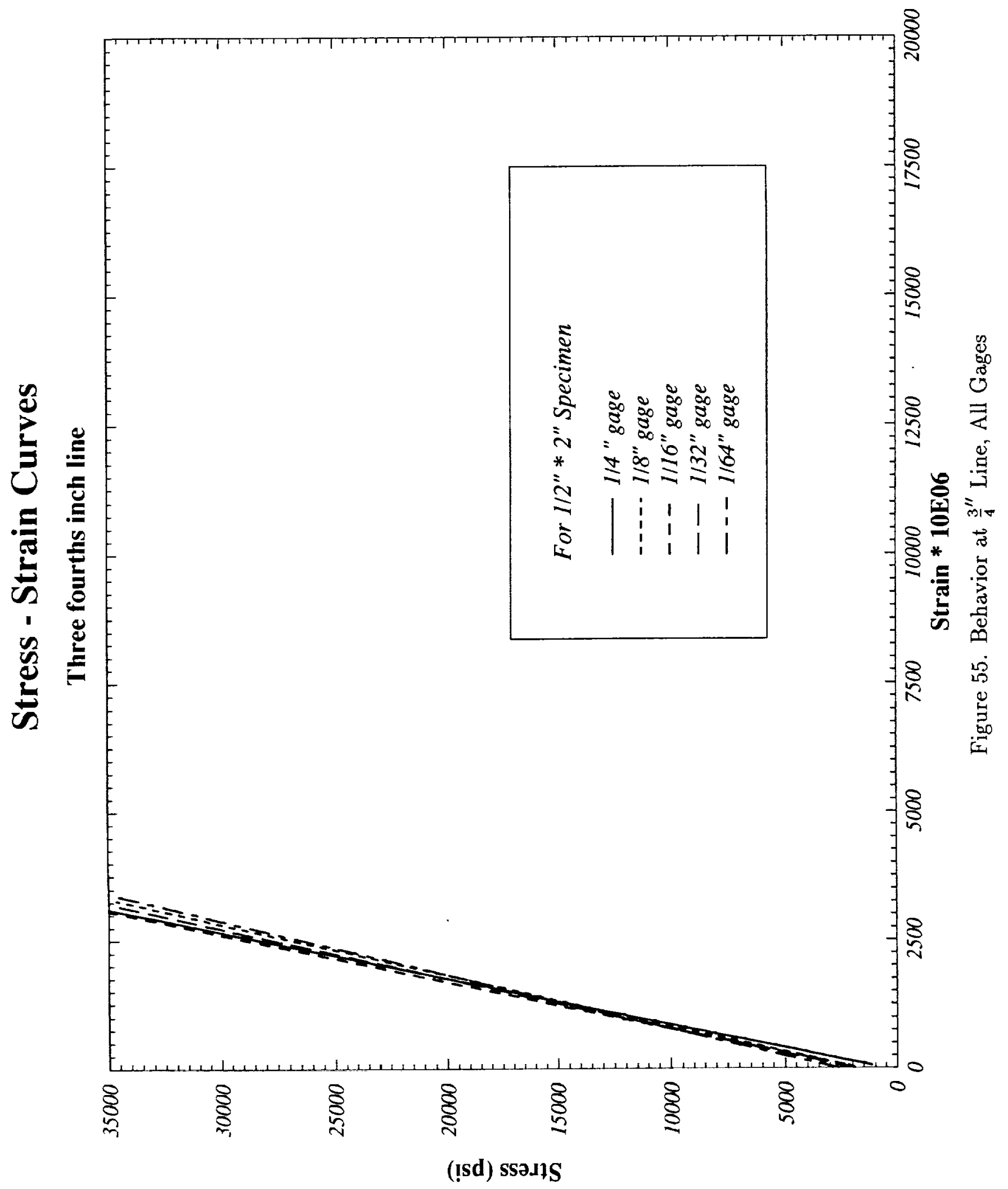




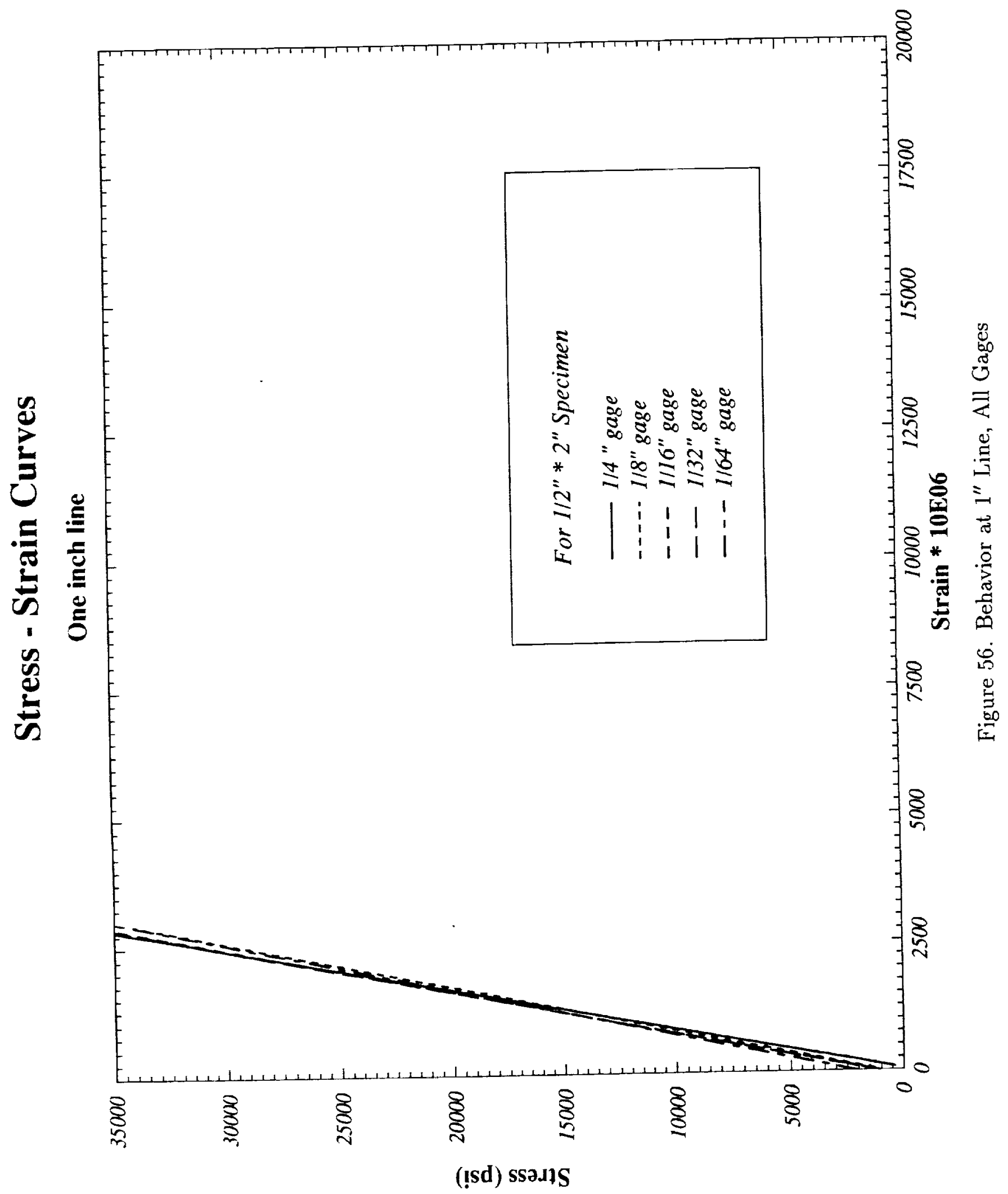




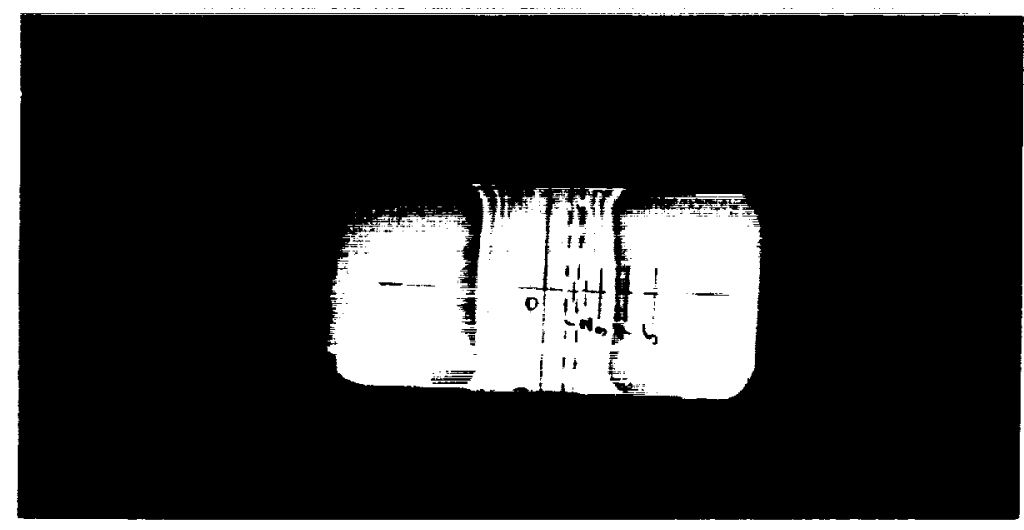

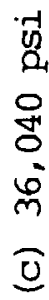

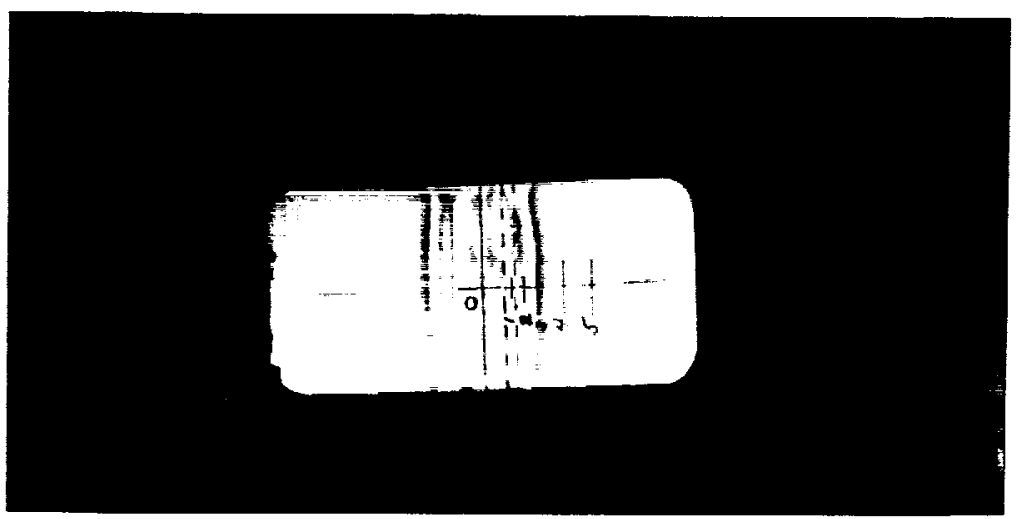

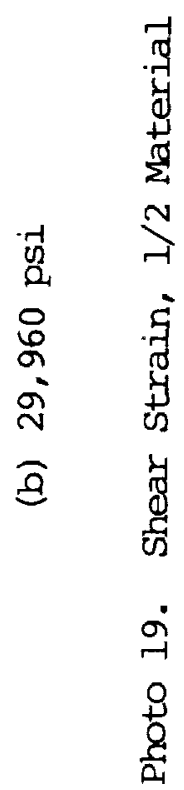

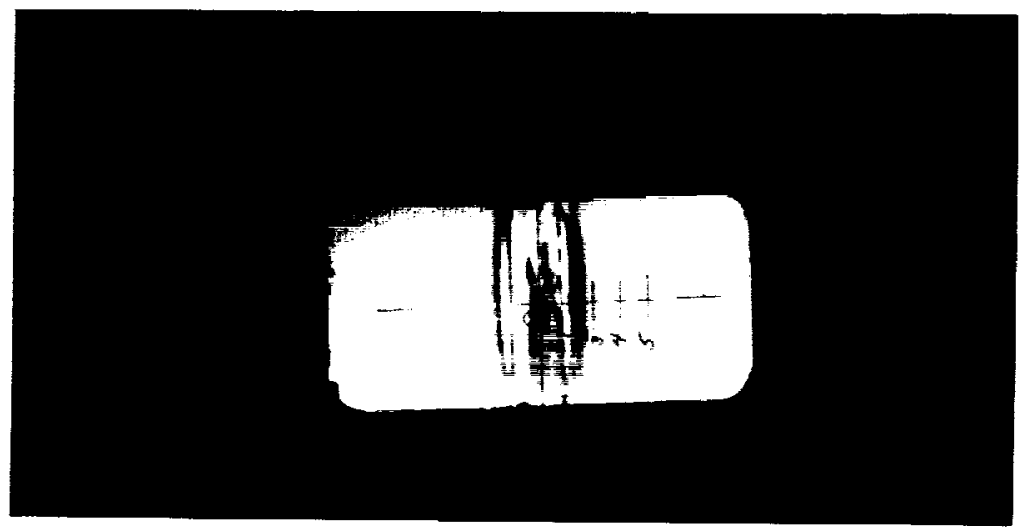

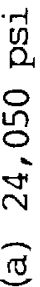




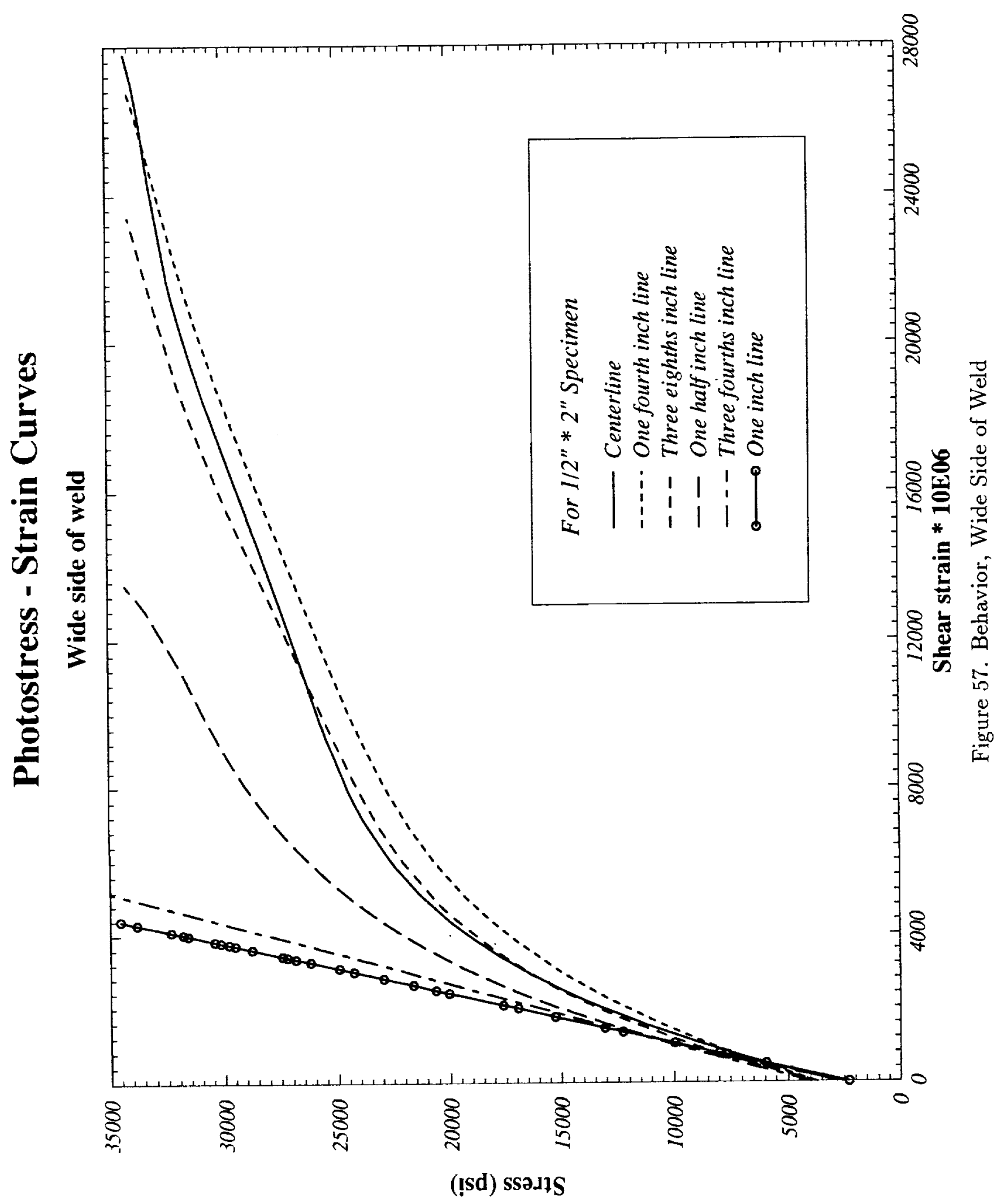




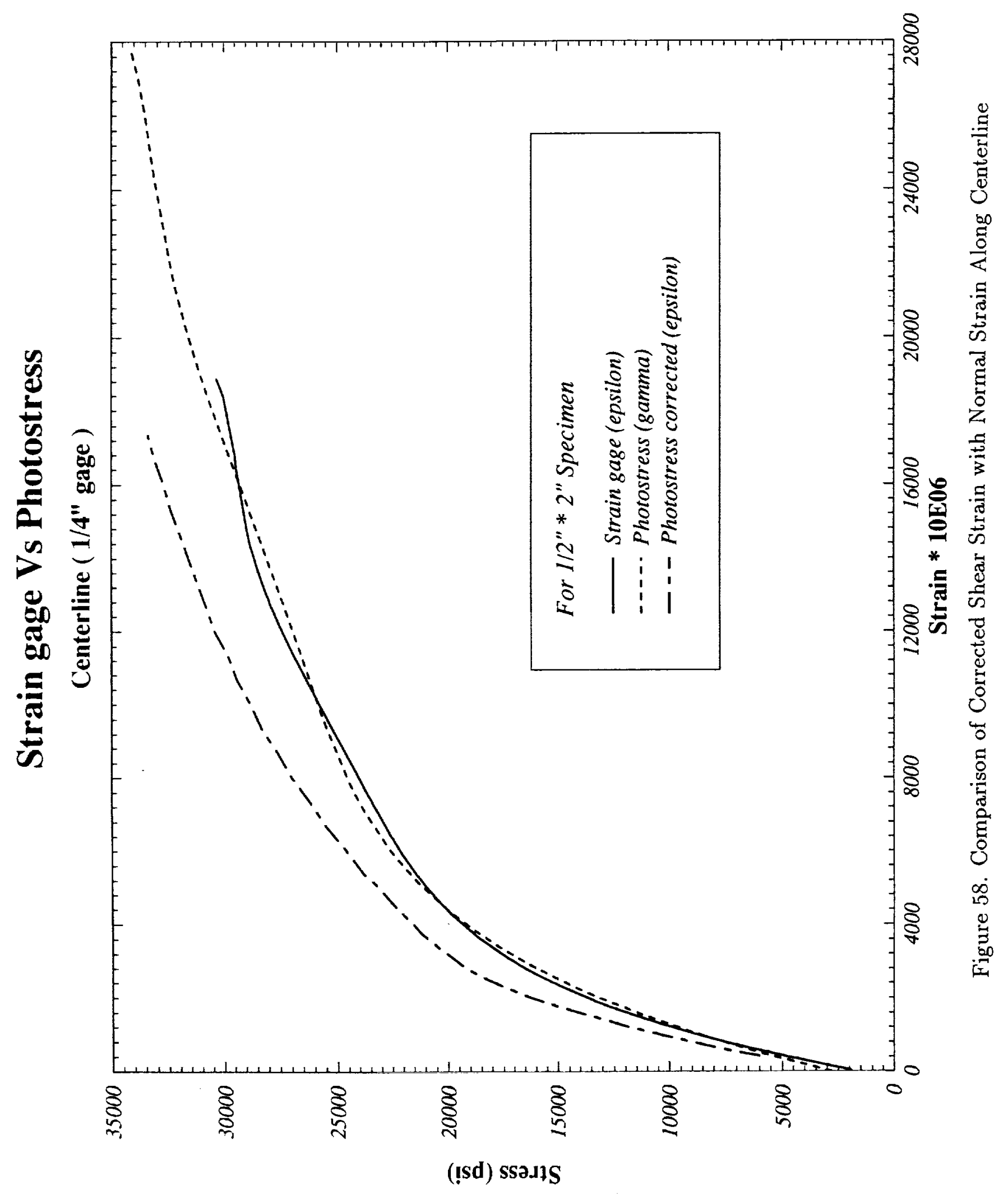




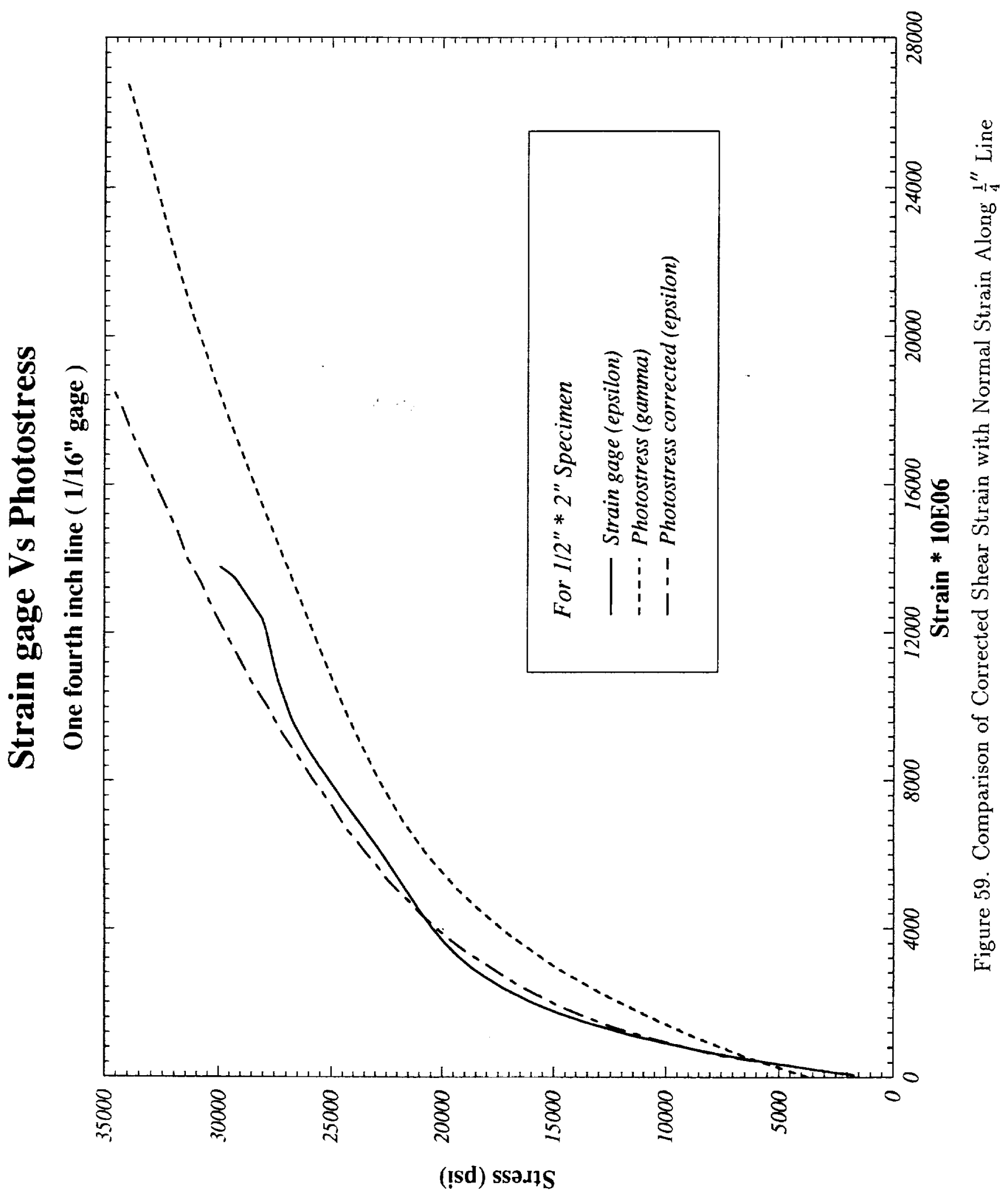




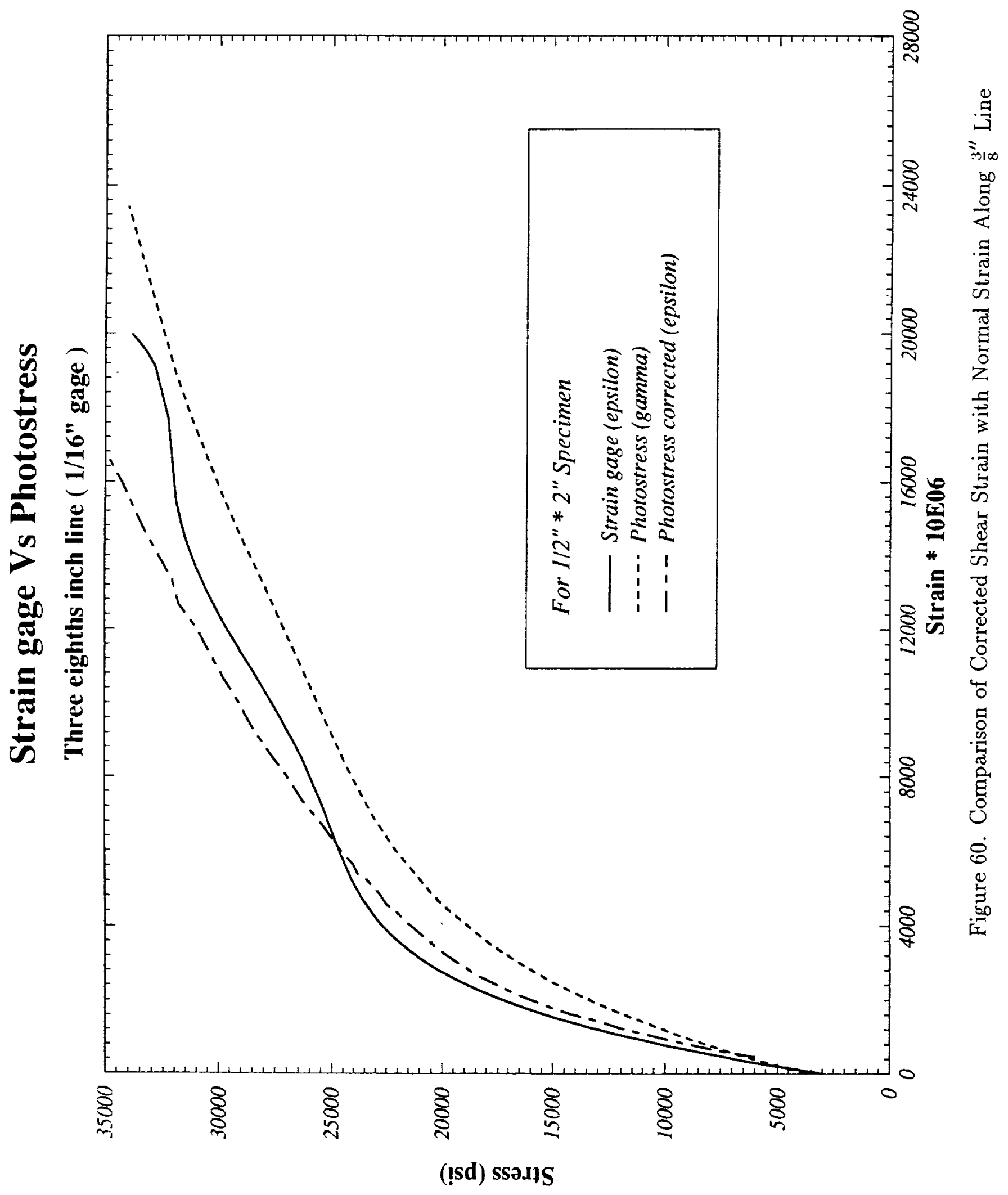




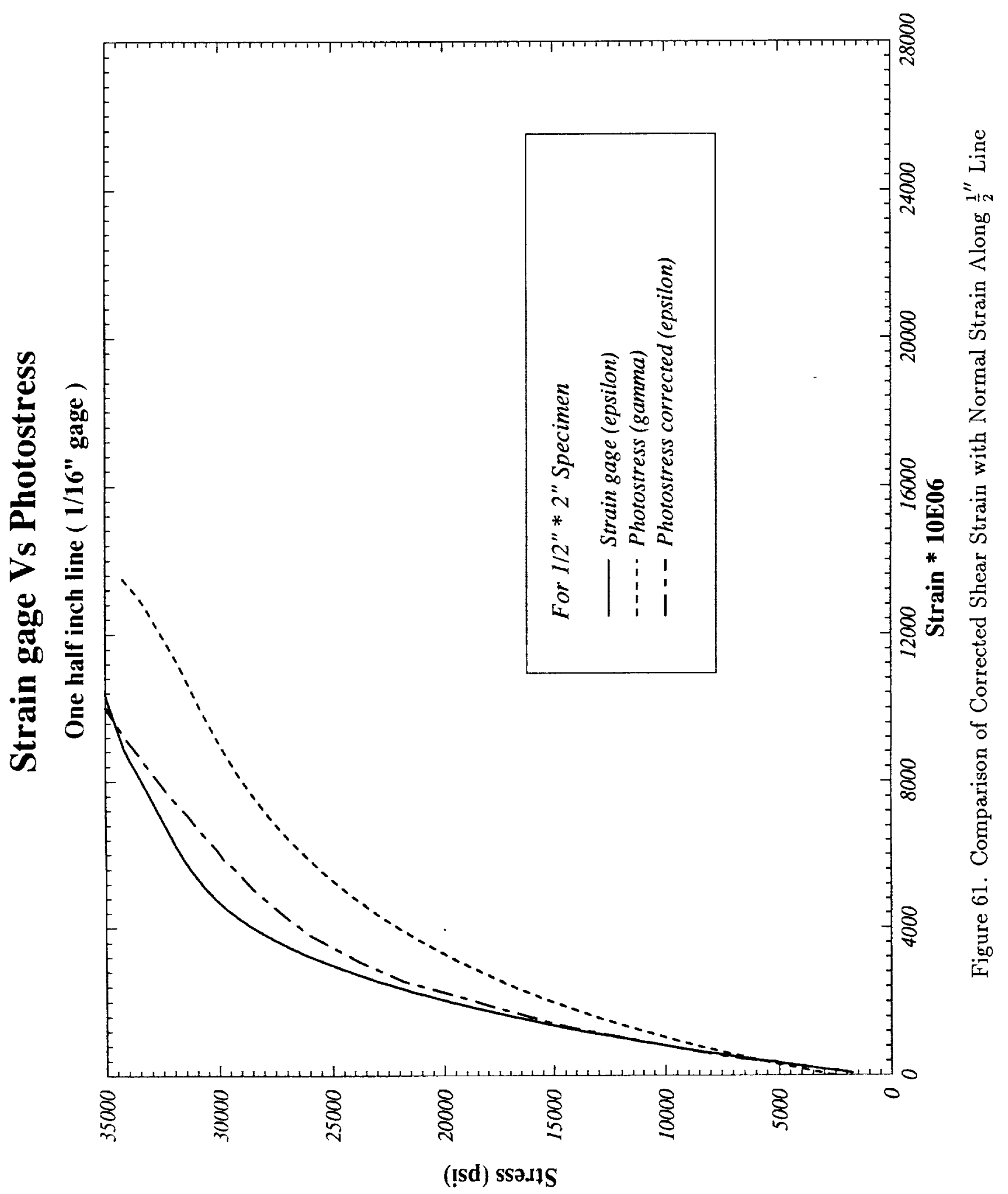




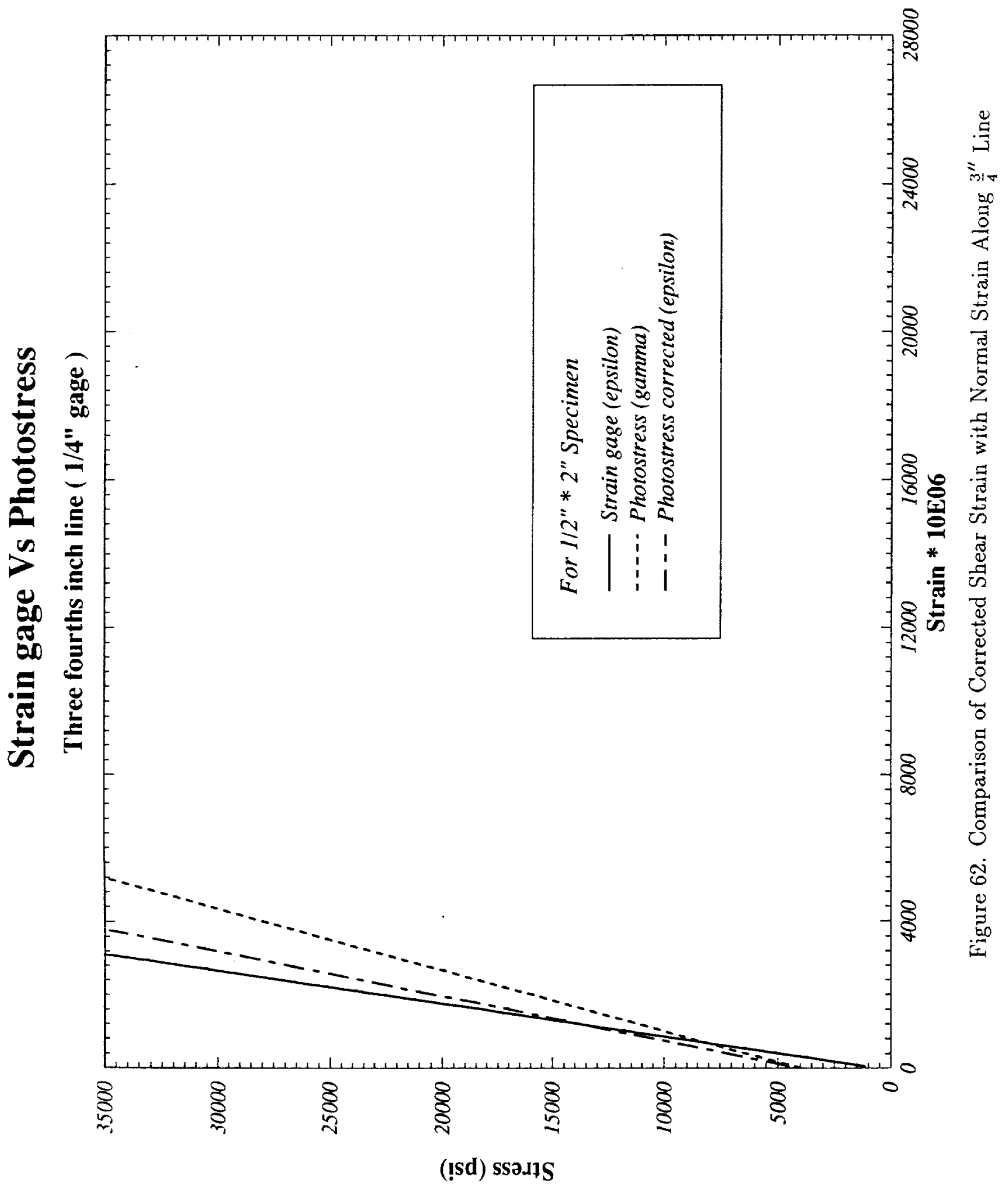




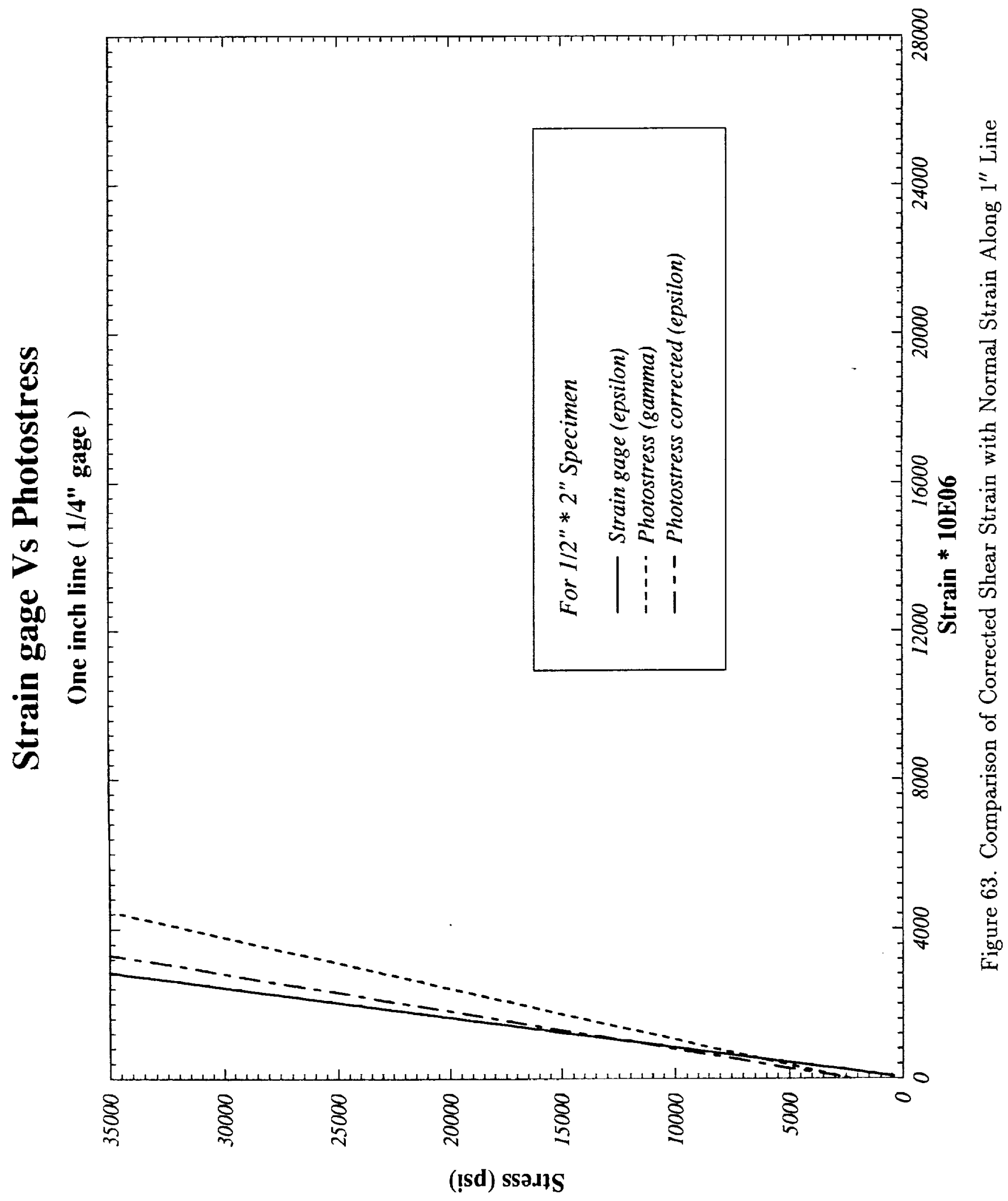


locations of $\frac{1}{4}$ " and farther from the center of the weld, the corrected values of shear strain do compare more closely with the values of normal strain. It is believed that this non-comparison seen in Figure 58 is due to the constraint of the parent material and fusion boundary on either side of the weld which does not allow the weld material to deform at constant volume when subjected to inelastic deformation. Chakrabarty's approximation assumes that the material deforms at constant volume as is normally done in inelastic behavior. It is likely that the contraction ratios in the constrained weld material are quite different from those calculated by using Chakrabarty's approximation.

As previously mentioned, discontinuous yielding was observed in all but one specimen and, in the $\frac{1}{2}$ thick material used in these tests, clear and distinct zones or bands of constant shear strain were observed in many specimens. Photo 20 shows a sample of the characteristic, constant strain, yield zones which were observed. Two distinct zones, one yellow and one green, can be clearly seen. Table 3 identifies the location and thickness of zones in three of the $\frac{1}{2}{ }^{\prime \prime} \times 2^{\prime \prime}$ specimens.

TABLE 3. Zone Locations and Thickness (Inches) $\frac{1}{2}^{\prime \prime} \times 2^{\prime \prime}$ Specimens

\begin{tabular}{|c|c|c|c|c|c|c|}
\hline & \multicolumn{2}{|c|}{ Zone 1 } & \multicolumn{2}{c|}{ Zone 2 } & \multicolumn{2}{c|}{ Zone 3 } \\
\hline Specimen No. & $y$ & $t$ & $y$ & $t$ & $y$ & $t$ \\
\hline $1-3$ & .124 & .108 & .191 & .133 & --- & --- \\
$4-1$ & .178 & .125 & .273 & .065 & .341 & .071 \\
$4-2$ & .249 & .047 & .308 & .071 & .377 & .067 \\
\hline
\end{tabular}




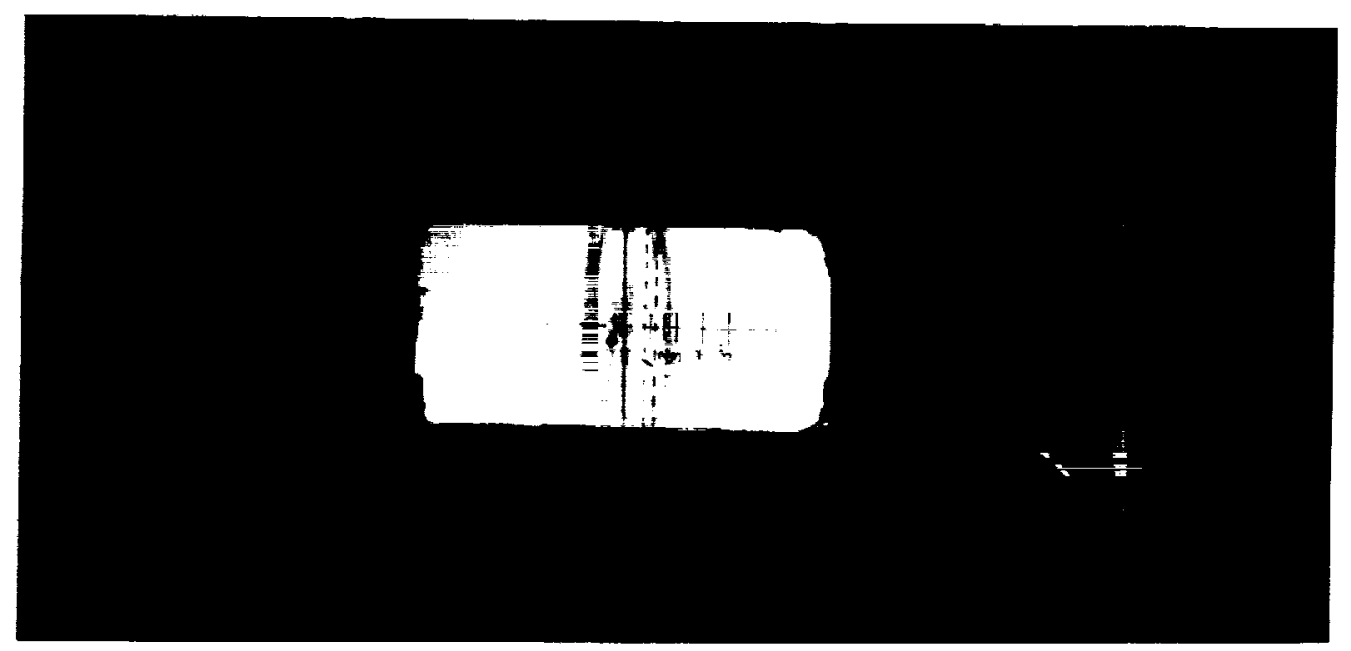

3
5
5
7
7
4
8
3
3

-
0
8
8
$\infty$
ñ

睰
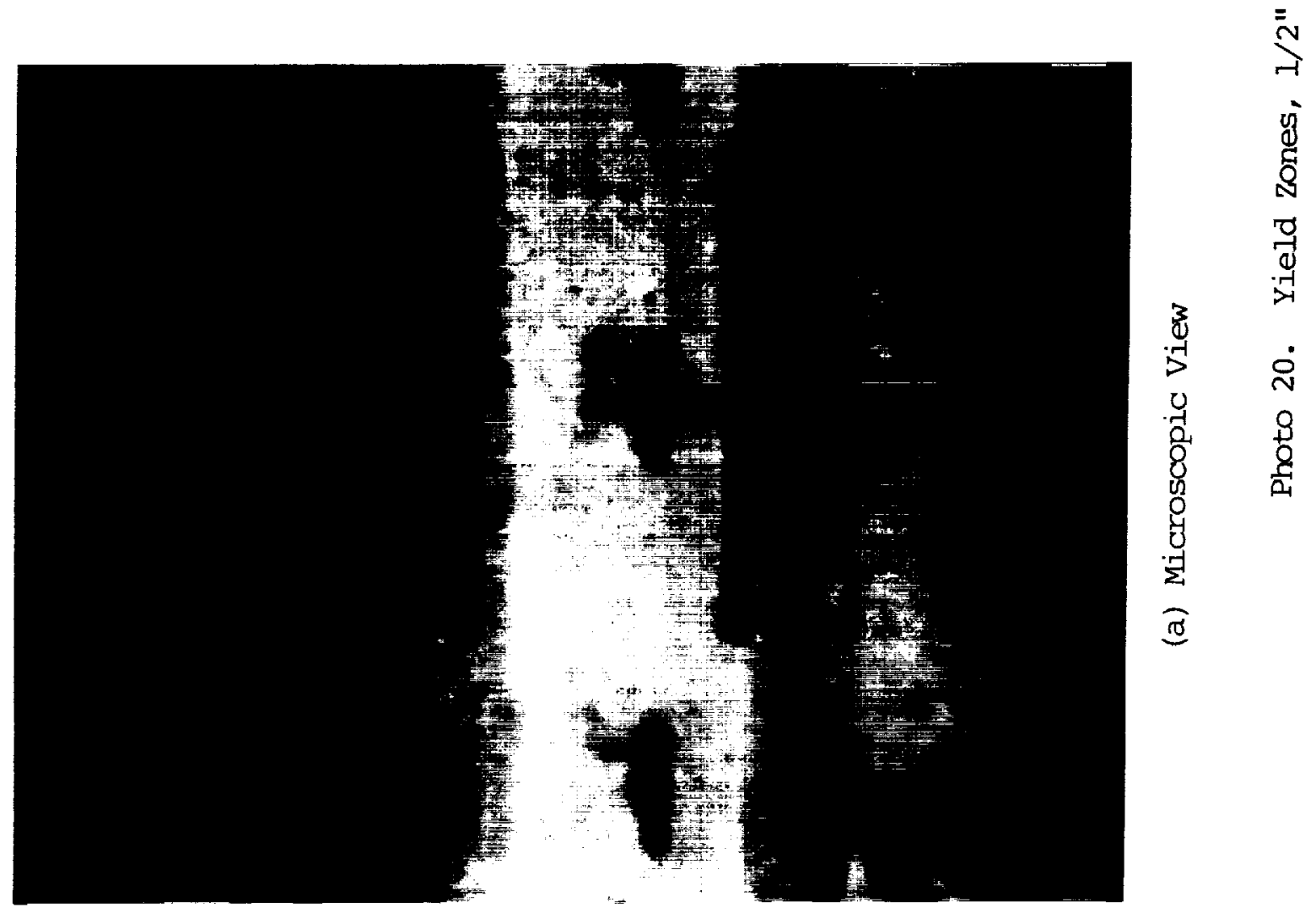
Figures 64-66 show stress-strain curves for three different specimens (1-3, 4-1, 4-2) which include behavior at the center of the weld and in different zones which were observed. Note that stress-strain curves in the several zones lie both above and below the curve obtained for the centerline of the weld. From Photo 20 , it is clear that quite different strains would be measured by a strain gage placed at any given point in the weld and fusion boundary and that, depending upon the gage length, the measured value would contain some kind of an average of many different strains occurring under the total gage length. Figure 67 shows average mechanical properties for the group of as welded $\frac{1}{2}^{\prime \prime} \times 2^{\prime \prime}$ specimens. As seen in previous graphs of mechanical properties (Figures 16,20,25, 26,35, and 46), it is clear that both the proportional limit and yield strength change quite a bit as one progresses from the centerline of the weld to a point 1 inch from the centerline. The values at the 1 inch location of $44 \mathrm{ksi}$ for the proportional limit and $54 \mathrm{ksi}$ for the yield strength (Figures 16, 20, 35,46 , and 67) were obtained from tests conducted at NASA during the summer of 1991 since, in this project, these specimens did not exhibit any yielding at the $\frac{3}{4}$ "and $1^{\prime \prime}$ locations when subjected to the maximum stress which was applied. However, in tests on the wide and narrow sides of the welds in the $0.71^{\prime \prime} \times 1.4^{\prime \prime}$ specimens (Figures 23 and 24), it is seen that yielding did occur at the $\frac{3}{4}^{\prime \prime}$ and $1^{\prime \prime}$ locations. Therefore, mechanical properties curves (Figures 25 and 26) indicate values obtained during these tests for proportional limit and yield strength at the $\frac{3}{4}^{\prime \prime}$ and $1^{\prime \prime}$ locations. 


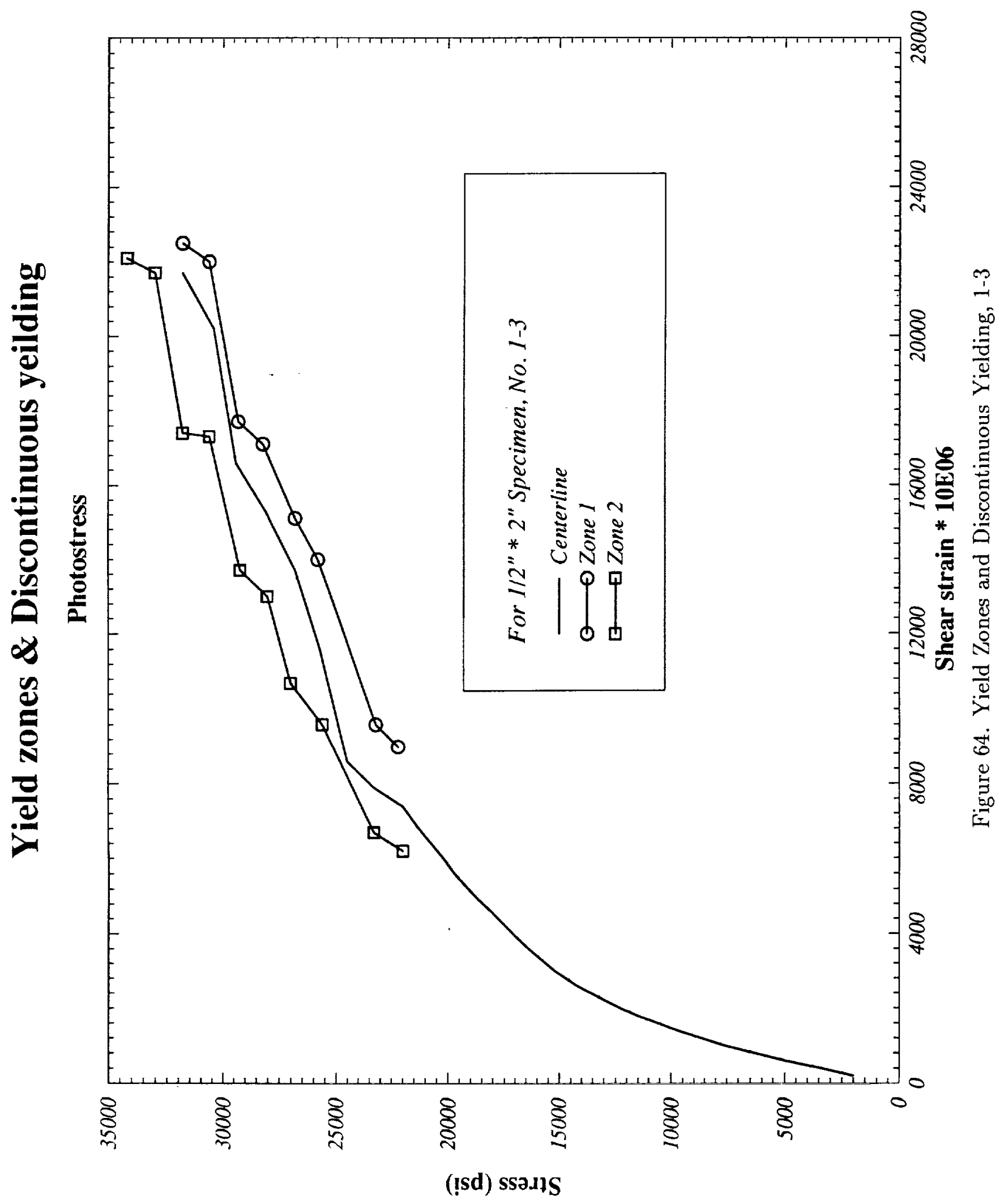




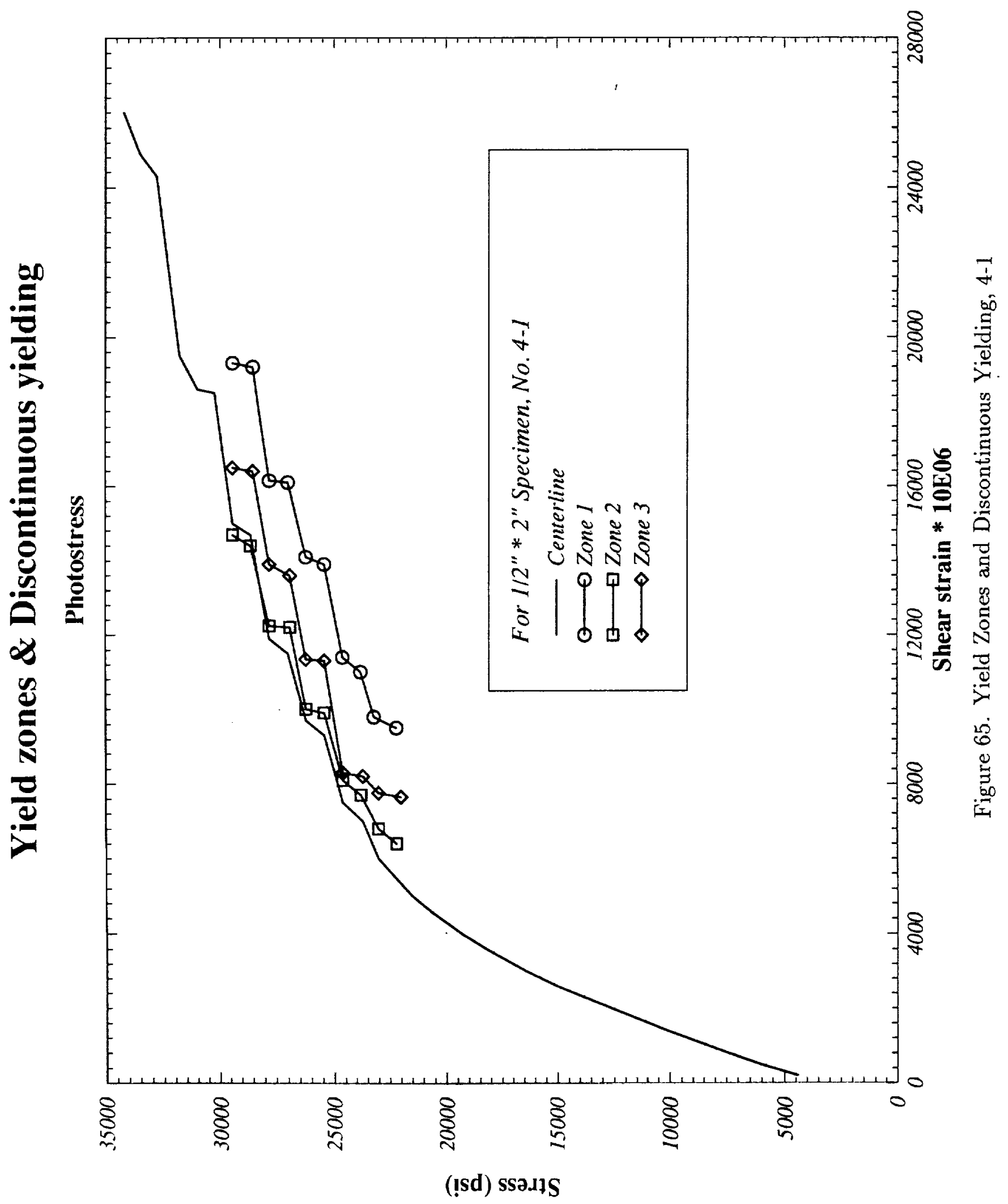




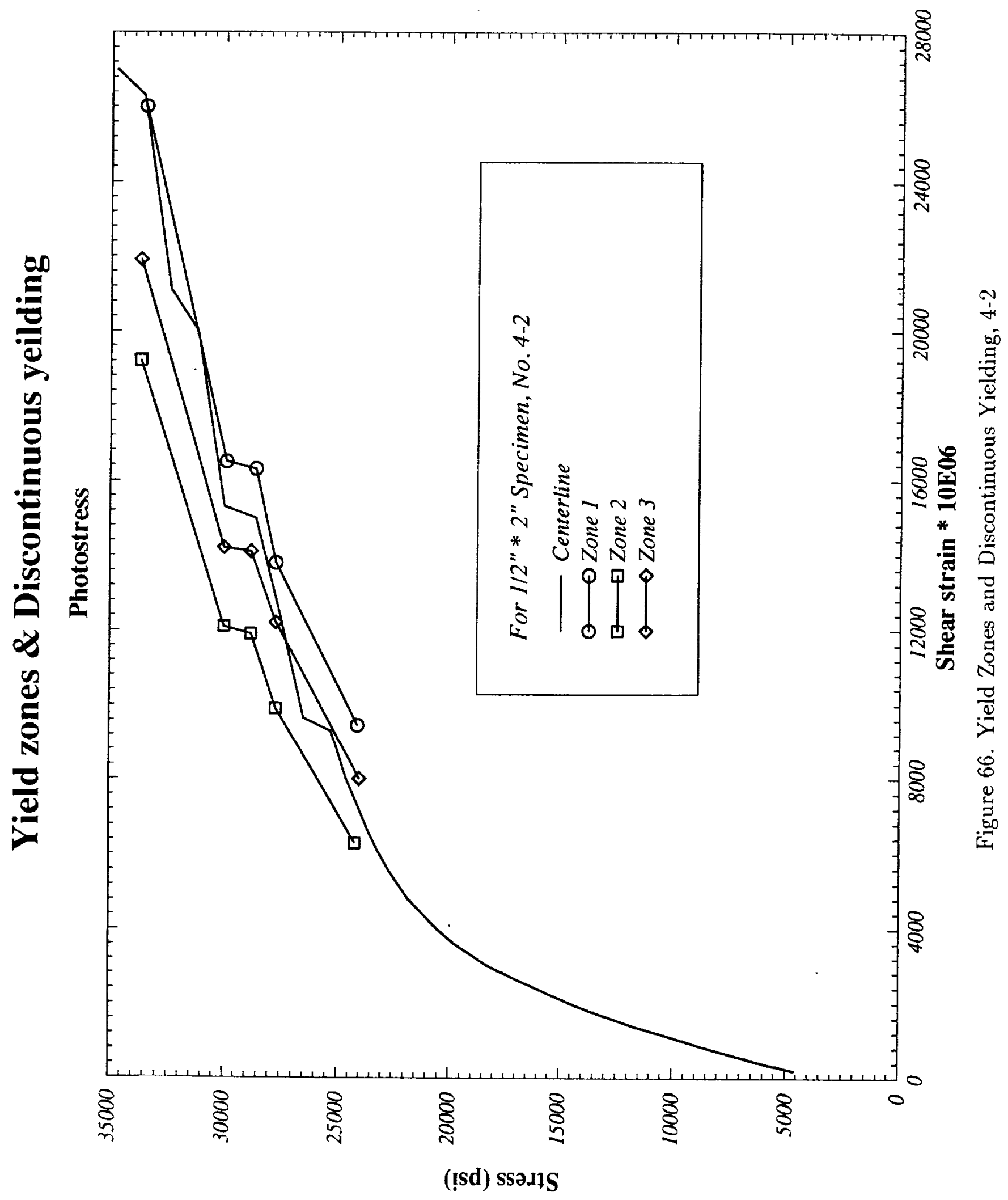




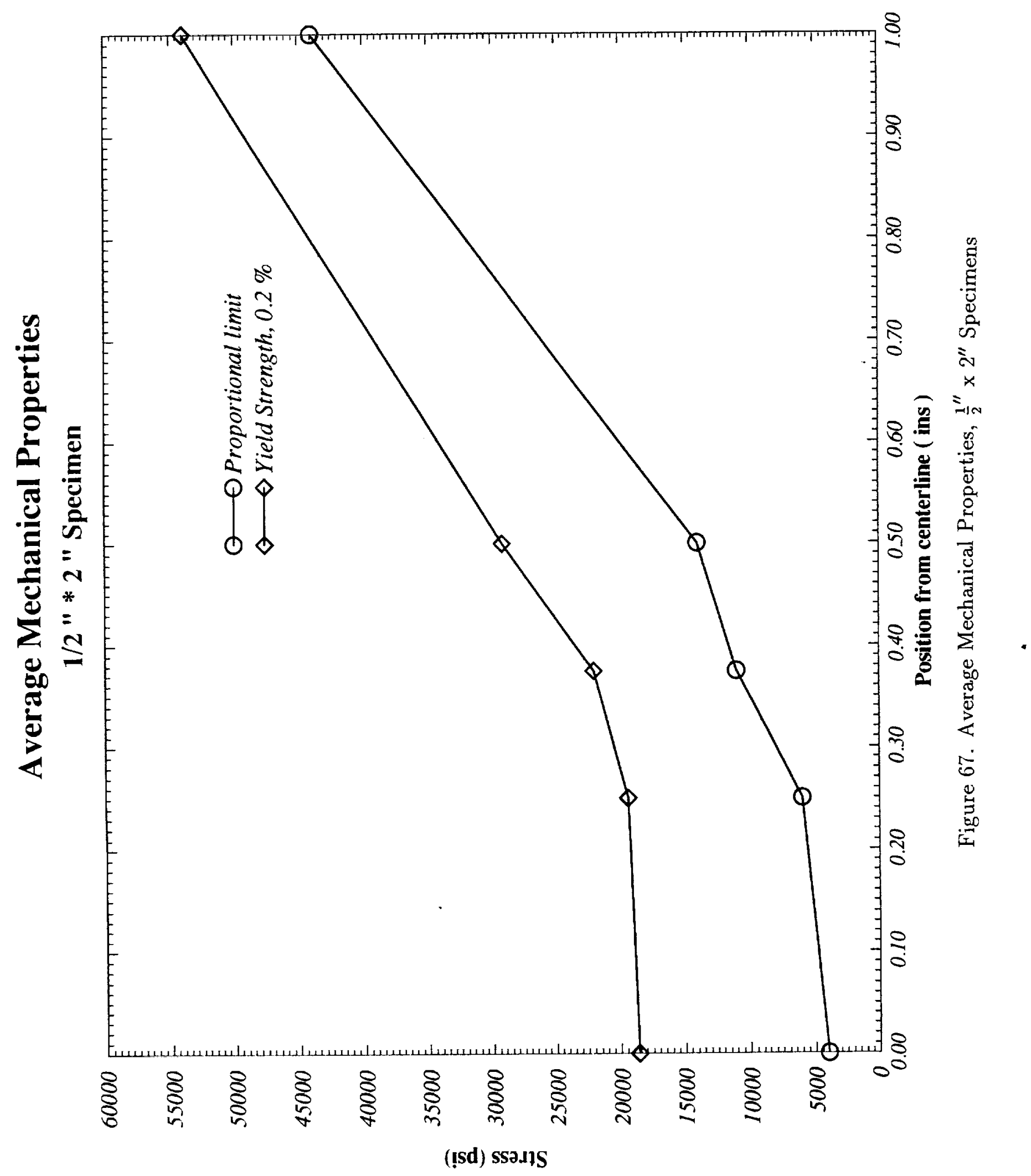




\section{SUMMARY AND CONCLUSIONS}

\section{A. Summary}

Behavior of aluminum TIG welded joints having 2219-T87 parent material and 2319 weld material has been determined using strain gages and photoelastic coatings (Photostress). Both heat treated and as welded specimens were tested. In the weld material and fusion boundary region, strains vary greatly from point to point and a general, non-uniform yield behavior was observed in these regions. Stress-strain and material properties curves indicate that heating affects heat treated specimens $1.4^{\prime \prime}$ thick at locations at least one inch away from the centerline of the weld while in others, the heating effects seems to disappear near the $\frac{3}{4}^{\prime \prime}$ location. In both as welded and heat treated material, discontinuous yielding was observed at various levels of stress from $20 \mathrm{ksi}$ to $45 \mathrm{ksi}$. In the slip-hold-slip-hold process of discontinuous yielding, energy requirements for slip required to progress from one hold position to another hold position were determined as a function of stress magnitude. Average energy requirements for slip at the weld centerline, the $\frac{1}{4}^{\prime \prime}$, and the $\frac{3}{8}^{\prime \prime}$ locations away from the weld center were essentially the same whereas energy requirements for slip at the $\frac{1}{2}^{\prime \prime}$ location were quite different. Material in the as welded condition having a thickness of $\frac{1}{2}^{\prime \prime}$ inch exhibited clear and distinct yield zones in which the shearing strain was constant. These zones vary in strain magnitude and position from specimen to specimen. In the as welded material, inelastic behavior was observed during the first loading of the specimen whereas perfect strain hardening was observed during the second loading up to the magnitude of stress applied in the first loading. 


\section{B. CONCLUSIONS}

1. Joints having a thickness of $1.4^{\prime \prime}$ in heat treated material exhibit a highly non-uniform behavior through the weld thickness and, consequently, have quite different material properties on either side or face of the weld.

2. Basic mechanical properties of proportional limit and yield strength are dependent upon location, relative to the weld, in both heat treated and as welded material.

3. Procedure for laying the weld material in the $1.4^{\prime \prime}$ thick specimens produces a nonuniform joint and affects yield characteristics of the joint.

4. A difference exists, although small, in mechanical behavior of the two sides, wide and narrow, of welds in as welded material $\frac{1}{8}^{\prime \prime}$ and $\frac{1}{2}^{\prime \prime}$ thick.

5. Chakrabarty's approximation is not sufficiently accurate to convert shearing strain to normal strain at points between the fusion boundaries in welded specimens subject to axial tensile loads. At points outside the fusion boundaries and within the variability from specimen to specimen, it is reasonably accurate for making the conversion.

6. Because of averaging of various strain values under the total gage length of a strain gage, gages having lengths between $\frac{1}{64} "$ and $\frac{1}{4}$ "produce approximately the same results at specific locations when used to measure strains on an in the vicinity of the weld in a welded joint. 
7. The specific values of stress at which discontinuous yielding begins is unpredictable, except to say that it usually starts at approximately 20 to $25 \mathrm{ksi}$ in as welded material and at approximately 36 to 38 ski in heat treated material.

\section{REFERENCES}

1. Gambrell, S. C., Jr., "Use of Photostress to Characterize the Mechanical Behavior of Weldments," Summary of Work, NASA/ASEE Summer Fellowship Program, Metallurgy Research Branch, Metallic Materials Division, Materials and Processes Laboratory, MSFC, May 28-August 2, 1991.

2. Chakrabarty, J., Theory of Plasticity, McGraw- Hill, 1987.

3. "Photostress Instrumentation," Measurements Group Inc. Literature, Raleigh, NC, Bulletin 315-B, 1989.

4. "How to Select Photoelastic Coatings," Measurements Group Inc. Literature, Raleigh, NC, TN-704, 1978.

5. "Automatic Data Acquisition," ADA-1 through ADA-8, Measurements Group Inc. Literature, Raleigh, NC.

6. "Operating Instructions and Technical Manual-Strain Measurement with the 030-Series Reflection Polariscope," Measurements Group Inc. Literature, Raleigh, NC.

7. "Instructions for Bonding Flat and Contoured Photoelastic Sheets to Test-Part Surfaces," Measurements Group Inc. Literature, Raleigh, NC, IB-223-F, 1982. 
8. "Instructions for Using PC-8 Adhesive," Measurements Group Inc. Literature, Raleigh, NC, IB-231, 1982.

9. Catalog 500, Part A - Strain Gage Listings, Measurements Group Inc. Literature, Raleigh, NC, 1988.

10. "Strain Gage Installations with M-Bond 200 Adhesive," Measurements Group Inc. Literature, Raleigh, NC, IB 127-12, 1979. 


\section{APPENDIX}

In the appendix, curves of tangent modulus and contraction ratio for 2219-T87 parent material and 2319 pure weld material have been included from the work during the summer of 1991. Since the contraction ratio applies only in the inelastic range, curves are plotted as (Stress-P.L.) versus tangent modulus and contraction ratio where P.L. is the proportional limit taken from tensile tests of parent material and pure weld material. Figure 68 gives the tangent modulus curves, and Figure 69 gives the contraction ratio curves.

To provide examples of how the non-linear and linear curve fitting software treated the scatter from tests using strain gages and Photostress, several graphs of each are presented showing the fitted curve within the scatter which was obtained by testing three different specimens. Figures 70-74 are examples of fit and scatter using $\frac{1}{4}^{\prime \prime}$ strain gages, Figures 75-79 are examples of fit and scatter using $\frac{1}{32}^{\prime \prime}$ strain gages, and Figures $80-85$ are examples of fit and scatter using Photostress. Recalling that, except as previously noted, the scatter represents all data taken from three different specimens, it may be seen that the scatter observed when using strain gages compares in all cases with the scatter observed when using Photostress.

In many instances, specimens have been referred to by panel and specimen number. For example, 3-4 refers to panel 3 and specimen 4 from that panel.

In several of the graphs, the curves tend to "tail off" in one direction or another at their ends. This is the result of not always having three sets of data for the curve fitting process at the extreme high values of strain. In some cases, one or two strain gages would fail just 
before the end of the test. Also, for both strain gages and Photostress, discontinuous yielding would occur at different stress levels in different specimens and, because of the extremely large jumps in strain (often more that $5000 \times 10^{-6}$ ), there would not always be three sets of data for curve fitting at the ends of the curve.

Table 4 gives a list, by size and description of specimen, of all specimens tested in this project. 


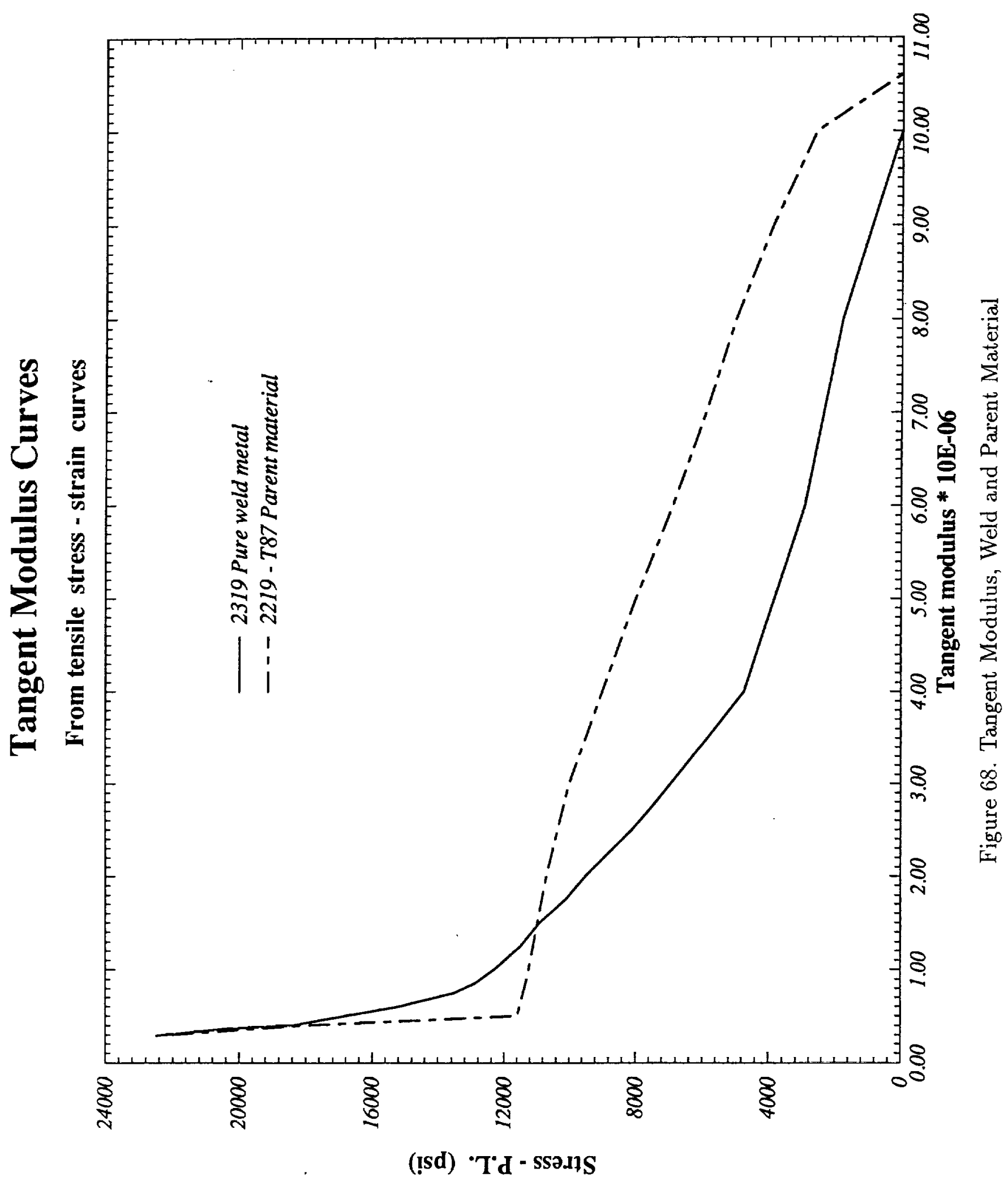




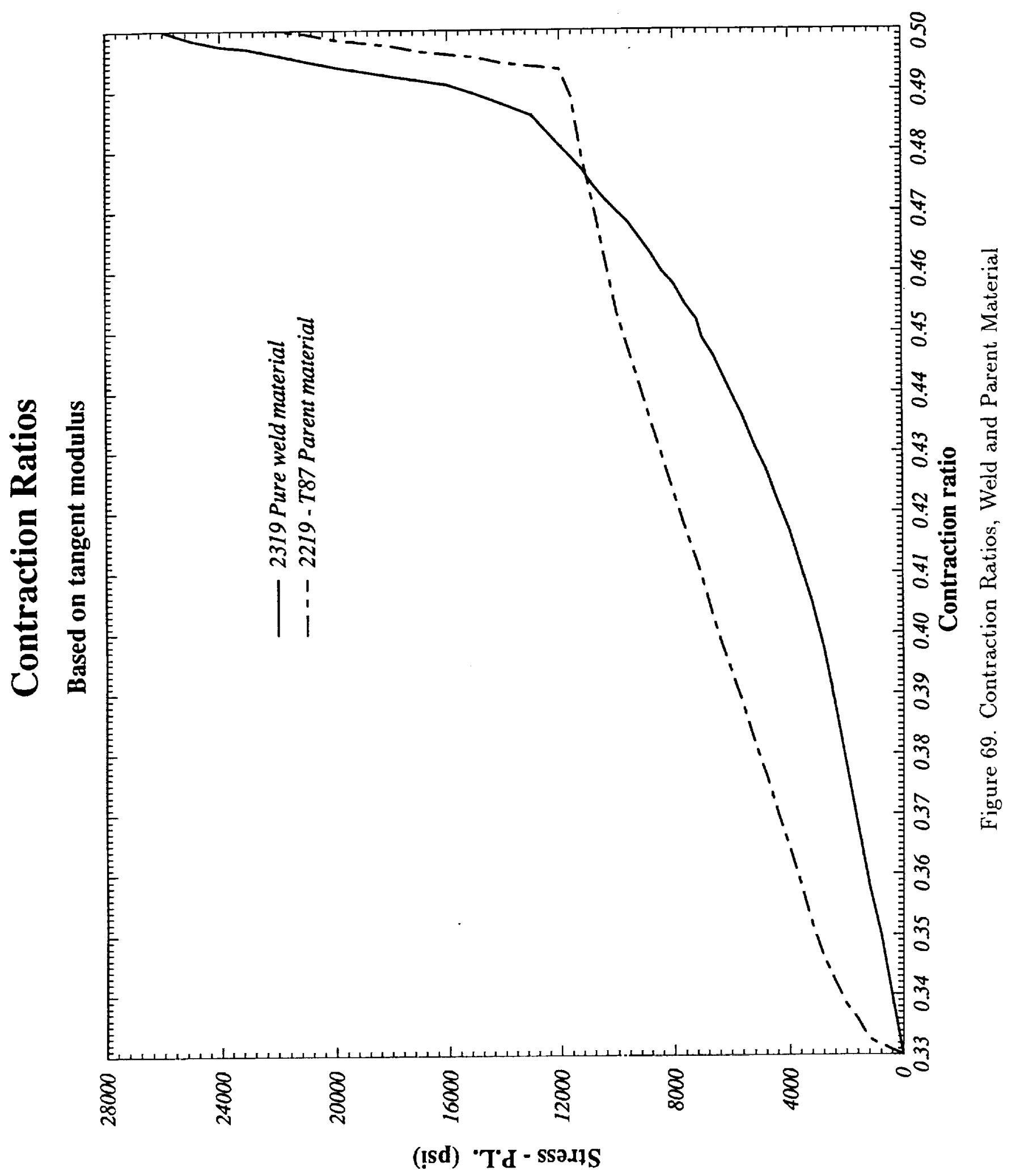




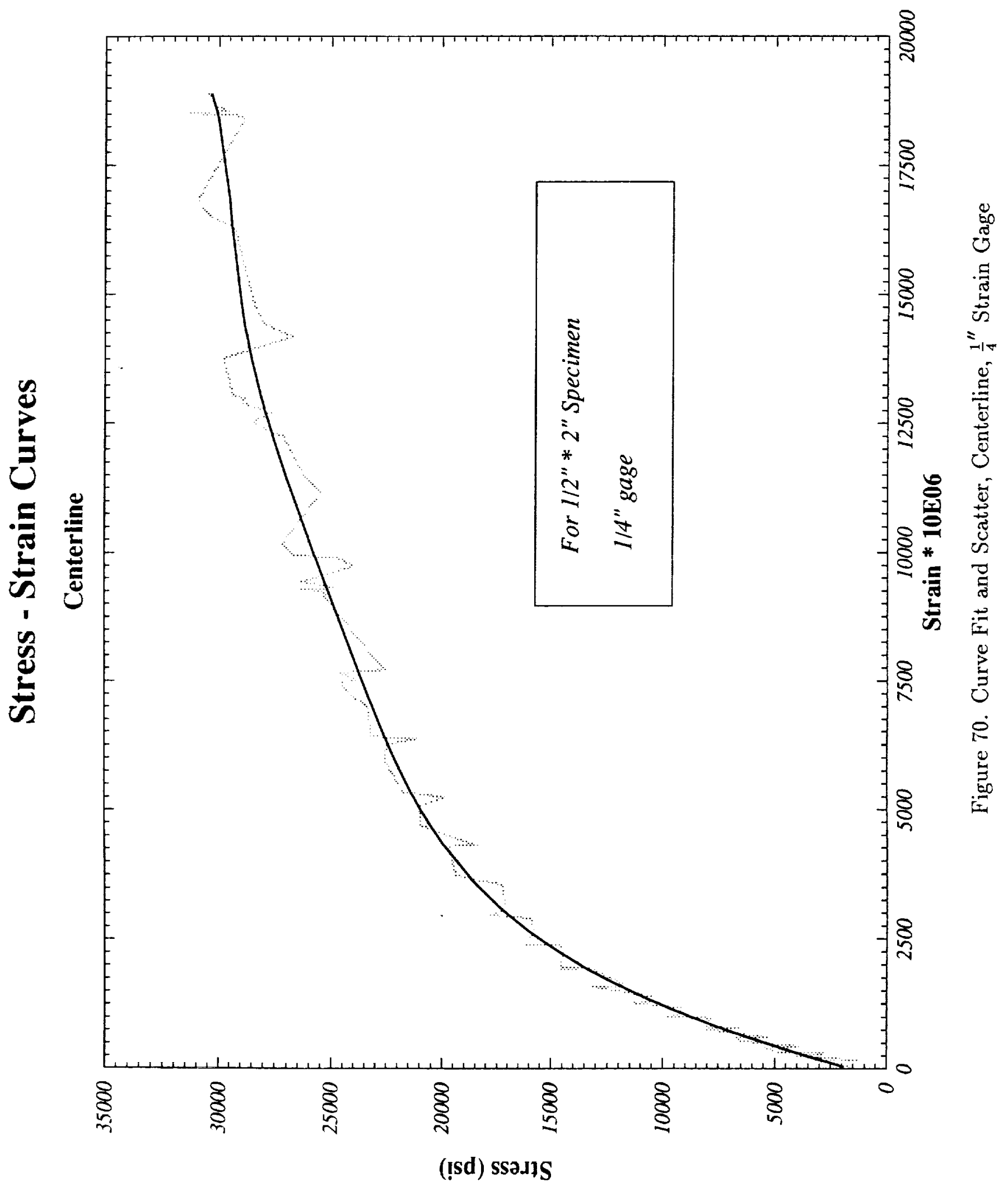




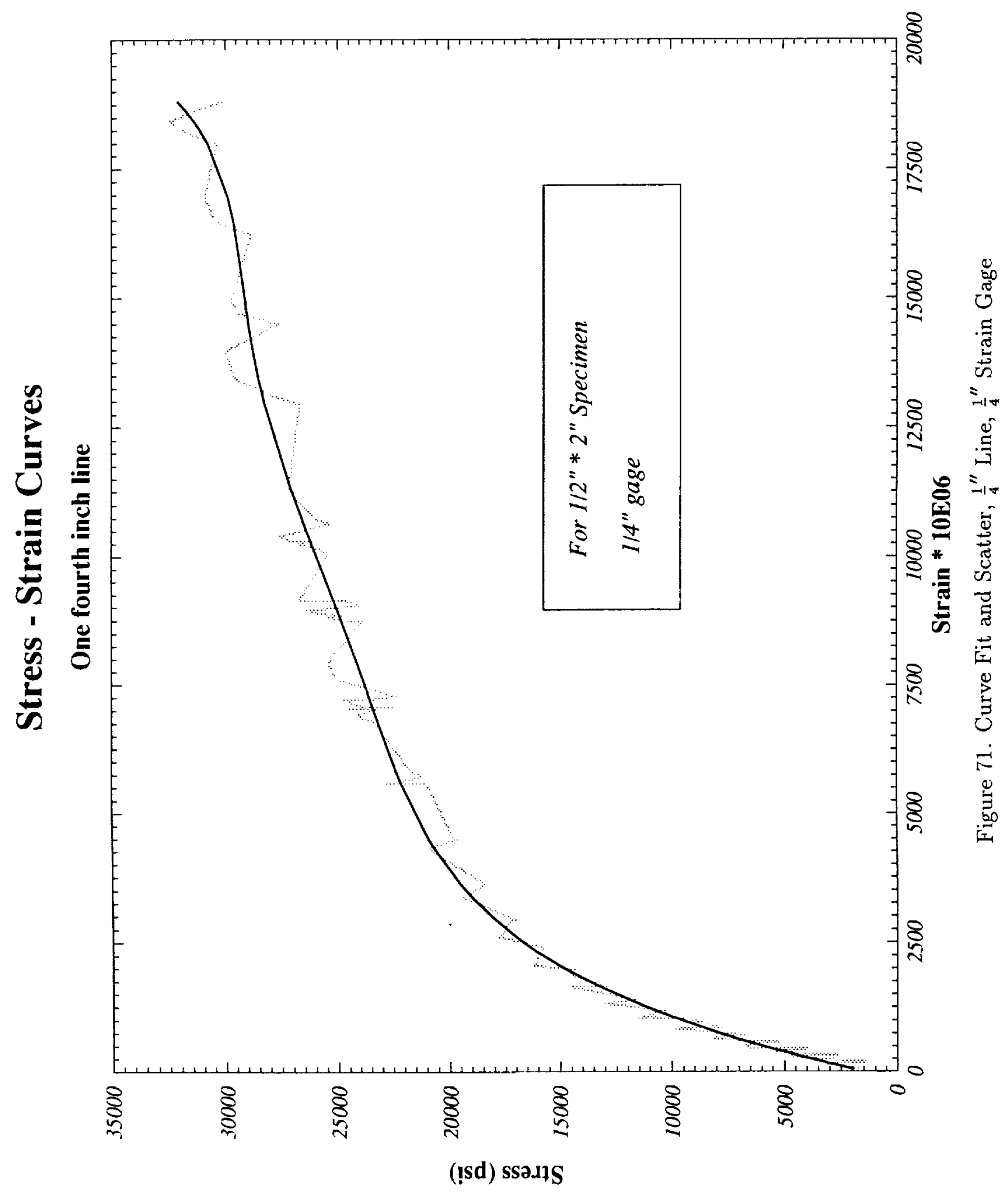




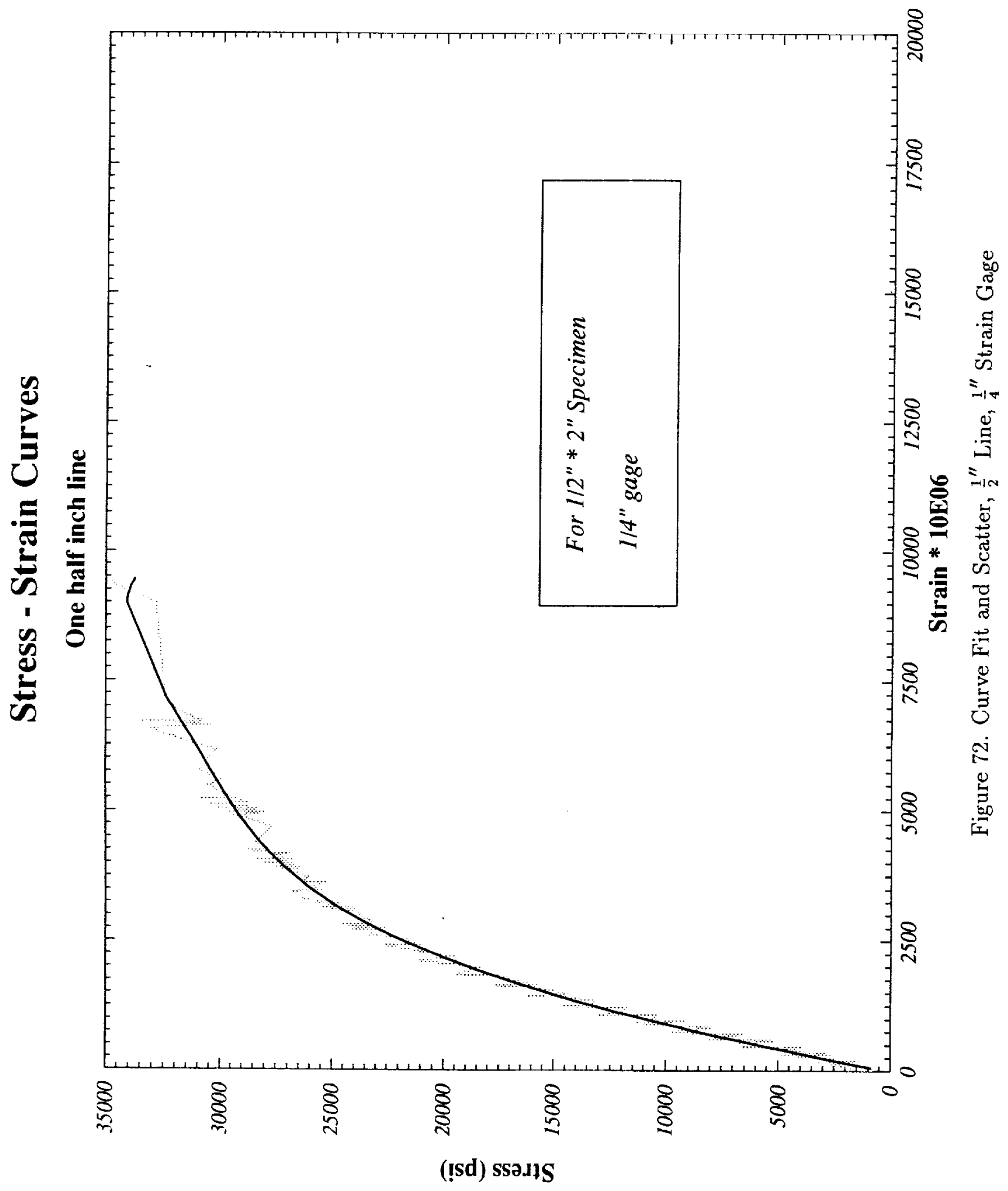




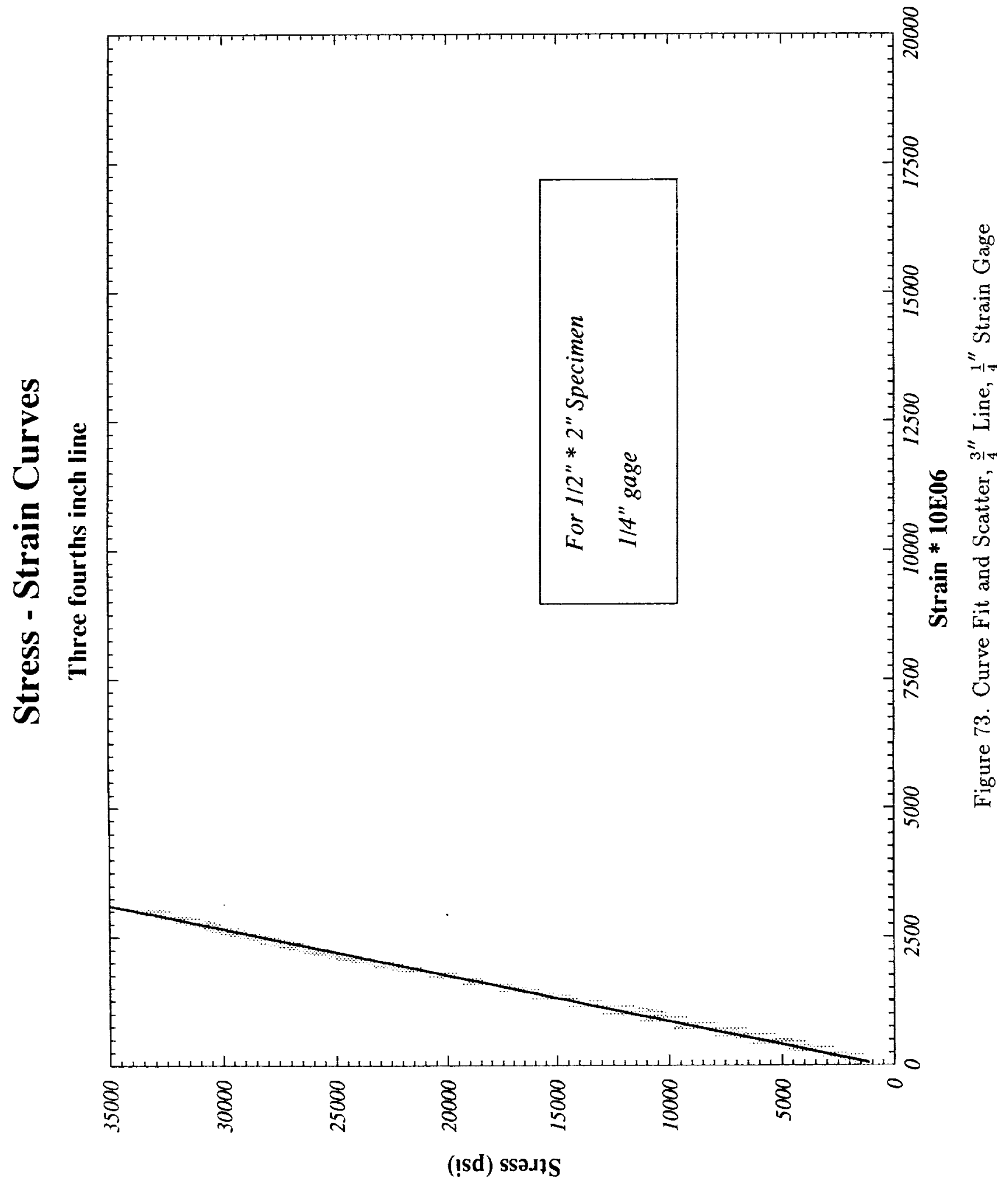




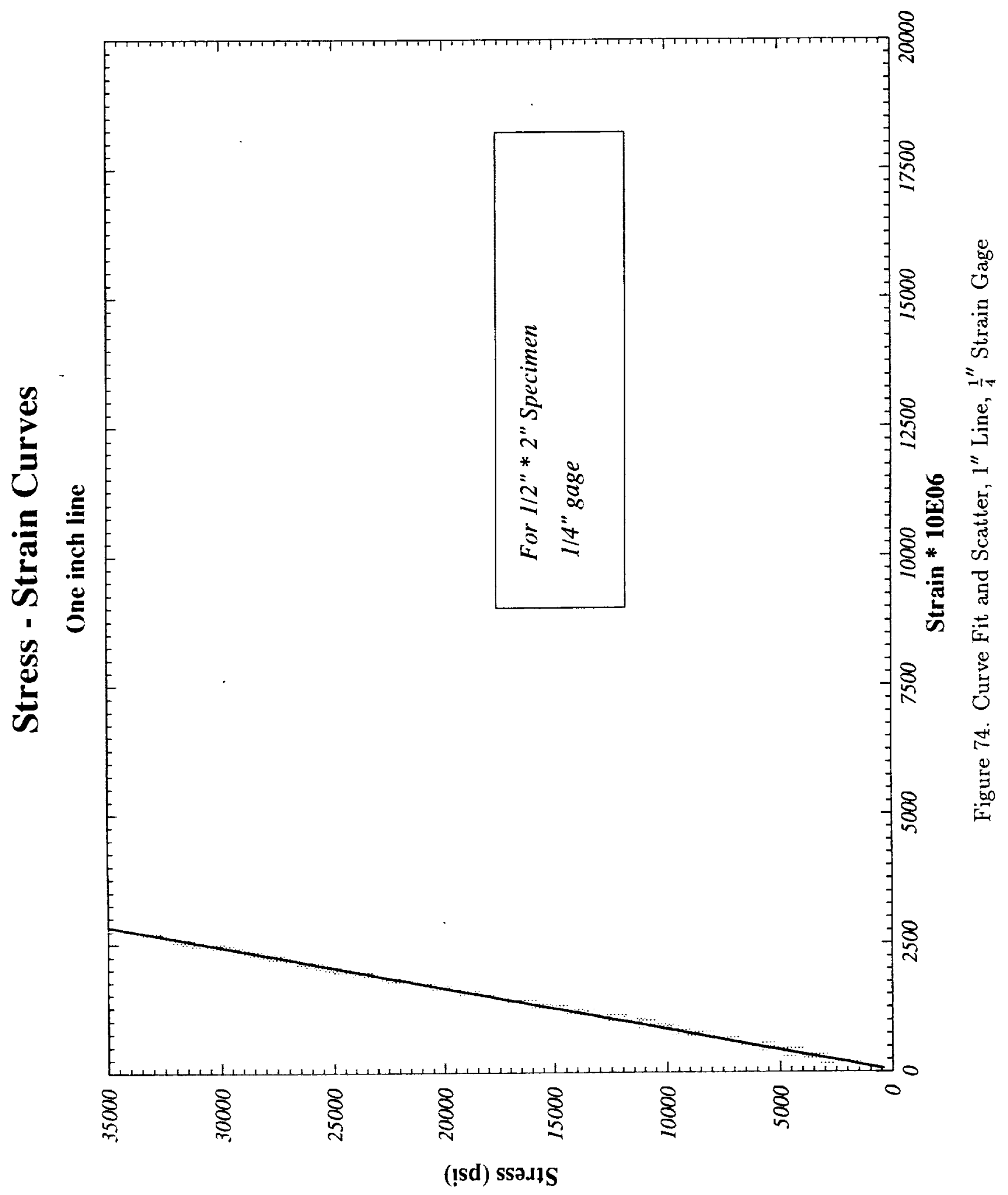




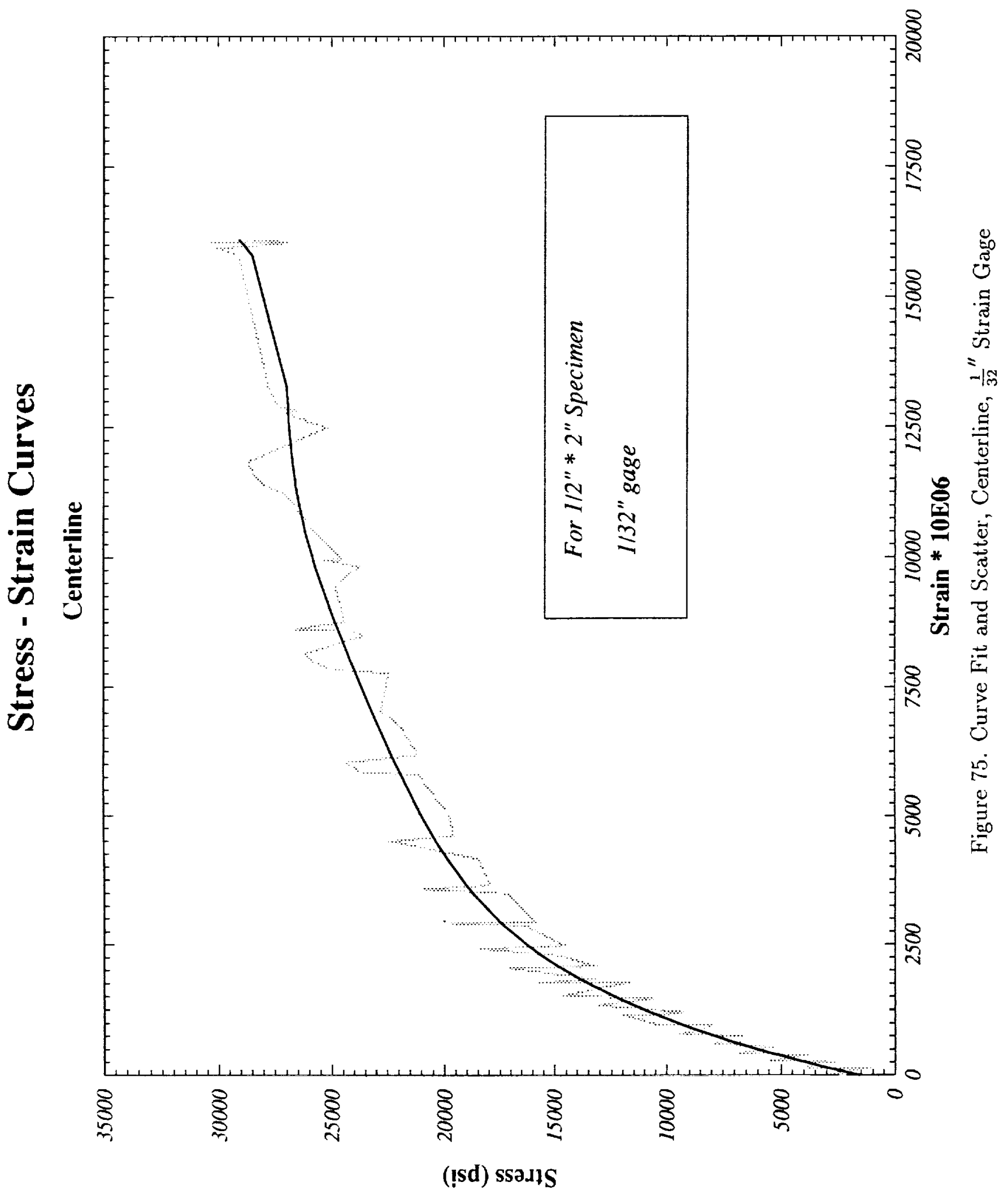




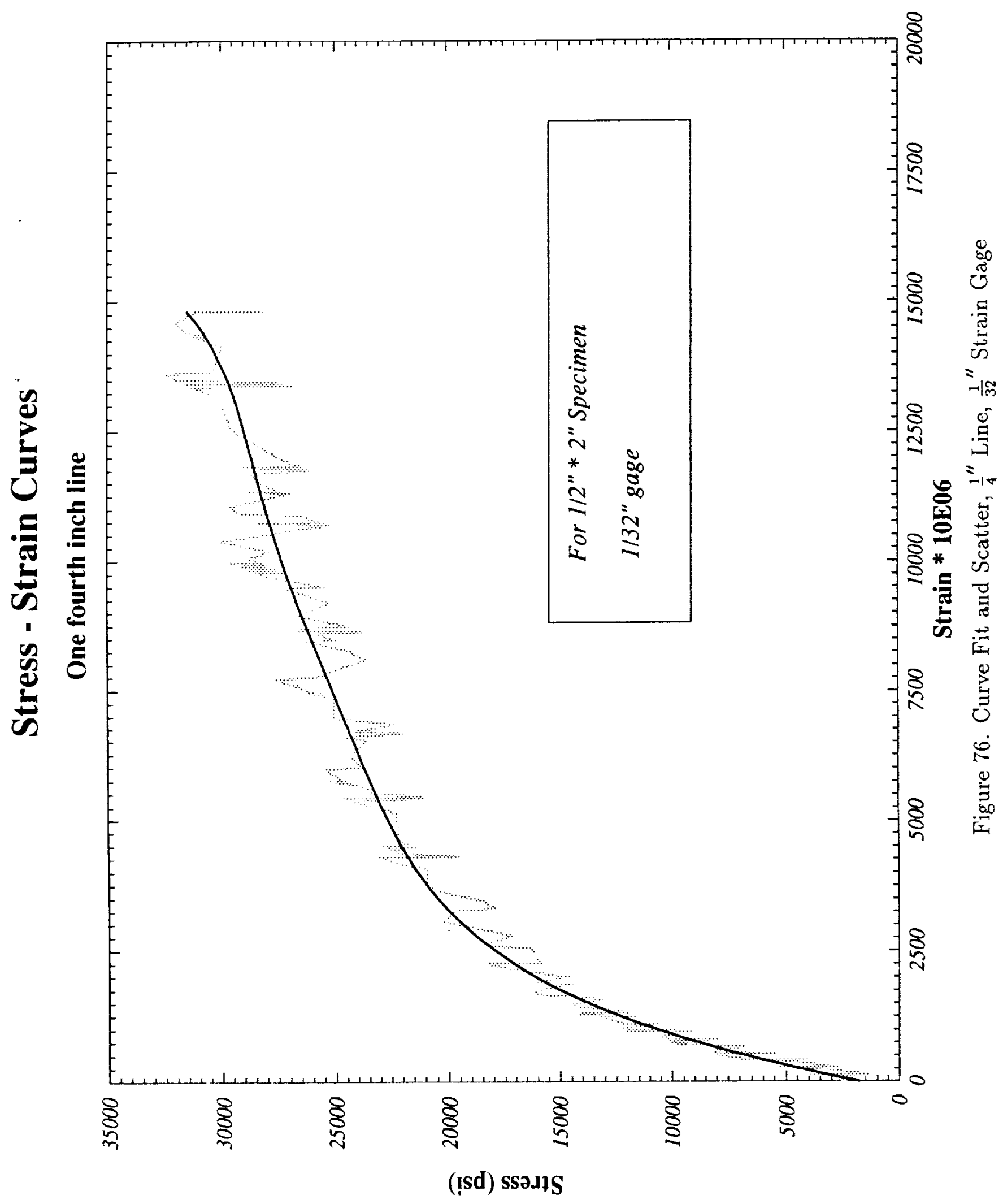




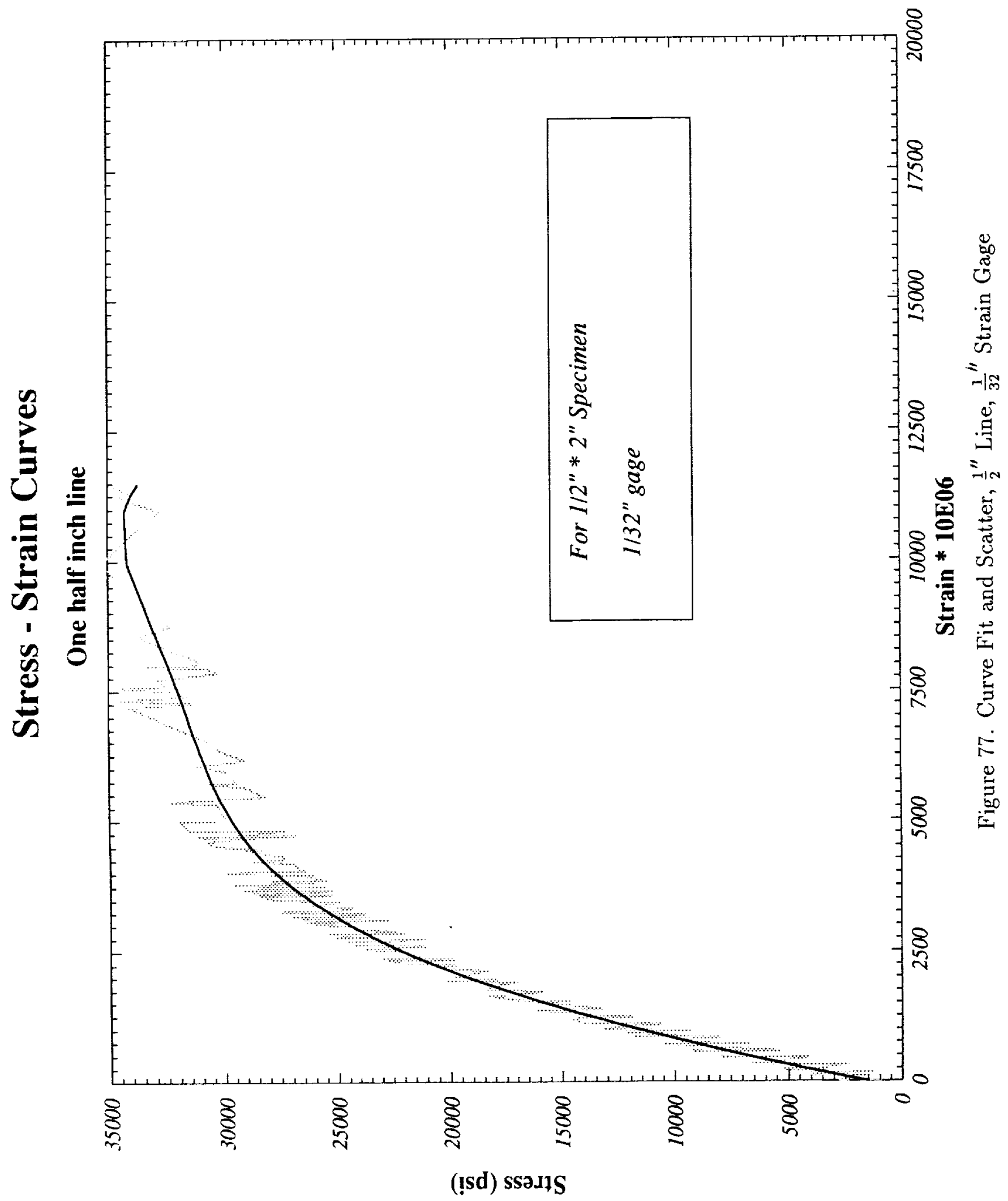




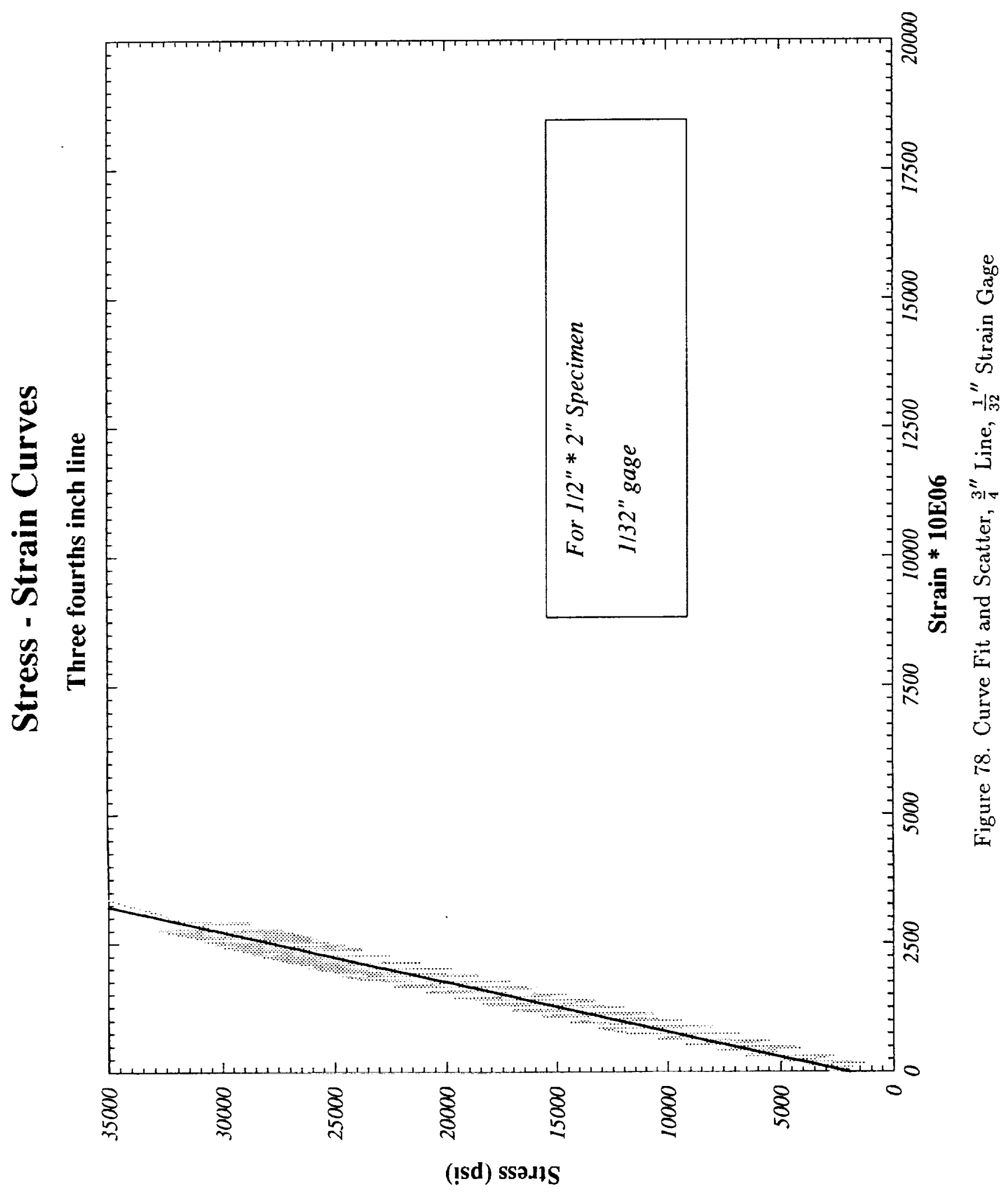




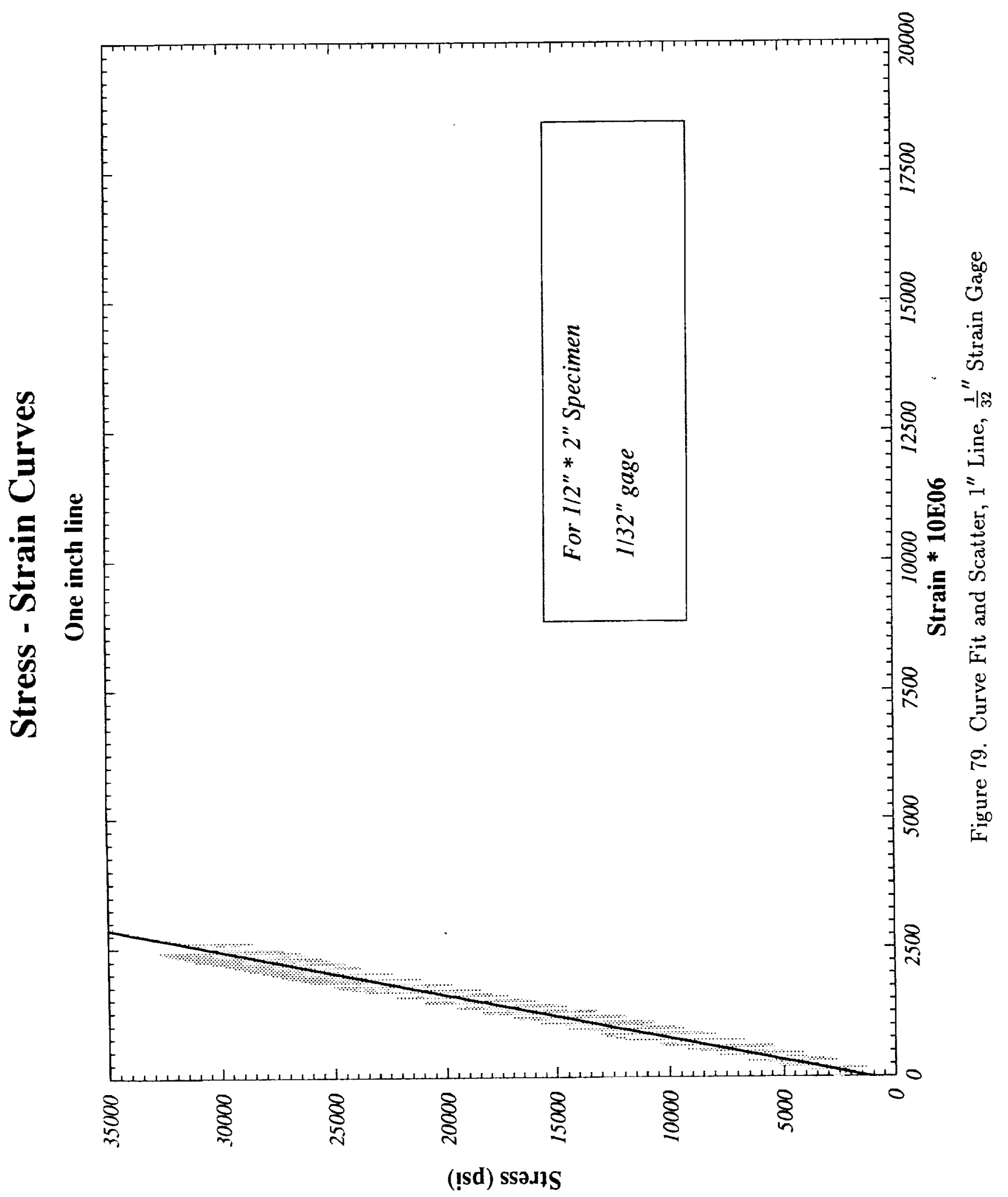




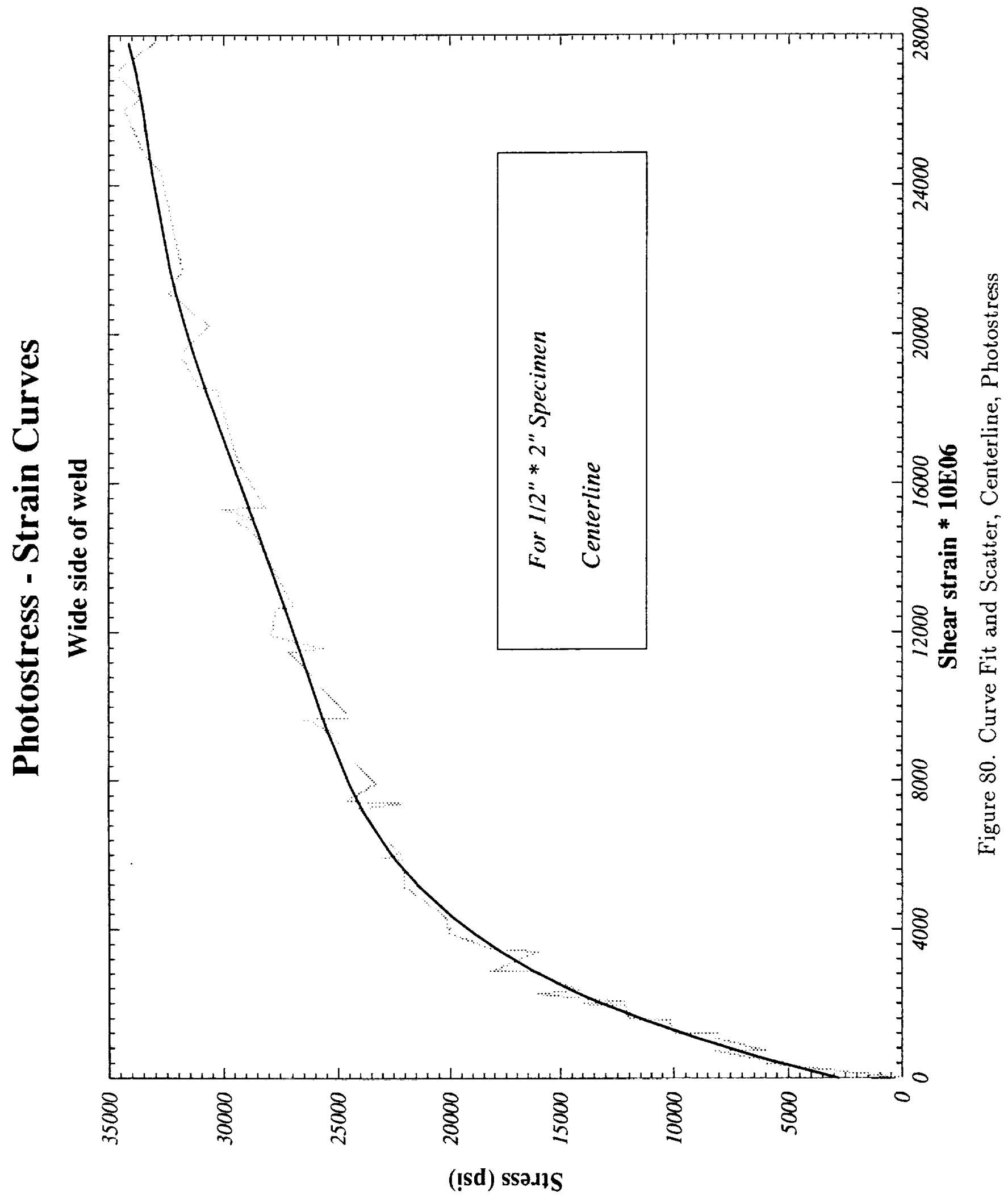




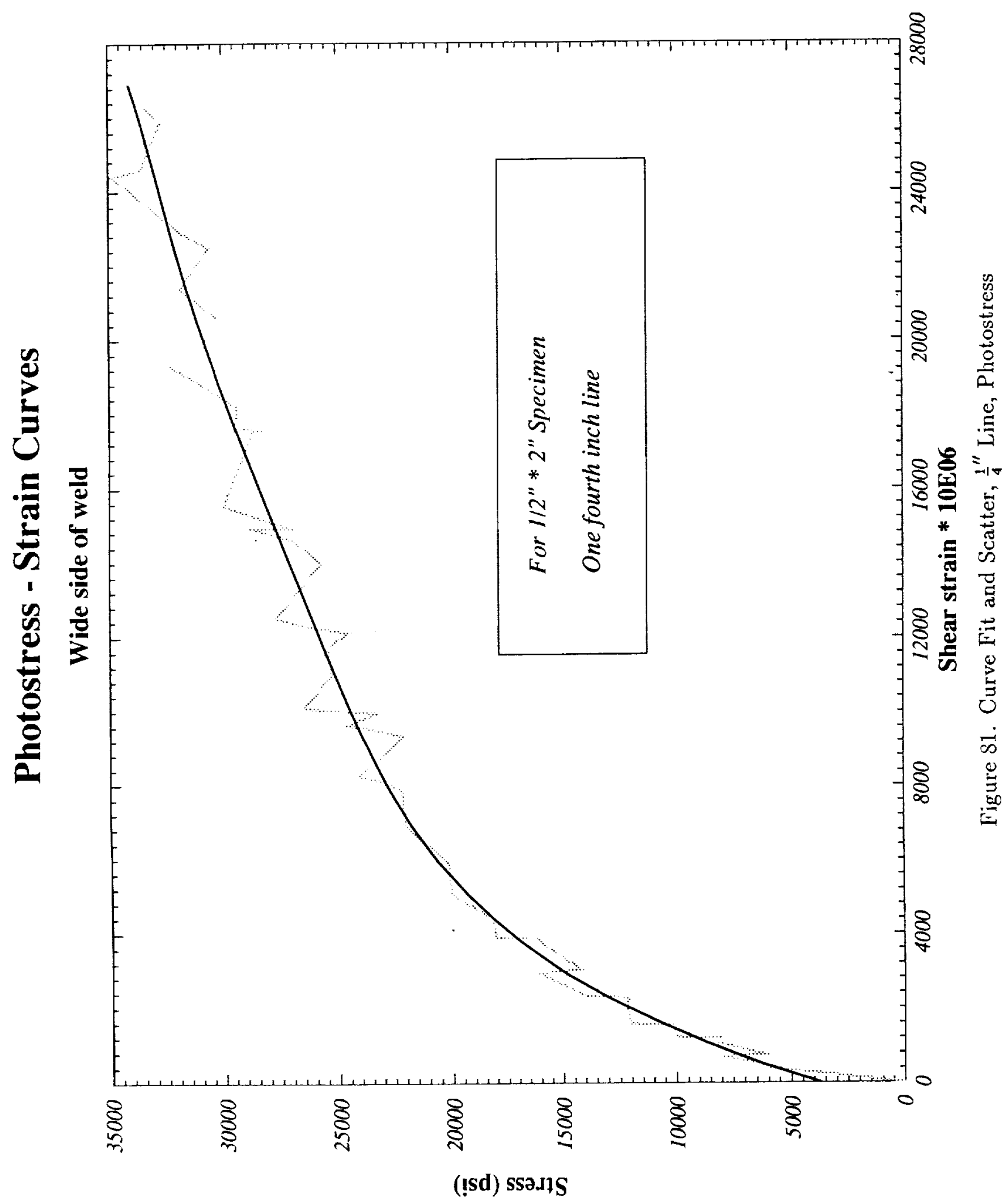




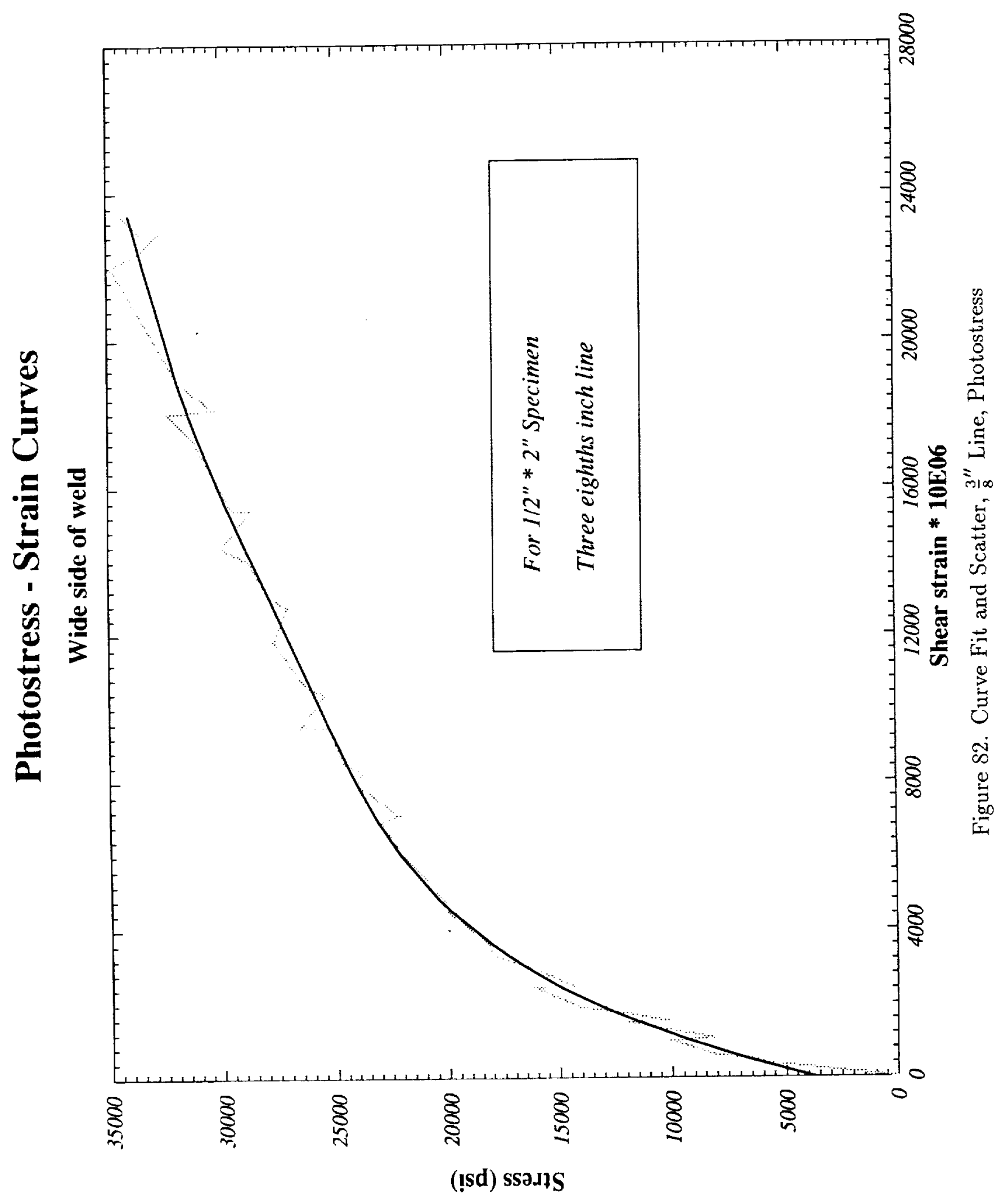




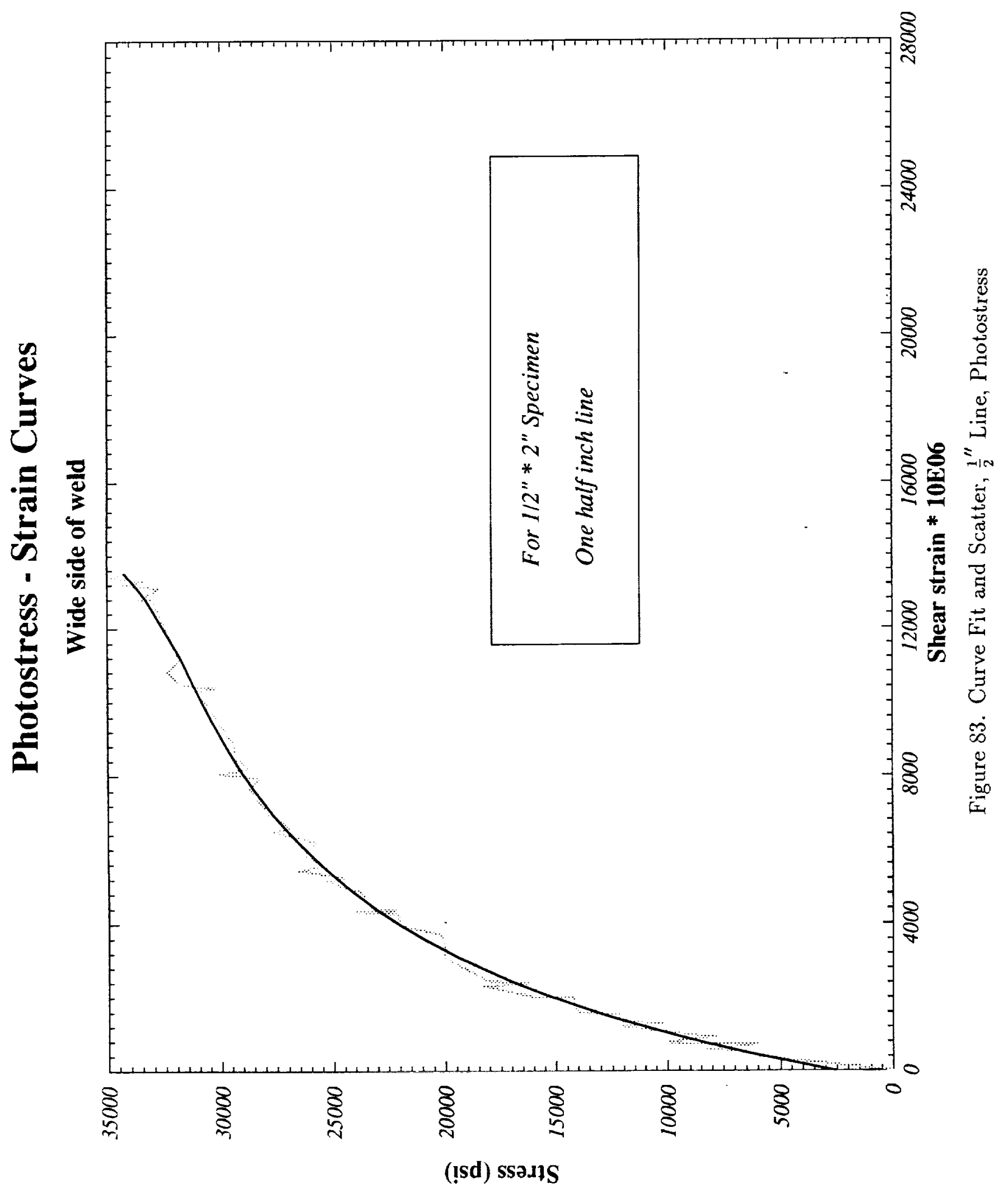




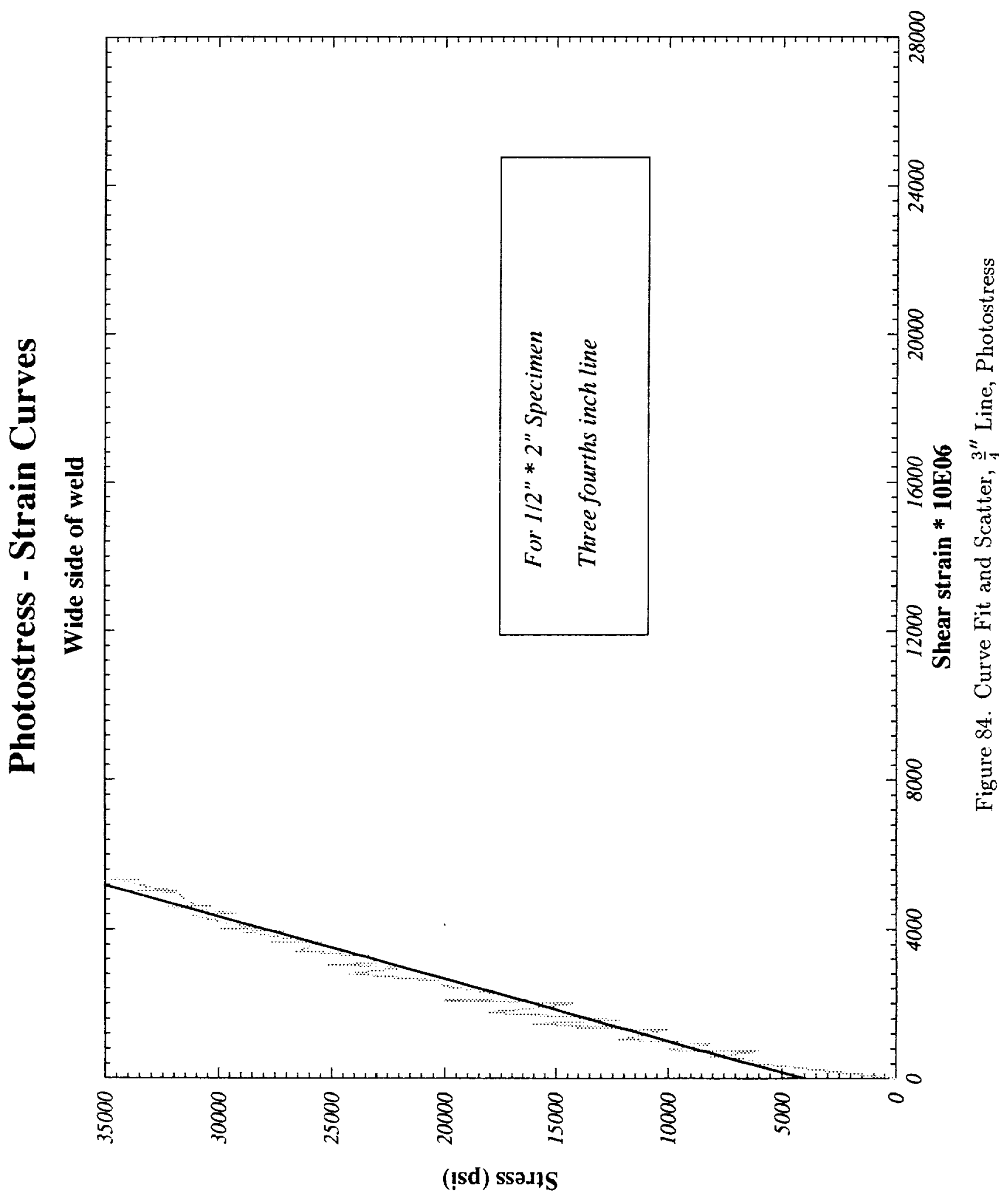




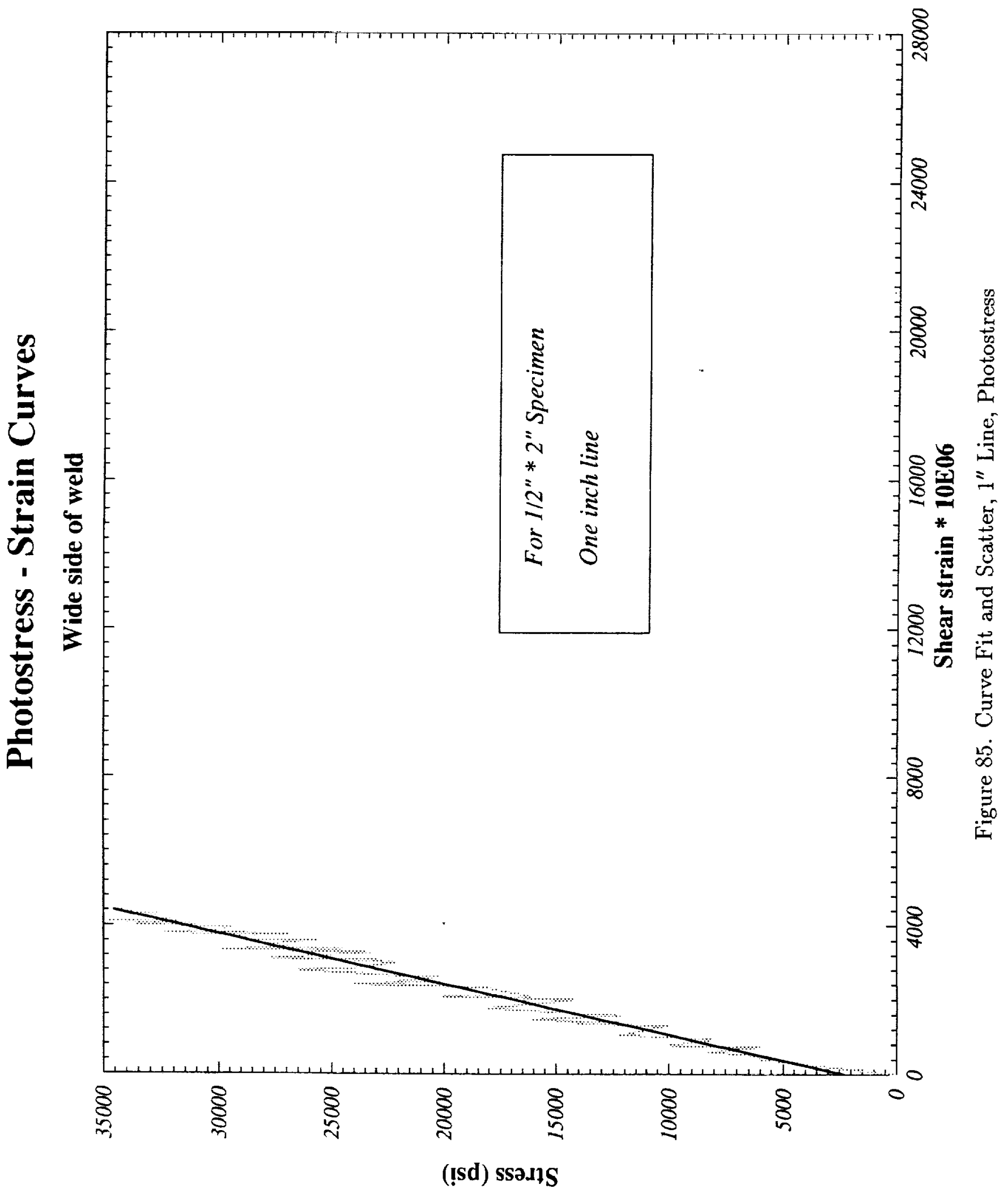


TABLE 4. Specimens Tested

size

$1.2 " \times 2 "$

as welded

$1 / 2 " \times 1.25$

as welded

$1 / 8 " \times 1.25 "$

as welded

$.071 " \times 1.4 "$

heat treated, weld off

$.071 " \times 1.4 "$

heat treated weld on
Panel Number - Specimen Numbers

$$
\begin{aligned}
& 1-1,2,3,4 \\
& 2-1,2 \\
& 3-1,2,3,4,5 \\
& 4-1,2 \\
& 5-1,2,3,4,5 \\
& 7-2,3,4 \\
& 8-1,2,3,4 \\
& 6-1,2,3,4,5 \\
& 7-1 \\
& 2-1,2,3,4 \\
& 3-1,2 \\
& 1-1,2,3,4 \\
& 2-1,2 \\
& 2-3 \\
& 3-1,2,3,4,5
\end{aligned}
$$

